\title{
Schismatoglottideae (Araceae) in Malesia I - Schismatoglottis
}

\author{
A. Hay and Yuzammi
}

\begin{abstract}
Hay, A. ${ }^{1}$ and Yuzammi ${ }^{1,2}\left({ }^{1}\right.$ Royal Botanic Gardens Sydney, Mrs Macquaries Road, Sydney, NSW 2000, Australia; ${ }^{2}$ School of Biological Sciences, University of New South Wales, Kensington, NSW 2033, Australia, permanent address: Kebun Raya Bogor, Jl. Ir. H. Juanda 13, Bogor 16122, Indonesia) 2000. Schismatoglottideae (Araceae) in Malesia I - Schismatoglottis. Telopea 9(1): 1-177. Schismatoglottis Zoll. \& Moritzi (Araceae) is revised for Malesia. An informal infrageneric classification, subregional keys to species and illustrations of a selection of species are provided. Generic relationships and limits, conservation status, geography and endemism, and foci for further study are discussed. Eighty-nine species are recognised and described in alphabetical order within informal groups. Of these, about one third are new to science: Schismatoglottis ahmadii A. Hay, S. bauensis A. Hay \& C. Lee, S. ciliata A. Hay, S. clarae A. Hay, S. clemensiorum A. Hay, S. corneri A. Hay, S. crinitissima A. Hay, S. decipiens A. Hay, S. elegans A. Hay, S. josefii A. Hay, S. lingua A. Hay, S. moodii A. Hay, S. niahensis A. Hay, S. nicolsonii A. Hay, S. pectinervia A. Hay, S. petri A. Hay, S. pudenda A. Hay, S. pyrrhias A. Hay, S. sejuncta A. Hay, S. silamensis A. Hay, S. trusmadiensis A. Hay \& J. Mood, S. unifolia A. Hay \& P.C. Boyce, S. venusta A. Hay, S. viridissima A. Hay, S. wongii A. Hay (all Borneo), S. ecaudata A. Hay (Sumatera), S. bogneri A. Hay, S. edanoi A. Hay, S. samarensis A. Hay (all Philippines), and S. eymae A. Hay (Sulawesi). Hottarum sarikeense Bogner \& M. Hotta is recombined as Schismatoglottis sarikeensis (Bogner \& M. Hotta) A. Hay \& Bogner. Newly proposed synonyms include: S. concinna Schott, S. kurimana Alderw., S. lavallei L. Linden, S. rubrocincta Engl. = S. acuminatissima Schott; S. rubiginosa M. Hotta = S. barbata Engl.; Colocasia humilis Hassk., S. acutangula Engl., S. angustifolia Engl., S. bitaeniata Engl., S. calyptratoides Alderw., S. djamuensis Engl., S. dorensis Gibbs, S. emarginata Engl., S. hellwigiana Engl., S. klossii Ridl., S. maculata Alderw., S. muluensis M. Hotta, S. nieuwenhuisii Engl., S. parvifolia Alderw., S. picta Schott, S. potamophila Alderw., S. pseudocalyptrata Alderw., S. ruttenii Alderw., S. sublaxiflora Alderw., S. tenuifolia Engl., S. vanvuurenii Alderw. = S. calyptrata (Roxb.) Zoll. \& Moritzi s. lat.; S. caulescens Ridl. = S. conoidea Engl.; S. forbesii Engl. = S. longicaulis Ridl.; S. beccariana var. cuspidata Engl., S. multiflora var. latifolia Ridl. = S. mayoana Bogner \& M. Hotta; S. ramosii Engl., S. rizalensis Engl. = S. merrillii Engl.; S. decora W. Bull, S. diversicolor Alderw., S. irrorata Engl., S. pulchra N.E. Br., S. winkleri Engl. = S. motleyana Schott s. lat.; S. bulbifera H. Okada, T. Tsukaya \& Y. Mori = S. multiflora Ridl.; S. batoensis Engl., S. brooksii Alderw., S. leptophylla Alderw., S. monticola Alderw., S. rotundifolia Engl. = S. mutata Hook. f. s. lat.; S. sylvestris Alderw. = S. ovata Schott; Alocasia merrillii Engl. \& K. Krause, S. cardiophylla Quisumb. \& Merr. = S. plurivenia Alderw.; S. latifolia Miq., S. treubii Engl., S. wigmannii Engl. = S. rupestris Zoll.; S. variegata Hook. f., S. beccariana Engl., S. crassifolia Engl., S. fasciata (Ridl.) Engl., S. homalomenoidea M. Hotta, S. opaca Engl., S. ornata Alderw., S. parviflora M. Hotta = S. tecturata (Schott) Engl.; S. colocasioidea M. Hotta = S. trifasciata Engl. s. lat.; S. engleriana Alderw. $=$ S. trivittata Hallier f.; S. conversa Alderw., S. longicuspis Engl. = S. wallichii Hook. f. The many described varieties and forms are no longer recognised as all are based on minor variations such as leaf pigment or leaf shape, which vary even within populations. Varieties and forms follow their species into synonymy and are not listed above, except where they had been segregated from the wrong species. Significant range extensions include S. brevicuspis Hook. f., S. brevipes Hook. f., S. mutata Hook. f. and S. wallichii in Sumatera, S. tecturata in the Riau Archipelago, S. longifolia Ridl. in Borneo and S. plurivenia Alderw. in Sulawesi. Schismatoglottis acutifolia Engl., S. eximia Engl., S. glauca Engl., S. penangensis Engl. and S. lancifolia Hallier f. ex Engl. are left as doubtful species, the last apparently misapplied in recent use. Schismatoglottis sumatrana Schott ex Miq. is newly excluded and recombined here in Scindapsus as Scindapsus sumatranus (Miq.) P.C. Boyce \& A. Hay - of which Scindapsus rupestris Ridl. is a synonym. Thirty-three epi-, lecto- or neotypifications are newly made.
\end{abstract}




\section{Contents}

\section{General Part}

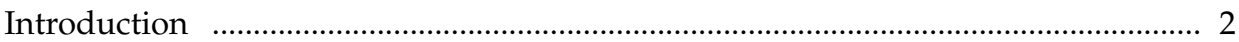

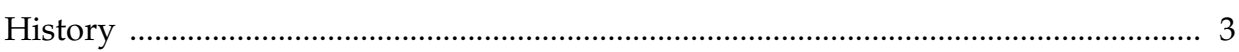

Relationship of Schismatoglottis and the Schismatoglottideae ……………….......... 5

Infrageneric classification .................................................................................... 5

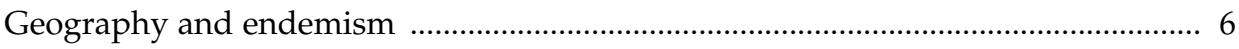

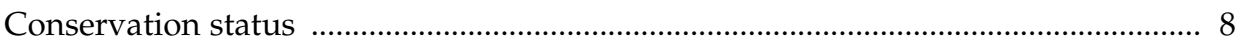

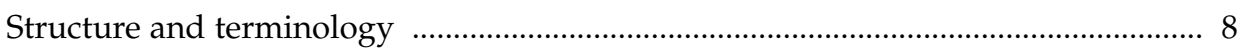

Schismatoglottis, the Bogor Gardens and the Gardens Herbarium ............................ 14

Foci for further study ........................................................................................ 16

\section{Taxonomic Part}

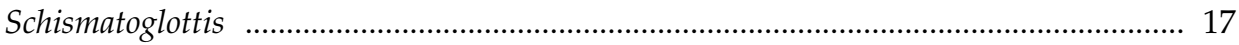

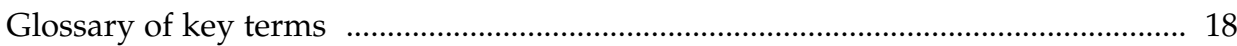

Key to informal species groups …………………………................................... 20

Keys to species and complexes by landmass or island group …………………...... 20

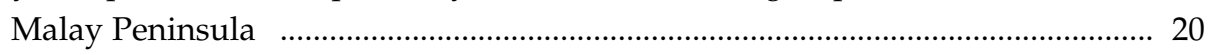

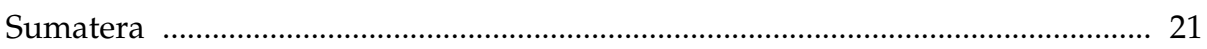

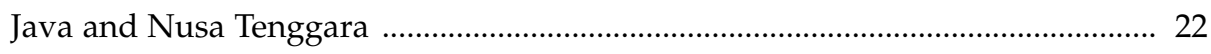

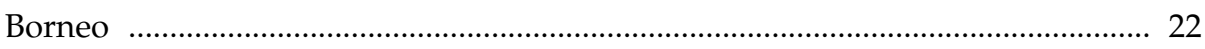

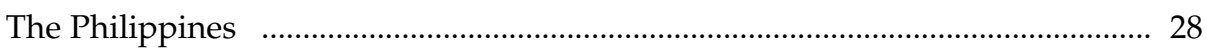

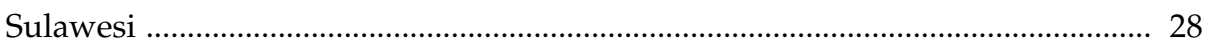

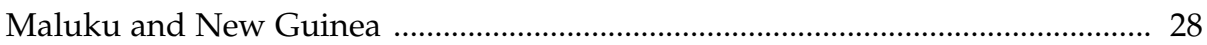

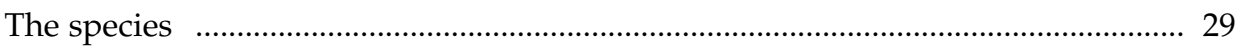

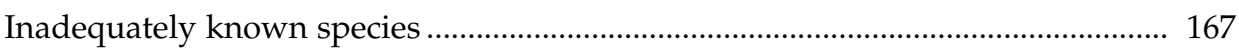

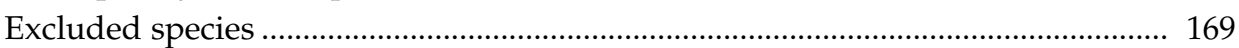

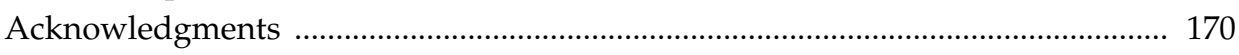

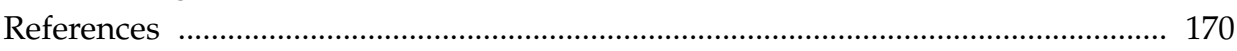

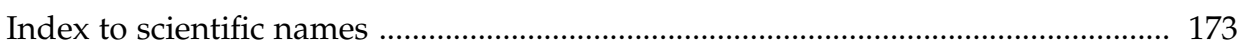

\section{General Part}

\section{Introduction}

Schismatoglottis is a tropical genus of about 100 species, the great majority of which are Malesian and, within Malesia, Bornean. The genus extends east to Vanuatu and north to subtropical China, with a very sharp fall-off in species richness and diversity through and east of Wallacea and north of the Malay Peninsula. It is absent from India and Australia. A few Neotropical species have been described, but it is not clear if they are really congeneric with those in Asia.

Virtually all species are confined to rainforest or to secondary vegetation in rainforest areas, from sea level to c. $1700 \mathrm{~m}$ altitude. None have a capacity for dormancy so the genus is largely excluded from strongly seasonal areas, species richness falling off very sharply as seasonality increases. While most species are terrestrial, often abundantly 
common in the forest herb layer, a significant number are rheophytes (van Steenis, 1981) or lithophytes, sometimes restricted to particular substrates. There is a very high degree of local endemicity of species in this genus, particularly in Borneo.

Most species are relatively diminutive plants, though Schismatoglottis corneri is a massive arborescent pachycaul. In about a third of the species (all related to S. calyptrata) shoot organisation is modified in a way remarkable in Araceae but not uncommon in monocotyledons, such that the stem is hypogeal and the sympodium physiognomically branched. However, the majority of species have a typical Araceous shoot organisation consisting of an epigeal physiognomically unbranched sympodium. All species have rather uncomplicated (for Araceae) simple entire leaves with striate venation. Many species have the leaves strikingly variegated in the wild state, and they are often polymorphic with regard to variegation pattern. They have horticultural potential, though this is somewhat constrained by the soft nature of the leaves of most species, and their consequent intolerance of low humidity. The leaves of some species are edible and a few species have been used as aquarium plants (e.g. S. roseospatha).

Schismatoglottis inflorescences are generally rather small and inconspicuous, characterised by a complex spadix with up to three different kinds of staminode present, the fertile elements segregated into male and female zones on the spadix often separated by a sterile zone, and a sterile appendix. The spathe limb characteristically falls at or soon after anthesis, and is often caducous. Structures corresponding unequivocally to flowers are unrecognisable in the female zone, which consists of a mass of pistils not regularly subtended by any other structures. Organisation of the stamens into male flowers is not (or barely) externally detectable in most species, though dissection may reveal some connation of filaments. The stamens themselves are highly variable in structure. The fruits and seeds are minute.

Schismatoglottis has not been revised for almost 90 years. This account, in which Yuzammi has contributed the Javan species (modified from Yuzammi, 2000), aims to provide revised species definitions and keys as a precursor to the Flora Malesiana account of Araceae. It is necessarily limited by time constraints, and by the usual difficulties in interpreting herbarium material of Araceae. Even though fairly extensive field work has been carried out and plants studied in a large living collection at the Royal Botanic Gardens Sydney, many species are still known to us only as dried specimens, and in others where we have seen living plants, variability has still had to be interpreted largely from herbarium material. For these reasons, together with the high level of endemism which results in new species being discovered on almost every expedition in Borneo, there is still much work to be done on this genus. We hope this revision will help stimulate it.

\section{History}

Rumphius (1747) made the first scientific description of a Schismatoglottis which he named Arisarum esculentum, based on plants from Ambon in Maluku; Roxburgh (1832) renamed it Calla calyptrata. When the genus Schismatoglottis was erected by Zollinger and Moritzi (in Moritzi, 1846) the combination S. calyptrata was made and that species became the type species of the genus. Prior to that however, Hasskarl (1842a) had recognised that Javan plants of this species were the same as Arisarum esculentum and (superfluously) named them Colocasia humilis. Zollinger (1854) added another Javan species, S. rupestris, based on his own material, which was named a second time by Miquel (1856) as S. latifolia, based on material collected by Junghuhn. Then Schott erected two allied genera (now regarded as synonyms), Apatemone (1858a; A. motleyana = Schismatoglottis motleyana (Schott) Engl., from Borneo based on Motley specimens 
collected on Labuan) and Apoballis (1858b; A. neglecta = Schismatoglottis rupestris). By 1860, in his account of the whole family, Schott still only recognised four species (including $S$. calyptrata and two species now regarded as its synonyms, and S. rupestris) in addition to those two in segregate genera. In 1865, Schott erected a third segregate genus now also regarded as a synonym of Schismatoglottis - Colobogynium (Bornean S. tecturata (Schott) Engl.). By the time of Engler's first revision of the family (1879a), there were still only 12 species in Schismatoglottis, together with two in segregate genera. Others were added to Schismatoglottis that year as Engler examined Bornean material collected by Beccari (Engler, 1879b). N.E. Brown, Kew's aroid expert in the late 19th Century, also described piecemeal some, mainly ornamental taxa in Schismatoglottis using material from British and European nurserymen's collections (e.g. Brown, 1882). Later, with Hooker's publication of Araceae for the Flora of British India (1893), additions to the genus were made for the Malay Peninsula and in the late 1890s Hallier, working from Bogor and accompanying Nieuwenhuis on one occasion to Borneo, described species and varieties from there and Sumatera (Hallier 1896, 1897).

Nieuwenhuis's expeditions to Borneo, made in the 1890s, were distinguished, in this context, by the collection by Indonesian assistants from Bogor of a substantial quantity of living material, among it an evidently large, but unknown, number of accessions of Schismatoglottis. After the death of Schott, Engler had emerged as the world authority on Aroids and he received at Berlin duplicate material collected from all over Malesia. He rarely went into the field, but did visit Bogor in 1905/6 and on that occasion examined the material still growing from the Nieuwenhuis expeditions as well as other sources, and he based a considerable number of new species on it. This was the lead up to the publication in 1912 of his Pflanzenreich revision of the genus where about six times as many species (including those in segregate genera which he merged with Schismatoglottis) were recognised as there had been in his revision of 1879 .

At about this time Ridley, that prodigious generalist who took something of a special interest in Araceae (e.g. Ridley, 1905), described piecemeal a number of species from the Malay Peninsula and Sarawak, and worked on collections from New Guinea made by Boden Kloss (Ridley, 1916).

Many species were later described from Bogor by van Alderwerelt van Rosenburgh (Alderwerelt, 1922 a \& b). He too worked on the living collection (still longer than Engler after the plants had been incorporated into it - see below), as well as herbarium material, naming Schismatoglottis from Sumatera, Borneo, Sulawesi, Maluku and New Guinea. He appears to have had little conception of variability within species, describing sometimes very narrowly defined taxa; he also never studied Schismatoglottis in the field, provided no keys and frequently omitted to make critical comparison of his new species with any already described.

Meanwhile, Merrill had left the Philippines species to Engler to describe. Elmer (1938, 1939) later (and abortively - without latin diagnoses) described two Philippine species. Furtado, based at Singapore, accompanied Joseph and Mary Strong Clemens to Mt Kinabalu in 1932. Of Araceae, he was mostly interested in Homalomena, but published one species of Schismatoglottis and collected material of others, including the gargantuan $S$. corneri (described here). Thereafter, there was virtually no work on the genus until that published by Hotta in 1966, describing several remarkable new species from Sarawak and Brunei, and, based on them, proposing an informal infrageneric classification. Since then some new names and/or new species have been published by Bogner (partly with Nicolson) and by Hotta in the 1980's and by Okada et al. very recently (1999). Hay (1996) gave an account of the genus in the Malay Peninsula. 
There are very few studies of the biology of any Schismatoglottis, with the noteworthy exception of those by Hotta et al. (1985) and by Okada and colleagues (Okada, 1984, 1986, 1989, 1992, 1993; Okada \& Hotta, 1987; Okada et al., 1999).

\section{Relationship of Schismatoglottis and the Schismatoglottideae}

The tribe Schismatoglottideae includes, besides Schismatoglottis, four small 'satellite' genera, Aridarum Ridl. (incl. Heteroaridarum M. Hotta), Bucephalandra Schott (incl. Microcasia Becc.), Phymatarum M. Hotta and Piptospatha N.E. Br. (incl. Gamogyne N.E. Br., Hottarum Bogner \& Nicolson and Rhynchopyle Engl.) These all comprise facultatively or obligate rheophytic species with ligular leaf sheaths and all are endemic to Borneo except the last, which extends to the Malay Peninsula and Thailand. The relationships of these genera within the Schismatoglottideae have not been assessed phylogenetically, but it seems likely that Schismatoglottis will turn out to be paraphyletic with respect to some or all of them. For the Flora Malesiana account, the satellite genera will be treated individually (see Bogner \& Hay, $2000-$ in this volume, where a key to the genera of Schismatoglottideae and the treatment of the tribe can be found).

The closest relationship of the Schismatoglottideae is, according to the most recent studies (French et al. 1995; Mayo et al., 1997), with Cryptocoryneae. This aquatic tribe includes Cryptocoryne - widespread in Indomalesia and centred on Borneo, and Lagenandra which is confined to India, Sri Lanka and Bangladesh. The system of French et al. (1995) is based on molecular data and influenced that of Mayo et al. (1997). With regard to the relationships of the Schismatoglottideae, systems based on morphological and anatomical data, such as those of Grayum (1990), Bogner and Nicolson (1991) and Seubert (1993), conflict to greater or lesser extent with each other and with the molecular findings, though Grayum was impressed by the similarities between Cryptocoryneae and Schismatoglottideae. Nevertheless, they agree, with the exception of Seubert (1993), in not supporting Engler's (e.g. 1912) placement of Schismatoglottidinae and Homalomeninae together in Philodendreae. Homalomena, which superficially resembles Schismatoglottis and is often confused with it by nonspecialist collectors, is now, together with West Malesian Furtadoa M. Hotta, more clearly allied with neotropical Philodendron while Schismatoglottis is not.

\section{Infrageneric classification}

The first infrageneric classification attempted for Schismatoglottis was that of Engler (1879a: 349). Only eight species were included in the genus, and the system simply differentiated S. tecturata (Schott) Engl. (as S. variegata Hook. f. ex Engl.) from the rest. In the Pflanzenreich revision (Engler, 1912) far more species were known, but no infrageneric classification was attempted at all. Hotta (1966) proposed some informal species groups, but these were almost entirely based only on the species he was describing as new in that paper. He proposed a S. homalomenoidea M. Hotta group, which included that species plus S. parviflora M. Hotta and S. beccariana Engl., all of which are treated here as synonyms of $S$. tecturata; a group of $S$. monoplacenta M. Hotta and S. platystigma M. Hotta - species with ligular leaf sheaths although Hotta did not specify characteristics; a Schismatoglottis barbata Engl. group, including S. cordifolia M. Hotta (= S. hottae Bogner \& Nicolson) and S. rubiginosa M. Hotta (here provisionally treated as a synonym of $S$. barbata) - a group defined by coarse indumentum on the leaves and by broad stigmas; a Schismatoglottis acutifolia (Engl.) M. Hotta [non Engl.] (=S. schottii Bogner \& Nicolson) group made up of two species previously described in Piptospatha, one of which, S. havilandii (Engl.) M. Hotta is regarded here as properly belonging in Piptospatha (and synonymous with P. grabowskii Engl.), plus a new species 
S. erecta M. Hotta - a group characterised by small orbicular stigmas with a basal constriction, ligular leaf sheaths and the spadix fertile to the apex. Lastly he recognised a $S$. calyptrata group containing four new species - a group characterised by a long, fully attached leaf sheath, small sessile stigmas, 2-4 placentas and an appendix of 'sterile male flowers'. These groups are partly congruent with those proposed here.

The informal infrageneric classification here is no more than a first attempt at grouping all the known species. A key to the species groups is provided and a short diagnosis of each given in the body of the taxonomic part of this paper, in which species are treated in alphabetical order under their species group heading. The classification is not generated by a rigorous approach nor is there any phylogenetic dimension. Those are beyond the scope of this Flora Malesiana precursor whose aim is simply, in a short time, to clear up an extremely messy genus enough for a flora account to be prepared and problem areas to be highlighted for further study (see below).

\section{Geography and endemism}

Schismatoglottis has the vast majority of its species in Indomalesia, while a handful is recorded from the Neotropics (Bunting, 1960; Bunting \& Steyermark, 1969). Those latter include species formerly recognised in the genus Philonotion Schott which Bunting (loc. cit.) reduced to a section in Schismatoglottis. Whether the neotropical species really belong in Schismatoglottis remains to be verified by macromolecular analysis. Within the Old World part of the range, the genus (and the tribe) is centred on Borneo, where 60 species are found, $95 \%$ of them endemic. While the majority of species and the greatest level of diversity of species is found in Borneo, one species group, that around S. rupestris, is absent from that island (save some dubious records probably attributable to mislabelling of Korthals material). This group extends from Thailand through the Malay Peninsula to Sumatera, where it is most diverse, and on to Java and Nusa Tenggara. The species in this group are, with a few exceptions, variable and difficult to define, which may in turn suggest recent origin on Sumatera and more recent extension into the Malay Peninsula and Java.

The Malay Peninsula, where there are only seven species, is remarkably diverse, with representation of all but one of the major species groups proposed here - there are no species with free leaf sheaths, though Piptospatha, to which some of these species may be closely allied, is represented (and all the remaining satellite genera are confined to Borneo). Only Schismatoglottis scortechinii, whose relatives in a diverse grouping around Schismatoglottis asperata are otherwise almost entirely confined to Borneo, is endemic, all other Malay Peninsula species of the genus being found as well in Sumatera and/or Borneo. Schismatoglottis calyptrata extends almost throughout the Old World range of the genus, from Indochina to Vanuatu. Its allies, which together form the largest infrageneric grouping, include in the Malay Peninsula Schismatoglottis wallichii, remarkable for its apparent homoeotic exchange of position of the male zone and appendix, which is commonest and most variable in the Malay Peninsula and extends to Sarawak and North Sumatera. Schismatoglottis longifolia, which appears something of an outlier in this group, having unusually long, slender, wiry and apically nodding peduncles (rather resembling those of Piptospatha), is restricted to Perak and a few localities in Sarawak and Brunei. The Schismatoglottis rupestris group is represented in the Malay Peninsula by $S$. brevipes and the highly variable S. mutata, both also in Sumatera. Schismatoglottis brevicuspis extends from the Malay Peninsula into Sumatera and is the only member of the $S$. asperata group there. The Bornean $S$. tecturata group, represented by two species, has an extension off the tip of the Malay Peninsula represented by disjunct records of $S$. tecturata itself in the Riau Archipelago. The gigantic S. corneri, here regarded as an isolated species in its own 'group', also Bornean, approaches the Malay Peninsula (though much less closely than S. tecturata) 
through representation in the Anambas Islands. This last species has a curious parallel in the also gigantic, also Bornean Alocasia robusta M. Hotta which extends to the Natuna Islands (Hay, 1998).

Schismatoglottis ecaudata is an endemic Sumateran member of the S. calyptrata group. Otherwise, besides the above-mentioned S. brevicuspis in the S. asperata group, and $S$. calyptrata and $S$. wallichii in the S. calyptrata group, the Sumateran represention of Schismatoglottis consists of members of the $S$. rupestris group, with all species except S. mutata, S. brevipes and S. rupestris itself (extending to Java and Nusa Tenggara) endemic, including the rheophytic S. okadae.

On current evidence it appears that northwestern Borneo is distinctly more speciesrich and diverse than eastern and southern Borneo, though it must be said that northwestern Borneo has been the more intensively collected both by general collectors and by specialists in Araceae and Schismatoglottis in particular. Most of the Bornean species are divided between the S. calyptrata group, the S. asperata group and the $S$. multiflora group. In addition are three species whose affinity is unclear. They are S. tecturata, with very short leaf sheaths and foliage leaves alternating with cataphylls which take on the role of the leaf sheath, and persistent/marcescent spathe limbs, $S$. petri (Brunei), which may be related to $S$. tecturata, and $S$. corneri - a gigantic arborescent pachycaul species from northwestern Borneo with pleionanthic shoots, fully attached sheaths and huge pendulous inflorescences with semi-persistent closed spathe limbs and apparently unspecialised organisation of the spadix.

The S. calyptrata group in Borneo includes the remarkable S. niahensis, which, very rarely for this group, has pleionanthic shoots - presumably a plesiomorphy in this alliance. This habit is also found, in this group, in Philippine S. merrillii and S. plurivenia, and possibly also $S$. luzonensis. Stem organisation is not determined for some species however, so the pleionanthic habit may turn out to be less uncommon in this species group. Besides S. calyptrata itself, there are three highly variable widespread endemic species in Borneo, S. motleyana, S. trifasciata and S. trivittata, which are somewhat difficult to distinguish from one another at the extremes of their variation. By contrast, there are also a number of more localised species, several with specialised ecology - for example, the rheophytic S. ahmadii, calcicolous S. viridissima, lithophytic and calcicolous S. venusta, and S. decipiens and S. silamensis confined to ultramafic substrate, and others.

While the S. calyptrata group extends well beyond Borneo, and is the only group extending north and east, the $S$. asperata group is, besides above-mentioned exceptions in the Malay Peninsula and Sumatera, endemic. Whether it is a natural unit remains to be ascertained. There is a very high level of local endemism in this grouping, though S. asperata - a variable species as conceived here - is widespread in northwestern Borneo, and S. patentinervia, circumscribed with some doubt owing to lack of adequate flowering material, is widespread though fragmented in Borneo. No species in this grouping is unequivocally rheophytic. The $S$. multiflora group, by contrast, is commonly rheophytic. It is entirely confined to Borneo, with only S. multiflora itself at all widespread.

All nine species in the Philippines are of the $S$. calyptrata group, with some considerable morphological and ecological diversity. Schismatoglottis plurivenia and others, as has been said, have pleionanthic shoots. Schismatoglottis luzonensis is a stenophyllous rheophyte, while $S$. mindanaoana is a diminutive, elongate, creeping lithophyte.

The two endemic species in Sulawesi (and the two non-endemic species) are also of the $S$. calyptrata group, and are one rheophytic and the other a calcicolous lithophyte. In Maluku, in addition to S. calyptrata, is one endemic terrestrial species in that same 
group, S. wahaiana, which is rather similar in inflorescence to the two endemic Sulawesi species. Extending east to New Guinea and Vanuatu, only Schismatoglottis calyptrata is represented. In New Guinea itself, this species, variable throughout the rest of its range, becomes even more highly so (and has been named there 11 times). On the basis of herbarium material and the limited number of living plants A.H. has been able to study from there, we are unable to distinguish separate species. But even if there transpires, on more intensive study, to be a set of closely allied segregates, this would not much alter the picture of very low diversity of Schismatoglottis in New Guinea relative to Borneo, Sumatera, the Malay Peninsula and even the Philippines.

The sharp falling off of diversity of Schismatoglottis east of Borneo, suggests that the genus has extended east of Wallacea relatively recently. This is in variably marked contrast to the distributions of other fairly large aroid genera, including monoecious Typhonium (Hay, 1992, 1993), Alocasia (Hay \& Wise, 1991; Hay, 1998) and Homalomena (Hay, 1999), but not dissimilar to Cryptocoryne.

\section{Conservation status}

Almost a quarter of the species of Schismatoglottis in Malesia are known only from their types, and nearly half are known from three or fewer herbarium records. Doubtless some apparent cases of rarity are artefacts of undercollecting, but the frequency of cases strongly suggests that there is a real high level of very local endemism in this genus, especially in Borneo. This is supported by examples of more frequently collected species with very restricted distributions within relatively well-known areas, such as S. mayoana (Matang, Sarawak), S. venusta (Gomantong, Sabah), S. clemensiorum and S. retinervia (Kinabalu, Sabah), S. viridissima (Lundu, Sarawak), S. nicolsonii (Bako, Sarawak), S. platystigma (Temburong, Brunei) and so on. Highly localised species are sometimes abundantly common within their range, for example S. ferruginea, S. bauensis, S. platystigma and S. venusta. Nevertheless, these species are, on the basis of currently available distribution data, potentially threatened by the destruction of quite small areas of habitat. Confirmation of their conservation status by botanists with ready field access is needed before any species are proposed for listing as endangered.

\section{Structure and terminology}

Aspects of the morphology of Schismatoglottis were discussed in Hay (1996) in a revision of the genus in the Malay Peninsula. However, some elaboration is required here as this revision covers a much greater diversity of species. Due to lack of adequate material, certain features have not been clearly observed in some species. Where this is the case, it is indicated by question marks in the descriptions. Terms used in the key, other than terms in very general botanical usage, appear in a short glossary before the keys.

\section{Habit}

Schismatoglottis vary from massive arborescent pachycauls (e.g. S. corneri) to very diminutive creeping herbs a few centimetres tall (e.g. S. mindanaoana). Stems are sometimes condensed, with much compressed internodes or in varying degree elongated with distinct internodes that may be several times longer than thick (e.g. $S$. convolvula). Tubers or other storage structures associated with dormancy are absent and it appears that almost all species are confined to 'everwet' habitats, particularly rainforest floor (from sea level to c. $1700 \mathrm{~m}$ alt). Schismatoglottis calyptrata and S. rupestris do however, occasionally penetrate more seasonal areas, surviving in damper 
pockets and persisting wilted through dry periods. Lithophytic Schismatoglottis venusta has somewhat coriaceous, slightly succulent leaves which appear to enable this species to survive irregular short periods of extreme drought. Schismatoglottis are commonly found on steep soil banks in forest where, perhaps, the minute seeds can adhere and and seedlings are less likely to be buried by leaf litter. A number of species are facultative (e.g. S. tecturata) or obligate (e.g. S. multiflora) rheophytes, but no truly submerged aquatic species is known. Several species are lithophytic, mostly but not exclusively on limestone (e.g. S. venusta, S. bauensis, S. puberulipes).

\section{Shoot systems}

The division of Schismatoglottis shoot systems into two broad categories as outlined in Hay (1996) still stands. In many species allied to S. calyptrata, the apical portion of the shoot does not renew growth after flowering (atypically for Araceae), and the plant persists by the release of lateral buds low on the shoot, the remainder of which subsequently dies. Stems are usually condensed (but sometimes arising on the ends of long stolons (e.g. colony-forming S. longispatha)) and hypogeal in these species, though in S. convolvula the shoots are elongate, epigeal and sprawling. Such shoots are termed hapaxanthic, and resemble a 'typical' herbaceous monocotyledonous shoot organisation, conforming to Tomlinson's Model of shoot architecture (Hallé et al., 1978). By comparison with the general plan in Araceae, it would appear that this state in Schismatoglottis is convergent with similar states in other monocotyledons. The remaining species of Schismatoglottis show a typical Araceous shoot organisation in which the apical portion (though not the anatomical shoot apex itself) renews growth more or less contemporaneously with flowering, forming a physiognomically unbranched sympodial and usually epigeal shoot, conforming to Chamberlain's Model (Hallé et al., 1978). These are termed pleionanthic. Shoots of this kind may be much condensed (e.g. S. puberulipes) or, more usually, elongate and then erect, decumbent or creeping. The two broad types of shoot organisation are present among rheophytic, lithophytic and forest floor species. No species in which both shoot types occur is yet known.

\section{Leaf}

The leaf base is sheathing, generally for about $1 / 3-3 / 5$ the length of the petiole, reflecting the fact that leaf emergence in Schismatoglottis takes place at a late stage in the expansion of the blade (cf. Cyrtosperma where leaf emergence takes place with the blade at an early stage of expansion and where the leaf sheath is relatively short Hay \& Mabberley, 1991). Schismatoglottis tecturata however, has very short leaf sheaths, with the role of protecting the next developing leaf blade being taken on by cataphylls which alternate with the foliage leaves (analogous to certain Alocasia species, e.g. A. peltata M. Hotta and A. kerinciensis A. Hay, as well as many Philodendron species). In several Schismatoglottis, e.g. S. roseospatha, S. schottii, S. barbata, the wings of the sheath are attached to the petiole only in the basal part, the rest being extended into a ligular portion. This condition is also found in other genera of the Schismatoglottideae, but within Schismatoglottis the ligular species, taken altogether, do not seem to represent a natural grouping. Its adaptive significance is unclear; however, most of the species of Schismatoglottis (and all other species of Schismatoglottideae) with ligular sheaths are rheophytic. Conceivably it frees the fragile shoot apex and developing leaves to some extent from torsion due to the effect of turbulent water catching the exposed leaf blades, but not all rheophytic species of Schismatoglottis have ligular sheaths (e.g. S. okadae, S. ahmadii), and not all species with such sheaths are rheophytic (e.g. S. erecta, S. schottii, S. bauensis). In species with fully 
attached leaf sheaths, the wings are generally perisistent, while typically in those with ligular sheaths, they are often marcescent and sooner or later deciduous. The majority of species allied to $S$. rupestris have, to a greater or lesser degree, fully attached leaf sheaths the wings of which wither and disintegrate as or soon after the enclosed leaf has emerged, which in turn may have pieces of dead leaf sheath wing attached to it.

Between the sheath and the blade, the petiole may be more or less terete, D-shaped in cross section, channelled and/or sometimes narrowly alate with the wings sometimes crisped. Rarely the petiole is conspicuously longitudinally ribbed (S. nervosa).

Many species have an indumentum on the leaves (extending sometimes to the peduncle and spathe). The most conspicuous examples are S. barbata, S. crinitissima, S. ciliata, S. pyrrhias and S. ferruginea, in which the petiole and sometimes the abaxial midrib and major venation, leaf margin and adaxial surface of the blade have dense to sparse coarse multicellular scale-like hairs up to c. $4 \mathrm{~mm}$ long. Some forms of the S. trifasciata complex have a fine velvety covering of straight slender hairs individually just visible to the naked eye, while a number of other species have a dense to sparse covering of minute unicellular hairs requiring a strong lens to see individually and giving the appearance of a glaucous bloom to the petiole (e.g. S. puberulipes). In some cases the fine indumentum is easily dislodged or even deciduous (e.g. S. hottae) and needs to be observed on younger leaves, which may have a mealy appearance as the indumentum detaches. Intergrading with such fine unicellular hairs are species in which they are much shortened into minute papillae, giving the petiole an asperous texture (e.g. S. ovata, forms of S. trifasciata), and this is elaborated in some forms of S. asperata (especially at Matang, Sarawak) in which the papillae are themselves collected onto larger papillae and the petiole is coarsly asperous with a glistening crystalline appearance. The majority of species however, are glabrous.

The leaf blade varies from lanceolate (common in, but not confined to, rheophytic species) to hastate, but is generally sagittate and always undivided. There is a midrib (or anterior costa) supplying the anterior lobe, but, when present, the posterior lobes are supplied by a collection of primary veins coming together at the junction of the blade and petiole and generally not by distinct posterior costae (in contrast to, for example, Alocasia), though in S. unifolia posterior costae are present. The apex is often acuminate and sometimes apiculate with a persistent cylindric or tubular mucro. Rarely (in some individuals of $S$. multiflora) the blade is bulbiliferous on the abaxial side close to the midrib.

Primary veins run pinnately off the midrib, the lowest ones often close together or basally united. Higher order venation is striate, and exists in a number of orders of decreasing magnitude. It is not always easy however, to consistently identify the number of orders (cf. Alderwerelt, 1922 a \& b). The convention used here is to recognise between the primary veins (the thickest arising from the midrib) interprimary veins which also arise from the midrib and which alternate with the primaries but which are generally distinctly more slender than them. Veins of similar thickness to the interprimaries may also arise from the primary veins themselves, giving the appearance of branched primary veins; these are termed subsidiary veins. Secondary veins are more numerous and finer than the interprimary veins. They run from the midrib and sometimes also arise from the bases or even from along much of the length of the primary veins so that the venation is bipinnate, at least in the lower part of the blade. There may be some variation in the thickness of the secondary veins, and arguably one could recognise one or more additional venation orders among them. However, we have not done so here, as attempts at doing so generally become excessively arbitrary. The finest venation consists of cross-veinlets linking the secondary veins. These are called tertiary veins here. They and the secondary venation are sometimes obscured by the thickness of the epidermis. However, in some species, 
the tertiary veins are characteristically conspicuous as a tessellate reticulum (e.g. S. mindanaoana, S. puberulipes, S. gamoandra) at least in the dry state.

Variegation of the leaf blade is a common phenomenon in Schismatoglottis, though many species are not recorded as being variegated at all. While there is no firm infrageneric classification of the genus, it appears that most species groups have species with variegated individuals. The Schismatoglottis rupestris group is unvariegated except for $S$. acuminatissima. Species of the big alliance around $S$. calyptrata are frequently variegated. Species around S. asperata are mostly not variegated (e.g. S. retinervia, S. patentinervia) but S. asperata itself, S. ciliata and S. scortechinii are. Schismatoglottis pudenda, rheophytic with ligular sheaths, has variegated leaves, while S. multiflora occasionally does. Several of the ligular species do not seem to have variegated leaves at all.

Variegation patterns typically vary within species, and similar, overlapping sets of patterns are found repeatedly in different, sometimes quite distantly related species. The simplest (in appearance) pattern is a single stripe down the middle of the leaf blade. This may be 'split' into two variegated bands, one on each side of the midrib generally about midway between the midrib and margin. To this may be added a central band, and this in turn may be 'split' so that there are two bands in the lamina on each side between the midrib and margin. This last state is found only in Schismatoglottis zonata. Several species have, instead or in addition, irregularly blotched variegation, variously fine (e.g. S. motleyana), or conspicuously bold (e.g. S. decipiens).

Almost all variegated species which are known from a reasonably large number of collections have a greater or lesser proportion of non-variegated individuals. Together with the occurrence of variegation in apparently all or most of the major groupings within the genus, and the occurrence of repeated sets of variegation patterns in more or less distantly related species, this may suggest that this mixed state is a plesiomorphy. Alternatively it suggests an interesting predisposition in different lineages within the genus not only to evolve variegation inself, but variegation in certain repeated sets of patterns. The biological significance of variegation in Schismatoglottis is unexplored.

\section{Inflorescence}

Inflorescences in Schismatoglottis are usually solitary in some species (e.g. S. retinervia, $S$. patentinervia), though typically in these, robust individuals will make a small synflorescence of two or three inflorescences in series. Most species however, usually generate synflorescences of several inflorescences. The first inflorescence may be subtended by a foliage leaf, or by a cataphyll or short series of cataphylls, subsequent inflorescences being subtended by prophylls (indicating the sympodial structure of the synflorescence) and cataphylls (these sometimes with reduced petiole and blade). In species in which the leaf sheath is fully attached to the petiole, the cataphylls typically have a terminal mucro representing the aborted distal parts of a leaf. In those species in which the sheath is ligular, the cataphyll has the mucro positioned low on the abaxial side corresponding roughly with the position of departure of the petiole from the sheath wings in the foliage leaf.

The peduncle is often short at anthesis, barely exserted from the subtending foliar member, though in some species the inflorescence is long-exserted (e.g. S. corneri, S. longifolia). Usually the peduncle elongates as fruits develop. In some species the peduncle (and lower spathe) is clearly coloured and ornamented in the same manner as the petiole. Examples are the coarsely hairy peduncles and lower spathes of S. ferruginea, and the black and asperous peduncles and lower spathes of a form of 
S. trifasciata at Sepilok, Sabah. These examples would appear to give some support to the contention of Hay and Mabberley (1991) that the inflorescence of Aroids is a hybrid structure incorporating a foliage leaf, repeating expression of leaf surface features in the peduncle and spathe.

The spathe in Schismatoglottis is almost always differentiated into a lower persistent portion enclosing the female zone of the spadix and a more ephemeral limb subtending the male zone and appendix. The point of differentiation is usually marked by a constriction which gapes at female anthesis to allow access by pollinators, and then tightens, apparently preventing self-pollen falling into the lower spathe chamber. At female anthesis the limb is usually inflated and gapes somewhat also, occasionally (e.g. S. elegans) opening wide and reflexing, or in some instances hardly opening at all (e.g. S. rupestris and immediate allies, S. corneri). The limb is caducous at male anthesis in species allied to $S$. calyptrata and in the S. multiflora group, abscising cleanly at the top of the lower spathe and falling while the tissue is still fresh, leaving the male zone and appendix (if present) exposed. Indeed this characteristic is the basis for the generic name. However, this is not universal in the genus. In Schismatoglottis asperata and allies such as $S$. scortechinii, the limb crumbles and disintegrates in a rather irregular manner. In species allied to $S$. rupestris, and in S. corneri, the limb persists for a while after anthesis, and then gradually degrades and falls still clasped around the spent parts of the spadix. In $S$. tecturata only the marginal and distal parts of the spathe limb begin to wither after anthesis, the remainder persisting well into infructescence. A particularly interesting case is that of $S$. barbata. Here the spathe is not constricted at all, but egg-shaped. This is characteristic of the allied genus Piptospatha, but the two examples are evidently not fully homologous. In Piptospatha, though there is no constriction, there is clear demarcation into a lower spathe associated with the female zone, and the caducous limb associated with the male zone (except for those species in which the whole spathe is persistent). In Schismatoglottis barbata however, only the extreme, acute tip of the spathe is deciduous, leaving the entire spadix within the remainder. Thus it appears that the bulk of the spathe in S. barbata is homologous to the lower spathe of other species, while the limb is reduced to the acute spathe tip, with the constriction obscured by the fact that the extreme distal portion of the spathe is narrowed anyway. This requires developmental analysis.

Spadix structure in Schismatoglottis is intricate. Broadly it is divided into a lower female zone, a middle male zone which may or may not be separated from the female zone by a sterile portion or interstice, and a terminal appendix. The female zone is often adnate, for up to two thirds of its length (rarely completely), to the lower spathe, though in many instances it is free. The distal part of the female zone, usually corresponding to the spathe constriction, is often attenuate and with the pistils more laxly arranged (and often squashed by the spathe) than lower down. The pistils are often intermixed by distinctly irregularly arranged staminodes here called interpistillar staminodes. In many species the interpistillar staminodes are confined to a basal ring or to a single row along the spathe/spadix adnation. Commonly the interpistillar staminodes are concentrated in the distal part of the female zone and may occupy the sterile interstice to the exclusion of pistils. This is not always the case however, and the sterile interstice may be absent, or occupied by apparently abortive pistils (e.g. S. elegans), or it may be occupied by staminodes which resemble sterile anthers rather than interpistillar staminodes. In some species, e.g. S. scortechinii, the sterile interstice may be in two parts, with a zone of interpistillar staminodes at the base and whorls of sterile anthers distally. In species allied to $S$. rupestris, the interstice is large and mostly naked, usually with a concentration of interpistillar staminodes at the base, distally with scattered groups of significantly smaller staminodes. An interesting case is that of $S$. wallichii, where the sterile interstice is very robust and occupied by staminodes which resemble those of the appendix of related species - 
this being absent in S. wallichii; it may be conjectured that the male zone and terminal appendix have 'switched' positions in this species. In Schismatoglottis zonata the sterile interstice is also composed of staminodes much resembling those of the appendix which, in this species, is well-developed. The male zone, as has been noted, is usually distal to the spathe constriction, but in S. pudenda it is completely within the lower spathe chamber, while in species such as $S$. motleyana and the $S$. trifasciata complex the lower part of the male zone is usually within the lower spathe chamber and the rest is exserted. The male zone is generally subcylindric, but frequently obconic. Schismatoglottis barbata is remarkable in having the fertile male zone reduced to a group of stamens on the ventral face of the spadix, the remainder of the normally male part being occupied by staminodes resembling those of the appendix. Whether there is a functional relationship between this and the remarkable spathe morphology of this species is unknown. Schismatoglottis sarikeensis also has the dorsal side of the male zone sterile, and in this case adnate to the spathe. The appendix in Schismatoglottis varies from narrowly cylindric and elongate, to hemispheric, and is composed of usually flat-topped (but sometimes rounded to pointed) irregularly polygonal columnar staminodes. There may thus be as many as three different types of staminode present in the spadix, and while these structures are termed staminodes, their homology is not well-established.

Aside from the sometimes present irregularly distributed interpistillar staminodes, the pistils are naked, and crowded to lax; they are generally small and numerous (thousands in S. corneri) and subglobose to bottle-shaped to cylindric. In general, the more robust species or more robust individuals within species have a tendency to produce cylindric pistils. Placentation, where known, is basal to parietal with 1-3 placentas. This characteristic has not been comprehensively studied for this rapid revision aimed at a Flora Malesiana account, which concentrates on using more easily observable characters (naked eye to hand lens) useful for identification. Stigmas are mostly sessile, sometimes raised on a short style, and discoid to punctiform and usually but not always papillate. Interpistillar staminodes are usually clavate - often strongly so, and flat- to round-topped. They are subsessile to long-stipitate and then sometimes as much as twice the height of the pistils.

The stamens of Schismatoglottis exhibit a remarkable range of form, and we hope that this revision will pave the way for a detailed systematic study of their morphology and function (some steps have already been taken by Hotta, 1966 \& 1993). In many instances the flowering parts of the species are known only from dried, scant and not always well-preserved material, and there are therefore limitations on the detail in which this aspect of the genus can be discussed at present. Viewed from the surface, the male zone consists of massed stamens not arranged or orientated into groups that might be termed male flowers (contrast Homalomena). The stamens are generally truncate and raised on short filaments or occasionally sessile (e.g. S. platystigma). The filaments are often but not always partially connate into small groups of two or three, and in S. ciliata, for example, the stamens are in pairs fully connate but for the raised narrowly pyramidal connectives. It can be argued that in these instances male flowers are identifiable. However, it does not seem particularly useful to do so for the purposes of species definition and identification, and seems of limited use in generating an infrageneric classification. Moreover, since no other floral parts are present, it can equally be argued that there is simply a mass of stamens in which there is a tendency for local connation of the filaments. One point of view is conservative, forcing the homology, the other radical, reflecting the absence of functional and weak structural individuation of groups of floral parts in this genus.

The anthers consist of two thecae more or less separated by a broader or narrower connective which is sometimes elevated into a tongue-shaped (e.g. S. bogneri) to 
narrowly pyramidal (e.g. S. ciliata) extension or, by contrast, exceeded by the thecae (e.g. S. motleyana and many other members of the $S$. calyptrata group). The thecae usually each include two pollen sacs which open through a common pore, but in S. mayoana, S. pudenda and S. schottii, for example, each pollen sac opens through its own individual pore. In $S$. erecta, the rather broad connective has a distinctive groove running between the pores. Schismatoglottis longispatha and S. motleyana, appear to have confluent thecae (the latter in some stamens of some specimens only) opening through a single pore. The remarkable $S$. gamoandra appears to have all the stamens connate, and while each has two thecae, the pollen sacs appear confluent within each one. However, it must be said that, in each of the three last cases, there is insufficient material available to confirm the stamen structure in the present study. In the descriptions here, measurements 'across' the stamen are taken along the long axis of the anther as seen from above, in situ.

\section{Fruit}

The developing fruits are contained within the persistent lower spathe, which may enlarge somewhat after flowering. Fruits are small berries, mostly greenish to yellowish, Mayo et al. (1997:125) reporting that they are occasionally dark red. The latter characteristic is apparently confined to the New World species however (Boyce, pers. comm.) When they are ripe, the fruiting spathe dehisces rather irregularly, more or less disintegrating. Seeds are usually numerous, and longitudinally ridged. In other genera of the Schismatoglottideae there is an elongate micropylar appendage. This appears not to be the case in Schismatoglottis, though the seeds have not been studied for the majority of species. There are no published observations on dispersal.

\section{Schismatoglottis, the Bogor Gardens and the Gardens Herbarium}

As has been mentioned, a considerable number of species of Schismatoglottis (and other Araceae) were described by Hallier, Engler and Alderwerelt based on living plants cultivated at Bogor. A number of problems arise from these. First, almost all the types are fragmentary, consisting of (sometimes barely) representative pieces picked from the living plants, rather than whole plants or intact flowering shoots. Second, in the case of some of Engler's species, the plants were sterile or in fruit, and are almost impossible to interpret in the absence of precise provenance data. Third, in some instances descriptions were based on living plants which were not cited, while wildcollected specimens that Engler thought matched were cited, but appear not to be conspecific with the living material which formed the basis of his illustrations and descriptions. Fourth, Alderwerelt made efforts to unravel some of the confusion, but it appears in some instances that the labels belonging to living plants that Engler studied had become transposed to other plants of different species, so that Alderwelt's attempts at sorting these problems out sometimes actually compounded them.

On the specimens which Engler made from the Bogor living collection in 1905/6 (deposited at B), he recorded a number (in addition to his collection number) pencilled onto the field labels. The purpose or origin of this number is not apparent from the labels, but in many of instances the number is the same as the plant number recorded in full (i.e. with garden bed number) by Alderwerelt (and anonymous collectors) when making specimens from the plants in the living collection in the late 1910s. Where both the plant number and specimen on Engler's and Alderwerelt's collections match, Alderwerelt's better material and completed accounts of Engler's inadequately described species are valuable in interpreting the application of those names. 
Alderwerelt also described from the Bogor garden species which Engler had not dealt with, though in many (but not all) instances the living material pre-dated Engler's visit. In the protologues, he usually indicated that he had based his description on living cultivated plants, but he did not cite the specimens he made from the cultivated plants, instead giving the original collection number given to the plant when it was gathered from the wild (e.g. 'Nieuwenhuis $1968^{\prime}$ etc.). Much of the living material that was collected for the gardens was not vouchered and therefore there are often no original preserved collections with the cited collector and number on them. The types, in these instances, are identifiable only by Alderwerelt's notations, as they often do not include the original collector number which he had cited. However, they do usually include Alderwerelt's own collection number and the Bogor Garden bed code and plant numbers, though these were usually not cited in the protologues. He often collected specimens from the same plant several times, so that lectotypes have to be selected. He often omitted to give, either in the protologues or on his specimen notes, the locality from which the plant had originally been gathered. In some instances we have not been able to find out the provenance, even with the plant's original collector's number. Nieuwenhuis's diaries may be deposited in the library at L, however, they have not yet been located (Hetterscheid, pers. comm.). If they are able to be located, they may provide the needed provenance data for the living plants on which a number of species were based.

It had been the practice to deposit specimens made from cultivated plants in a separate Gardens Herbarium under the administration of Herbarium Bogoriense. This herbarium served as a database of the living collection, and consequently was not systematically arranged, except in so far as the garden itself was systematically ordered. Instead, the Gardens Herbarium is arranged by bed code, which is the key to finding specimens in it. Within boxes of a given garden bed code (e.g. XI.B.X.) the specimens are ordered by an arabic numeral plant number suffixed to the bed code (e.g. XI.B.X.63). Bed codes and plant numbers for named taxa can sometimes be found by searching the printed gardens catalogues for the relevant period.

Specimens from the Gardens Herbarium were transferred to the General Herbarium when and if the living plants from which they were made died. However, this practice has evidently not been kept up exhaustively for many decades, leaving a considerable number of specimens of long-dead 'type plants' still in the Gardens Herbarium, while others have found their way into the General Herbarium. Thus types of aroids (and presumably other taxa) described from the gardens (few of which specimens are identified as such) should be searched for in both the General and Gardens Herbaria. The Gardens Herbarium was, until a few years ago, a physical and administrative annexe of the Herbarium Bogoriense (BO), but now resides in the administratively separate Kebun Raya. However, spirit material associated with the Gardens Herbarium specimens is still in Herbarium Bogoriense spirit collection (BO spirit). The Gardens Herbarium has no formal acronym and is here cited as BOKR (Bogor Kebun Raya). It has been proposed (Dedy Darnaedi, pers. comm.) that scientifically important material from the Gardens Herbarium will, once it has been identified, be incorporated into BO. In view of these factors, we consider it reasonable to look upon the two herbaria as one for the purpose of designating types. In the meantime, however, it is desirable to identify those type sheets that are in the Gardens Herbarium to avoid their being overlooked by subsequent workers.

Where Alderwerelt indictated that a protologue was based on cultivated plants observed flowering at various times, though specimens were not explicitly cited, it is found that he made corresponding gatherings with unique collection numbers, and lectotypes have been selected accordingly. In the numerous instances here in which types are cited as consisting of dried and spirit material, there is original cross- 
referencing on the sheets to the relevant spirit material, so that the elements can acceptably be considered as single specimens. [See Arts $8.2 \& 8.3$ of the Saint Louis Code (Greuter et al., 2000)].

\section{Foci for further study}

1. Though not a focus as such, the high level of endemism in this genus makes it a particular candidate for collection in 'off the beaten botanical track' locations, especially in Borneo. Un-named species have been found with great frequency on recent expeditions.

2. Verification of the restricted distributions of species known from few collections and/or localities is required, together with an assessment of threat factors and listing of conservation status.

3. Molecular and cladistic analysis is required, following this alpha-taxonomic review, in order to generate a phylogenetic classification which could form a framework for the study of biogeography and comparative pollination ecology of the genus. The latter would seem particularly important in understanding both the highly intricate morphology of the inflorescence, the diverse stamen anatomy of the genus (and tribe), and the evidently frequent evolution of extremely localised endemic species.

4. The Schismatoglottis rupestris group, especially in Sumatera, presents particular taxonomic problems, as inflorescences are very similar in structure among several of the species. Research foci include re-collection and an assessment of those species known only from their types, and intensive field study and analysis of variation of S. mutata, here treated as a highly variable species. Schismatoglottis mutata shows wide morphological and ecological diversity which may be able to be resolved into a number of closely allied species. Its distinction from $S$. rupestris is also problematic.

5. In the Schismatoglottis tecturata group, S. tecturata itself requires further evaluation, particularly in the Indonesian parts of its range. The current circumscription includes a wide range of variation in leaf shape and size, and inflorescence details are not well known for the representation in Kalimantan and the Riau Archipelago. Its relationship to $S$. petri requires re-examination in the light of further collection of that species.

6. Schismatoglottis calyptrata, the most widespread species in the genus, requires ecological study throughout its range. There is enormous morphological variation in the current circumscription, especially in New Guinea. Generally, detailed ecological (substrate, habitat) data are lacking in most collections, but where such data are available, such as for A.H.'s Bornean collections, it has been possible to segregate morphologically very closely allied, eco-geographically distinct species. Refinement of the circumscription of $S$. calyptrata and the recognition of segregate species in other parts of its range (particularly Sulawesi) seems a likely outcome of further field study. Attention to dispersal mechanisms in this widespread species with no obvious long-distance dispersal syndrome would likely inform understanding of the biogeography of the genus.

7. Schismatoglottis trifasciata, here treated as a complex ochlospecies (sensu White, 1962) which intergrades throughout its range but in which locally discrete entities appear to be able to coexist, would make an interesting subject in studying evolution in this genus.

8. Schismatoglottis motleyana, S. trivittata, S. trifasciata and S. calyptrata (with S. bifasciata, S. canaliculata and $S$. decipiens more or less linking them) are difficult to distinguish 
at the extremes of their variation and could repay detailed morphometric analysis. Study of edaphic preferences and pollination biology may well assist, by providing an ecological dimension, in delineating species in this alliance (and others) more confidently.

9. The issue of the relationship of the genera of Schismatoglottideae requires phylogenetic analysis, since at least some of those genera seem likely to be nested within Schismatoglottis (specifically the S. multiflora group). Further morphological and anatomical studies are required, especially of seeds.

\section{Taxonomic Part}

\section{Schismatoglottis Zoll. \& Moritzi}

Schismatoglottis Zoll. \& Moritzi, Syst. Verz. (1846) 83; Miq., Fl. Ind. Bat. 3 (1855) 214; Miq., Bot. Zeit. 14 (1856) 565; Schott, Syn. Aroid. (1856) 120; Schott, Gen. Aroid. (1858) 55; Schott, Prodr. Syst. Aroid. (1860) 320; Schott, Ann. Mus. Bot. Lugduno-batavum 1 (1863) 125 \& (1864) 281; Engl. in A. \& C. DC., Monogr. Phan. 2 (1879) 349; Náves, Noviss. App. (1882) 291; Hook. f., Fl. Brit. Ind. 6 (1893) 537; Ridl., Materials Fl. Mal. Pen. 3 (1907) 30; Koord., Exkurs.-Fl. Java 1 (1911) 259; Engl. \& K. Krause, Pflanzenr. 55 (IV.23Da) (1912) 82; Koord., Fl. Tjibodas 6 (1922) 35; Merr., Enum. Philipp. Fl. Pl. 1 (1922) 181; Ridl., Fl. Mal. Pen. 5 (1925) 110; Henderson, Mal. Wildfl. Monoc. (1954) 231; Backer, Bekn. fl. Java 17 (1957) 32; Backer \& Bakh.f., Fl. Java 3 (1968) 115; Hay, Sandakania 7 (1996) 8; Mayo et al., Genera of Araceae (1997) 182; Beaman \& Beaman, Pl. Mt. Kinabalu 3 (1998) 82. - Type species: Schismatoglottis calyptrata (Roxb.) Zoll. \& Moritzi.

Apatemone Schott, Gen. Aroid. (1858) t. 57 \& Prodr. Syst. Aroid. (1860) 318; Engl. in A. \& C. DC., Monogr. Phanerogam. 2 (1879) 355. - Type species: Apatemone motleyana Schott [= Schismatoglottis motleyana (Schott) Engl.].

Apoballis Schott, Oest. Bot. Zeitschr. 8 (1858) 317. - Type species: Apoballis neglecta Schott [ = Schismatoglottis rupestris Zoll. \& Moritzi ex Zoll.].

Colobogynium Schott, Oesterr. Bot. Zeit. 15 (1865) 34. - Type species: Colobogynium tecturatum Schott [= Schismatoglottis tecturata (Schott) Engl.].

Evergreen, sometimes colony-forming small to massive and subarborescent herbs mostly of rain forest floor or rheophytes or lithophytes, with clear sap and the vegetative tissue not or barely aromatic. Stem hapaxanthic (no renewal growth of axis after flowering) hypogeal and then rhizomatous (except epigeal S. convolvula) and suckering or stoloniferous, or epigeal and sympodial, erect, decumbent or creeping. Leaves solitary or more usually several together, simple, lanceolate to cordate, often variegated, with pinnate primary venation and striate secondary venation, pink, bronze or green when young; petiole well developed, sheathing basally, sometimes narrowly and thinly alate on adaxial angles and the wings then often crisped, sometimes asperous or coarsely to minutely hairy or velvety; sheath persistent to marcescent, crumbling or deliquescent, sometimes ligular. Inflorescence mostly powerfully fragrant (esters), anatomically terminal, sometimes physiognomically lateral by displacement, rarely and irregularly anatomically lateral where lateral 'vegetative' shoots flower 'terminally' without producing foliage leaves (e.g. S. brevicuspis), solitary or more usually several to many together in sympodial series interspersed with cataphylls forming a synflorescence; pedicels generally short and erect at anthesis, sometimes long and abruptly down-turned apically (S. longifolia, S. corneri), after anthesis often actively declinate. Spathe weakly to strongly constricted approximately at the mid-point (except $S$. barbata), the lower part convolute and more 
or less ovoid, persistent into fruiting, the upper part ('limb') broad and inflated to gaping (rarely reflexed $-S$. elegans) at anthesis and then caducous to deciduous, to narrow and clasping (opening slightly at anthesis, then closing) and shortly persistent then falling, often conspicuously mucronate, green to yellowish to white to pink, occasionally with the lower spathe matching the colour and texture of the petioles (e.g. black and scabrid in forms of S. trifasciata, coarsely hairy in S. ferruginea). Spadix shortly stipitate to sessile, often in the female zone partly adnate to the spathe, subequalling the spathe in length; female zone of naked pistils accompanied by clavate to mushroom-shaped to globose sterile organs usually interpreted as staminodes, these very irregularly interspersed among the pistils, distant to clumped, sometimes occurring in two sizes (S. brevipes, S. mutata), sometimes absent from among the pistils but then occurring as a single ring at the base of the female zone or as a sterile zone at its distal end; male zone contiguous with female zone or separated by a sometimes partly naked sterile zone; a distal appendix of staminodes usually present, sometimes entirely absent or very much reduced; ovaries globose to flaskshaped, unilocular with (1-)2-4 parietal placentas, multiovulate; ovules anatropous or hemianatropus; style short to nil; stigmas mostly papillate, discoid to more or less punctate, occasionally laterally contiguous; male flowers not (at least externally) recognizable as such, the zone a mass of stamens, or male flowers 2-3-staminate, occasionally the stamens all partially united (S. gamoandra); stamens usually truncate and dumbbell-shaped, the thecae much shorter than, to equalling, to exceeding the occasionally dilated, elevated or grooved connective, the pollen sacs in each theca usually opening through a common apical pore or with individual or partly confluent pores, occasionally with the thecae themselves confluent within the anther (S. longispatha); pollen shed in monads, powdery or rarely extruded in thin filaments (S. asperata, S. scortechinii), small - c. $17 \mu \mathrm{m}$, inaperturate, boat-shaped, elliptic to oblong, bilaterally symmetrical, exine sculpturing psilate (microscopic details from Grayum, 1992); staminodes of the appendix generally different in form, colour and reaction to alcohol from those of the female zone (appendical and interpistillar type staminodes occurring together between the male and female zones in S. scortechinii); ripening fruit enclosed by persistent spathe base; ripe fruit green to red, exposed by spathe dehiscing acropetally or disintegrating (where known); seeds numerous, small, longitudinally striate (where known), minutely strophiolate, albuminous; $x=13 ; 2 n=$ 26, 39, 52, with B chromosomes sometimes present (Petersen, 1989).

Distribution - Southern China, Indochina to Vanuatu; Malesia: throughout in wetter areas.

Habitat - Terrestrial, rheophytic or lithophytic in rainforest or secondary situations in rainforest areas from sea level to c. $1700 \mathrm{~m}$ alt. While often associated with flowing water (whether as rheophytes or not), the genus is poorly represented in swamp forest except at elevated points. The genus is often common on steep soil banks in forest, where, perhaps, the minute seeds are less likely to be smothered by leaf litter. Several species are restricted to particular substrates - especially limestone and ultramafic rock.

\section{Glossary of key terms}

Appendical staminodes - staminodes which make up the surface of the appendix.

Appendix - the variously shaped sterile apical portion of the spadix.

Arborescent pachycaul - a plant with palm-like construction, having a massive more or less self-supporting shoot. 
Caducous - having the characteristic of falling off while the tissue is not aged or decayed.

Connective - the top part of the staminal filament (stalk) on the sides of which the thecae are attached.

Deliquescent - becoming translucent and wet during senescence (aging).

Dumbbell-shaped - swollen at each end and rather abruptly narrowed in the midportion; used of the shape of stamens in situ when seen from above.

Epigeal stem - one extending above the ground.

Female anthesis - when the pistils are receptive to pollination - the female phase of the flowering process (anthesis).

Female zone - the part of the spadix bearing fertile pistils.

Hapaxanthic shoot - one which ceases growth after flowering and does not flower again.

Hourglass-shaped - swollen at each end and rather gradually narrowed towards the middle.

Hypogeal stem - one mainly underground.

Interpistillar staminodes - infertile organs (probably derived from sterile stamens) occurring in irregular association with the pistils.

Interprimary veins - veins more or less regularly alternating with and running parallel to the primary veins; intermediate in thickness between the primary and secondary venation.

Interstice - a sterile zone of the spadix between the male and female zones.

Ligular sheath - when the wings or margins of the leaf sheath, instead of being attached for their length to the petiole, are attached only at the base and are united for most of their length with each other and free from the petiole.

Lower spathe chamber - the cavity created by the convolute lower part of the spathe; always houses the female zone, and sometimes also the sterile interstice and part or rarely all of the male zone.

Male anthesis - when the stamens release pollen — the male phase of the flowering process.

Male zone - the part of the spadix bearing fertile stamens.

Marcescent - remaining attached even after the tissue has died.

Neuter organs - a generic term for infertile structures on the spadix, whether their homology is with female or male parts.

Persistent - remaining alive and attached when otherwise the part dies and/or falls.

Pleionanthic shoot - one which resumes growth after flowering and may flower again.

Pollen sacs - structures within the thecae of the stamens which contain the pollen.

Pores - openings in the stamen through which pollen is released from the pollen sacs; each pollen sac may release pollen directly through its own pore (then each theca has two pores), or each theca has a single pore through which both pollen sacs release their pollen. 
Pseudostem - a structure formed by tighly overlapping and elongate leaf-bases, which elevates the petioles and leaf-blades; resembling (but here much smaller than) the trunk of a banana plant.

Spathe limb - the upper part of the spathe distal to the spathe constriction, usually having a different colour and more membranous texture than the part below the constriction (the lower spathe).

Spathe/spadix adnation - the area of joining between the spadix and the spathe.

Sterile stamens - structures closely resembling stamens but which contain no pollen; such structures can be called staminodes, but in the usage here that term is restricted to interpistillar and appendical staminodes, which do not closely resemble stamens.

Tessellate reticulum - a squared, net-like pattern (of tertiary veins).

Thecae - usually bilobed structures on either side of the connective of the stamen, which contain the pollen sacs.

\section{Key to informal species groups}

1a. Stem pleionanthic

1b. Stem hapaxanthic S. calyptrata group

2a. Spathe limb caducous

2b. Spathe limb marcescent to crumbling and/or deliquescent

3a. Leaf sheath fully attached to petiole

3b. Leaf sheath ligular

4a. Petiole sheathing only at base; foliage leaves alternating with cataphylls

4b. Petiole usually sheathing for at least a third of its length (rarely less); foliage leaves not

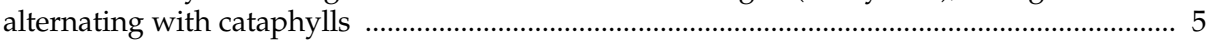

5a. Spathe limb irregularly crumbling and breaking away at or after male anthesis

S. asperata group

5b. Spathe limb clasping the spadix and more or less marcescent after anthesis, finally falling with spent parts of spadix

6a. Leaf sheath wings persistent; inflorescence nodding; male and female zones of spadix more or less contiguous

S. corneri group

6b. Leaf sheath wings usually (but not always) deciduous; inflorescence more or less erect; male and female zones separated by a conspicuous partly naked interstice

S. rupestris group

\section{Keys to the species and complexes by landmass or island group}

Keys are provided for the major Malesian landmasses or island groups, as there does not seem to be anything to be gained from making the user wade through a key to almost the entire genus in a group in which endemism is so high.

\section{Malay Peninsula}

1a. Stem epigeal; pleionanthic 
2a. Leaf sheath persistent; spadix covered with flowers/floral organs

$2 \mathrm{~b}$. Leaf sheath deliquescent-deciduous, turning brown; spadix axis partly naked between male and female zones

3a. Leaves of a rich deep green with distinctly tessellate fine venation, never variegated; upper spathe bright green, hardly opening, semi-persistent; male zone about equalling appendix; widespread

16. S. brevicuspis

$3 b$. Leaves dull mid/dark green to pale green with obscure tertiary venation, sometimes glaucous, sometimes variegated; upper spathe opening cowl-like, pale greyish green, more or less caducous, blackening; male zone much shorter and narrower than appendix; widespread

32. S. scortechinii

4a. Feeble plants with decumbent to creeping stem c. $1 \mathrm{~cm}$ diam.; leaf bases obtuse to slightly cordate; male zone and appendix together less than half the length of the spadix; widespread 4. S. brevipes

4b. Robust herbs with erect to decumbent stem c. 2-4 cm diam.; leaf base deeply cordate; male zone and appendix together exceeding half the length of the spadix; widespread

9. S. mutata

5a. Inflorescences nodding on long slender peduncles; Perak

61. S. longifolia

5b. Inflorescences erect, the exposed part of the peduncle shorter than the inflorescence 6

6a. Spadix cylindric with a distinct sterile zone between the male and female zones and the appendix absent or extremely reduced (a few terminal staminodes); widespread

84. S. wallichii

6b. Spadix hourglass shaped, with the narrowest portion at the junction of the male and female zones; sterile interstice more or less absent (sometimes a small concentration of interpistillar staminodes) and the appendix conspicuous, hemispherical to half-ellipsoid; widespread

51. S. calyptrata

\section{Sumatera}

1a. Stem epigeal (sometimes creeping, rarely condensed), pleionanthic 2

1b. Stem hypogeal, hapaxanthic 14

2a. Stem condensed; leaf sheath very short; leaves alternating with cataphylls; Riau Archipelago 89. S. tecturata

2b. Stem with conspicuous internodes; leaf sheath one third or more of the length of the petiole; leaves not alternating with cataphylls

3a. Sterile interstice completely occupied by staminodes; leaf sheath persistent; Aceh and North Sumatera 16. S. brevicuspis

3b. Sterile interstice predominantly naked, often with sparse, scattered groups of small staminodes; leaf sheath usually deliquescent/marcescent

4a. Stem repent to creeping; plants sometimes rheophytic …......................................................... 5

4b. Stem erect to decumbent; plants not rheophytic

5a. Internodes and petiole bases rugose-asperous; North and West Sumatera

11. S. ovata

$5 b$. Internodes and petiole bases smooth

6a. Plants rheophytic; leaf blades with the midrib and primary lateral veins tough and abaxially strongly prominent; primary veins diverging at c. $30^{\circ}$; Aceh, North and West Sumatera

6b. Plants not rheophytic; midrib and primary lateral veins not strongly prominent; primary lateral veins diverging at $50-80^{\circ}$ 
7a. Peduncle upturned elevating the inflorescence above the spreading leaves; lower spathe very broadly ovoid; interpistillar staminodes absent from among the pistils; North Sumatera and Lampung 8. S. longicaulis

7b. Peduncle not markedly up-turned; lower spathe narrowly ovoid to ovoid; interpistillar staminodes frequent to few among the pistils; Aceh and North Sumatera 4. S. brevipes

8a. Leaf blade broadly oblanceolate to oblong-lanceolate to narrowly ovate with the base acute to retuse (rarely very shallowly cordate), often variegated; plants generally confined to rather dry slopes and ridges; Aceh, West Sumatera and Jambi .................................. 2. S. acuminatissima

8 b. Leaf blade ovato-sagittate to narrowly hasto-sagittate with the base more or less deeply divided into posterior lobes; not recorded variegated; plants usually in moist sites ............. 9

9a. Leaf blade triangular-sagittate or narrowly hasto-sagittate ................................................... 10

9b. Leaf blade ovato-sagittate 12

10a. Leaf blade narrowly hasto-sagittate; Talu, West Sumatera

13. S. sagittifolia

10b. Leaf blade triangular-sagittate

11a. Interprimary and secondary veins conspicuous; spathe thick and spongy; lower spathe broadly ovoid; Bilah, North Sumatera

6. S. hastifolia

11b. Interprimary and secondary veins inconspicuous; spathe membranous; lower spathe ovoid with a long neck; Aceh and North Sumatera

2. S. belophylla

12a. Spathe limb coriaceous and opening wide; G. Talamau, West Sumatera ... 5. S. grandiflora

12b. Spathe limb not markedly coriaceous, clasping the spadix 13

13a. Primary veins $9-15$ on each side of the midrib; spathe c. $7-15 \mathrm{~cm}$ long; plants generally in forest 9. S. mutata

13b. Primary veins $18-24$ on each side of the midrib; spathe c. 17-22 cm long; plants generally in disturbed habitat and open sites

12. S. rupestris

14a. Appendix clearly present, hemispheric to half-ellipsoid; widespread

51. S. calyptrata

14b. Appendix absent or reduced to a few terminal staminodes

15a. Sterile interstice absent; Medan-Brastagi, North Sumatera

56. S. ecaudata

15b. Sterile interstice present and robust, covered in staminodes; Aceh, West Sumatera, North Sumatera, Riau

84. S. wallichii

\section{Java and Nusa Tenggara}

1a. Stem hapaxanthic, hypogeal; spathe limb inflated then caducous; sterile interstice ill-defined; appendix hemispheric to half-ellipsoid; widespread in Java, Bali

51. S. calyptrata

1b. Stem pleionanthic, epigeal; spathe limb clasping, persistent-marcescent; sterile interstice welldefined, partly naked with scattered groups of small staminodes; appendix elongate ........... 2

2a. Stem repent; appendix about half the length of the male zone; West and East Java

$2 b$. Stem erect to decumbent; appendix about equalling the male zone; West and Central Java, Flores

\section{Borneo}

1a. Petiole with coarse multicellular scale-like hairs

1b. Petiole asperous to finely velvety pubescent or glabrous ……................................................ 6

2a. Leaf blade narrowly obovate; spathe not constricted, only the topmost part deciduous; Sarawak 15. S. barbata

2b. Leaf blade narrowly obovate to broadly oblong-ovate; spathe constricted and only the basal part persistent 
3a. Most leaf blades narrowly obovate; peduncle hairy, exserted; spathe hairy; spathe limb lanceolate; [stamens unknown]; eastern Sabah .....

22. S. ferruginea

$3 \mathrm{~b}$. Leaf blades oblong-ovate; peduncle very short and concealed by cataphylls and spathe not hairy; spathe limb inflated over swollen spadix; stamens in adnate pairs with elevated connectives;

4a. Blade hairy abaxially and adaxially; Brunei, Sabah

20. S. crinitissima

4b. Blade hairy only on the margin and/or abaxial side; Sarawak 5

5a. Blade hairy on margin and abaxial side of midrib

17. S. ciliata

5 b. Blade hairy on midrib, primary and secondary venation abaxially

30. S. pyrrhias

6a. Wings of leaf sheath attached to the petiole only at the base, the rest ligular and at least half as long as the entire sheath

6b. Wings of leaf sheath fully attached to the petiole (sometimes with a short apical ligular portion)

7a. Leaf blade narrowly lanceolate with a central variegated stripe; male zone of spadix entirely or almost entirely contained within the lower spathe chamber; ?rheophytic, Sarawak

44. S. pudenda

$7 \mathrm{~b}$. Leaf blade various; male zone exserted from lower spathe chamber .. 8

8a. Appendix absent or very reduced (a few terminal staminodes) .............................................. 9

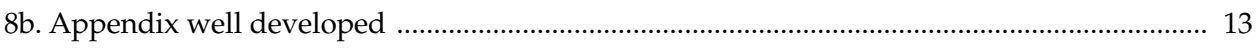

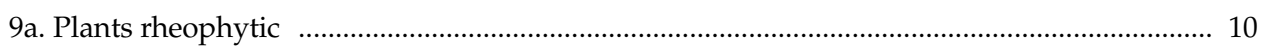

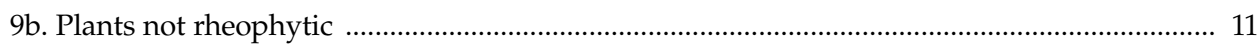

10a. Spadix c. $4.5 \mathrm{~cm}$ long; spathe inflated at anthesis; Sarawak

45. S. roseospatha

10b. Spadix c. 6-8 cm long; spathe unrolling slightly at anthesis but not inflated; Sarawak and W Kalimantan

41. S. multiflora

11a. Male zone subcylindric; pollen sacs opening through a common pore in each theca; lithophytic on limestone; Bau, Sarawak

34. S. bauensis

11b. Male zone clavate to ellipsoid; pollen sacs opening through paired pores in each theca; terrestrial

36. S. erecta

12a. Connective deeply 1-grooved from theca to theca; Bintulu, Sarawak

12b. Connective slightly raised between the thecae, but not grooved; Central Kalimantan

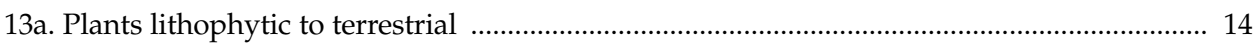

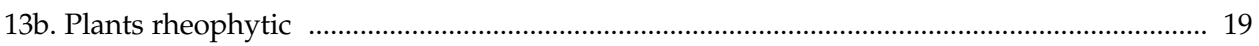

14a. Leaf blade ovate to broadly ovate and densely but deciduously hairy adaxially and abaxially; Brunei

24. S. hottae

14b. Leaf blade variously lanceolate to oblong-ovate, glabrous 15

15a. Secondary venation very fine and dense -2 veins per $\mathrm{mm}$; thecae of stamens each with two pores

$15 \mathrm{~b}$. Secondary venation density various but 1.5 veins or fewer per $\mathrm{mm}$; thecae of stamens each with one pore

16a. Spadix usually c. $8 \mathrm{~cm}$ long, with a short sterile interstice of sterile stamens between the fertile zones; stamens and appendical staminodes large, c. $1 \mathrm{~mm}$ across; Matang, Sarawak

39. S. mayoana

16b. Spadix usually c. $4.5 \mathrm{~cm}$ long, with the fertile zones contiguous; stamens and appendical staminodes small, c. $0.3 \mathrm{~mm}$ across; Bako, Sarawak

42. S. nicolsonii 
17a. Inflorescence solitary to two together; stigmas broadly discoid; anthers sessile with low broadly dilated connective and almost spherical thecae; Temburong, Brunei

43. S. platystigma

17b. Inflorescences c. 4-6 together; stigmas discoid, narrower than the ovary; anthers with short filaments, rectangular-dumbbell-shaped, the connective not markedly dilated; thecae ellipsoid to subcylindric

18a. Plants very robust; leaf c. $40 \mathrm{~cm}$ long; spadix c. $9 \mathrm{~cm}$ long; placentas 2-3 per ovary; lithophytic on wet shale; Kuala Belalong, Brunei ..... 35. S. cyria

18b. Plants moderately robust; leaf c. $30 \mathrm{~cm}$ long; spadix c. $6 \mathrm{~cm}$ long; placenta 1 per ovary; lithophytic or terrestrial on limestone; Mardi, Sarawak and possibly SE Kalimantan

40. S. monoplacenta

19a. Part of male zone dorsally adnate to the spathe; male zone dorsally sterile; Sarikei, Sarawak

19b. Male zone free and fertile all round 46. S. sarikeensis 20

20a. Leaf blade narrowly oblanceolate; primary lateral veins $4-8$ on each side of midrib; interpistillar staminodes absent; appendix tapering; Brunei and possibly Sarawak

37. S. gillianae

20b. Leaf blade narrowly lanceolate; primary lateral veins only faintly distinguishable from secondaries, 3 on each side of midrib; interpistillar staminodes confined to a basal row along the spathe/spadix adnation; appendix ellipsoid-clavate; Entabai, Sarawak ...... 38. S. josefii

21a. Petiole sheathing only at extreme base; foliage leaves solitary, subtended by cataphylls; Tenom, Sabah

80. S. unifolia

21b. Petiolar sheath extending $1 / 5$ or usually more along the petiole; if sheathing only at extreme base, then leaves not solitary and regularly alternating with cataphylls 22

22a. Leaves regularly alternating with cataphylls, with the sheath confined to the extreme base of the petiole; spathe limb more or less persistent/marcescent

$22 \mathrm{~b}$. Leaves not regularly alternating with cataphylls and with the sheath extending along at least $1 / 5$ of the petiole; spathe limb usually caducous to deliquescent (more or less persistent in S. corneri) 24

23a. Anthers with the connective much elevated above the thecae; appendix clavate-cylindric, distinctly thicker than male zone; Brunei

88. S. petri

23b. Anthers with the connective not or hardly elevated; appendix cylindric, more or less isodiametric with top of male zone; Borneo and Riau Archipelago 89. S. tecturata

24a. Shoot epigeal (sometimes much condensed), pleionanthic; spathe limb crumbling to deliquescent, or more or less persistent

24b. Shoot usually hypogeal and hapaxanthic (rarely epigeal, rarely pleionanthic); spathe limb

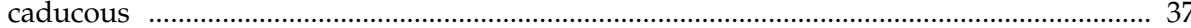

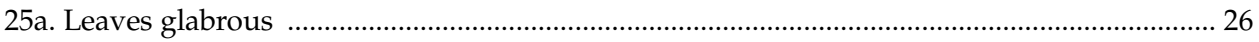

$25 \mathrm{~b}$. Leaves (at least petiole) minutely velvety pubescent to minutely papillate and asperous

26a. Lower spathe about equalling limb in length; appendix absent or reduced to a few staminodes; sterile interstice about as long as female zone and covered with crowded flat-topped irregularly polygonal staminodes; Sarawak

19. S. conoidea

26b. Lower spathe shorter than the limb; appendix prominent; sterile interstice various but not as above

27a. Sterile interstice well-defined and conspicuous, naked; Brunei

27

$27 \mathrm{~b}$. Sterile interstice various, sometimes ill-defined, sometimes with lax neuter organs, but not naked 
28a. Massive arborescent pachycaul; inflorescences nodding; Sabah, Anambas Islands 1. S. corneri

28b. Robust to small herbs; inflorescence erect at anthesis 29

29a. Male zone held mostly within lower spathe chamber; leaves more or less ovato-sagittate with the base cordate; SE Kalimantan

23. S. grabowskii

29b. Male zone exserted from lower spathe chamber; leaves oblong-lanceolate to more or less elliptic, the base cuneate to rounded

30a. Leaf more or less broadly (oblong-)lanceolate, with few (about 5) widely spaced primary lateral veins on each side, sometimes variegated; stigmas discoid; stamens rectangularrhomboid; appendix about two thirds of the length of the spadix; Kinabalu, Sabah

18. S. clemensiorum

30b. Leaves more or less elliptic with 8-12 primary lateral veins on each side, not known to be variegated; stigmas small, almost punctate to button-like; stamens dumbbell-shaped; appendix less than half the length of the spadix

31a. Spathe limb broadly ovate, gaping at anthesis; appendix conic-ellipsoid; Kinabalu, Sabah

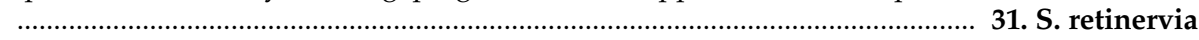

31b. Spathe limb broadly lanceolate, acuminate, opening wide and reflexing at anthesis; appendix tapering-subcylindric; scattered in Borneo

21. S. elegans

32a. Appendix subcylindric 33

32b. Appendix conic-ellipsoid to broadly conic-ovoid 35

33a. Petiole conspicuously and thickly longitudinally ridged; stigmas minute, punctate, sterile interstice absent (or reduced to a whorl of incompletely abortive stamens); Southern Sarawak

27. S. nervosa

33b. Petiole finely longitudinally ridged and/or asperous; stigmas button-like to discoid; sterile interstice well-defined

34a. Petiole not ridged; stigma discoid; appendix about two thirds of the length of the spadix; NW Borneo

14. S. asperata

34b. Petiole finely longitudinally ridged; appendix about or less than one third of the length of the spadix; Sarawak and possibly W Kalimantan

25. S. latevaginata

35a. Leaf blade lanceolate to narrowly obovate, with the base broadly acute to cuneate; scattered in Borneo

28. S. patentinervia

35b. Leaf blade narrowly oblong-lanceolate to broadly ovate, with the base cordate 36

36a. Leaf blade broadly ovate, c. $9 \mathrm{~cm}$ wide; tertiary venation forming a rather indistinct tessellate reticulum (dry); terrestrial; G. Mulu, Sarawak

26. S. multinervia

36b. Leaf blade various, but not recorded over $5.5 \mathrm{~cm}$ wide; tertiary venation forming a conspicuous tessellate reticulum (dry); usually lithophytic on limestone; scattered in Sarawak

29. S. puberulipes

37a. Peduncles thin, wiry, elongate, erect and apically down-turned; Serian, Sarawak; Brunei ......

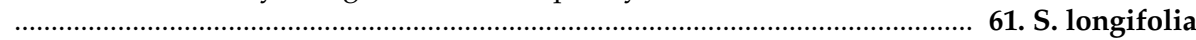

37b. Peduncles not so 38

38a. Stems elongate, slender and sprawling-epigeal; Bukit Manok, Sarawak .. 54. S. convolvula 38b. Stems more or less condensed and hypogeal, if epigeal then thick and erect.....

39a. Appendix absent (or reduced to a few terminal staminodes); sterile interstice robust; Sarawak 84. S. wallichii

39b. Appendix conspicuous (if reduced - as sometimes in S. ahmadii, then sterile interstice illdefined); sterile interstice various 
40a. Appendix narrowly cylindric to tapering-cylindric (if very shortly cylindric to narrowly conoid, then male zone cylindric, partly within lower spathe chamber and posterior lobes of leaf blade much reduced or absent $-S$. motleyana)

40b. Appendix hemispheric to bullet-shaped to conoid (if shortly cylindric to narrowly conoid, then male zone obconoid, exserted from lower spathe chamber and posterior lobes of leaf blade well developed)

41a. Leaf blade broadly oblanceolate, the base cuneate to decurrent, with c. 20 primary lateral veins on each side of the midrib; Temburong, Brunei

70. S. pectinervia

41b. Leaf blade ovate to sagittate, the base acute to deeply divided into posterior lobes, with 5-13 primary lateral veins on each side of the midrib .............................................................. 42

42a. Plants stoloniferous and forming carpets, to loose open colonies ........................................ 43

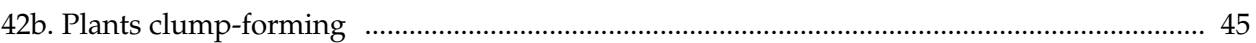

43a. Stamens each with the thecae confluent; appendical staminodes squat; nr Kuching, Sarawak 62. S. longispatha

43b. Stamens each with the thecae differentiated; appendical staminodes columnar 44

44a. Spadix length to width ratio (dry; width at appendix base) about 15:1; leaf base acute to truncate; widespread in Borneo 68. S. motleyana

44b. Spadix length to width ratio about 40:1; leaf base shallowly cordate; Eastern Sabah 86. S. wongii

45a. Male zone fully exserted from lower spathe chamber; known only from cult. ex Kalimantan

45b. Male zone held partly within the lower spathe chamber 49. S. bifasciata 46

46a. Spadix length to width ratio (dry; width at appendix base) about 40:1 (range 30:1-50:1); widespread in Borneo [Note: extremely variable in leaf] ..... 77. S. trifasciata complex

46b. Spadix length to width ratio (dry; width at appendix base) about 15:1 (range 10:1-22:1(-26:1))

47a. Leaf blade with the posterior lobes absent to very reduced; widespread in Borneo 68. S. motleyana

47b. Leaf blade with the posterior lobes well-developed; known only from cult. ex Kalimantan 52. S. canaliculata

48a. Sterile interstice a well-defined zone of crowded more or less columnar, polygonal staminodes 49

48b. Sterile interstice absent or ill-defined and/or composed of more or less abortive usually lax pistils and anthers and/or interpistillar staminodes 51

49a. Leaf blade oblong-lanceolate to narrowly obovate, the base acute to rounded - not at all cordate; appendix bullet-shaped; Bintulu, Sarawak 53. S. clarae

49b. Leaf blade sagittate; appendix conic . .50

50a. Leaf narrowly cordato-sagittate, not known to be variegated; spadix c. $3 \mathrm{~cm}$ long; known only from cult. ex Kalimantan 72. S. pumila

50b. Leaf blade ovato-sagittate, only known to be variegated with four longitudinal bands; spadix c. $8 \mathrm{~cm}$ long; lithophytic; G. Amai Ambit, Kalimantan

87. S. zonata

51a. Lower part of male zone shortly cylindric and held within the lower spathe chamber, the rest obconic and exserted; on limestone; Southern Sarawak 82. S. viridissima

51b. Male zone obconic, exserted from the lower spathe chamber (sometimes included in the extreme base only); various substrates 
52a. Interpistillar staminodes very numerous, filling spaces between lax pistils in lower half of female zone, barely stipitate, clavate-prismatic and shorter than ovaries; lithophytic on ultramafic rocks; G. Silam, Sabah

75. S. silamensis

52b. Interpistillar staminodes few to many, stipitate, more or less clavate, usually equalling to exceeding the ovaries

53a. Stamens large, c. $1.3 \mathrm{~mm}$ across, the anthers partly connate throughout the male zone; pollen sacs in each theca confluent; Bintulu, Sarawak

59. S. gamoandra

53b. Stamens smaller, less than $1 \mathrm{~mm}$ diam., the anthers and pollen sacs discrete

54a. Leaves distinctly hasto-sagittate (i.e. posterior lobes distally acutely rounded and out-turned)

55

54b. Leaves narrowly oblong-lanceolate to elliptic to ovato-sagittate (posterior lobes absent to rounded and not out-turned) ................................................................................................ 56

55a. Appendix shortly cylindric, abruptly wider than top of male zone; female zone obliquely inserted but not otherwise adnate to spathe; Tenom, Sabah

67. S. moodii

55b. Appendix bluntly conoid, indistinctly wider than top of male zone; female zone adnate to the spathe in the lower half; G. Trus Madi, Sabah

79. S. trusmadiensis

56a. Appendix shortly cylindric-bullet-shaped, basally isodiametric with top of male zone; anthers with the connective almost as broad as the thecae; ultramafic substrate; scattered in Sabah

55. S. decipiens

56b. Appendix bullet-shaped to conic to hemispheric, usually basally slightly and abruptly wider than the top of the male zone (if not then hemispheric)

57a. Stem erect, epigeal and pleionanthic; limestone; Niah, Sarawak

69. S. niahensis

57b. Stem hapaxanthic and hypogeal

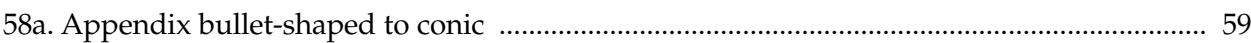

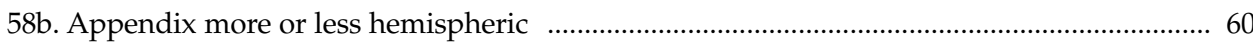

59a. Spadix c. $3 \mathrm{~cm}$ long; appendix conic; apex of interstice with 1-2 irregular whorls of enlarged, scale-like staminodes at base of male zone; known from a single unspecified locality in Kalimantan

66. S. modesta

59b. Spadix 8.5-13 cm long; appendix bluntly conic; apex of interstice with a concentration of more or less headless interpistillar staminodes and the base of the male zone usually with a few whorls of sterile anthers; widespread in Borneo

78. S. trivittata

60a. Leaves with rather closely spaced tough, abaxially prominent primary lateral veins which typically dry straw-coloured; fruiting peduncle erect; facultatively (and usually) rheophytic; NW Borneo

48. S. ahmadii

60b. Leaves with the primary lateral veins not as above; fruiting peduncle declinate; terrestrial or lithophytic

61a. Leaf bases strongly overlapping and more or less forming a pseudostem; leaf blades oblonglanceolate; inflorescence solitary with the peduncle more than half the length of the petiole; kerangas forest; Southern Sabah

60. S. lingua

61b. Leaf bases sheathing but not forming a pseudostem; leaf blades variable in shape, usually more or less ovato-sagittate; inflorescences produced in series on peduncles less than half the length of the petioles

62a. Leaf blades matte and very dark green adaxially, somewhat coriaceous; interpistillar staminodes shorter than to about equalling the ovaries; lithophytic on limestone; Eastern Sabah and NE Kalimantan

81. S. venusta

62b. Leaf blades usually dull mid-green, membranous; interpistillar staminodes usually exceeding the ovaries; terrestrial; widespread in Borneo

51. S. calyptrata 


\section{The Philippines}

1a. Tertiary venation forming a distinct tessellate pattern on the abaxial side of the lamina; plants mostly small with dark green (sometimes variegated) upper and sub-glaucous lower leaf surfaces

1b. Tertiary venation tessellation inconspicuous; abaxial leaf surface paler than adaxial, but not markedly contrasting

2a. Plants minute, c. $12 \mathrm{~cm}$ tall, lithophytic, stem creeping; Mindanao

65. S. mindanaoana

2b. Plants small, c. $20 \mathrm{~cm}$ tall, terrestrial, stem condensed; Luzon, Panay, Catanduanes 73. S. pusilla

3a. Male zone of spadix enclosed for at least the lower third of its length within the lower spathe chamber

3b. Male zone of spadix (almost entirely) exserted from lower spathe chamber

4a. Robust plants with petiole to c. $65 \mathrm{~cm}$ long; spadix c. $9 \mathrm{~cm}$ long, appendix cylindric; Samar 57. S. edanoi

4b. Plants smaller with petiole c. $18 \mathrm{~cm}$ long; spadix c. $5 \mathrm{~cm}$ long; appendix conic; Samar 74. S. samarensis

5a. Anthers with the connective extended for c. $1 \mathrm{~mm}$, tongue-like; Luzon, Mindoro 50. S. bogneri

$5 \mathrm{~b}$. Anthers with the connective not extended, or merely slightly raised 6

6a. Plants usually colony-forming by stolons; shoots hapaxanthic; widespread 51. S. calyptrata 6b. Plants clump-forming, not stoloniferous; shoots pleionanthic 7

7a. Plants rheophytic; leaves mostly narrowly lanceolate; widespread

63. S. luzonensis

7b. Plants not rheophytic; leaves narrowly elliptic to broadly ovato-sagittate

8a. Male zone of spadix narrowly obconic; appendix narrowly conic; leaves oblong-lanceolate; Sagapan, Mindanao 85. S. warburgiana

8b. Male zone obconic; appendix bluntly conic to hemispherical; leaves elliptic to broadly ovate

9a. Base of leaf distinctly cordate; widespread

71. S. plurivenia

$9 \mathrm{~b}$. Base of leaf acute to truncate, sometimes faintly cordate; Luzon

64. S. merrillii

\section{Sulawesi}

1a. Leaves lanceolate to narrowly elliptic; spadix subcylindric; sterile interstice well defined and fully occupied by staminodes

1b. Leaves broadly elliptic to ovato-sagittate; spadix hourglass-shaped; sterile interstice ill-defined

a. Stem pleionanthic, epigeal; Talaud Islands and Central Sulawesi

71. S. plurivenia

2b. Stem hapaxanthic, hypogeal; widespread

51. S. calyptrata

3a. Appendix bluntly conoid with elongate upward-facing staminodes, especially in the upper part; South Sulawesi

76. S. subundulata

3b. Appendix subcylindric with closely-packed flat-topped staminodes; Central Sulawesi 58. S. eymae

\section{Maluku and New Guinea}

1a. Spadix subcylindric; sterile interstice well-defined and fully occupied by staminodes; Ceram 83. S. wahaiana

1b. Spadix hourglass-shaped; sterile interstice ill-defined; widespread 51. S. calyptrata 


\section{The species}

\section{Schismatoglottis corneri group}

Shoot pleionanthic; leaf sheath fully attached. Inflorescence pendulous. Spathe limb hardly opening and semi-persistent. Not rheophytic.

1 species, NW Borneo.

\section{Schismatoglottis corneri A. Hay, sp. nov.}

[Schismatoglottis megaphylla Furtado, mss].

$\mathrm{Ab}$ aliis speciebus Schismatoglottidis stature gigantea, inflorescentia nutante maxima, ovario cylindroideo, stigmate sessile capitato, interstitio sterile brevissimo, stamine truncato, appendice elongato-conoidea differt. - TYPUS: Malaysia, Sabah, Kinabatangan Distr., Maliau Basin, Gunung Rara Forest Reserve, $2.5 \mathrm{~km}$ up-river from main Maliau Falls, 15 Apr 1996, A. Hay, K. M. Wong and Ahmad 12095 (SAN, holo - 2 sheets \& spirit; photo K, KEP, L, NSW).

Massive arborescent pachycaul to c. $2.3 \mathrm{~m}$ tall; trunk erect to decumbent, to $1.2 \mathrm{~m}$ long $\times 12 \mathrm{~cm}$ diam. Leaves several together in a terminal crown; petiole to c. $90 \mathrm{~cm}$ long, sheathing in the lower $1 / 3-1 / 2$; wings of sheath tapering, fully attached to the petiole; blade mid-green adaxially, slightly paler abaxially, sagittate, to c. $80 \mathrm{~cm}$ long $\times 50 \mathrm{~cm}$ wide; anterior lobe to c. $70 \mathrm{~cm}$ long, tip obtuse and apiculate for c. $2 \mathrm{~cm}$; posterior lobes to c. $23 \mathrm{~cm}$ long, narrowly rounded; midrib abaxially prominent, often adaxially whitish when fresh; primary lateral veins c. 8 on each side of midrib, distant, alternating with lesser interprimaries and diverging at c. $80^{\circ}$, occasionally branched near base of blade, adaxially impressed (the lamina bullate in between), abaxially prominent when fresh (not so when dry); secondary venation somewhat obscure, arising from the midrib and the primary veins; tertiary venation obscure. Inflorescences 2-several together; peduncle about half the length of the petioles, to c. $45 \mathrm{~cm}$ long, apically down-turned so inflorescences nodding, subtended by lanceolate green cataphylls to $30 \mathrm{~cm}$ long. Spathe to $36 \mathrm{~cm}$ long, lower spathe green, subcylindric, c. $7.5 \mathrm{~cm}$ long, differentiated from the limb by a weak constriction; limb white, lanceolate, hardly opening, deciduous, apically acuminate for 5-6 cm. Spadix sessile, narrowly spindle-shaped, to $29 \mathrm{~cm}$ long; female zone subcylindric-slightly conic, to $6.5 \mathrm{~cm}$ long, c. $2 \mathrm{~cm}$ wide at base, obliquely inserted; pistils very numerous and crowded; ovary more or less cylindric, $3 \mathrm{~mm}$ long; stigma sessile, button-like, papillate, as wide as ovary, $0.5 \mathrm{~mm}$ diam.; interpistillar staminodes irregularly scattered through female zone, clavate, about the height of the pistils, c. $0.4 \mathrm{~mm}$ diam. at top; sterile interstice isodiametric with top of female zone, very short in proportion to total spadix length, c. $5 \mathrm{~mm}$ long, composed of a mixture of crowded interpistillar staminodes, sterile and incompletely fertile stamens and ?abortive pistils; male zone $9 \mathrm{~cm}$ long $\times 1.7 \mathrm{~cm}$ thick, slightly obconic in the lower $2 \mathrm{~cm}$, the rest cylindric; stamens white to yellow, very crowded, more or less dumbbell-shaped, truncate with the connective not or hardly exceeding the thecae, c. $1 \times 0.5 \mathrm{~mm}$; appendix white to creamy pink, $12 \mathrm{~cm}$ long, basally isodiametric with top of male zone, tapering to a fine point; staminodes of appendix flat-topped, irregularly polygonal, c. $1 \mathrm{~mm}$ diam. Fruiting spathe to c. $10 \mathrm{~cm}$ long (not seen in ripe fruit), narrowly urceolate. - Fig. 1.

Distribution - Malesia: Borneo (western Sabah), and the Anambas Islands.

Habitat - Disturbed forest or open sites by rivers among rocks, sometimes in great numbers together, 550-1000 m alt. 


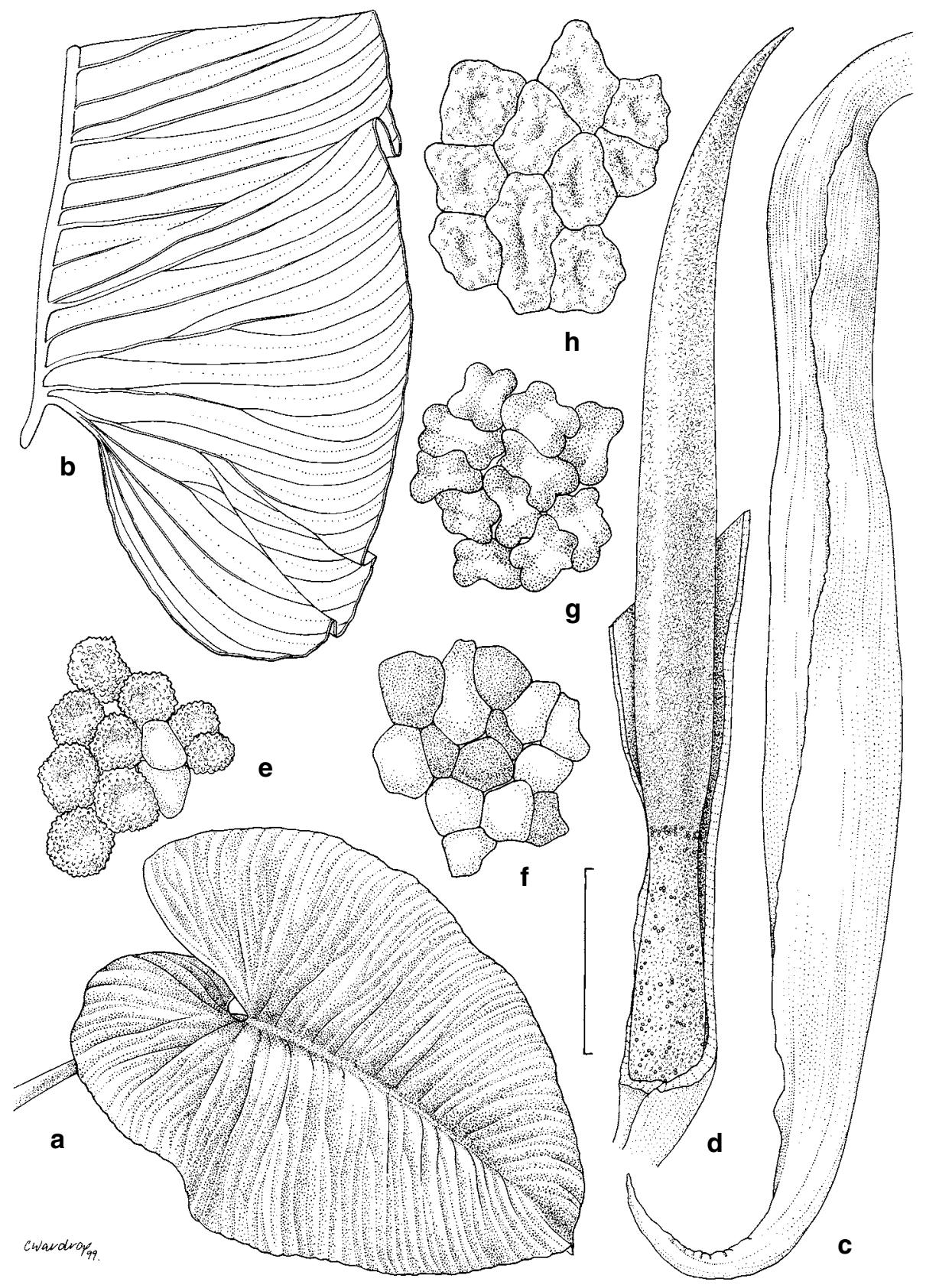

Fig. 1. Schismatoglottis corneri A. Hay. a, Leaf; b, Venation; c, Inflorescence; d, Spadix; e, Pistils and interpistillar staminodes; $\mathbf{f}$, Staminodes of sterile interstice; $\mathbf{g}$, Stamens; $\mathbf{h}$, Staminodes of appendix (Mood M807; b: Chew et al. 642). Scale bar: $\mathrm{a}=20 \mathrm{~cm} ; \mathrm{b}=10 \mathrm{~cm} ; \mathrm{c}, \mathrm{d}=5 \mathrm{~cm} ; \mathrm{e}-\mathrm{h}=2 \mathrm{~mm}$. 
Notes - Schismatoglottis corneri is named for the late E.J.H. Corner (despite his distaste for eponymy (Mabberley, 1999)), who collected this plant while leading the Royal Society expeditions to North Borneo in 1961. The Durian Theory (Corner, 1949) predicts the occurrence of massively constructed species in large genera. No other species in this genus of generally rather diminutive plants comes close to S. corneri in size.

Besides its very large size, S. corneri is remarkable in its nodding inflorescence, otherwise known only in S. longifolia Ridl., and in the apparently not or hardly opening limb of the spathe, which recalls $S$. rupestris and allied species characterised by a large partly naked sterile interstice and, mostly, by deciduous leaf sheaths. The relatively huge spadix is not associated with enlarged floral parts which, except for the somewhat elongate ovary, are of normal dimensions for the genus. However, they are present in enormous numbers. Spirit material of this species characteristically blackens.

Other specimens examined: ANAMBAS ISLANDS: P. Siantan, E of Terimpa, van Steenis 773 (BO). BORNEO: SABAH: Ranau Distr., Sg. Nabutan, Aban Gibot SAN 94553 (K); Mt Kinabalu, Eastern shoulder, Chew, Corner \& Stainton RSNB 642 (BO, K, L); Mt Kinabalu, Dallas, Clemens $\mathcal{E}$ Clemens 26820 (NY) \& 29157 (BM, G, GH, K, L); within 1 mi Kahung on path to Singarron, Darnton 298 (BM); Kinabalu NP, en route from Poring Hot Springs and Langanan waterfall, Kokawa \& Hotta 4732 \& 4797 (both KYO); Kinabalu NP, along Sg. Mamut, nr Poring, Kokawa $\mathcal{E}$ Hotta 4885 (KYO); Kengaran, Trusmadi, Mood M807 (NSW).

\section{Schismatoglottis rupestris group}

Shoot pleionanthic; leaf sheath long, developing fully attached, then usually deciduous. Interstice of spadix prominent, mostly naked with a few groups of small more or less sessile staminodes. Spathe usually hardly opening and semi-persistent. Occasionally rheophytic.

12 species, Thailand, Malay Peninsula, Sumatera, Java, Nusa Tenggara.

\section{Schismatoglottis acuminatissima Schott}

Schismatoglottis acuminatissima Schott, Ann. Mus. Lugd.-Bat. 1 (1864) 281; Engl. in A. \& C. DC., Monogr. Phanerogam. 2 (1879) 352 \& Pflanzenr. 55 (IV.23Da) (1912) 95, ?p.p., excl. specim. cit. Schlechter 13555 (Borneo; B十). - Type: Indonesia, Sumatera, without precise locality, P.W. Korthals s.n. (L, holo; iso K).

Schismatoglottis concinna Schott, Ann. Mus. Lugd.-Bat. 1 (1864) 281; Engl., Pflanzenr. 55 (IV.23Da) (1912) 95 ('var. typica'). — Schismatoglottis acuminatissima var. concinna (Schott) Engl. in A. \& C. DC., Monogr. Phanerogam. 2 (1879) 353. - Type: Indonesia, 'Borneo' [almost certainly Sumatera], P.W. Korthals s.n. (L, holo).

Schismatoglottis lavallei L. Linden, Ill. Hort. 28 (1881) 71, Pl. 418. - Type: Ill. Hort. 28 (1881) 71, Pl. 418. - Neotype: Cult. RBG Kew ex Hort. Linden, 16 Apr 1881, N.E. Brown s.n. (K; designated here).

Schismatoglottis lavallei var. purpurea N.E. Br., Gard. Chron., n.s. 18 (Sep 1882) 298. - Schismatoglottis concinna var. purpurea (N.E. Br.) Engl., Pflanzenr. 55 (IV.23Da) (1912) 96. - Type: Cult. RBG Kew ex Hort. Veitch, 23 May 1882, N.E. Brown s.n. (K, holo).

Schismatoglottis lavallei var. immaculata N.E. Br., Gard. Chron. n.s. 18 (Sep 1882) 298. - Schismatoglottis concinna var. immaculata (N.E. Br.) Engl., Pflanzenr. 55 (IV.23Da) (1912) 96. - Type: Cult. RBG Kew ex Hort. Linden, 2 Jun 1882, N.E. Brown s.n. (K, holo).

Schismatoglottis lavallei var. lansbergiana L. Linden ex N.E. Br., Ill. Hort. 29 (Nov 1882) 173, Pl. 468. - Type: Ill. Hort. 29 (1882) Pl. 468. 
Schismatoglottis rubrocincta Engl., Pflanzenr. 55 (IV.23Da) (1912) 106; Alderw., Bull. Jard. Bot. Buitenzorg III, 4 (1922) 205. - Type: Cult. Hort. Bogor. (provenance unknown), Feb 1906, A. Engler 4068 (B, holo).

Schismatoglottis kurimana Alderw., Ann. Jard. Bot. Buitenzorg III, 4 (1922) 207. — Type: Indonesia, Sumatera, West Sumatera, Brani, Sungei Kuriman, 24 Jun 1918, H.A.B. Bünnemeijer 3255 (BO + BO spirit, holo).

[Schismatoglottis lancifolia sensu auctt. non Hallier f. \& Engl.: Hotta et al., Contr. Biol. Lab. Kyoto Univ. 27 (1985) 13].

Herb c. $20-60 \mathrm{~cm}$ tall. Stem epigeal, erect to decumbent, $1.5-2 \mathrm{~cm}$ diam., with internodes $1-3 \mathrm{~cm}$ long, pleionanthic. Leaves several in a terminal cluster; petiole $12-27 \mathrm{~cm}$ long, usually glabrous, occasionally sparsely to densely and minutely pubescent, sheathing in the lower $1 / 2-3 / 4$; wings of sheath fully attached, tapering, persistent to slowly degrading in the marginal distal part; blade (broadly oblanceolate to) oblonglanceolate to narrowly ovate, usually rather distinctly asymmetric, bright to midgreen, sometimes suffused with purple and/or purple-backed, adaxially sometimes variegated with sparse to dense irregular grey-green spattering, $16-31 \mathrm{~cm}$ long $\times 3-8 \mathrm{~cm}$ wide, the base (acute to) obtuse to emarginate (to very shallowly cordate), the tip acute to long-acuminate; midrib slightly prominent abaxially (dry) or not, with 6-13 primary lateral veins on each side, more or less regularly alternating with lesser interprimaries and diverging at $45-60(-70)^{\circ}$; secondary venation arising mainly from the midrib; tertiary venation obscure. Inflorescences to 4 together, subtended by lanceolate cataphylls sometimes bearing long mucros (reduced petiole) or reduced petioles and blades; peduncle to c. $8 \mathrm{~cm}$ long. Spathe $8.5-10.5 \mathrm{~cm}$ long, green to suffused dark red; lower spathe $2.5-4 \mathrm{~cm}$ long, ovoid to narrowly ovoid, differentiated from the limb by a rather gradual constriction; limb 6-7.5 cm long, oblong-lanceolate, often with the margins not overlapping and exposing part of the male zone and appendix on the ventral side in bud, hardly opening at anthesis then persistent, finally degrading and falling with the spent parts of the spadix. Spadix sessile, $7.3-9.4 \mathrm{~cm}$ long, subcylindric; female zone $1.8-2.3 \mathrm{~cm}$ long, adnate to the spathe in the lower $0.7-1 \mathrm{~cm}$, $5-7 \mathrm{~mm}$ thick at the middle, slightly conic in the distal half; pistils slightly lax to densely crowded, oblong to ovoid to bottle-shaped, c. 0.7-1 mm diam.; stigma variable, sessile to elevated on a short style, punctate to button-like to discoid, $0.3-0.8 \mathrm{~mm}$ diam., papillate, when pistils dense and stigma large then adjacent stigmas contiguous, when pistils lax and stigmas small then adjacent stigmas wide-spaced (+ intermediate states); interpistillar staminodes 0-very few among the pistils, 0 -few at the base of the female zone (clustered on the ventral side forming an incomplete basal row), concentrated at the interface of the female zone and the sterile interstice, sessile to stalked, lower than to 1.5 times the height of the ovary, the heads more or less rounded, c. $0.5 \mathrm{~mm}$ diam.; sterile interstice $0.7-1.4 \mathrm{~cm}$ long, slightly attenuate, held within and reaching the mouth of the lower spathe chamber, partly naked with scattered groups of interpistillar staminodes in the naked part, the distal part composed of (1-)2-8 irregular dense whorls of sterile anthers at the base of the male zone; male zone $0.9-2.2 \mathrm{~cm}$ long, $4-7 \mathrm{~mm}$ thick at the top, subcylindric to faintly obconic; stamens crowded, truncate, weakly dumbbell-shaped (irregularly rectangular) with the connective rather thick but not or hardly exceeding the thecae, c. $0.8 \mathrm{~mm}$ across; appendix $2.6-3.5 \mathrm{~cm}$ long, subcylindric and apically obtuse to fusiform and apically acute, $5-8 \mathrm{~mm}$ diam.; staminodes of the appendix flat-topped, irregularly polygonal, c. 1-1.5 mm diam. Fruiting peduncle not or hardly elongating; fruiting spathe urceolate, c. $3-5 \mathrm{~cm}$ long.

Distribution - Malesia: endemic to Sumatera (Aceh, West Sumatera and Jambi Provinces). 
Habitat - Terrestrial in hill forest and lower montane forest in very well drained sites: steep slopes, ridge tops, often over sandstone, c. 400-1500 m alt.

Notes - Schismatoglottis acuminatissima and S. concinna were described at the same time. Engler (1879a) came to consider them conspecific (later changing his mind), reducing $S$. concinna to varietal status in S. acuminatissima. The priority that Engler thus established is followed here. The holotypes of Schismatoglottis acuminatissima and S. concinna are both incomplete, neither having inflorescences other than in early fruit. There is however, enough to ascertain that both specimens have epigeal stems and that both have a partially naked interstice. The leaf shape is similar - somewhat more elongate in S. acuminatissima, and the blade is variegated in S. concinna but not S. acuminatissima. The type of S. acuminatissima was cited by Schott as originating from 'Borneo nisi Sumatra'. Why Schott should have thought that Borneo was a more likely provenance than Sumatera, with which the specimen is labelled, is unclear, though possibly he mistrusted the labelling on Korthals specimens. Subsequently, S. acuminatissima came to be attributed to Borneo without qualification (Engler, 1879a, 1912), and Engler (1912) attributed a Bornean collection (Schlechter 13555 at B, now lost) to this species, nonetheless noting that the Bornean specimen did not have the characteristic more or less naked sterile interstice. The type of S. concinna, on the other hand is labelled Borneo, but is unmatched by any Bornean material. It is, however, vegetatively matched very closely by variegated plants of this species from Sumatera. Korthals of course collected in both Borneo and Sumatera and it would appear entirely possible that some of his material was mislabelled or labels became misplaced in the long intervening period between the bundles of specimens being received at Leiden and the material being mounted (Veldkamp, pers. comm.). That the type of $S$. acuminatissima is this Sumateran species defined here can be now verified by examination of a fertile isotype at Kew, which apparently neither Schott nor Engler saw.

Schismatoglottis lavallei and its varieties were all described from horticultural material grown in Europe variously attributed to Sumatera, Java and Borneo. Evidently attribution to the latter two was erroneous. Incorrect provenances were not uncommonly provided for plants coming to be known through horticultural importation, such as certain species of Alocasia (Hay, 1998). The type sheet of S. lavallei is mixed and includes, as well as the type specimen, specimens of the same taxon grown at Kew from Beccari material, dated 1 Dec 1880 and another cultivated plant ex Hort. Bull, dated 23 Jul 1881. The elements are clearly differentiated by Brown's annotations. The type sheet of $S$. lavallei var. purpurea is also mixed and includes, as well as the type specimen, a specimen of $S$. lavallei cultivated at Kew and dated 14 Nov 1887. Once again the elements are clearly differentiated by Brown's annotations.

Schismatoglottis rubrocincta was described from material of unknown origin cultivated at Bogor. It falls uncontroversially within S. acuminatissima except in the dimensions of the leaves, spathe and spadix being smaller than usual (approximately half the normal size). While S. rubrocincta is placed here in the synonymy of S. acuminatissima, these smaller dimensions are not incorporated into the species description as they may be artefacts of cultivation. Later material in the Bogor Gardens Herbarium collected in 1916 from plant XI.B.X.59 is also sterile and of the same small dimensions as the type.

The specimen which Hotta et al. (1985) interpreted as the type of S. lancifolia (q.v.), for the purpose of applying a name to the species on which they made a valuable population study, does not appear to be the type after all. The plants in their study of polymorphic variation and population structure (one of very few of its kind on a Malesian Aroid) are undoubtedly conspecific with S. acuminatissima.

This species is highly polymorphic, not only in respect of leaf shape, pigmentation and variegation, which Hotta et al. (1985) studied, but also in pubescence, leaf venation 
and in inflorescence - particularly with respect to the form of the interpistillar staminodes, the shape of the ovary and the size of the stigma. The collection Hay et al. 13026, the only one from Jambi Province, represents rather an extreme of variation, with very close-packed oblong ovaries and large contiguous sessile stigmas, (sub)sessile interpistillar staminodes, densely pubescent petioles and primary lateral veins in the upper range of numbers.

Other specimens examined: SUMATERA: West Sumatera, Air Putih, E of Pajokumbuh, Alston 14365 (BM); West Sumatera, Anai Valley, Bogner 1797 (M); West Sumatera, Gunung Tandikat, Hay et al. 13109 (NSW); Cult. RBG Sydney Acc. No. 942719 ex cult. HB Leiden Acc. No. 940817 ex West Sumatera Prov., c. $3 \mathrm{~km}$. N of Aeksah, c. $28 \mathrm{~km}$ N of Sipirok (orig. coll. Hetterscheid), Herscovitch s.n. (BO, NSW); Cult. RBG Sydney Acc. No. 942721 ex cult. HB Leiden ex West Sumatera Prov., c. $3 \mathrm{~km}$. N of Aeksah, c. $28 \mathrm{~km}$. N of Sipirok (orig. coll. Hetterscheid), Herscovitch s.n. (BO, NSW); Cult. RBG Sydney Acc. No. 970467 ex Jambi Prov., Kerinci Seblat National Park, Muara Emat (orig. coll. Hay et al. 13026, voucher NSW), Herscovitch s.n. (BO, NSW); Cult. RBG Sydney Acc. No. 970507 \& 970508 both ex West Sumatera, Hutan Raya Bung Hatta, Gunung Gadut (orig. coll. Hay et al. 13078 \& 13079), both Herscovitch s.n. (BO, NSW); Cult. RBG Sydney Acc. No. 970520 \& 970529 both ex West Sumatera, Lembah Anai FR, (orig. coll. Hay et al. 13091 (voucher NSW) \& 13103), both Herscovitch s.n. (BO, NSW); West Sumatera, Ulu Gadut, c. 15 km E from Padang, Hotta 25092 \& 25099 (both KYO); West Sumatera, around Air Sirah plot, nr pass of Padang-Solok rd, Hotta 26374 (KYO); West Sumatera, Bt. Gajabuih, Ulu Gadut, c. 15 km E from Padang city, Hotta 25824, 25860 $\mathcal{E} 26027$ (all KYO); West Sumatera, along valley of Ulu Gadut, c. $15 \mathrm{~km}$ E of Padang city, Hotta 25767 (KYO) \& Hotta \& Okada 123 (KYO); West Sumatera, en route from base camp to G. Kambot, c. $15 \mathrm{~km}$ E from Padang city, Hotta $\mathcal{E}$ Tamin 249, 250, 251, 253 (+ BO), 254, 257, 278, 279 \& 280 (all KYO); West Sumatera, Harau Natural reserve, c. $16 \mathrm{~km} N$ of Payakumbuh, Hotta \& Tamin 303 (KYO); West Sumatera, Setia Mulia, Bot. Gard. Of Andalas Univ., c. 20 km E of Padang city, Hotta et al. 1053 (KYO); West Sumatera, ridge of Bt. Batu Bajolang, G. Gadut, c. $15 \mathrm{~km}$ E of Padang City, Hotta et al. 1312 \& 1314 (both KYO); West Sumatera, Taram, E of Pajakumbuh, Meijer 6994 (L); West Sumatera, Harau, E of Pajakumbuh, Okada \& Mori 1162 (BO); Aceh, Kloët nature reserve, S Kloët, along Krung Lembang, c. $20 \mathrm{~km}$ upstream E of Kandang, de Wilde \& de Wilde-Duyfjes 19625 (L); Aceh, Middle Alas R. (Lae Sauraya) area, c. $15 \mathrm{~km} \mathrm{~N}$ of Gelombang, S of Bengkong R, de Wilde $\mathcal{E}$ de Wilde-Duyfjes 20285 (L, p.p. — vel. 1 only) \& 20286 (L).

\section{Schismatoglottis belophylla Alderw.}

Schismatoglottis belophylla Alderw., Bull. Jard. Bot. Buitenzorg III, 4 (1922) 203. - Type: Indonesia, Sumatera, North Sumatera, Sibolangit, 2 Dec 1917, J.A. Lörzing 5450 (BO, holo; iso L).

[Schismatoglottis hastifolia sensu auct. non Hallier f. ex Engl.: Alderw., Bull. Jard. Bot. Buitenzorg III, 4 (1922) 203].

Herb to c. $60 \mathrm{~cm}$ tall. Stem epigeal, erect to decumbent, pleionanthic, 1-2 cm diam. with internodes to $2 \mathrm{~cm}$ long. Leaves c. 4 together; petiole $25-40 \mathrm{~cm}$ long, minutely and rather sparsely puberulent to papillate or glabrous, often tinged red, purplish or pink in the lower part, sheathing in the lower $1 / 4-1 / 3$; wings of sheath initially fully attached, tapering, soon degrading and deciduous especially in the upper part; blade matte dark green adaxially, sometimes glaucous, paler beneath, rather narrowly triangular, (somewhat ovato- to somewhat hasto-) sagittate, $14-36 \mathrm{~cm}$ long $\times 6-14 \mathrm{~cm}$ wide, the base deeply divided into two acute (finally narrowly rounded) posterior lobes $4-10 \mathrm{~cm}$ long with the sinus acute to obtuse; midrib somewhat prominent abaxially, with c. 9 primary lateral veins on each side regularly alternating with fine interprimaries and diverging at $45-70^{\circ}$; secondary venation rather inconspicuous abaxially and adaxially, arising from the midrib and from the primary veins, especially in the lower part of the blade; tertiary venation obscure. Inflorescences 1-2 together; peduncle hardly exserted from the subtending cataphylls, to c. $2 / 5$ the length of the petiole; cataphylls lanceolate, to $9 \mathrm{~cm}$ long, soon degrading. Spathe 6-10.5 cm long; lower spathe greenish, $2.5-3.5 \mathrm{~cm}$ long, ovoid with a long neck (reaching the top of the interstice of the spadix), tapering 
into the limb but not differentiated from it by a constriction; limb narrowly oblonglanceolate, 3.5-7.5 cm long, whitish cream, barely opening, clasping the spadix, persisting after anthesis and finally falling with the spent parts of the spadix. Spadix subequalling the spathe, $5-8.5 \mathrm{~cm}$ long, subcylindric, sessile; female zone $1.5-2 \mathrm{~cm}$ long, c. $4 \mathrm{~mm}$ wide, obliquely inserted; pistils more or less crowded, ovoid to oblong, 0.5-1 mm diam.; stigma sessile, rather thick, discoid, c. $0.5 \mathrm{~mm}$ diam.; interpistillar staminodes lower and larger than the ovary, very few scattered among the pistils, a group at the base of the female zone, and a concentration of up to 8 irregular whorls above and adjacent to the uppermost pistils and forming the base of the interstice; interstice c. $1.5 \mathrm{~cm}$ long, covered at the base with aforementioned interpistillar staminodes, the rest naked but for small scattered groups of smaller staminodes and distally scattered sterile, incompletely fertile and fertile anthers; male zone cylindric, $1.2-1.5 \mathrm{~cm}$ long $\times 2-3 \mathrm{~mm}$ thick (dry); stamens crowded, truncate, dumbbell-shaped, c. $0.5 \mathrm{~mm}$ across, with the connective narrow and not or hardly elevated and the thecae with conspicuous annular rims; appendix 1.5-4 cm long, slender cylindric, about isodiametric with the male zone, finally tapering to an acute tip; staminodes of the appendix flat-topped, irregularly polygonal, c. $1 \mathrm{~mm}$ diam. Fruiting spathe ovoid with a pronounced neck, c. $4 \mathrm{~cm}$ long.

Distribution - Malesia: endemic to Sumatera (confined to Aceh and North Sumatera provinces).

Habitat - Terrestrial in sloping, well-drained sites in primary lowland to lower montane rainforest, occasionally on forest edge, 50-1300 m alt.

Notes - Schismatoglottis belophylla is closely allied to the polymorphic S. mutata complex. It can be distinguished from almost all species in the $S$. rupestris group by its narrowly triangular-sagittate leaves. It differs from $S$. hastifolia, the other member of this group with a narrowly triangular-sagittate leaf, by the weak interprimary and less conspicuous secondary venation, the narrowly ovoid, long-necked lower spathe and the more membranous spathe.

Other specimens examined: SUMATERA: North Sumatera, Sibolangit, Boren Bandar, Lörzing 4358 (BO); North Sumatera, Bandarbaru, G. Sebayok, Nur 7396 (BO, K); North Sumatera, headwaters of Aek Liang (region between Dolok Si Manuk-manuk and Tor Matutung, Rahmat Si Boeea 10787 (GH, L); Aceh, G. Leuser Nature Reserves, Ketambe, valley of Lau Alas, nr tributary of Lau Ketambe, c. 35 km NW of Kutacane, Mt Guhra, de Wilde \& de Wilde-Duyfjes 12694 (L); Aceh, G. Leuser Nature Reserves, Ketambe, valley of Lau Alas, nr tributary of Lau Ketambe, c. $35 \mathrm{~km}$ NW of Kutacane, de Wilde \& de Wilde-Duyfjes 15691 (L); Aceh, G. Leuser Nature Reserves, G. Manas, $5 \mathrm{~km}$ SW of mouth of Lau Ketambe, c. $30 \mathrm{~km}$ NW of Kutacane, de Wilde $\mathcal{E}$ de Wilde-Duyfjes 16585 (L) \& 16587 (BO); Aceh, G. Leuser Nature Reserves, Alas R. valley, nr mouth of Bengkong R.; c. 50 km S of Kutacane, de Wilde $\mathcal{E}$ de Wilde-Duyfjes 18770 (L); Aceh, Middle Alas R. (Lae Sauraya) area, c. $15 \mathrm{~km}$ N of Gelombang, S of Bengkong R., de Wilde \& de Wilde-Duyfjes 20285 (L).

4. Schismatoglottis brevipes Hook. $\mathrm{f}$.

Schismatoglottis brevipes Hook. f., Fl. Brit. Ind. (1893) 538; Engl. \& K. Krause, Pflanzenr. 55 (IV.23Da) (1912) 102, fig. 56; Hay, Sandakania 7 (1996) 17, fig. 2, c. — Type: Malaysia, Perak, Scortechini $623 b$ (K, holo).

Schismatoglottis minor Hook. f., loc. cit.; Ridl., Materials Fl. Mal. Pen. 3 (1907) 32, Fl. Mal. Pen. 5 (1925) 113; Engl. \& K. Krause, Pflanzenr. 55 (IV.23Da) (1912) 105. — Type: Malaysia, Perak, Scortechini $532 b$ (K, holo).

[Schismatoglottis brevicuspis auctt. non Hook. f.: Engl. \& K. Krause, Pflanzenr. 55 (IV.23Da) (1912) 98, p. p. quoad specim. cit. Curtis s.n. (Penang, Waterfall Garden), Ridley s.n. (Pahang, Tahan R.; Selangor, Petaling), see below]. 
[Schismatoglottis scortechinii auct. non Hook. f.: Ridl., Fl. Mal. Pen. 5 (1925) 113, p. p. quoad S. brevipes in synon.].

Stem epigeal, pleionanthic, to c. $30 \mathrm{~cm}$ long, c. $8 \mathrm{~mm}$ diam., decumbent, creeping to trailing, internodes c. 1-3 cm long. Leaves 1-6 per module; petiole c. $15 \mathrm{~cm}$ long, c. $3 \mathrm{~mm}$ diam., the margins minutely alate and sometimes crisped, slightly asperous, minutely hairy/spinulous (hand lens required), pale green to purplish, sheathing in the lower $1 / 2-3 / 4$; wings of sheath fully attached, tending to degrade at least in the upper half, becoming dark brown and flaking shortly after the emergence of the enclosed leaf, c. $5 \mathrm{~mm}$ wide, more or less straight, tapering, not ligular; blade c. 9-12 cm long $\times$ c. 4-6 cm wide, pale to mid-green, slightly glossy to dull, not variegated, usually tinged bronze when young, (elliptic to) ovate, widest about the mid-point, the base obtuse to rather weakly cordate with posterior lobes (0-) c. $8 \mathrm{~mm}$ long, the tip acute to weakly acuminate, the margin smooth to weakly undulate; midrib abaxially prominent, with 6-9 primary lateral veins on each side, diverging from the midrib at $50-70^{\circ}$, c. $1 \mathrm{~cm}$ apart; interprimary veins irregularly present; secondary venation flush adaxially and abaxially, arising from the midrib and the bases of the primary veins; tertiary venation not or faintly visible adaxially, visible abaxially, forming a tessellate reticulum. Inflorescences 1-5 together; peduncle to c. $5 \mathrm{~cm}$, thin, $2.5 \mathrm{~mm}$ diam., erect at anthesis, then dangling. Spathe $5.5-7.5 \mathrm{~cm}$ long; lower spathe narrow ovoid, to $3.5 \mathrm{~cm}$ long, c. $1.5 \mathrm{~cm}$ wide, green; limb persistent until well after anthesis, then deliquescing, lanceolate, acuminate tipped, opening only slightly, the distal portion remaining convolute, with only the ventral part of the male zone exposed. Spadix 5-6 cm long; female zone $2-2.5 \mathrm{~cm}$ long, more or less cylindric, slightly curved towards dorsal side of spathe, obliquely inserted to adnate for c. $1 / 3$ its length; pistils c. $0.75 \mathrm{~mm}$ diam., globose-polyhedral, pale green, somewhat distant and sometimes patchily distributed; style nil; stigmas globose; interpistillar staminodes numerous, irregularly distributed, c. $1 \mathrm{~mm}$ high, larger than the pistils, globular, very shortly stalked, white; sterile interstice 1-1.3 cm long, cylindric to slightly tapering, 5-8 mm thick, partly naked, consisting proximally of rather crowded structures resembling interpistillar staminodes, distally of scattered groups of much smaller staminodes resembling the stamens; male zone c. $1.5 \mathrm{~cm}$ long, $5 \mathrm{~mm}$ thick, cylindric to slightly spindle-shaped, the lower part corresponding with the spathe constriction; stamens dumbbell-shaped, c. $1 \mathrm{~mm}$ across, with the connective rather slender, slightly shorter than the thecae; pollen dusty, white; appendix very short, 3-5 mm long, conic; staminodes of appendix columnar, ivory white, c. $1 \mathrm{~mm}$ diam. Fruiting spathe declinate, urceolate.

Distribution - Malesia: widespread in Peninsular Malaysia; a single collection from each of Aceh and North Sumatera provinces in Sumatera.

Habitat - In lowland and hill rainforest, in damp places and occasionally along streams (but not properly rheophytic) to c. $1000 \mathrm{~m}$ alt.

Notes - The type of S. brevipes, which has only the female portion of the spadix and the corresponding lower spathe, was considered by Ridley (1907) to represent a young plant of S. scortechinii. However, it is a clearly distinct and not closely related species. Engler's (1912) description (based on Wray 1206) of a white spathe appears to be incorrect.

S. minor represents a weak, creeping aspect of this species. Plants corresponding with this in cultivation maintain their slender habit and smaller dimensions of their reproductive parts. However, there are linking intermediates to more robust decumbent-stemmed forms in which the inflorescences are substantially larger and with larger ovaries and interpistillar staminodes. In the smaller forms, the lower part of the female zone is adnate to the spathe (to c. $1 / 3$ in our observation, not the $1 / 2$ noted by Hooker and repeated by Engler and Ridley), in more robust plants oblique 
insertion rather than adnation better describes the attachment of the lower part of the female zone.

Other specimens examined: PENINSULAR MALAYSIA: Penang, Waterfall, Curtis s.n. (SING), Curtis 1884 (SING); Pahang, Bentong-Raub boundary, Furtado s.n. (SING); Cult. RBG Sydney, Acc. No. 940168, 940171, 940198 ex Perak, Bukit Larut, (orig. coll. Hay et al. 9072, 9075, 9104, (all UPM)), all Herscovitch s.n. (NSW); Cult. RBG Sydney Acc. No. 942586 ex Perak, foothills of Gunong Bubu, (orig. coll. Hay et al. 9128a), Herscovitch s.n. (NSW); Kelantan, base of Bukit Batu Papan, Henderson 29562 (SING); Johor, Bukit Tunjok Laut, Ngadiman 36933a (SING), 36947 (BO, K, SING), 37088 (SING); Pahang, Tahan R., Ridley s.n. (SING); Selangor, Petaling station, Ridley s.n. (SING); Perak, Temangoh, Ridley 14308 (K, SING); Gua Batu Puteh, Wray 1206 (CAL, SING). SUMATERA: Aceh, Gunung Leuser Nature Reserve, Ketambe, valley of Lau Alas, nr tributary of Lau Ketambe, c. $35 \mathrm{~km}$ NW of Kutacane, de Wilde \& de Wilde Duyfjes 12365 (K, US); North Sumatera, North Tapanuli, Balige, Sidulang, Yoshida 2055 (KYO).

\section{Schismatoglottis grandiflora Alderw.}

Schismatoglottis grandiflora Alderw., Bull. Jard. Bot. Buitenzorg III, 4 (1922) 201. - Type: Indonesia, Sumatera, West Sumatera, Mt Talamau, 1 May 1917, H.A.B. Bünnemeijer 536 (BO + BO spirit, holo).

Herb to c. $40 \mathrm{~cm}$ tall. Stem epigeal, ?pleionanthic, c. $1.5 \mathrm{~cm}$ diam., with internodes c. $1 \mathrm{~cm}$ long. Leaves few clustered at the top of the stem; petiole $16-25 \mathrm{~cm}$ long, minutely, densely and deciduously pubescent, sheathing in the lower c. $1 / 3$; wings of sheath fully attached, degrading, tapering; blade ovato-sagittate, $13-16 \mathrm{~cm}$ long $\times 5.5-9 \mathrm{~cm}$ wide, the base cordate with rounded posterior lobes to $3 \mathrm{~cm}$ long, the tip obtuse and very abruptly acuminate for c. $1 \mathrm{~cm}$; midrib slightly prominent adaxially, abaxially more or less flush with the blade and, like the primary and subsidiary veins, minutely and densely pubescent, with c. 10 primary lateral veins on each side, irregularly alternating with $0-2$ interprimary veins, diverging at $60-90^{\circ}$ and usually each with $1-2$ subsidiary veins, particularly in the basal half of the blade; secondary venation arising from the midrib and the lower parts of the primary veins; tertiary venation obscure. Inflorescence ?solitary (arrangement not observed); peduncle length unknown. Spathe c. $12 \mathrm{~cm}$ long; lower spathe narrowly ovoid, c. $4.5 \mathrm{~cm}$ long, differentiated from the limb by a more or less weak constriction; limb broadly oblong-lanceolate, $8 \mathrm{~cm}$ long, thickly coriaceous, apically abruptly acuminate for c. $6 \mathrm{~mm}$, wide open and apically reflexed, apparently caducous (the type has the limb partly abscised but not degrading). Spadix sessile, $10.5 \mathrm{~cm}$ long, subcylindric; female zone very obliquely inserted (lower $1 / 3$ adnate to the spathe), slightly conoid, $2 \mathrm{~cm}$ long, distally c. $6 \mathrm{~mm}$ diam.; pistils crowded, shortly cylindric, c. $0.5 \mathrm{~mm}$ diam.; stigma sessile, thickly button-like, as wide as the ovary, papillate; interpistillar staminodes absent from among the pistils; sterile interstice subcylindric (slightly conoid), $1.3 \mathrm{~cm}$ long, apically $5 \mathrm{~mm}$ thick, largely naked but for scattered small groups of minute sessile staminodes, the apex corresponding with the spathe constriction; male zone more or less cylindric, the base slightly attenuate and with c. 2 irregular whorls of sterile stamens, the apex slightly obconoid, $2.5 \mathrm{~cm}$ long $\times 4 \mathrm{~mm}$ thick; stamens crowded, broadly dumbbell-shaped to more or less rectangular, truncate with the connective faintly raised between the thecae, c. $0.5 \mathrm{~mm}$ across; appendix subcylindric c. $5 \mathrm{~cm}$ long $\times 6 \mathrm{~mm}$ diam., widest c. $1.5 \mathrm{~cm}$ from the base, tapering to a blunt point; staminodes of appendix irregularly polygonal, flat-topped, c. $0.7 \mathrm{~mm}$ diam. Fruit unknown.

Distribution - Malesia: endemic to Sumatera (West Sumatera); known only from the type.

Habitat — Forest at c. $500 \mathrm{~m}$ alt.

Notes - Vegetatively, and in spadix morphology, this species bears a strong resemblance to $S$. mutata. However, the open spathe is unique in the $S$. rupestris group (with the possible exception of S. monticola - discussed under S. mutata). 
6. Schismatoglottis hastifolia Hallier f. ex Engl.

Schismatoglottis hastifolia Hallier f. ex Engl., Pflanzenr. 55 (IV.23Da) (1912) 116. — Type: Cult. Hort. Bogor, Bed XI.B.X.56, Jan/Feb 1906, A. Engler 4052 (B, holo). - Epitype: Indonesia, Sumatera, North Sumatera Province, general region of Marban, Bilah, nr Bilah Pertama (Parbasiran), Feb-Mar 1928, Rahmat Si Toroes 119 (NY; designated here).

Herb to ?70 cm tall. Stem epigeal, erect to decumbent, at least $20 \mathrm{~cm}$ long, $3 \mathrm{~cm}$ diam., with internodes c. $1.5 \mathrm{~cm}$ long, probably pleionanthic (renewal not observable on available material); petiole $40-55 \mathrm{~cm}$ long, sheathing in the lower $1 / 4-1 / 3$, minutely and rather sparsely pubescent; wings of sheath fully attached, tapering, ?persistent; blade narrowly triangular-sagittate, $27-34 \mathrm{~cm}$ long $\times 10-13 \mathrm{~cm}$ wide across the tips of the posterior lobes, the base deeply divided into two acute triangular posterior lobes $5-10 \mathrm{~cm}$ long, the apex acute and acuminate for c. $1 \mathrm{~cm}$; midrib prominent abaxially (dry), minutely and densely pubescent abaxially especially in the distal part, with c. 11 primary lateral veins on each side, alternating with lesser but robust interprimaries and diverging at rather erratic angles between $45^{\circ}$ and $90^{\circ}$, the nexus of primary veins of the posterior lobes more or less forming posterior costae; secondary venation abaxially conspicuous, arising from the midrib and from the primary veins; tertiary venation obscure. Inflorescences 2 (?or more) together; peduncle c. $10 \mathrm{~cm}$ long, slender. Spathe $8.5 \mathrm{~cm}$ long, thick and spongy; lower spathe broadly ovoid, $1.5 \mathrm{~cm}$ long, differentiated from the limb by an abrupt constriction; limb $7 \mathrm{~cm}$ long, oblonglanceolate, apiculate for $1 \mathrm{~cm}$, deciduous. Spadix c. $7 \mathrm{~cm}$ long, subcylindric; female zone $1 \mathrm{~cm}$ long, obliquely inserted, not adnate to spathe, cylindric, $2 \mathrm{~mm}$ thick (dry); pistils crowded, subglobose, c. $0.3 \mathrm{~cm}$ diam.; stigma sessile, discoid, papillate, slightly narrower than the ovary; interpistillar staminodes few among the pistils through most of the female zone, a concentration at the base of the female zone, robust, more or less globular, subsessile, c. $0.5 \mathrm{~mm}$ diam and slightly higher than the pistils (drying translucent yellow); interstice $8 \mathrm{~mm}$ long, slightly narrower than either fertile zone, mostly naked with a concentration of interpistillar staminodes at the base, distally with few increasingly distant small groups of interpistillar staminodes, apically with 2 very irregular whorls of enlarged sterile anthers c. $0.7 \mathrm{~mm}$ diam.; male zone cylindric $1.3 \mathrm{~cm}$ long, $3 \mathrm{~mm}$ diam. (dry); stamens crowded, truncate, weakly dumbbell-shaped (almost rectangular), with the connective thick but not or hardly exceeding the thecae, c. $0.5 \mathrm{~mm}$ across; appendix subcylindric-tapering, apically acute, $3 \mathrm{~cm}$ long, basally slightly wider than the male zone, c. $4 \mathrm{~mm}$ diam.; staminodes of appendix flat-topped, irregularly polygonal, c. $1 \mathrm{~mm}$ diam. Fruiting peduncle slightly elongating, declinate. Fruiting spathe broadly ovoid-urceolate, $4 \mathrm{~cm}$ long.

Distribution - Malesia: endemic to Sumatera (North Sumatera); known only from the epitype locality.

Habitat - Unknown.

Notes - Schismatoglottis hastifolia was described from a sterile living plant in the Bogor gardens, and all that was preserved was a leaf. It was ascribed to Borneo without precise locality. The type and description do not match any Bornean material. However the leaf, which has a distinctive narrow-triangular shape and venation pattern (with strong interprimary and secondary venation), matches very closely the specimen designated here as the epitype, which also includes a fragment of epigeal stem and inflorescences. Ascription of the plant cultivated at Bogor to Borneo appears to have been in error, perhaps through misplacement of labels in the living collection. There does not seem to be any way of establishing where the original plant came from.

Schismatoglottis hastifolia resembles S. belophylla Alderw., differing in the much more conspicuous interprimary and secondary venation, the shorter, plumper lower spathe, the thick spongy texture of the entire spathe and the less elongate male zone and 
appendix. Some later material cultivated at Bogor XI.B.X.56 (BOKR) under the name S. hastifolia and studied by Alderwerelt is S. belophylla.

The name has been applied to a hastate-leaved, also incompletely known, species on Mt Kinabalu (Beaman \& Beaman, 1998), but this would appear to be incorrect. Engler described the stem as $3 \mathrm{~cm}$ thick, $20 \mathrm{~cm}$ long and oblique (from which is understood epigeal and more or less decumbent). Material of hastate-leaved species from Kinabalu all has short hypogeal stems.

\section{Schismatoglottis javanica Engl.}

Schismatoglottis javanica Engl. in Engl. \& K. Krause, Pflanzenr. 55 (IV.23Da) (1912) 108 (excl. fig 67); Alderw., Bull. Jard. Bot. Buitenzorg III, 4 (1922) 208; — Type: Java, Cult. Hort. Bogor., A. Engler 4053 (B, holo)

Small herb c. $30 \mathrm{~cm}$ tall. Stem repent to creeping, c. $1 \mathrm{~cm}$ diam., with internodes to c. $2.5 \mathrm{~cm}$ long. Leaves several together; petiole slender, c. $18-36 \mathrm{~cm}$ long, green to dark purple, sheathing in the lower $1 / 3-1 / 4$; wings of sheath fully attached, tapering, marcescent; blade (narrowly) ovate, shallowly sagittate, dull dark green adaxially, light green abaxially, c. 12-24 cm long $\times$ c. 6-12 cm wide, the base more or less cordate with rounded posterior lobes c. 2-4 cm long, the apex acuminate for c. 1-1.5 cm; primary lateral veins c. 8-13 on each side of the midrib, slightly raised abaxially, somewhat sunken adaxially, diverging from the midrib at 50-60\%, irregularly alternating with interprimary veins; submarginal veins c. $1 \mathrm{~mm}$ from the margin; secondary veins parallel to primary venation; tertiary venation forming an obscure tessellate reticulum. Inflorescences mostly in pairs; peduncle c. 4-11 cm long. Spathe yellowish-green, c. $7 \mathrm{~cm}$ long, constricted at the level of sterile zone of the spadix; lower spathe ovoid, c. $3 \mathrm{~cm}$ long, c. $2 \mathrm{~cm}$ wide, yellowish with darker green striation; limb yellowish-green, c. $4 \mathrm{~cm}$ long, c. $1 \mathrm{~cm}$ wide, gaping only slightly at the level of male zone to base of appendix of the spadix during anthesis, withering. Spadix sessile, free from the spathe, slightly curved, c. $5 \mathrm{~cm}$ long, shorter than spathe; female zone greenish, c. 1-1.5 cm long, c. $0.8 \mathrm{~cm}$ wide; ovary light green, ovoid-cylindric, 1.5-2 mm long, $0.5 \mathrm{~mm}$ diam.; stigma sessile, whitish, button-like; interpistillar staminodes 1 whorl at the base of female zone, taller than pistils, sometimes one or two amongst ovaries and crowded distally; sterile interstice c. $1 \mathrm{~cm}$ long, c. $0.6 \mathrm{~cm}$ diam., with a few staminodes, almost naked; male zone yellow, c. $2 \mathrm{~cm}$ long, c. $0.7 \mathrm{~cm}$ diam.; stamens more or less rectangular from above, distorting on dehiscence, $1.5 \mathrm{~mm}$ long, $0.5 \mathrm{~mm}$ diam., sunken-topped; thecae opening through apical pores; appendix white, c. $1 \mathrm{~cm}$ long, shorter than male zone, tapering toward the apex; staminodes of appendix flat-topped, irregularly polygonal. Fruit unknown. - Fig. 2.

Distribution - Malesia: endemic to and widespread in Java.

Habitat - Terrestrial in secondary forest, at c. 150-1300 m altitude.

Notes - Engler (1912) based Schismatoglottis javanica on material cultivated at the Bogor gardens from an unknown locality.

S. javanica is closely related to S. rupestris but differs in having creeping stems and the appendix shorter than the male zone, whereas the latter has erect to decumbent stems and the appendix equal to or longer than the male zone. In these respects S. javanica resembles Sumateran $S$. ovata, differing in the more conspicuously sagittate and more membranous leaves, the larger number of primary lateral veins, glabrous internodes and more slender, elongate inflorescence.

In the protologue, Engler's illustration of Schismatoglottis javanica is inaccurate. The habit is shown as erect instead of creeping and the spadix illustrated belongs to S. calyptrata. 


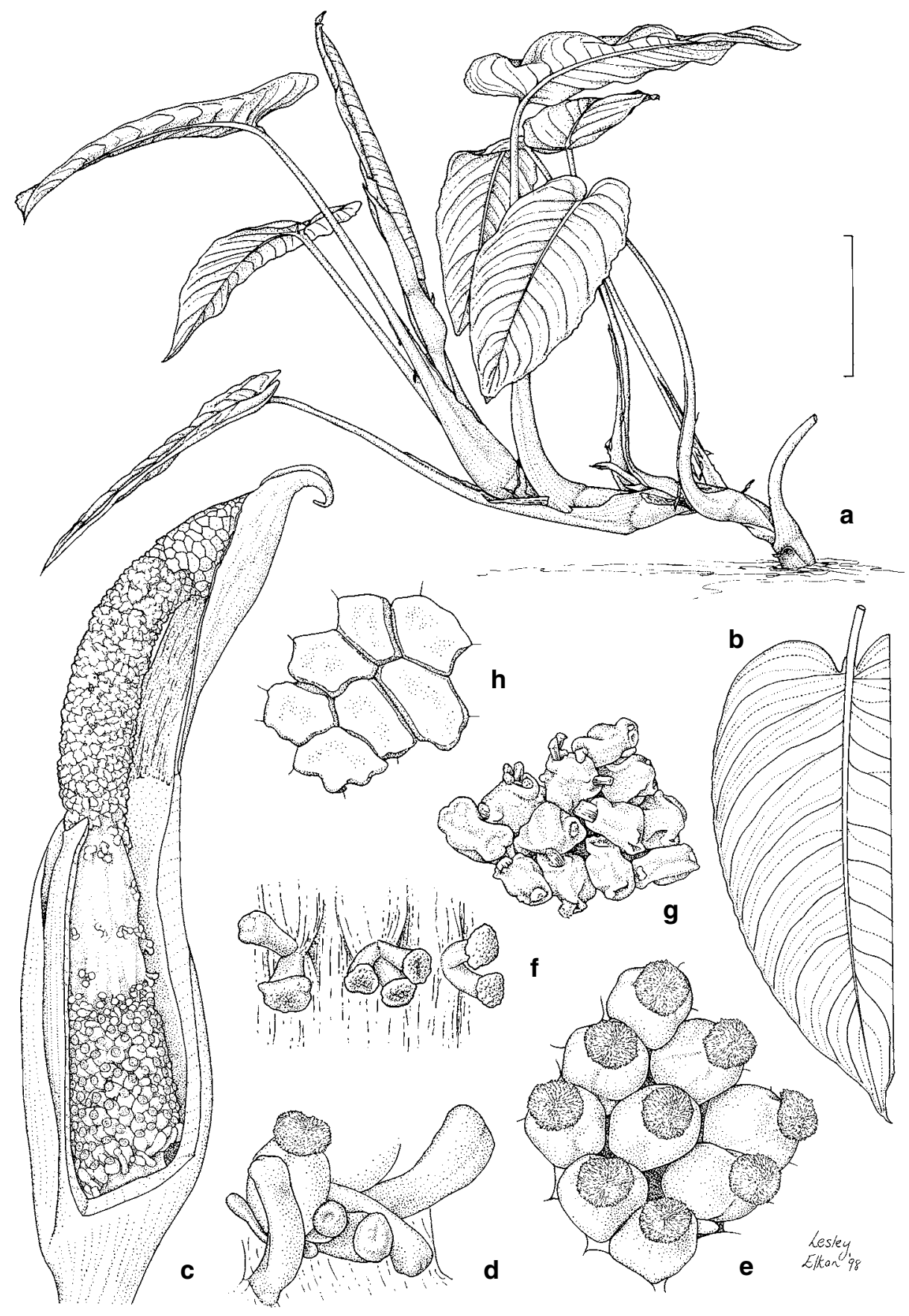

Fig. 2. Schismatoglottis javanica Engl. a, Habit; b, Leaf; c, Inflorescence; d, Basal interpistillar staminodes; e, Pistils; $\mathbf{f}$, Staminodes of sterile interstice; $\mathbf{g}$, Stamens; $\mathbf{h}$, Staminodes of appendix (RBG Sydney Acc. No. 980090). Scale bar: $a=5 \mathrm{~cm} ; \mathrm{b}=4 \mathrm{~cm} ; \mathrm{c}=1 \mathrm{~cm} ; \mathrm{d}-\mathrm{h}=2 \mathrm{~mm}$. 
Other specimens examined: JAVA: West Java, Buitenzorg, Boerlage s.n. (L); East Java, Djember, Danser 7800 (L); West Java, Tjiampea, Buitenzorg, Koorders $31451 b$ (BO); West Java, Tugu, Gunung Mas Tea Estate, Meijer 37 (L, K); Java, Kuhl \& Van Hassel s.n. (L); East Java, Hutan Lindung Merawa, Jember, Yuzammi 297059 (NSW). ); Cult. RBG Sydney Acc. No. 980090 ex East Java, Hutan Lindung Merawa, Jember (orig. coll. Yuzammi 297060), Herscovitch s.n. (BO, NSW).

\section{Schismatoglottis longicaulis Ridl.}

Schismatoglottis longicaulis Ridl., J. Bot. 40 (1902) 37; Engl., Pflanzenr. 55 (IV.23Da) (1912) 103; Rendle, J. Bot. 63 (1925) 125. - Type: Indonesia, Sumatera, Lampung, G. Trang, Jul 1880, H.O. Forbes 1491 (BM ?†, holo; iso CAL).

Schismatoglottis forbesii Engl., Pflanzenr. 55 (IV.23Da) (1912) 103. - Type: Indonesia, Sumatera, Lampung, G. Trang, Jul 1880, H.O. Forbes 1491 (CAL, holo).

Herb to c. $15 \mathrm{~cm}$ tall. Stem repent, branching, to c. $30 \mathrm{~cm}$ long, c. $1 \mathrm{~cm}$ diam., with internodes to $2 \mathrm{~cm}$ long, pleionanthic. Leaves c. 4 clustered at the end of the shoot; petiole to c. $6-14 \mathrm{~cm}$ long, sheathing in the lower c. $1 / 5-1 / 3$, faintly alate on the adaxial side between the sheath and the lamina; wings of sheath fully attached, persistent, broad and apically obtuse; blade more or less ovate, $6-11 \mathrm{~cm}$ long $\times 3-4.5 \mathrm{~cm}$ wide, the base obtuse to very slightly cordate with the posterior lobes c. $3 \mathrm{~mm}$ long and $1 \mathrm{~cm}$ wide, the apex acute to slightly acuminate, somewhat coriaceous, slightly glossy; midrib flush with the lamina adaxially, prominent abaxially, with 6-9 primary lateral veins on each side, alternating with interprimaries (these rather obscure in the fresh state), diverging at $60-80^{\circ}$; secondary venation arising mostly from the midrib, some from the lower parts of the lower primary veins; tertiary venation obscure. Inflorescence solitary; peduncle c. $4 \mathrm{~cm}$ long, upturned to bring the inflorescence erect on the repent stem. Spathe 3.5-6.5 cm long; lower spathe c. 1-2 cm long, green, very broadly ovoid, distally tapering sharply into the limb but not constricted; limb oblong-lanceolate 2.5-4 cm long, apiculate, whitish to yellowish, barely opening - gaping slightly at anthesis then clasping the spadix and persistent until falling with spent parts of spadix enclosed. Spadix sessile, 3-5.5 cm long, subcylindric; female zone obliquely inserted, 1-1.2 cm long, slightly conoid, c. $5 \mathrm{~mm}$ diam. at the top; pistils crowded, more or less cylindric, c. $0.5 \mathrm{~mm}$ diam.; stigma sessile, button-like, about as wide as the ovary, papillate; interpistillar staminodes absent from among the pistils, confined to one or two incomplete rings at the top and bottom of the female zone, stalked, clavate, more or less flat-topped, about the height and diameter of the pistils; interstice $0.5-1.5 \mathrm{~cm}$ long, cylindric, about the thickness of the female zone but slightly and abruptly attenuate at junction with fertile zones, almost completely naked but for few, scattered small groups of staminodes about half the size of the interpistillar staminodes, stalked near the base of the interstice, distally sessile and impressed; male zone 1-1.7 cm long, cylindric, $4 \mathrm{~mm}$ diam.; stamens crowded, truncate, dumbbell-shaped with the thecae somewhat elevated above and spread apart by the broad connective, c. $1 \mathrm{~mm}$ across; appendix slightly to distinctly shorter than the male zone, c. $0.5-1.4 \mathrm{~cm}$ long, basally isodiametric with male zone, tapering to an acute tip; staminodes of appendix flattopped, irregularly polygonal, c. $0.7 \mathrm{~mm}$ across.

Distribution - Malesia: endemic to Sumatera (North Sumatera, Lampung).

Habitat - Reported from disturbed lowland rainforest along valley bottoms and from a dry stream bed; altitude not recorded except for Forbes' specimen at c. $160 \mathrm{~m}$.

Notes - This species appears to be most closely allied to S. okadae. It differs in the leaves with more numerous more spreading primary veins, the larger inflorescence with a much broader lower spathe and female zone of the spadix, a short but nevertheless much longer appendix and the stamens with the connective rather dilated, spreading the thecae apart. It does not appear to be a true rheophyte. 
Engler (loc. cit.) attributed S. longicaulis as a new species to himself. This appears to have been a simple mistake, as that 'protologue' finishes with the otherwise strange remark 'Speciem non vidi'. The type was at BM, but it seems not to be there now. Some Araceae specimens were destroyed at BM in WWII, and it seems likely that this specimen was among them. [Although there is a considerable amount of material of Schismatoglottis at BM, most of it dates from the 1930s and would almost certainly not have been incorporated until after the war (R. Vickery, pers. comm.)].

Engler based S. forbesii on the Calcutta duplicate of the holotype of S. longicaulis. Ridley had not cited a specimen number in the protologue of the latter and Engler had evidently not examined the type, so he would not have been aware that he was examining a duplicate. He cited the date of collection as July 1878, but Forbes did not arrive in Malesia until November of that year, and did not go to Sumatera until 1880 (van Steenis-Kruseman, 1950: 169).

Other specimens examined: SUMATERA: North Sumatera, Asahan, along the Toba trail from Pargambiran to Adian Langga, Bartlett 7689 (NY, US); Cult RBG Sydney Acc. No. 801573 ex North Sumatera, between Bukit Lawang and Bahorok orang utan rehabilitation centre (orig. coll. Rodd 32), Herscovitch s.n. (BO, NSW).

\section{Schismatoglottis mutata Hook. f.}

Schismatoglottis mutata Hook. f., Fl. Brit. Ind. 6 (1893) 538; Ridl., Materials Fl. Mal. Pen. 3 (1907) 32 \& Fl. Mal. Pen. 5 (1925) 111; Engl., Pflanzenr. 55 (IV.23Da) (1912) 110. Henderson, J. Malayan Br. Roy. Asiat. Soc. 5 (1927) 275 \& J. Malayan Br. Roy. Asiat. Soc. 17 (1939) 84; Chin, Gard. Bull. Sing. 35 (1982) 182; Hay, Sandakania 7 (1996) 19, fig.2, D. - Type: Malaysia, Perak, Bukit Larut, King's Collector 4443 (K lecto; isolecto CAL; selected by Hay, 1996).

Schismatoglottis linguiformis Engl., Pflanzenr. 55 (IV.23Da) (1912) 93; Ridl., Fl. Mal. Pen. 5 (1925) 112. - Type: Malaysia, Perak, Scortechini 1197 (CAL, holo).

Schismatoglottis batoensis Engl., Pflanzenr. 55 (IV.23Da) (1912) 111; Alderw., Bull. Jard. Bot. Buitenzorg III, 4 (1922) 201. - Type: Indonesia, Sumatera, Batu Island, Sep 1896, H. Raap 267 (BO, lecto; selected by Nicolson in mss; isolecto B).

Schismatoglottis ridleyana Engl., Pflanzenr. 55 (IV.23Da) (1912) 116. — Type: Perak, Bukit Larut, Curtis 2076 (SING, lecto; selected by Hay, 1996).

? [see notes] Schismatoglottis rotundifolia Engl., Pflanzenr. 55 (IV.23Da) (1912) 116; Alderw., Bull. Jard. Bot. Buitenzorg III, 4 (1922) 201. - Type: Cult. Hort. Bogor. XI.B.X.27, Jan/Feb 1906, A. Engler 4066 (B, holo).

Schismatoglottis monticola Alderw., Bull. Jard. Bot. Buitenzorg III, 4 (1922) 202. - Type: Indonesia, Sumatera, Deli, Bandar Baru, 30 Dec 1916, J.A. Lörzing 4584 (BO + BO spirit, holo).

Schismatoglottis leptophylla Alderw., Bull. Jard. Bot. Buitenzorg III, 4 (1922) 210. — Type: Indonesia, Sumatera, Jambi Province, G. Kerinci, 12 Mar 1920, H.A.B. Bünnemeijer 8731 (BO, lecto; isolecto L; selected here).

Schismatoglottis brooksii Alderw., Bull. Jard. Bot. Buitenzorg III, 4 (1922) 341. - Type: Cult. Hort. Bogor. XI.B.X.64, C.R.W.K. van Alderwerelt van Rosenburgh 374 (BOKR + BO spirit, holo).

Slender to moderately robust erect herbs c. $0.35-1.1 \mathrm{~m}$ tall. Stem epigeal, pleionanthic, c. 2-4 cm thick, in the upper part often clothed with the remains of old leaf bases, the lower part naked as these rot; internodes c. 1-4 cm diam., often with conspicuous rather thick roots. Leaves c. 5 per module, very variable in size; petiole c. $20-45 \mathrm{~cm}$ long, smooth to very faintly asperous to minutely velvety-hairy (hand lens), adaxially 
flattened to slightly channelled with the angles rounded to distally inconspicuously alate, pale green to bright dark red, sometimes somewhat glaucous (due to minute hairs, not wax), sheathing in the lower $1 / 3-3 / 5$; wings of sheath membranous, fully attached and tapering, deliquescent/marcescent more or less immediately after emergence of leaf within; blade broadly to narrowly ovato-sagittate, somewhat glossy bright mid-green to dull mid-green, usually bronze-tinged to pink when newly emerged; c. 12-40 cm long $\times 6-30 \mathrm{~cm}$ wide, widest from at the base to about $1 / 3$ along midrib, the base more or less cordate with posterior lobes prominent, c. 3-12 cm long, triangular to rounded, sometimes almost overlapping across the sinus and posterior costae sometimes clearly differentiated for a few millimetres before dividing into primary venation of posterior lobes, occasionally naked in the sinus for $2-3 \mathrm{~mm}$, more usually with lamina to the sinus and occasionally sub-peltate, the tip acute to shortly acuminate; midrib abaxially prominent, with 9-15 primary lateral veins per side, sometimes branched, diverging at c. $50-70^{\circ}$, impressed adaxially, prominent abaxially; interprimary veins rather conspicuous and raised abaxially, impressed adaxially; secondary venation flush with lamina and mostly inconspicuous; tertiary venation inconspicuous. Inflorescences 2- several together on rather short slender peduncles which sometimes flop out of the subtending leaf sheath or cataphyll as these deliquesce/marcesce. Spathe c. 7-15 cm long; lower spathe c. 1/3 the length of the whole, ovoid to subglobose at female anthesis, green to red (correlated with petiole colour); limb narrowly lanceolate, clasping the spadix, barely opening at anthesis, thence closing again and temporarily persistent, eventually marcescent or breaking away after senescing, yellowish ivory to pale orange. Spadix more or less cylindrictapering, subequalling the spathe, sessile, obliquely inserted; female zone c. $1 / 3$ the length of the spadix, cylindric, c. 8-10 mm diam. at base, slightly tapering distally; interpistillar staminodes very sparsely to irregularly densely distributed amongst the ovaries, but usually concentrated at the very base of female zone, stalked and clavateheaded, taller than and conspicuously larger than the pistils; sterile interstice $1-2 \mathrm{~cm}$ long, 4-7 mm diam., composed of basal sessile interpistillar staminodes, then a concentration of smaller sessile staminodes, these becoming distant distally in small groups of commonly 2-4 surrounded by naked spadix tissue, these then usually concentrated again in an incomplete ring adjunct to the male zone; male zone more or less cylindric, c. $1.3-3.3 \mathrm{~cm}$ long, slightly thicker than top of sterile interstice, $5-8 \mathrm{~mm}$ diam.; stamens small, rectangular-dumbbell-shaped from above, $0.5 \times 1 \mathrm{~mm}$, with the thecae impressed; pollen ivory, dusty; appendix exceeding to shorter than the male zone, c. 1.5-3 cm long, tapering and pointed to cylindric and round-tipped, basally the same diameter as the male zone, rarely narrowly ovoid, composed of columnar flattopped staminodes. Fruiting spathe declinate, narrowly ovoid.

Distribution - Burma to Thailand and Malesia: widespread in Peninsular Malaysia and Sumatera.

Habitat - Lowland rain forest to lower montane forest; sometimes on limestone in wet places; robust forms particularly found in disturbed habitat and along stream banks in the Malay Peninsula; to $1500 \mathrm{~m}$ alt.

Notes - As interpreted here, this is, in both Sumatera and the Malay Peninsula, a highly variable species or a species complex which more intensive field study may resolve into further taxa. However, at present it does not seem possible to divide it further without recourse to describing individual collections as species. Schismatoglottis ridleyana represents a usually robust form with dull green broad leaves with rather prominent and closely spaced primary lateral veins and a fine dense velvety indumentum on the petioles and abaxial midrib. The new leaves are often a rather bright pink. It is common at mid-elevation on Bukit Larut in West Malaysia. $S$. linguiformis is a less robust, narrow-leaved aspect. Forms occur with shiny pale 
green leaves (pale bronze when young) and more delicate forms with deep red stems and petioles (leaves bronze when young) and orange-yellow spathes. Schismatoglottis leptophylla Alderw. is a rather slender aspect of the complex. The indumentum on the leaves is commonly reduced (with intermediate states) to minute finely scattered excrescences on the petiole and midrib surface which may appear glabrous to the naked eye. The inflorescence is variable as to overall size, and in particular the relative length of the appendix and male zone. The unifying features are the narrow, shortly persistent, hardly opening spathe limb, the part-naked interval between the male and female zones, the rather to very robust more or less erect stem, deeply cordate leaves and deliquescent leaf sheath.

When revising the Peninsular Malaysian species, Hay (1996) suggested that Schismatoglottis mutata might prove indistinguishable from $S$. rupestris. The two are certainly closely allied, but $S$. rupestris, which overlaps geographically with $S$. mutata in Sumatera but also extends to Java, can be distinguished by its generally much more robust habit, the larger inflorescence, and the larger number of primary lateral veins.

Synonymy of Peninsular Malaysian elements was discussed in Hay (1996). The type of Schismatoglottis batoensis is fragmentary. The leaf and inflorescence are small, but the leaf blade has the large number of rather closely spaced primary lateral veins characteristic of S. rupestris. Alderwerelt (loc. cit.) provided a 'completion' to Engler's description, but did not cite any specimens on which this was based, nor did he specify how $S$. batoensis differed, in his opinion, from allied species. It is placed here in the synonymy of $S$. mutata somewhat provisionally.

Schismatoglottis rotundifolia was described from sterile material of uncertain origin. The leaf shape and size are reminiscent of $S$. hottae, but the venation is less dense and less prominent. Schismatoglottis rotundifolia has thickly and minutely puberulent petioles, a feature not noted by Engler, and the broad leaf sheath appears to detach from the petiole. Moreover, the internodes are well-developed. These features together suggest affinity with $S$. rupestris and allied species, and though Engler indicated the plant might be Bornean, it seems much more likely to be Sumateran, as that species group is best developed there and apparently absent from Borneo. Hotta 26157 includes a juvenile plant of $S$. mutata, with rotund leaves. Since the type of $S$. rotundifolia is sterile, it is possible that it too represents a juvenile stage of $S$. mutata, and it is provisionally placed in synonymy here.

The type sheet of $S$. monticola is extremely badly damaged, but vegetatively, as far as it can be interpreted, this species represents a rather slender aspect of S. mutata. Alderwerelt described the spathe limb as being open, whereas it clasps the spadix in most species of the $S$. rupestris group including $S$. mutata. If indeed this species does have an open spathe limb, it shares this feature with $S$. grandiflora Alderw., also in the $S$. rupestris group, from which it differs in the narrower and significantly more membranous spathe limb. However, the spirit-preserved inflorescence is quite distorted, apparently due to having been pickled after being (partially) dried - as with some other Lörzing material. It is not clear that the more or less open spathe is not an artefact. This species cannot be properly interpreted without re-collecting from the area of the type locality, where the plant was found at $1200 \mathrm{~m}$ alt in forest. In the mean time it is placed provisionally in the synonymy of $S$. mutata.

Alderwerelt cited four Sumateran Bünnemeijer collections $(8547,8731,8975$ and 9037) in the protologue of Schismatoglottis leptophylla. The second has been selected as the Type: it is the most complete and it clearly agrees with Alderwerelt's description. Schismatoglottis leptophylla represents a slender, depauperate aspect of S. mutata s. lat.

Other specimens examined: PENINSULAR MALAYSIA: Perak, Bukit Larut, Boyce 689 (K); Perak, Kuala Kangsar, Boyce 708 (K); Penang, Moniots Rd, Burkill 2678 (SING); Pahang, Bukit Fraser, 
Burkill \& Holttum 8696 (SING); Selangor, Ulu Gombak, Croat 53310 (K); Penang, Moniots Rd, Curtis s.n. (SING); Perak, Bukit Larut, Engler 5312 (B); Perak, Sungei Batang Padang, Tapah Hill reserve, Furtado 33097 (K, SING); Cult. RBG Sydney, Acc. No. 940086 ex Selangor, Gombak Valley, (orig. coll. Hay et al. 9042), Herscovitch s.n. (K, KEP, NSW, SING); Cult. RBG Sydney Acc. No. 940181, 940182 ex Perak, Bukit Larut, (orig. coll. Hay et al. 9087, 9088), Herscovitch s.n. (KEP, NSW); Cult. RBG Sydney Acc. No. 940124, 940130 ex Perak, foothills of Gunung Bubu, (orig. coll. Hay et al. 9128, 9134), Herscovitch s.n. (K, KEP, L, NSW, SING, US); Cult. RBG Sydney Acc. No. 940142, 940143 ex Negeri Sembilan, Bukit Tangga, nr Jelebu, (orig. coll. Hay et al. 9146, 9147), Herscovitch s.n. (NSW); Cult. RBG Sydney Acc. No. 940151 ex Negeri Sembilan, Jaram Toi Recreation Area, (orig. coll. Hay et al. 9155), Herscovitch s.n. (K, KEP, NSW); Cult. RBG Sydney Acc. No. 940291, 940306, 940307 ex Terengganu, Ayer Terjun, Sekayu F.R., (orig. coll. Hay et al. 9223, 9238, 9239), Herscovitch s.n. (NSW); Cult. RBG Sydney Acc. No. 940340, 940342 ex Pahang, Bukit Fraser, (orig. coll. Hay et al. 9273, 9275), Herscovitch s.n. (K, KEP, NSW, SING); Perak, Batang Padang, Henderson 10890 (K); Perak, Lubok Tamang, Henderson 10892 (SING); Pahang, Cameron Highlands, No. 4 Camp, Henderson 11079 (SING); Pahang, Bukit Fraser, Henderson 11270 (SING); Pahang, Bukit Fraser, Henderson 11464 (SING); Pahang, Cameron Highlands, Robinson Falls, Henderson 17979 (SING); Pahang, base of Kota Gelanggi, Henderson 22427 (K, SING); Pahang, Cameron's Highlands, Henderson 23353 (CAL); Negeri Sembilan, Ulu Brudok Forest Reserve, Holttum 9878 (SING); Terengganu, G. Padang, Kiah E Moysey 33942 (SING); Pahang, Bukit Fraser, Mohd. Nur 11283 (K); Perak, Bukit Larut (Maxwell's Hill), Mohd. Nur 12932 (SING); Perak, roadside Thaiping to Maxwell's Hill Station, Nicolson 1090 (SING); Kuala Lumpur-Bukit Fraser Highway, Nicolson 1162 (L, SING); 15th Mile, Pahang Rd, Ridley 8487 (CAL); Selangor, Gua Batu, Ridley s.n. (SING); Selangor, Genting Peras, Ridley s.n. (SING); Pahang, Telom, Ridley s.n. (SING); Selangor, Bukit Kutu, Ridley s.n. (SING); Perak, Scortechini 267 (K); Gua Panjang, Ulu Kelantan, UNESCO Limestone Expedition (1962) 528 (K, L). SUMATERA: North Sumatera, Tapanuli, 1 km W of Lae Pondoon, Sidikalang, Alston 14968 (BM); North Sumatera, Asahan, Pargambiran, Bartlett 8182 (US); West Sumatera, Ophir Distr., NW of Talamau, Bünnemeijer 518 (BO); West Sumatera, G. Singgalang, Bünnemeijer 2757 (L); West Sumatera, G. Kerinci, Bünnemeijer 8547 (BO), 8975 E 9037 (both BO, L); Cult. RBG Sydney Acc. No. 801575 ex North Sumatera, between Bukit Lawang and Bahorok orang utan rehabilitation centre (orig. coll. Rodd 47), Herscovitch s.n. (BO, K, L, NSW); West Sumatera, Bukit Gajabuih, Ulu Gadut, c. $15 \mathrm{~km}$ E of Padang, Hotta 25427, $25852 b$ \& 25984 (all KYO); West Sumatera, along valley of Ulu Gadut, c. 15 km E of Padang, Hotta 26116 (BO), 26120 (BO, KYO) \& 26133 (BO, KYO); West Sumatera, around Anai waterfall, W of Pandangpanjiang, Hotta 26157 (KYO); West Sumatera, Setia Mulia, Bot. Gard.of Andalas Univ., c. 20 km E of Padang, Hotta et al. 1049 \& 1052 (both KYO); West Sumatera, Rimbu Panti, Anak Sengai, Barameh Tetek, N from Lubuk Sikaping, Okada et al. 22 (BO); Batu Eiland, Raap 167 (BO); Riau, Marbau, Bilah, nr Bilah Pertama (Parbasiran), Rahmat Si Toroes 104 (NY); North Sumatera, Berastagi, Ridley s.n. (K); North Sumatera, Bukit Lawang-Bokosok-Langkat, Soedarsono 225, 315 (both BO); Jambi Prov., Palembang, N of G. Pahewang, NW side of Ranaumeer, van Steenis 3487 (BO); Aceh, G. Leuser Nature Reserve, 8-15 km SW of Lau Ketambe, c. $40 \mathrm{~km}$ NW of Kutacane, de Wilde $\mathcal{E}$ de Wilde-Duyfjes 13806 (L); Aceh, G. Leuser Nature Reserve, Upper Manas Valley, c. $15 \mathrm{~km} \mathrm{~W}$ of Kutacane, de Wilde \& de Wilde-Duyfjes 18350 (BO).

\section{Schismatoglottis okadae M. Hotta}

Schismatoglottis okadae M. Hotta, Contr. Biol. Lab. Kyoto Univ. 27 (1987) 151, fig. 1; van Steenis, Allertonia 4 (1987) 293. - Type: Indonesia, Sumatera, Sumatera Barat, Karang Puteh, 16 Feb 1981, M. Hotta \& H. Okada 276 (KYO, holo; iso BO).

[Schismatoglottis lancifolia sensu auct. ?non Hallier f. \& Engl.: Alderw., Bull. Jard. Bot. Buitenzorg. III, 4 (1922) 206. — see discussion under S. lancifolia].

Small to moderately robust rheophytic herb c. $15-40 \mathrm{~cm}$ tall. Stem creeping to decumbent, with internodes to 1-4 cm long, 1-3 cm thick. Leaves several along the stem; petiole generally longer than the blade, 5-40 cm long, sheathing in the lower $2 / 5-3 / 5$; wings of sheath fully attached (later tending to degrade) and tapering; blade oblanceolate to ovate, $7-26 \mathrm{~cm}$ long $\times 2-10 \mathrm{~cm}$ wide, the base acute to shallowly cordate, sometimes markedly asymmetric, the tip acuminate for $1-3 \mathrm{~cm}$; midrib and primary veins tough and abaxially prominent; primary lateral veins $3-9$ on each side 
of the midrib, irregularly alternating with interprimaries ill-differentiated from the secondary venation, diverging at c. $30^{\circ}$; secondary venation mostly arising from the midrib, some from near the bases of the primary veins in the lower part of the leaf; tertiary venation obscure. Inflorescence solitary; peduncle more or less half the length of the petiole at anthesis (later elongating). Spathe green, 5-8 cm long; lower spathe narrowly ovoid to ovoid, 2-3 cm long, differentiated from the limb by a weak constriction; limb oblong-lanceolate, shortly acuminate, $3-5.5 \mathrm{~cm}$ long, whitish, persistent after anthesis, finally deciduous. Spadix shortly stipitate, $3-3.5 \mathrm{~cm}$ long; female zone and stipe obliquely inserted to partly adnate to the spathe in the basal $1 / 4$; female zone 1-1.5 cm long, subcylindric, c. $2 \mathrm{~mm}$ diam. (dry); pistils crowded (distally more lax), oblong-subglobose, c. $0.5 \mathrm{~mm}$ diam.; stigma sessile, discoid, slightly narrower than the ovary; interpistillar staminodes absent from among the pistils, a few or an incomplete whorl at the base of the female zone, more or less globose, sessile, slightly larger than the pistils; sterile interstice $5-8 \mathrm{~mm}$ long, within and reaching the mouth of the lower spathe chamber, naked except for scattered small groups of sessile staminodes smaller than the basal ones, c. $0.3 \mathrm{~mm}$ diam.; male zone more or less cylindric-fusiform, c. $1.2-2 \mathrm{~cm}$ long $\times 3-5 \mathrm{~mm}$ thick; stamens crowded, truncate with the connective thick but not elevated between the thecae, c. $0.6 \mathrm{~mm}$ across; appendix shorter than and basally isodiametric with the male zone, c. $5 \mathrm{~mm}$ long, apically acute; staminodes of the appendix flat-topped, irregularly polygonal, c. $0.7 \mathrm{~mm}$ diam. Fruiting spathe urceolate becoming pyriform, c. 3-4 cm long.

Distribution - Malesia: endemic to Sumatera (widespread but scattered in Aceh, North Sumatera and West Sumatera).

Habitat - Rheophytic on rocks or in sand and gravel by streams, often forming large colonies in well illuminated conditions by branching of the decumbent and creeping stems; found over a variety of substrates including limestone and sandstone, $50-400 \mathrm{~m}$ alt.

Notes - Schismatoglottis lancifolia Hallier f. \& Engl. may have priority - see discussion there.

This species is very variable in size, apparently according to microhabitat — plants established on boulders generally reach and flower at the smallest dimensions, while those established in sand and gravel may be much more robust and then generally with relatively much wider leaf blades. Okada \& Hotta (1987) discussed its morphological variation, noting that the creeping stem associated with the rheophytic habit is not always genetically fixed in some populations (when the stem becomes erect in cultivation), but is in others (where the creeping or decumbent habit persists in cultivation).

We made a living collection of this species from Lembah Anai Forest Reserve (West Sumatera) where it has not previously been recorded; unfortunately the cultivated plants died before specimens were preserved from them.

Other specimens examined: SUMATERA: Cult. RBG Sydney Acc. No. 801571 ex North Sumatera, between Bukit Lawang and Bahorok orang utan rehabilitation centre (orig. coll. Rodd 6), Herscovitch s.n. (NSW, spirit only); West Sumatera, around Air Sirah plot, nr pass of Padang-Solok rd, Hotta 26450-b (KYO); West Sumatera, between Padang and Solok, nr Kg Airsirah, Hotta 27200 (BO, KYO); West Sumatera, Karang Putih, E of Padang City, Hotta \& Okada 275 \& 309 (both BO, KYO); West Sumatera, K. Putih, E of Padang, Okada \& Hotta 273, 317 \& 350 (all KYO); West Sumatera, Bukit Gadang, Bancah, Talang Babungo, Okada et al. 05 (BO); North Sumatera, Asahan, vicinity of Huta Bagasan, Rahmat Si Boeea 6678 (US); North Sumatera, Asahan, Adian Rindang, vicinity of Huta Tomuan Dolok, Rahmat Si Boeea 8682, 8809 and 8931 (all US); North Sumatera, Bukit Lawang Bohorok-Langkat, Soedarsono 288 (K, L); Cult. Hort. Bogor ex North Sumatera, Sibolangit, Deli (orig. coll. Jaheri), van Alderwerelt van Rosenburgh s.n. (BOKR); North Sumatera, Suaka Margasatwa, Bolok Surungan, Widjaja 1819 (BO); Aceh, middle Alas R. (Lae Suraya) Area, c. 15 km N of 
Gelombang, S of Bengkong R., de Wilde E De Wilde Duyfjes 20139 (L); Aceh, Sekundur Forest Reserve, upper Besitang R. area, Langkat, base camp at Aras Napal, de Wilde $\mathcal{E}$ de Wilde Duyfjes 21167 (L).

\section{Schismatoglottis ovata Schott}

Schismatoglottis ovata Schott, Ann. Mus. Lugd.- Bat. 1 (1863) 125. - Type: Indonesia, 'Borneo' [almost certainly Sumatera], Korthals s.n. (L, holo - 2 sheets).

Schismatoglottis sylvestris Alderw., Bull. Jard. Bot. Buitenzorg III, 4 (1922) 199. - Type: Indonesia, Sumatera, West Sumatera, G. Malintang, 22 Jul 1918, H.A.B. Bünnemeijer 3813 ( $\mathrm{BO}-2$ sheets $+\mathrm{BO}$ spirit, lecto; isolecto L; selected here).

Schismatoglottis sylvestris var. subcordata Alderw., Bull. Jard. Bot. Buitenzorg III, 4 (1922) 199. - Type: Indonesia, Sumatera, Mt Talamau, 25 Apr 1917, H.A.B. Bünnemeijer 434 (BO + BO spirit, lecto; selected here).

Herb c. $15-30 \mathrm{~cm}$ tall. Stem to c. $40 \mathrm{~cm}$ long, decumbent to sprawling, pleionanthic, sometimes tinged deep red, c. 1-2 cm diam., with coarsely scabrid verruculate to rugose internodes. Leaves to c. 10 along the stem; petiole 9-18 cm long, scabrid-rugose abaxially at the base, the rest densely and minutely puberulent, sheathing in the lower $1 / 3-1 / 2$ the wings of the sheath at first fully attached and tapering, then withering and partly deciduous, especially in the distal part; blade ovate to broadly ovate, dull dark green adaxially, paler abaxially, 8-17 cm long $\times 6-10 \mathrm{~cm}$ wide, the base obtuse to retuse, occasionally narrowly and shallowly cordate with posterior lobes to c. $1 \mathrm{~cm}$ long, the apex obtuse to acute, not at all acuminate, if obtuse then apiculate for c. $4 \mathrm{~mm}$; midrib prominent abaxially, with 7-11 primary lateral veins on each side diverging at $45-60^{\circ}$; interprimary veins not differentiated, or very sporadic and hardly thicker than the secondary venation; secondary veins mostly arising from the midrib, some from near the bases of the primary veins in the lower part of the leaf; tertiary venation obscure. Inflorescence solitary; peduncle not or hardly exserted from the subtending leaf base, c. $3 \mathrm{~cm}$ long. Spathe $4.5-6 \mathrm{~cm}$ long, thick and spongy; lower spathe narrowly ovoid, c. 2-2.5 cm long, differentiated from the limb by a weak constriction; limb $2-2.5 \mathrm{~cm}$ long, oblong-lanceolate, not much opening, withering after anthesis and then deciduous, whitish. Spadix $3.5-4.5 \mathrm{~cm}$ long, subcylindric; female zone 1-1.3 cm long, obliquely inserted, subcylindric, c. $3 \mathrm{~mm}$ diam.; pistils more or less crowded, subcylindric-bottle-shaped, c. $0.7 \mathrm{~mm}$ diam.; stigma sessile, discoid, papillate, somewhat narrower than the ovary; interpistillar staminodes in 1-2 irregular whorls around the base of the female zone, shorter than and about the same diameter as the ovaries, more or less flat-topped, recurring in 1-4 very irregular whorls at the top of the female zone marking the base of the interstice; sterile interstice somewhat attenuate, $0.8-1.2 \mathrm{~cm}$ long, naked but for scattered groups of small sessile staminodes resembling sterile anthers; male zone somewhat thicker than the interstice, subcylindric, c. $1.4 \mathrm{~cm}$ long $\times 3 \mathrm{~mm}$ thick; stamens crowded, truncate, more or less dumbbell-shaped, c. $0.5 \mathrm{~mm}$ across; appendix much reduced, sometimes merely a terminal cluster of staminodes, or up to c. $4 \mathrm{~mm}$ long and conic, the base isodiametric with the top of the male zone; staminodes of appendix irregularly polygonal, more or less flat-topped, c. $0.7 \mathrm{~mm}$ diam. Fruiting peduncle somewhat declinate, not much further exserted than at flowering; fruiting spathe broadly urceolate, to $3 \mathrm{~cm}$ long. - Fig. 3.

Distribution - Malesia: endemic to Sumatera (North and West Sumatera).

Habitat - Terrestrial on forest floor, sometimes locally very abundant (possibly with the decumbent branching stems forming clonal colonies), c. 500-1200 m alt.

Notes - Schismatoglottis ovata is closely allied to Malay Peninsula S. brevipes Hook. f., sharing the sprawling habit and very reduced appendix. It differs in having rough 


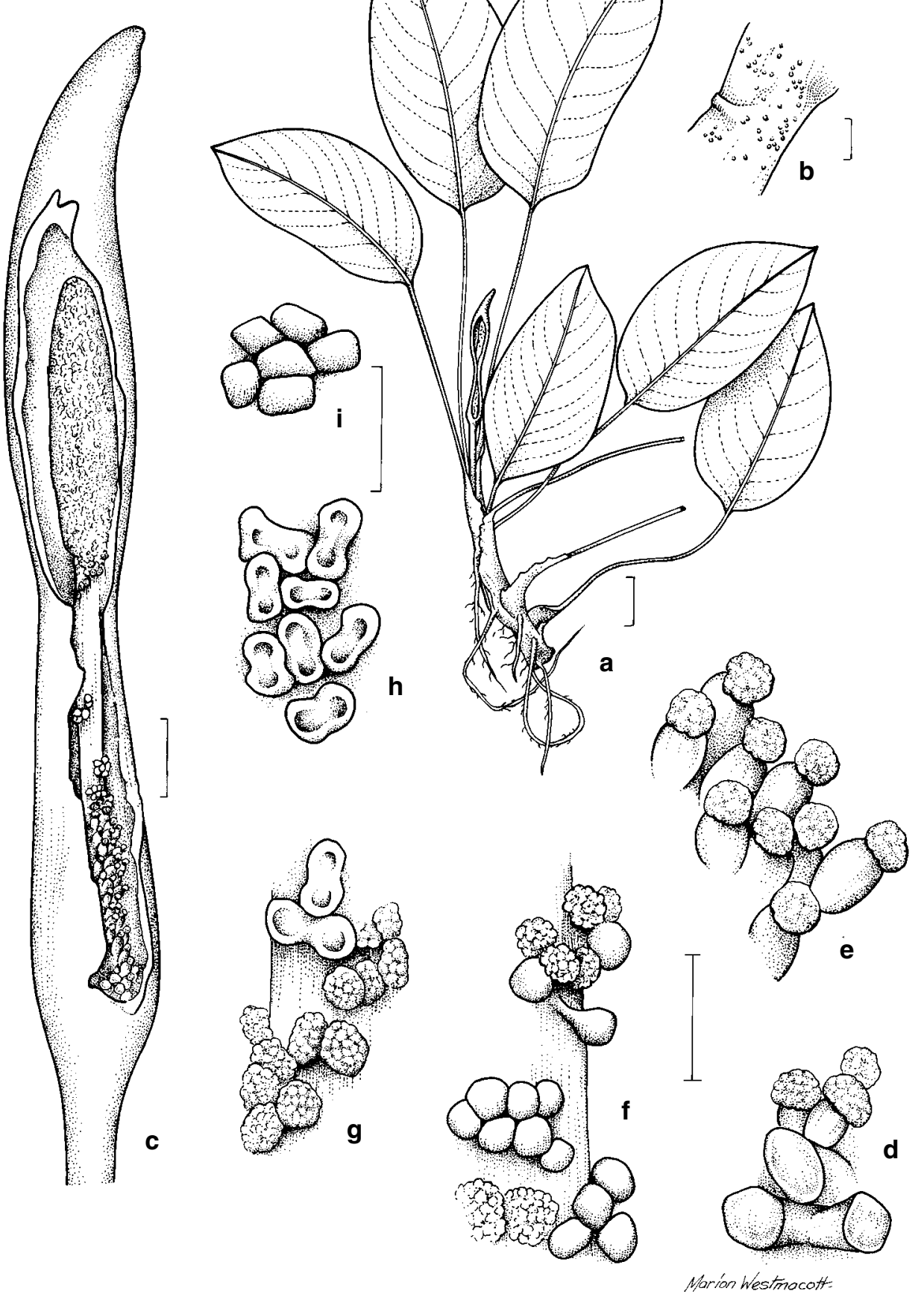

Fig. 3. Schismatoglottis ovata Schott. a, Habit; b, Node with verruculae; $\mathbf{c}$, Inflorescence with part of spathe removed; d, Pistils and interpistillar staminodes; e, Pistils; $\mathbf{f}$, Neuter organs in the interstice; g, Top of interstice; h, Stamens; i, Appendical staminodes (Bünnemeijer 3813). Scale bar: $\mathrm{a}=2 \mathrm{~cm} ; \mathrm{b}=4 \mathrm{~mm} ; \mathrm{c}=4 \mathrm{~mm} ; \mathrm{d}-\mathrm{i}=1 \mathrm{~mm}$. 
internodes and puberulous, longer petioles, and interpistillar staminodes confined to each end of the female zone.

The type of Schismatoglottis ovata is incomplete, but the leaf blade can be matched to the smaller S. sylvestris via other conspecific material intermediate in size. Moreover, a scabrid indumentum is present on the petioles of the type of S. ovata and on one sheet there is part of a rugose internode present. In the protologue Schott noted that the sheath was partly deciduous, a third feature in which the type of $S$. ovata matches $S$. sylvestris. This species is evidently variable in size, and the type of $S$. ovata represents a more robust facies. The type of $S$. sylvestris is a delicate plant, but Alderwerelt's var. subcordata is intermediate.

The type of Schismatoglottis ovata is a Korthals collection allegedly from Borneo. No more precise locality is given on the label. It matches no other Bornean material, and it is probably mislabelled (cf. S. concinna - see under S. acuminatissima).

Alderwerelt cited two collections in the protologue of Schismatoglottis sylvestris, Bünnemeijer 3813 and 3850. Of the latter, a sheet has not been found, though wellpreserved spirit material of inflorescence is at BO. The former is represented by two sheets at $\mathrm{BO}$ no longer with inflorescence (but there is a poorly preserved inflorescence in spirit) and a duplicate at $\mathrm{L}$ which includes an inflorescence. Comparison of the inflorescences of each collection makes it clear that they represent the same species, and therefore the more complete 3813 is selected as the lectotype. Schismatoglottis sylvestris var. subcordata is lectotypified with Bünnemeijer 434, which includes spirit material. The second syntype, Bünnemeijer 387, is less complete.

Other specimens examined: SUMATERA: West Sumatera, Mt Talamau, Bünnemeijer 387 (BO); West Sumatera, Mt Malintang, Bünnemeijer 3850 (BO spirit); West Sumatera, Lembah Anai Forest Reserve, Hay et al. 13092 (BO, K, NSW); Cult. RBG Sydney Acc. No. 970496 ex West Sumatera, Hutan Raya Bung Hatta, G. Gadut (orig.coll. Hay et al. 13067) =; West Sumatera, Setia Mulia, Bot. Gard. Of Andalas Univ., c. 20 km E of Padang, Hotta et al. 1061b (KYO) \& Hotta \& Okada 594 (KYO); Tapianoeli, Padang Si Dimpoean, Padang Lawas, nr waterfall of the Aek Si Olip, Rahmat Si Toroes 5286 (L); Tapianoeli, Padang Si Dimpoean, Padang Lawas, Sopsopan on Aek Si Olip, Rahmat Si Toroes 5565 (GH, L, US).

\section{Schismatoglottis rupestris Zoll. \& Moritzi ex Zoll.}

Schismatoglottis rupestris Zoll. \& Moritzi ex Zoll., Syst. Verz. 1 (1854) 77; Miq., Fl. Ind. Bat. 3 (1856) 214; Schott, Syn. Aroid. (1856) 120; Engl. in A. \& C. DC., Monogr. phan. 2 (1879) 350; Engl., Bot. Jahrb. Syst. 25 (1898) 19; Koord., Exkurs.-Fl. Java 1 (1911) 259; Backer, Beknopte Fl. Java 17 (1957) 33; Bakh.f. \& Koster, Blumea 12 (1963) 67; Backer \& Bakh.f., Fl. Java 3 (1968) 116. - Type: Java, Bogor, Zollinger 84 (L, holo; iso P).

Schismatoglottis latifolia, Bot. Zeit. 14 (1856) 565; Miq., Fl. Ind. Bat. 3 (1856) 214; Schott, Prod. syst. Aroid. (1860) 322; Engl. in Engl. \& K. Krause, Pflanzenr. 55 (IV.23Da) (1912) 117; Alderw., Bull. Jard. Bot. Buitenzorg III, 4 (1922) 214. - Type: Indonesia, Central Java, Mount Merapi, Junghuhn s.n. (U, holo; iso L [barcode L 0041978]).

Apoballis neglecta Schott, Oesterr. Bot. Zeit. 8 (1858) 318; Schott, Prod. syst. Aroid.(1860) 321.- Type: Schott Ic., no. 915-916 (W, lecto; selected here). — Fiche no. 46: c8-c9 in the microfiche edition.

Schismatoglottis latifolia var. rubescens Engl., Type: ?A. Engler (?Bt, holo - see note). - Neotype: Cult. RBG Sydney Acc. No. 980097 ex West Java, Mount Tilu (orig. coll. Yuzammi 297031), Yuzammi s.n. (NSW; designated here).

Schismatoglottis latifolia var. viridis Engl., Pflanzenr. 55 (IV.23Da) (1912) 118. nom. superfl. pro var. typ.)] 
Schismatoglottis treubii Engl., Pflanzenr. 55 (IV.23Da) (1912) 119, fig. 73. - Type: Cult. Hort. Bogor XI.B.X.52 ex Sumatera, North Sumatera, Deli (orig. coll. M. Treub, Sep 1894), A. Engler 4070 (B, holo).

Schismatoglottis wigmannii Engl., Pflanzenr. 55 (IV.23Da) (1912) 118, fig. 72. - Type: Cult. Hort. Bogor. Bed XI.B.X.21, Jan/Feb 1906, A. Engler 4072 (B, holo).

Schismatoglottis treubii f. viridipes Alderw., Bull. Jard. Bot. Buitenzorg III, 4 (1922) 214. - Type: Cult. Hort. Bogor. XI.B.X.53, C.R.W.K. van Alderwerelt van Rosenburgh s.n. (BOKR, holo).

Moderately to very robust herb to c. $1 \mathrm{~m}$ high. Stem erect to decumbent, up to $2 \mathrm{~m}$ long (usually less), c. 3-10 cm diam. with internodes c. 1-5 cm long. Leaves several together; petiole green to brownish red, c. 18-90 cm long, sheathing in the lower $1 / 3-1 / 2$; wings of sheath fully attached, tapering, marcescent and crumbling; blade ovato-sagittate, sometimes slightly cordate-sagittate, green to mid-green adaxially, dull yellowish green abaxially, thinly leathery, c. $23-40 \mathrm{~cm}$ long $\times$ c. $16-28 \mathrm{~cm}$ wide, the base divided with posterior lobes acute to rounded, c. 5-12 cm long, the apex acuminate; midrib abaxially prominent, with c. 15-24 primary lateral veins on each side, sometimes branching, prominent abaxially, sunken adaxially, diverging from the midrib at $50^{\circ}-70^{\circ}$, alternating with lesser interprimary veins; secondary and tertiary veins obscure; posterior costae absent. Inflorescences 4-6 together, subtended by dried cataphylls; peduncle yellowish green, sometimes tinged red at the base, c. $10 \mathrm{~cm}$ long. Spathe c. $17 \mathrm{~cm}$ long, slightly curved, constricted at the level of sterile zone of the spadix; lower spathe c. $6 \mathrm{~cm}$ long, c. $2.2 \mathrm{~cm}$ diam., narrowly ovoid, yellowish green; the limb narrowly lanceolate, pale yellow, c. $11 \mathrm{~cm}$ long, c. $1 \mathrm{~cm}$ diam., open only slightly between male zone and lower part of appendix during anthesis, withering. Spadix subequalling the spathe, sessile; female zone light green, c. $4.5 \mathrm{~cm}$ long, c. $1.2 \mathrm{~cm}$ diam. at the base, not or barely adnate to the spathe; ovary subcylindric, c. $2-2.5 \mathrm{~mm}$ long, c. $0.75 \mathrm{~mm}$ diam.; stigma raised on a very short style, rounded (button-like); interpistillar staminodes scattered among the pistils, dirty white, taller than the pistils, a few concentrated at the base and more crowded between female zone and sterile inyterstice; sterile interstice almost naked, c. 1-2 cm long, the base of staminodes sometimes somewhat sunken into spadix, crowded at the base then scattered toward the apex; male zone yellowish-ivory, c. $3.5 \mathrm{~cm}$ long, c. $0.8 \mathrm{~cm}$ diam., cylindric; anthers c. $0.5 \mathrm{~mm}$ across, dumbbell-shaped; appendix subequalling or longer than male zone, c. $5 \mathrm{~cm}$ long, tapering, creamy, c. $0.5-0.8 \mathrm{~cm}$ diam. at the base; staminodes of appendix irregularly hexagonal. Fruiting spathe urceolate, to $5 \mathrm{~cm}$ long. - Fig. 4.

Distribution - Malesia: Sumatera, West to Central Java, Nusa Tenggara (Flores).

Habitat - Terrestrial, usually near streams or waterfalls or on very moist slopes in lowland and lower montane rainforest, often forming abundant stands, c. 200-1400 m alt.

Notes - Schismatoglottis rupestris has been attributed to Borneo, the Philippines and Sulawesi in the past (see Engler, 1912). However, it is almost certainly absent from any of those areas with the possible exception of Sulawesi (see below), records either being based on misidentifications or (in the case of Borneo) very probably mislabelled specimens.

For Sulawesi, Engler cited a Warburg collection (Warburg 14608) now lost at Berlin. There are also at Leiden two duplicate sheets of a specimen collected by Forsten in July 1840 near Tonando, one of which was determined by Schott (but nowhere cited) as Apoballis neglecta (= S. rupestris). Both sheets are sterile (but for some loose seeds), and it cannot be ascertained by standard morphological methods whether they do indeed represent this species. No more recent material is known of this species from Sulawesi.

The name Schismatoglottis rupestris was initially proposed by Zollinger and Moritzi and published by Zollinger (1854). Engler (1912) considered that S. rupestris was a nomen nudum and included it as a synonym of S. latifolia Miq. However, in the 


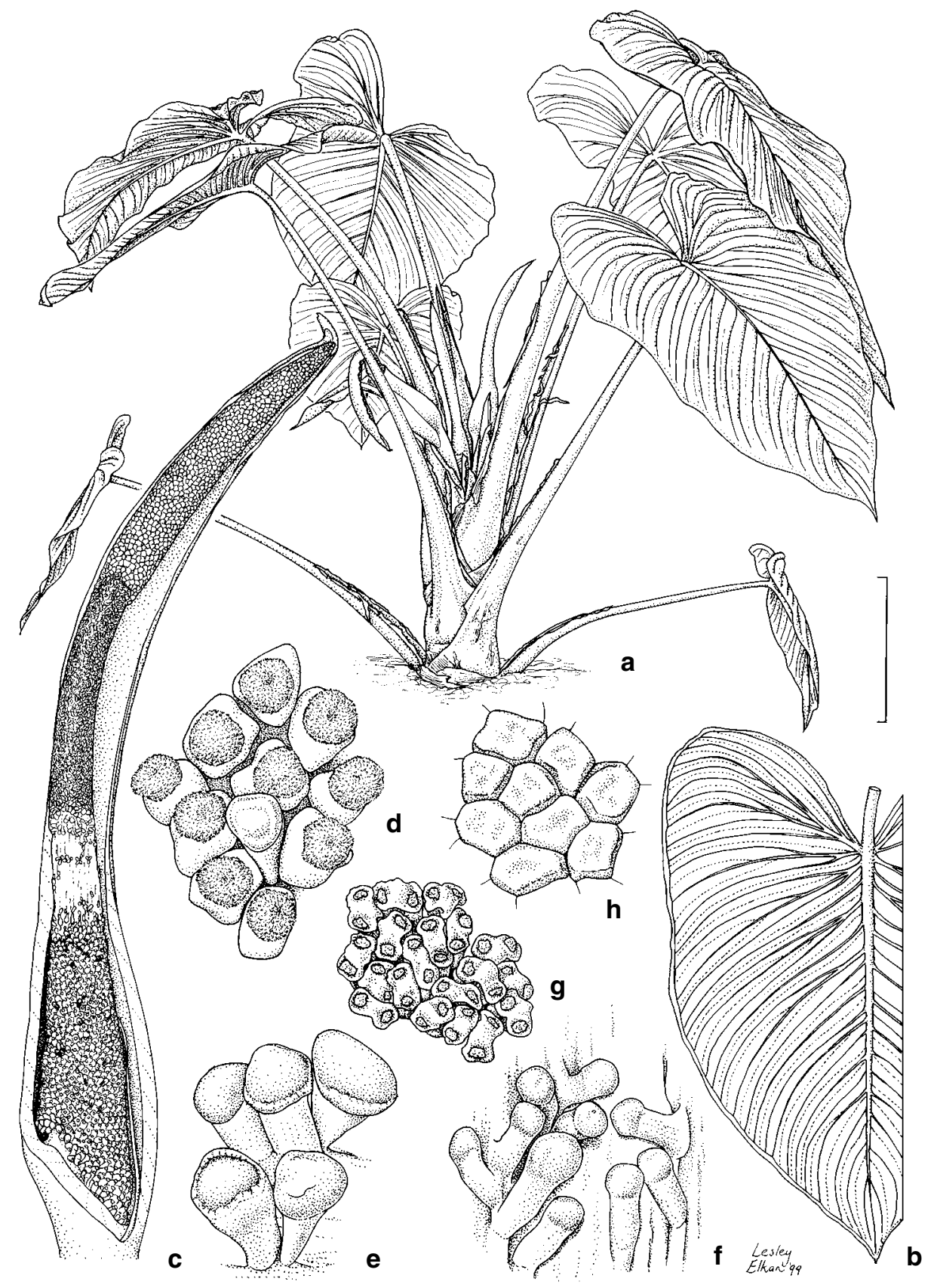

Fig. 4. Schismatoglottis rupestris Zoll. \& Moritzi. a, Habit (young mature plant before development of epigeal stem); b, Leaf; c, Inflorescence; d, Pistils and interpistillar staminode. e, Staminodes from top of female zone; $\mathbf{f}$, Staminodes from sterile interstice; $\mathbf{g}$, Stamens; $\mathbf{h}$, Staminodes of appendix (RBG Sydney Acc. No. 980092, cultivated from Yuzammi 297009). Scale bar: $a=10 \mathrm{~cm} ; \mathrm{b}=6 \mathrm{~cm}$; $\mathrm{C}=2.5 \mathrm{~cm} ; \mathrm{d}-\mathrm{h}=2 \mathrm{~mm}$. 
protologue Zollinger gave a very brief diagnosis: "Sch. rupestris Z. Mor. ined. HZ. 84. a. Spatha alba. In umbra habitac. pr. Bogor. XI. Ad rupes ibid. IV." Although Zollinger's description is not adequate to determine the species, it is nonetheless a description and the name cannot be considered a nomen nudum. Moreover, Zollinger cited a specimen (H. Zollinger 84) so that the application of the name is unambiguous. Schismatoglottis rupestris (1854) therefore has priority over S. latifolia Miq. (1856). The types of the two names are clearly conspecific, having the same broad ovate leaf, primary veins close to each other and the wing of the sheath marcescent/deciduous.

Schott (1858b) created the new genus Apoballis with A. neglecta as its type. He erected this taxon based on material known in cultivation as 'Homalomena cordata', (different from $H$. cordata sensu Schott). He did not cite any element that can serve as a type but the painting that Schott had made of this plant is very detailed and agrees with the protologue. It is therefore selected as lectotype.

Engler (1912) used the name Schismatoglottis latifolia for this taxon and recognised two varieties, var. viridis and var. rubescens, based on the colour of the petiole. However, the difference in colour is a matter of minor variation not worthy of taxonomic recognition. S. latifolia var. viridis is also a superfluous name for the antonymous variety.

There is no evidence that Engler preserved a specimen of S. latifolia var. rubescens. In the protologue, he mentioned that the variety was described from cultivated material at the Bogor Botanic Garden. He provided a diagnosis with an illustration, which he said was from the original plant. As no herbarium specimen can be found, it is presumed that Engler's type of this variety was either lodged at Berlin and destroyed during World War II or it was never preserved.

Designation of a type for Schismatoglottis latifolia var. rubescens, however, is necessary. Engler's illustration [Pflanzenreich 55 (IV.23Da) p. 118, fig. 71] could serve as an iconotype. However, the illustration is misleading in depicting the appendix of the spadix shorter than the male zone (as occurs in S. javanica) rather than equal or longer. Besides that, it depicts the female zone as ellipsoidal instead of elongate-ovoid. Alderwerelt (1922a) pointed out these errors and provided a new description using the same material that Engler had used. In view of the misleading nature of this plate, a neotype is designated. The neotype of $S$. latifolia var. rubescens is taken from cultivated material (RBG Sydney Acc. No. 980097), which originated in Java. It resembles Engler's description in having red-brown leaves and conforms with S. rupestris.

Schismatoglottis wigmannii was described from a plant cultivated at Bogor allegedly from Borneo. Engler's label records that the plant had the number 21, but does not record the bed number. Alderwerelt (1922a) noted that at that later time, plants representing two species were cultivated under the name $S$. wigmannii, and that one with the number 21 disagreed with Engler's description of $S$. wigmannii (and Alderwerelt then based S. engleriana on it), while that with the number 51 did not and was, in Alderwerelt's opinion, the same plant on which S. wigmannii was based. This plant was of unknown origin and conspecific with S. latifolia. Whether Engler misnoted the number, or whether over the years plant labels became misplaced (which seems not at all improbable), the leaf, which is all that remains of the type of S. wigmanii, and the incomplete description, are compatible with $S$. rupestris and are unmatched by any authentically Bornean material.

Schismatoglottis treubii appears to be no more than a robust form of S. rupestris. Engler distinguished it as the largest of all Schismatoglottis (a distinction now belonging to S. corneri), with the stem c. $30 \mathrm{~cm}$ long and $6-8 \mathrm{~cm}$ thick. Plants as large as this and larger, with stems to c. $2 \mathrm{~m}$ (though with much of the length collapsed on the ground) and $10 \mathrm{~cm}$ diam., can be encountered, for example in Kerinci Seblat National Park where they intergrade with plants of lesser dimensions corresponding to S. rupestris. 
The other feature that Engler used to distinguish S. treubii was the cylindric ovary. We have observed in other species with a wide range of vigour (e.g. S. wallichii) that the more robust forms, with larger spadices, tend to have more crowded, cylindric ovaries while in the less robust they tend to be more ovoid.

Alderwerelt (loc. cit.) distinguished Schismatoglottis treubii f. viridipes from S. treubii sensu Engler merely on the basis of petiole colour.

Other specimens examined: SUMATERA: North Sumatera, Medan Brastagi rd km 59-61, Bangham \& Bangham 1150 (GH); West Sumatera, Kota Baru, Bogner 1737 (M); West Sumatera, G. Talamau [= Ophir], Bünnemeijer 384 \& 522 (both BO); West Sumatera, G. Malintang, Bünnemeijer 4170 (BO); Cult. RBG Sydney Acc. No. 970453 ex Jambi Prov., Rd Bangko-Sungeipenuh, c. $120 \mathrm{~km}$ from Sungeipenuh, (orig. coll. Hay et al. 13012) (=); Cult. RBG Sydney Acc. No. 970465 ex Jambi Prov., Muara Emat, Kerinci Seblat National Park, (orig. coll. Hay et al. 13024) (=); Cult. RBG Sydney Acc. No. 970477 ex Jambi Prov., up Manjunto R. from Lempur vill., Kerinci Seblat National Park, (orig. coll. Hay et al. 13042) (=); West Sumatera, Hutan Raya Bung Hatta, G. Gadut, Hay et al. 13074 (NSW); West Sumatera, Lembah Anai Forest Reserve, Hay et al. 13106 (NSW); West Sumatera, around Rafflesia reservation at Batang Palupuh, N of Bukit Tinggi, Hotta 25031 (KYO); West Sumatera, Ulu Gadut, c. 15 km E of Padang, Hotta 25084 \& 25138 (both KYO); West Sumatera, along valley of Ulu Gadut, c. 15 km E of Padang, Hotta 25786, 25816 \& 26099 (all KYO); West Sumatera, around Anai waterfall, W of Padangpanjiang, Hotta 26154 \& 26155 (both KYO); West Sumatera, Bukit Gajabuih, Ulu Gadut, c. 15 km E of Padang, Hotta 25423 (KYO); West Sumatera, Karang Puteh, E of Padang, Hotta \& Okada 285, 287 \& 331 (all KYO); West Sumatera, Setia Mulia (Bot. Gard. Of Andalas Univ.) c. $20 \mathrm{~km}$ E of Padang, Hotta \& Okada 573, 580 \& 596 (all KYO); West Sumatera, Pinang-Pinang Plot, Ulu Gadut, c. $15 \mathrm{~km}$ E of Padang, Hotta \& Okada 618 (KYO); West Sumatera, en route from Base Camp to G. Kambot, c. 15 km E of Padang, Hotta \& Tamin 295 (KYO); West Sumatera, Arau Natural Reserve, c. $16 \mathrm{~km}$ N of Payakumbuh, Hotta \& Tamin 301 (BO, KYO); West Sumatera, en route from base camp to Pinang Pinang Plot, Ulu Gadut, about $15 \mathrm{~km}$ E of Padang, Hotta et al. 893, 1063 \& 1090 (all KYO); West Sumatera, Setia Mulia (Bot. Gard. Of Andalas Univ.) c. 20 km E of Padang, Hotta et al. 1050 (KYO); North Sumatera, Bandarbaru, Lörzing 5826 (BO);West Sumatera, nr, Pajakumbuh, Mt Sago, Meijer 7471 (L); North Sumatera, Sibilangit, Bukit Kluang, Nur 7413 (BO, K); West Sumatera, Kab. Pasaman, Lurah Berangin, from Sg. Marameh to Air Ujung Rajo, c. 12 km $\mathrm{N}$ from Lubuk Sikaping, Okada et al. 69 (BO); West Sumatera, Kab. Padang Pariaman, Sipisang, 40 km N from Padang, Anak Air Ganggu, Okada et al. 1313 (BO); West Sumatera, Kab. Padang Pariaman, Sipisang, $40 \mathrm{~km} \mathrm{~N}$ from Padang, from Anak Air Pinyangek to Batang Pinang, Okada et al. 1335 (BO); Aceh, G. Kemiri, van Steenis 9551 (L). JAVA: West Java, Pasir Honje, Tjiampea, Bakhuizen f. 625 (U); West Java, Mount Salak, Blume 2047 (2 sheets) (L); Java, Blume s.n. (L, barcode 0235816); West Java, Tjibeureum, Tjiomas, Buitenzorg, Boerlage s.n. (L, barcode L 0235807-8); West Java, Soekamantri, Hallier 550 b. (L); West Java, Dusun Kali Bata, Buitenzorg, Hallier 550 c. (L); Java, Hasskarl s.n. (K); West Java, Pelabuhan Ratu, Koorders $34460 \beta$ (BO); West Java, Tasikmalaya, Koorders 44357 (BO); Java, Kuntze s.n. (NY); Jagaranten, Kuntze 5225 (NY); West Java, Kebun Percobaan, P.T. Eisai Indonesia, Gakbrong, Cianjul, Murata et al. J-1652 (KYO); West Java, Cibodas Botanic Garden, Nicolson 892 (BO, US); West Java, Mount Salak, Ridley s.n. (K); West Java, Mount Gede, near the waterfalls, Ridley s.n. (K); West Java, Gunung Beser, Tjiherangm Kampung Toenggilis, van Steenis 11766 (BO); Cult. Hort. Bogor., Teijsmann s.n. (L); West Java, nr Bogor, G. Solok, Yoshida 1532 (KYO); West Java, Desa Ciomas, Kampung Pabuaran, close to Rawa Danau N.R., Yuzammi 297009 (NSW); West Java, Mount Tilu, Yuzammi 297029 (NSW); West Java, Mount Tilu, Yuzammi 297030 (NSW); West Java, Desa Sodong Cijambu Garut, Pameumpeuk, Yuzammi 297032 (NSW); West Java, Bojong Jengkol, Jampang Tengah, Sukabumi, Yuzammi 297078 (NSW); West Java, Lengkong forest, Sukabumi, Yuzammi 297085 (NSW); West Java, Mount Bunder, near Kawah Ratu, Yuzammi 399010 (NSW); Central Java, Western Mount Slamet, Batu Raden, Purwokerto, Yuzammi 399032 (NSW); West Java, Hutan Lindung Darajat, Kampung Pasir Hayam, Desa Sukamulya, Talegong, Garut, Yuzammi 399057 (NSW). NUSA TENGGARA: Flores, Manggarai, Schmutz 4090 (L); Flores, Verheijen 2972 (L). 


\section{Schismatoglottis sagittifolia Alderw.}

Schismatoglottis sagittifolia Alderw., Bull. Jard. Bot. Buitenzorg III, 4 (1922) 204. — Type: Indonesia, Sumatera, West Sumatera, Ophir Distr., West of Taloe, 8 Apr 1917, H.A.B. Bünnemeijer 64 (BO + BO spirit, holo).

Herb to c. $60 \mathrm{~cm}$ tall. Stem ?erect, ?pleionanthic (specimen fragmentary), c. $1.5 \mathrm{~cm}$ diam. Leaves few together; petiole ?30-35 cm long (see Alderwerelt, loc. cit.), minutely pubescent, sheathing in the lower $1 / 5$; wings of sheath fully attached, ?degrading, tapering; blade broadly lanceolato-sagittate, $25 \mathrm{~cm}$ long $\times 6 \mathrm{~cm}$ wide, the base divided into two rather narrowly triangular, apically acutely rounded posterior lobes c. $4 \mathrm{~cm}$ long, the apex acute and acuminate for c. $3 \mathrm{~cm}$; midrib somewhat prominent abaxially and adaxially, abaxially pubescent like the petiole, with c. 18 abaxially sparsely pubescent primary lateral veins on each side irregularly and infrequently (within a leaf) alternating with lesser interprimaries, diverging at c. $80-100^{\circ}$ and acropetally deflected more or less abruptly and running into a rather conspicuous intramarginal vein c. $1.5 \mathrm{~mm}$ from the margin, the primary veins of the posterior lobes united into posterior costae from which they emerge at a low angle thence abruptly acropetally reflexed; secondary venation arising from the midrib and sometimes from some distance along the primary veins, adaxially obscure, faint and fine abaxially; tertiary venation obscure. Inflorescence ?solitary; peduncle c. $7.5 \mathrm{~cm}$ long (see Alderwerelt). Spathe c. $9 \mathrm{~cm}$ long; lower spathe more or less obovoid, c. $1.75 \mathrm{~cm}$ long; limb lanceolate, clasping the spadix (but inflorescence immature), c. $7.25 \mathrm{~cm}$ long, ?semi-persistent. Spadix (immature and incomplete) white; female zone oblong-ellipsoid, c. $1 \mathrm{~cm}$ long; ovary oblong; stigma discoid, rotund, broad; interpistillar staminodes absent from among the pistils, concentrated at the top of the female zone; sterile interstice c. $5 \mathrm{~mm}$ long, with scattered very short apically flattened and rotund staminodes; male zone and appendix unknown; infructescence unknown.

Distribution - Malesia: endemic to Sumatera; known only from the type.

Habitat - In low montane forest c. $600 \mathrm{~m}$ alt.

Notes - This species is known only from incomplete material. It almost certainly belongs to the S. rupestris group, judging from the form of the sterile interstice and the species' provenance of Sumatera. The very narrowly sagittate leaf blade with numerous primary lateral veins is not matched by any other species in this group, though it approaches $S$. hastifolia. Re-collection from the type locality is required.

\section{Schismatoglottis asperata group}

Shoot pleionanthic; leaf sheath nearly always fully attached and persistent. Spathe limb opening more or less wide and then crumbling-deliquescent. Rarely rheophytic.

19 species, nearly all in Borneo; two species in the Malay Peninsula with one of these extending to Sumatera.

This is a very diverse and possibly heterogeneous grouping.

\section{Schismatoglottis asperata Engl.}

Schismatoglottis asperata Engl., Bull. Soc.Tosc. Ortic. 4 (1879) 11 \& in Becc., Malesia 1 (1883) 285. - Type: Malaysia, Sarawak, Matang, Apr 1866, O. Beccari P.B. 1498 (FI, lecto; selected here).

Schismatoglottis asperata var. albomaculata Engl., Bull. Soc. Tosc. Ortic. 4 (1879) 11 \& in Becc., Malesia 1 (1883) 285; Alderw., Bull. Jard. Bot. Buitenzorg III, 4 (1922) 200. - Type: Malaysia, Sarawak, Matang, Apr 1866, O. Beccari P.B. 1497 (FI, holo). 
Schismatoglottis crispata Hook. f., Curtis's Bot. Mag. 107 (1881) descr. ad t. 6576. - Type: Curtis's Bot. Mag. 107 (1881) t. 6576.

Herb to c. $40 \mathrm{~cm}$ tall. Stem condensed, suberect, becoming epigeal, to c. $1.5 \mathrm{~cm}$ diam., pleionanthic, sometimes red internally; internodes not conspicuous. Leaves few together (c. 4); petiole 7-19(-43) cm long, c. $1 / 2$ the length of to exceeding the blade, sheathing in the lower $(1 / 4-)_{1 / 3}-2 / 3$, more or less asperous and glistening owing to being variably clothed in short stiff minute hairs, and/or these borne on small, approx. hemispherical to elongate tubercles, narrowly alate on each side on the adaxial face, the wing usually crisped; wings of sheath attached to petiole throughout or almost so, broad and subparallel (then free-auriculate at the top for c. $0.5-1 \mathrm{~cm}$ ) to tapering and then not apically auriculate; blade obovate to ovate to broadly oblong-ovate, rather leathery to subsucculent, $14-26(-32) \mathrm{cm}$ long $\times 7-17(-21) \mathrm{cm}$ wide, pale bluish green and sometimes adaxially variegated with two longitudinal zones of irregular greenish white blotches, or greenish white between the primary veins, paler abaxially, the base acute (and finally very narrowly truncate) to more or less narrowly cordate and sometimes slightly hastate, the tip acute to obtuse and then apiculate for c. $1 \mathrm{~cm}$; midrib not prominent on either surface (dry), broad, adaxially with the vascular bundles of the primary lateral veins individually conspicuous throughout; primary lateral veins $6-8$ on each side, alternating with lesser interprimaries (inconspicuous in thick-leaved forms), diverging at c. $60^{\circ}$; secondary venation almost all arising from the midrib; tertiary venation indistinct, especially in thick-leaved forms. Inflorescence solitary, rarely two together, subtended by one or more broad cataphylls; peduncle short, not exserted from leaf bases (but see Notes). Spathe 6-13 cm long, subcylindric, tapering; lower spathe 1.5-3 cm long, ovoid, green, differentiated from the limb by a weak constriction corresponding with the upper part of the fertile male zone; limb 4.5-10 cm long, lanceolate, white, crumbling-deliquescent, fragile. Spadix sessile, shorter than the spathe, to $9 \mathrm{~cm}$ long; female zone $0.7-1.5 \mathrm{~cm}$ long, with oblique to shortly adnate (to spathe) insertion, $0.5-1 \mathrm{~cm}$ diam. at base, faintly conoid; pistils crowded, squat mushroom-shaped, c. $1 \mathrm{~mm}$ diam.; stigma sessile, discoid to irregularly polygonal, centrally impressed, papillate, wider than ovary and contiguous with neighbouring stigmas; interpistillar staminodes few, scattered among the pistils, slightly shorter to slightly taller than the pistils, c. $0.5 \mathrm{~mm}$ diam.; sterile interstice c. 1-3 mm long, isodiametric with top of female and base of male zones, 1-3 whorls of irregularly polygonal sterile stamens c. $1 \mathrm{~mm}$ diam., interspersed with a few interpistillar staminodes; male zone $0.8-1.5 \mathrm{~mm}$ long, cylindric, slightly attenuate at top; stamens white, turning orange after anthesis, crowded, truncate with the thick connective slightly elevated above the thecae, more or less rectangular to triangular from above; pollen extruded in strands; appendix white, about twice the length of the rest of the spadix, widest shortly above the base and there somewhat wider than male zone, then gradually tapering to a narrow blunt tip; staminodes of appendix more or less flat-topped, irregularly polygonal, c. $1 \mathrm{~mm}$ diam., crowded (fresh), tending to clump into groups of c. 10 on drying. Fruiting spathe broadly urceolate, c. $3 \mathrm{~cm}$ long. - Fig. 5.

Distribution - Malesia: endemic to Borneo (West Kalimantan, Sarawak, Brunei, western Sabah).

Habitat - Terrestrial in lowland to low montane forest, from wet places to ridge-tops, on a variety of substrates (shale, sandstone, limestone; ?other) to c.1200 m alt.; occasionally seen in open wet spots such as roadside ditches.

Notes - Schismatoglottis asperata is broadly circumscribed here, characterised by the pleionanthic stem, verruculose-pubescent alate petiole, the almost always solitary inflorescence, narrow, hardly constricted spathe, the large discoid contiguous stigmas, truncate anthers with thick slightly swollen connective, and the relatively long 


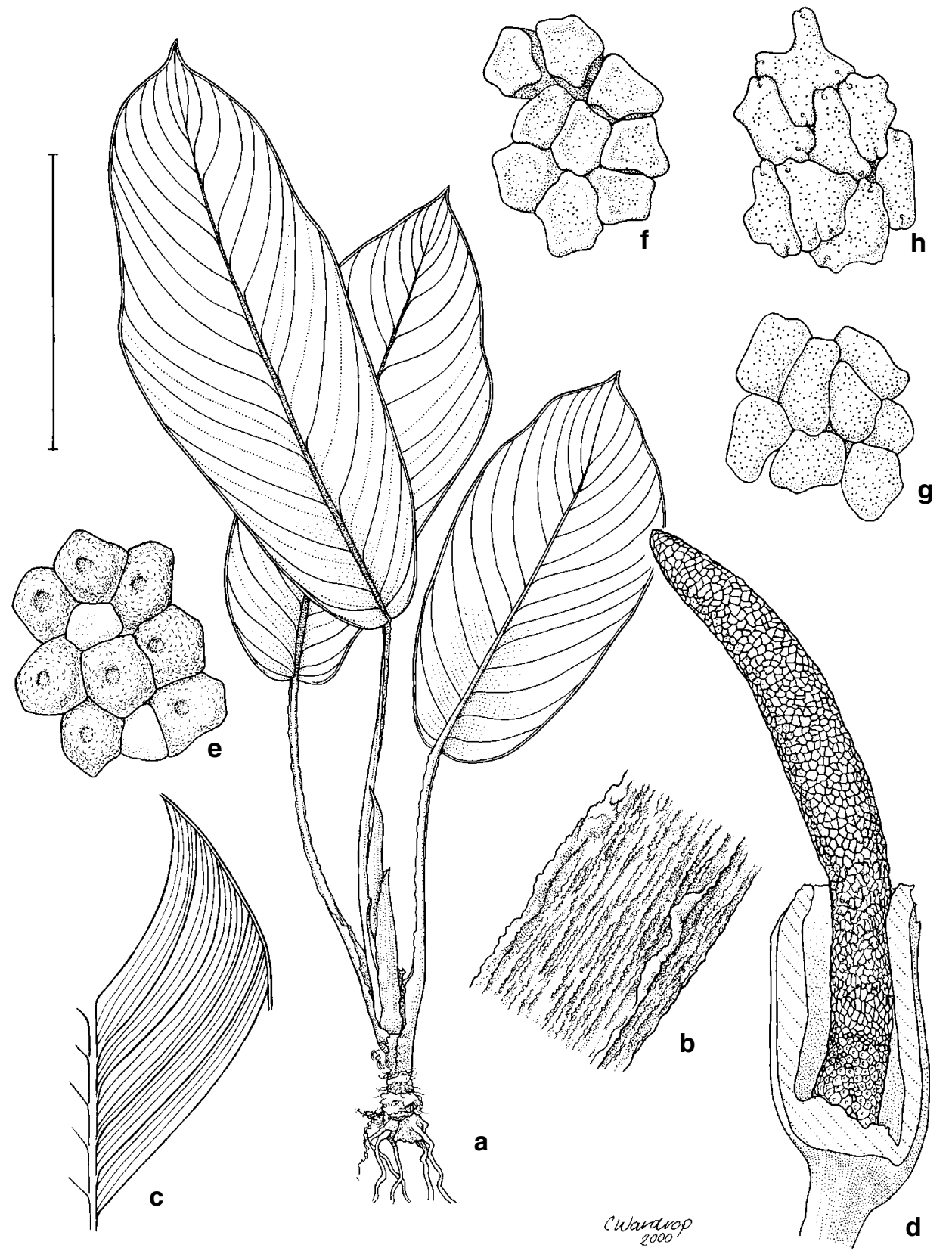

Fig. 5. Schismatoglottis asperata Engl. a, Habit; b, Portion of petiole; $\mathbf{c}$, Venation; d, Inflorescence with limb of spathe fallen and part of lower spathe removed; e, Pistils and interpistillar staminodes; f, Staminodes of interstice; g, Stamens; h, Staminodes of appendix (a-c: Yii S.40792; d-h: RBG Sydney Acc. No. 940563). Scale bar: $\mathrm{a}=10 \mathrm{~cm} ; \mathrm{b}=6 \mathrm{~mm} ; \mathrm{c}=6 \mathrm{~cm} ; \mathrm{d}=4 \mathrm{~cm} ; \mathrm{e}-\mathrm{h}=5 \mathrm{~mm}$. 
appendix. In general, in the southern part of the range - especially around Matang, Sarawak, the plants are squatter with broader leaf bases, shorter more heavily ornamented petioles, thicker leaf blades and a shorter female zone of the spadix. Flowering material is very limited, but specimens from the more northerly part of the range seem to have relatively longer female zones as well as more slender vegetative habit. Flowering specimens collected by Clemens and Clemens cited below from Dahobang River (Sabah) have exserted peduncles. Some non-flowering Sarawak specimens have the more slender, elongate habit and less ornamented petioles of the northern examples. Possibly it will transpire on further field study that more than one taxon has been included here, but at present there is insufficient evidence on which to base a split.

Nicolson 1274 has exceptionally large leaves whose dimensions are indicated in parentheses in the description.

Beccari's two collections cited as syntypes in the protologue of $S$. asperata could be equally well chosen as lectotype.

Schismatoglottis asperata var. albomaculata is merely a variegated form occurring in presumably interbreeding populations including non-variegated forms. It does not seem useful to continue to recognise this variant with formal nomenclature.

Schismatoglottis crispata is a short-petioled form with particularly strongly crisped petiole wings, but does not differ significantly from specimens from the type locality of S. asperata.

Other specimens examined: BORNEO: Cult. RBG Kew ex Hort. Veitch, N.E. Brown s.n. (K). SARAWAK: Bau, Anderson 59 (K); Belaga, Ulu Sebako, Ashton S.18204 (US); Penrissen Rd, 18 mi S of Kuching, Sg. Retien, Bogner 1367 (K); Penrissen Rd, 18 mi S of Kuching, Bogner 1564 (US); 1st Divn, Matang, Matang Family Park, Sg. Cina, Boyce 717 (K); 3rd Divn, Teneong, Brooke 9143 (BM, G); 13th mi, Matang, Brooke 9466 (G) \& 9717 (BM, L); Lundu, Gunung Gading, Clemens \& Clemens 21925 (NY); cult. RBG Sydney Acc. No. 940554 ex Lundu, Gunung Gading (orig. coll. Hay et al. 9401) Herscovitch s.n. (K, KEP, NSW, SAR); Kapit, Batang Balleh, Sg. Mengiong, Sg. Entulu, Lee S.54513 (US); Matang FR, $10 \mathrm{mi}$ W of Kuching, Nicolson 1272, 1273 E 1274 (all US); Kuching, Stapok FR, Nitta E Yoshida 73 (KYO); Serian Distr., Gunung Penrissen, Paie S.16347 (K, L); Sri Aman Divn, Kelimngkang Range, Abok, Rena et al. S.58942 (SAR); 1st Divn, Klingkang Range, Sabal FR, 74 mi Kuching/Simanggang Rd, Yii S. 40792 (K, KEP, L). BRUNEI: Belait Distr., Labi, Mendaram waterfall, Boyce et al. 265 (K, L); Temburong, en route from Bangar to Sg. Betia, Hotta 13464 \& 13465 (both KYO); Temburong, along Sg. Lacquan, a branch of Sg. Batu-Apoi, Hotta 13851 (KYO); Temburong Prov., Batu Apoi FR, Sg. Belalong, Poulsen 192 (AAU, K); Temburong Prov., Batu Apoi FR, Ridge W of Kuala Belalong Field Studies Centre, Poulsen 238 (AAU). SABAH: Tenom Distr., Sg. Kaang, Asik Mantor SAN 120214 (K, KEP, SAN); Sunsuron, km 54 jalan Tambunan/Penampang, Asik Mantor SAN 127895 (K); Penampang Distr., Crocker Range, km 41 Kota Kinabalu/Tambunan Rd, Beaman \& Beaman 7092 (K, US) \& 8819 (US); Mt Kinabalu, Penibukan, Dahobang R., Clemens $\mathcal{E}$ Clemens 31345 (BM); Mt Kinabalu, Penibukan, ridge E of Dahobang R., Clemens \& Clemens 50079 (BM); Kinabaki R., Collenette A114 (BM); Penampang Distr., Tunggol FR, km 45 jalan Kota Kinabalu, Sumbing Jimpin SAN 115773 (SAN). KALIMANTAN: West Kalimantan, Landak R., Djambu Pankalan, Teysmann 11545 (BO).

\section{Schismatoglottis barbata Engl.}

Schismatoglottis barbata Engl., Bull. Soc. Tosc. Ortic. 4 (1879) 298 \& in Becc., Malesia 1 (1883) 286, pl. 22, figs 11-20 \& Pflanzenr. 55 (IV.23Da) (1912) 97, fig. 62, A-H; van Steenis, Rheophytes of the World (1981) 195. - Type: Malaysia, Sarawak, Rapide del Rejang, Oct 1867, O. Beccari P.B. 3833 (FI, holo).

? Schismatoglottis rubiginosa M. Hotta, Mem. Coll. Sci. Univ. Kyoto, ser. B, 32 (1966) 231, fig. 4, J-Q. - Type: Malaysia, Sarawak, Bintulu, along Sg. Bejangang, a branch of Sg. Anap, 23 Nov 1963, M. Hotta 15581 (KYO, holo). 
Very small to small terrestrial to lithophytic (?facultatively rheophytic) herb c. 8-17 cm tall. Stem very condensed, usually concealed in a mat of roots and leaf bases, c. $8 \mathrm{~mm}$ diam., pleionanthic. Leaves numerous, crowded, up to 20 together; petiole shorter than to exceeding the blade, $3.5-10.5 \mathrm{~cm}$ long, densely clothed in white (drying brown) coarse multicellular hairs to $4 \mathrm{~mm}$ long, sheathing in the lower $1 / 10^{-1 / 8}$ with the sheath extended into a more or less triangular ligular portion c. $0.8-3 \mathrm{~cm}$ long; blade narrowly obovate, $3.5-11 \mathrm{~cm}$ long $\times 1.3-4 \mathrm{~cm}$ wide, dark green adaxially, paler abaxially, the base narrowly rounded to truncate, the apex acute to slightly acuminate for c. $8 \mathrm{~mm}$; adaxial side glabrous to sparsely pubescent, the margin not ciliate, the abaxial side densely hairy on the midrib (at least at the base), the rest glabrous or more usually hairy on the primary and secondary veins but not on the lamina in between; midrib slightly prominent abaxially, with 3-7 primary lateral veins on each side, alternating with lesser interprimaries and diverging at $30-45^{\circ}$; secondary venation adaxially rather obscure, arising mainly from the midrib, with a few from the bases of the primary veins; tertiary venation forming an indistinct tessellate reticulum abaxially. Inflorescence solitary; peduncle glabrous, very short, completely concealed by leaf bases. Spathe $2.5-4 \mathrm{~cm}$ long, more or less narrowly elliptic, unconstricted, green to greenish pink, only the apical c. $1 / 5$ deciduous, the persistent part about equalling the entire spadix. Spadix c. 2-2.6 cm long, more or less cylindric but slightly constricted at the sterile interstice, sessile; female zone 5-8 $\mathrm{mm}$ long and wide, dorsally adnate to the spathe for more than half its length; interpistillar staminodes absent, but some sterile ovaries present at the base of the female zone; pistils more or less subglobose (somewhat rhomboid from above), close packed, rather large, c. $0.9 \mathrm{~mm}$ diam.; stigmas sessile, more or less rhomboid-discoid, as wide as the ovary, centrally impressed; sterile interstice c. $3 \mathrm{~mm}$ long, on the dorsal side of the spadix confluent with the appendix, composed of flat-topped irregularly polygonal staminodes c. $1 \mathrm{~mm}$ diam.; male zone c. $5 \times 5 \mathrm{~mm}$, formed of a patch of fertile stamens on the ventral face of the spadix completely surrounded by staminodes of the interstice and appendix; stamens with the connective bifid and extended slightly above the thecae, ?or truncate (see Notes) c. $0.5 \mathrm{~mm}$ diam.; appendix composed of staminodes similar to those of the sterile interstice, tapering to a blunt point.

Distribution - Malesia: endemic to Borneo (Sarawak).

Habitat - Lithophytic in sandstone crevices by river banks or in secondary forest near streams at low elevation.

Notes - This species is distinguished from S. ferruginea (Sabah) by its hairy obovate leaves not cordate at the base, and its very remarkable unconstricted spathe with only the extreme tip deciduous. The spadix of S. ferruginea is unknown, but the ventral male zone of $S$. barbata (in the concept here) appears to be unique in the genus.

The types of Schismatoglottis barbata and S. rubiginosa are, in aspect, indistinguishable, except for the ligular portion of the sheath in the latter. Similar structures were not illustrated by Engler $(1883,1912)$ for the former, and this was one of the distinguishing features which Hotta (1966) used to differentiate S. rubiginosa. However, these structures are very fragile and it would appear that they have broken off most of the leaves of the type of $S$. barbata. Nevertheless there are some present. Hotta did not describe the deciduousness of the spathe in S. rubiginosa, however in material matching that species in spadix characters (particularly of the male zone) the spathe is deciduous only in the extreme distal portion exactly as Engler figured for S. barbata.

So similar are the plants of both species that it seems probable that the spadix of $S$. barbata was partly misdescribed by Engler. This remains to be verified by microscopic examination of the holotype specimen at FI. However, there are some suggestive anomalies. In Engler $(1883,1912)$ the spadix is drawn from the ventral face; 
observation only from this side would cause both the adnation of the female zone with the basal part of the spathe, and the failure of the male zone to extend right around the spadix, to remain concealed. Engler did not note staminodes between the fertile zones in S. barbata, but they are fairly clearly depicted in the illustration. Perhaps the least ambiguous differentiating feature is the stamens which Engler depicts as truncatetopped in S. barbata and which Hotta describes and illustrates with a slightly extended bifid connective in $S$. rubiginosa. The three collections cited below all conform to Hotta's description of $S$. rubiginosa, having the male zone only on the ventral side of the spadix and somewhat prominent connectives.

There are variable colour notes for the spadix: Chai $\$ 36472$ records the female flowers as orange-red, the stamens light yellow and the fruits white. Mokhtar S44882 records the spadix as white. Lee $S 45459$ records the inflorescence (spadix) as orange.

Other specimens examined: BORNEO: SARAWAK: Sg. Belaga, by upper rapids, Ashton S. 18238 (US); 7th Divn, Ulu Belaga, nr R. Nyaving, Chai S.36472 (K, L, US); 7th Divn, Sg. Iban, Ulu Belaga, Lee S.45459 (K, KEP, L); 4th Divn, Ulu Anap, Tatau, Sg. Kana, Abg. Mokhtar S. 44882 (K, KEP, L, SAN, US).

\section{Schismatoglottis brevicuspis Hook. $\mathrm{f}$.}

Schismatoglottis brevicuspis Hook. f., Fl. Brit. Ind. 6 (1893) 537; Ridl. Materials Fl. Mal. Pen. 3 (1907) 33 \& J. Straits Branch Roy. Asiat. Soc. 57 (1910) 113 \& Fl. Mal. Pen. 5 (1925) 113; Engl. \& K. Krause, Pflanzenr. 55 (IV.23Da) (1912) 98, p. p. excl. specim. cit. Curtis (Penang, Waterfall), Ridley (Selangor, Petaling; Pahang, Tahan River) - [i.e. S. brevipes Hook. f., q.v.]. - Type: Malaysia, Perak, Scortechini 612 (K, holo; iso CAL, SING).

Stem epigeal, pleionanthic, decumbent, rooting in the internodes, dull dark green, c. $2 \mathrm{~cm}$ diam. Leaves 3-6 together; petiole 5-25 cm long, to $6 \mathrm{~mm}$ diam., with the margins sharp to minutely winged, minutely hairy and faintly rough, deep dull green, sheathing in the lower $1 / 2-3 / 4$; wings of sheath membranous, persistent, eventually marcescent, completely attached to petiole, tapering; blade pale green when young, later slightly glossy dark green adaxially, paler abaxially, not known to be variegated, somewhat chartaceous, broadly ovate to oblong ovate, to c. $20 \mathrm{~cm}$ long, base obtuse to auriculate, tip rather abruptly acuminate for c. $1-2 \mathrm{~cm}$, margin irregularly wavy; primary lateral veins numerous, slightly prominent adaxially near the midrib, the rest flush, prominent abaxially, c. $1 \mathrm{~cm}$ apart, diverging at $60-80^{\circ}$, regularly alternating with lesser interprimaries; secondary venation flush abaxially and adaxially, emerging from the midrib and the basal parts of the primary veins; tertiary venation forming a distinct tessellate pattern abaxially. Inflorescences 1-3 together, often smaller ones produced on somewhat reduced lateral leafy, occasionally only cataphyll-bearing, shoots following flowering of the main axis; peduncle c. $4 \mathrm{~cm}$ long, $3 \mathrm{~mm}$ diam., erect at and after anthesis. Spathe 5-12 cm long, conspicuously mucronate for up to $2 \mathrm{~cm}$, shiny mid-green throughout, with a resinous odour from the bruised spathe tissue; lower spathe narrowly ovoid to ovoid, 2-4 cm long, 1-2 cm wide; limb narrowly lanceolate, separated from the lower spathe by a rather weak constriction, gaping slightly in the upper part, the lower part - like the lower spathe - convolute, rather leathery, persistent shortly after anthesis but eventually yellowing and deliquescent. Spadix 4.5-9 cm long; female zone 1.5-3 cm long, slightly tapering distally, c. $8 \mathrm{~mm}$ thick, obliquely inserted to adnate for c. half its length; pistils $0.5 \mathrm{~mm}$ diam., subglobose with 3-4 conspicuous longitudinal bulges, green; stigma sessile, faintly 3-4-lobed, minutely papillate; interpistillar staminodes absent or a very few except for a single ring around the spadix immediately below the female zone, stalked, more or less flat-topped and irregularly polygonal, about twice the height of the pistils, white; sterile interstice $0.5-1 \mathrm{~cm}$ long, more or less cylindric, $4-8 \mathrm{~mm}$ thick; staminodes mushroom-shaped, c. twice height of pistils, c. $1 \mathrm{~mm}$ diam., white, resembling the interpistillar staminodes; male zone $1.2-2 \mathrm{~cm}$ long, slightly thickening distally (the 
base corresponding with spathe constriction), 4-8 mm thick, pale yellow; stamens c. $1 \mathrm{~mm}$ across, filament slab-like, anther flat-topped; pollen dusty, ivory-white; appendix $1.4-3 \mathrm{~cm}$ long, tapering to a point, deeper yellow than the male zone; appendical staminodes columnar, flat-topped, circular to reniform in outline, c. $1 \mathrm{~mm}$ diam., slightly taller than stamens so that appendix slightly but abruptly thicker than male zone. Fruiting spathe erect, rather narrowly urceolate, dehiscing from the base; fruits grey-green.

Distribution - Malesia: Malay Peninsula and Sumatera (North Sumatera and Aceh provinces).

Habitat - In wet gullies and among rocks by streams in lowland rain forest and lowland hill forest, to c. $900 \mathrm{~m}$ alt.

Notes - This species is very distinctive and easily recognisable with its epigeal stem, deep green rather thinly coriaceous ovate leaves with obtuse bases and the tertiary venation forming an easily visible tessellate pattern on the abaxial side of the lamina. The spathe is more or less uniformly green, held down amongst the leaf bases and hardly opening. Not apparently closely related to other species in the Malay Peninsula or Sumatera; however, several related species occur in Borneo.

Other specimens examined: PENINSULAR MALAYSIA: Kedah, G. Bongsu, nr Terap, Bogner 1692 (K); Pahang, Pulau Tioman, Jason Bay, Burkill 1042 (K, SING); Pahang, Kemaman, Ulu Ayam, Bukit Kajang, Corner 30249e (SING); Selangor, Ulu Gombak, Croat 53276 (K); Negeri Sembilan, Beremban Forest Reserve, foot of G. Angsi, Furtado s.n. (SING); Perak, Sungei Batang Padang, Tapah, Furtado 33096 (SING); Pahang, Raub-Bentong boundary, Furtado 33097a (BO, SING); Cult. RBG Sydney Acc. No. 940084 ex Selangor, Gombak valley, (orig. coll. Hay et al. 9040), Herscovitch s.n. (NSW); Cult. RBG Sydney Acc. No. 940126 ex Perak, foothills of Gunong Bubu, (orig. coll. Hay et al. 9130), Herscovitch s.n. (NSW); Cult. RBG Sydney Acc. No. 940240 ex Johor, Gunong Ledang (Mt Ophir), (orig. coll. Hay et al. 9172), Herscovitch s.n. (NSW); Johor, Bukit Tunjok Laut, Ngadiman 37088 (SING); Selangor, nr Klang Gates Reservoir, Nicolson 1140; Melaka, Base of G. Mering, Ridley s.n. (SING); Selangor, Genting Peras, Ridley s.n. (SING); Pahang, Temango, Ridley 14308 (CAL). SUMATERA: North Sumatera, Sibolangit, Alston 14481 (BM); North Sumatera, Sibolangit, Lörzing 4807 (BO); North Sumatera, Sibolangit, Bukit Semiak, Md Nur 7368 (K); Aceh, Middle Alas River (Lae Sauraya) area, c. $15 \mathrm{~km} \mathrm{~N}$ of Gelombang, S of Bengkong R., de Wilde E de Wilde-Duyfjes 20188 (L).

\section{Schismatoglottis ciliata A. Hay, sp. nov.}

Schismatoglottidem crinitissimam A. Hay simulans, sed folii lamina variegata, tantum ad marginem grosse pubescenti, nervis primariis prominentibus, secundariis sparsis, spathae lamina abrupte inflato, spadice spatham subaequante, interstitio sterile valde crassiore, appendice ovoidea differt. — TYPUS: Malaysia, Sarawak, 4th Divn, nr Long Kapa, Mt Dulit (Ulu Tinjar), 19 Nov 1932, P.W. Richards 2633 (K, holo).

Herb to c. $30 \mathrm{~cm}$ tall. Stem condensed, ?erect, c. $1 \mathrm{~cm}$ diam., pleionanthic. Leaves few together (c. 4); petiole shorter than the blade, to $14 \mathrm{~cm}$ long, densely clothed in coarse multicellular hairs (rusty brown when dry), to $4 \mathrm{~mm}$ long, sheathing in the lower c. 1/10 with the sheath extended into a blunt ligular portion c. $1 \mathrm{~cm}$ long; blade rather narrowly oblong ovate, $13-18 \mathrm{~cm}$ long $\times 7-8 \mathrm{~cm}$ wide, dark green above and variegated with two (one on each side of midrib) irregularly blotchy bands of whitish green running about midway between the margin and midrib, paler below, hairy on the margins and midrib on the abaxial side, the base rather narrowly cordate with the posterior lobes overlapping or nearly so, the tip abruptly acuminate for $1 \mathrm{~cm}$; posterior lobes c. $2 \mathrm{~cm}$ long; midrib prominent abaxially, not prominent adaxially; primary lateral veins fine and abaxially strongly raised, c. 12 on each side of the midrib, glabrous, diverging at $70-80^{\circ}$, frequently with one or two branches arising less than half way from the midrib, alternating with lesser interprimaries and all running to a rather conspicuous abaxially raised intramarginal vein c. 1-2 $\mathrm{mm}$ from the margin; secondary venation adaxially obscure, abaxially rather sparse, c. $3 \mathrm{~mm}$ apart; tertiary 
venation obscure. Inflorescences two together, subtended by blunt cataphylls $1.5-2.5 \mathrm{~cm}$ long; peduncle extremely short, completely hidden within the cataphylls and leaf bases. Spathe $2.2 \mathrm{~cm}$ long, green; lower spathe narrowly funnel-shaped, $5 \mathrm{~mm}$ long, differentiated from the limb by a barely perceptible constriction; limb $1.6 \mathrm{~cm}$ long, subcylindric corresponding with male zone of spadix, then abruptly inflated over the appendix, finally abruptly apiculate for $2 \mathrm{~mm}$, deciduous. Spadix $2 \mathrm{~cm}$ long; female zone subcylindric, $4 \mathrm{~mm}$ long (adnation?); pistils subglobose, crowded, c. $0.75 \mathrm{~mm}$ diam.; stigma sessile, discoid, c. $0.3 \mathrm{~mm}$ across; interpistillar staminodes not observed; sterile interstice $2 \mathrm{~mm}$ long, somewhat thicker than the female and male zones, composed of 2 whorls of more or less rhomboid staminodes c. $0.75 \mathrm{~mm}$ across; male zone cylindric, $5 \mathrm{~mm}$ long, c. $2 \mathrm{~mm}$ diam.; stamens rather laxly arranged, mostly in adnate pairs, with the connective extended well above the thecae, c. $0.25 \mathrm{~mm}$ across; appendix ovoid, c. $5 \mathrm{~mm}$ long, $4 \mathrm{~mm}$ across, composed of more or less flat-topped irregularly polygonal staminodes c. $1.1 \mathrm{~mm}$ diam. Fruiting spathe very broadly urceolate, c. $7 \mathrm{~mm}$ long $\times 9 \mathrm{~mm}$ wide. - Fig. 6 .

Distribution - Malesia: endemic to Borneo (Sarawak).

Habitat - Terrestrial on forest floor, below $300 \mathrm{~m}$ alt.

Notes - This species is distinguished from S. crinitissima, to which it is clearly closely allied, by the more elongate leaf shape, the absence of hairs on the blade except the margin (hence the specific epithet) and the abaxial side of the midrib, the abaxially more prominent and numerous primary lateral veins, the more distant secondary veins (c. $3 \mathrm{~mm}$ apart), the shorter more abruptly inflated spathe, the spadix subequalling the spathe, the more prominent sterile interstice and the broadly ovoid appendix. The leaves are variegated in this species, while they are not in S. crinitissima, however, this is not likely to be a reliable specific character given the way this feature varies in many Schismatoglottis species.

Brooke 9157 has leaf dimensions about half those in the type and it lacks that specimen's abaxially prominent primary venation. However, it does share the ciliate margin and variegated leaf blade. The specimen is sterile and may be of a juvenile plant. The US duplicate has an elongate creeping stem. Its dimensions have not been incorporated into the description here.

Other specimen examined: BORNEO: SARAWAK: 3rd Divn, Teneong, Brooke 9157 (G, US).

\section{Schismatoglottis clemensiorum $A$. Hay, sp. nov.}

Schismatoglottidem acuminatissimam Schott in aspectu simulans, sed stigmate late discoideo, interstitio neutro compacto differt. - TYPUS: Malaysia, Sabah, Mount Kinabalu, Penibukan, March 1933, J. E M. S. Clemens 32205 (BM, holo; iso BO, NY).

[Schismatoglottis lancifolia sensu auct. non Hallier f. \& Engl.: Beaman \& Beaman, Pl. Mt Kinabalu 3 (1998) 83.]

Herb to c. $40 \mathrm{~cm}$ tall. Stem erect to decumbent, condensed to somewhat elongate with internodes to $1 \mathrm{~cm}$ long, pleionanthic. Leaves several together; petiole $11-21 \mathrm{~cm}$ long, not or minutely to distinctly crisped-alate on the distal adaxial edges, sheathing in the lower $1 / 4-1 / 2$, wings of sheath fully attached and tapering; blade broadly (oblong-) lanceolate (to ovate), sometimes variegated ?grey-green in a blotched band on either side about midway between the midrib and margin, $16-23 \mathrm{~cm}$ long $\times 5-8.5 \mathrm{~cm}$ wide, the base cuneate to rounded, the apex acute to obtuse and then acuminate for c. $1.5 \mathrm{~cm}$; midrib slightly prominent abaxially, adaxially flush with the lamina; primary lateral veins distant, often subopposite, c. 5 on each side of the midrib, alternating with lesser interprimaries, diverging at $45-60^{\circ}$, evenly ascending and then joining a rather 


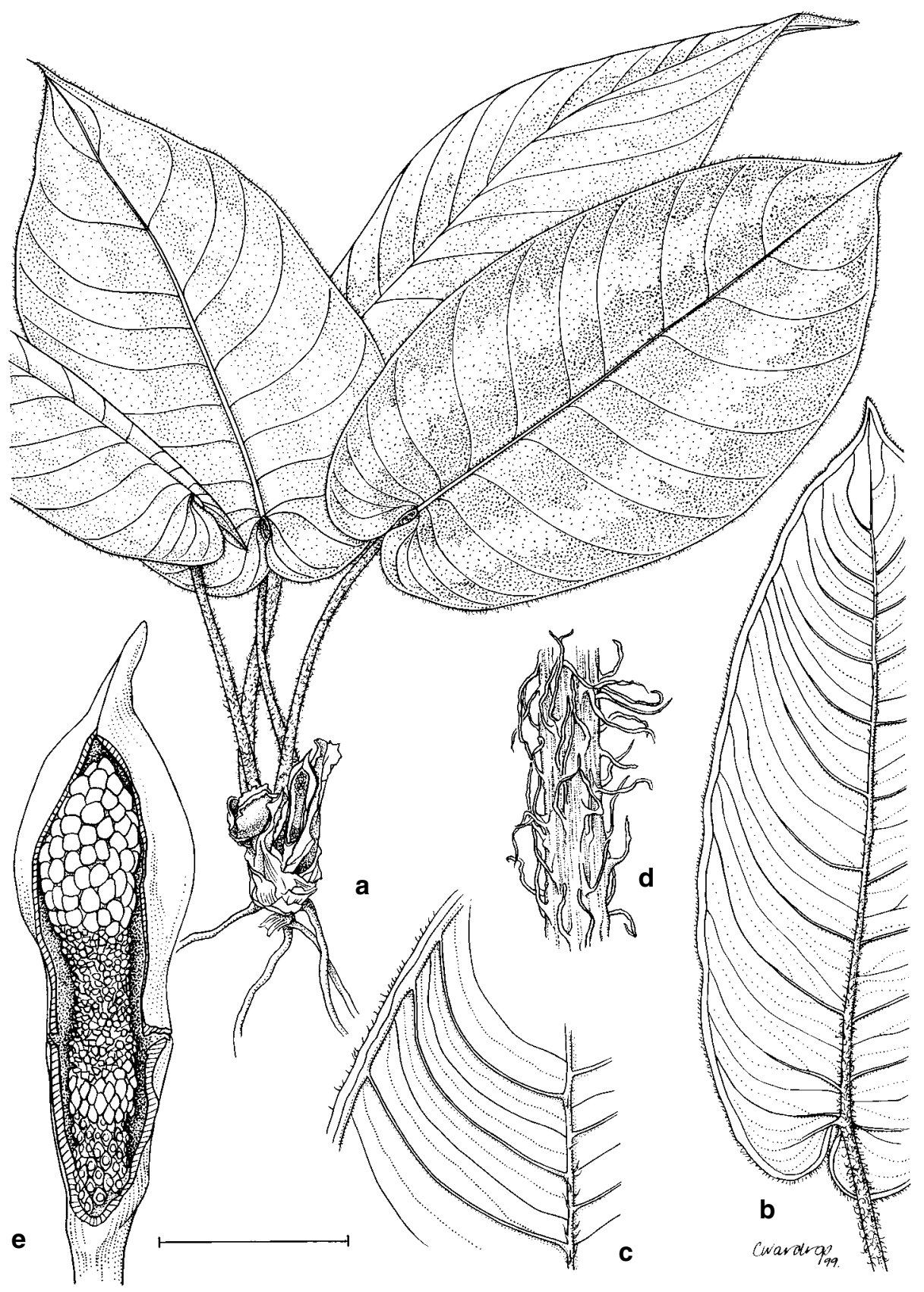

Fig. 6. Schismatoglottis ciliata A. Hay. a, Habit; b, Leaf underside; c, Venation; d, Petiole hairs; e, Inflorescence (Richards 2633). - Scale bar: $\mathrm{a}, \mathrm{b}=4 \mathrm{~cm} ; \mathrm{c}=2 \mathrm{~cm} ; \mathrm{d}=5 \mathrm{~mm} ; \mathrm{e}=6.6 \mathrm{~mm}$. 
conspicuous submarginal vein c. $1 \mathrm{~mm}$ from the margin; secondary venation faint, arising from the midrib; tertiary venation inconspicuous. Inflorescence solitary (occasionally 2 together); peduncle exserted for c. $3 \mathrm{~cm}$ from leaf base and cataphyll; spathe $5.5-8 \mathrm{~cm}$ long, slender, whitish; lower spathe $2-2.5 \mathrm{~cm}$ long, narrowly ovoid, differentiated from the limb by a weak constriction; limb lanceolate, 3.5-5.5 cm long including a $2-2.5 \mathrm{~cm}$ long acumen, deciduous; spadix sessile, slender almost as long as the spathe; female zone $7 \mathrm{~mm}$ long $\times 3 \mathrm{~mm}$ wide; ovaries squat, almost completely concealed by the stigmas; stigma broadly discoid, flat-topped, drying black, c. $0.5 \mathrm{~mm}$ diam., neighbouring stigmas contiguous; interpistillar staminodes few among the pistils, more or less flat-topped, about the same height as the stigmas, c. $0.3 \mathrm{~mm}$ diam.; sterile interstice hardly attenuate, short, 1-2 whorls of interpistillar staminodes; male zone about equalling the female zone, c. $2 \mathrm{~mm}$ wide; stamens crowded, mainly longitudinally aligned, truncate, more or less rectangular to rhomboid with the connective somewhat expanded laterally but not exceeding the thecae in height; pores depressed; appendix very long and slender, about twice the length of the combined fertile zones, c. $3.5 \mathrm{~cm}$ long, subcylindric and isodiametric with male zone in the basal $2 / 3$, the upper $1 / 3$ gradually tapering to a fine point; staminodes of appendix crowded, flat-topped, slightly impressed, irregularly polygonal, $0.5 \mathrm{~mm}$ diam. Fruiting spathe narrowly urceolate then ovoid, to $2.5 \mathrm{~cm}$ long.

Distribution - Malesia: endemic to Borneo (Sabah); restricted to the vicinity of G. Kinabalu.

Habitat - Terrestrial in forest on slopes, ridges and on stream banks, occasionally on rocks but not rheophytic, $1200-1600 \mathrm{~m}$ alt.

Notes - Schismatoglottis clemensiorum resembles S. acuminatissima Schott (Sumatera) in leaf and habit, but differs in the large stigma and small, condensed sterile interstice.

This species is named for Joseph and Mary Strong Clemens, prodigious collectors of Malesian plants, who repeatedly visited Mount Kinabalu and made many collections of Aroids (and other plants) there.

Other specimens examined: BORNEO: SABAH: Tambunan Distr., G. Trusmadi, Asik Mantor SAN 125483 (K, SAN) \& 125486 (K, SAN); Penampang Distr., Tunggol FR, km 45 Penampang-Tambunan Rd, Asik Mantor SAN 131313 (K, SAN); Penampang Distr., Togudon/Tunggol km 48 Jalan Tambunan/Penampang, Asik Mantor SAN 127707 (SAN); Penampang Distr., Crocker Range, km 49.5 on KK-Tambunan Rd, Beaman et al. 10439 (K, US); Mt Kinabalu, Tenompok, Clemens $\mathcal{E}$ Clemens 29272 (BM, G, K, L, NY); Kinabalu, Clemens \& Clemens 51694 (K, L); Tambunan Distr., G. Alab, Fidilis SAN 121675 (SAN); Penampang Distr., Tunggol FR, km 45 Jalan Kota Kinabalu, Fidilis E Sumbing SAN 114613 (K, SAN); Keringan Distr., Trusmadi FR, Joseph B et al. SAN 124005 (SAN); Kinabalu NP, Sosopodon and Sg. Liwagu, Kokawa \& Hotta 4648 (KYO); Kinabalu NP, Sosopodon FR, nr Kundassan, Kokawa \& Hotta 4513 (KYO); Ranau Distr., Kinabalu above Sosopodon, Meijer SAN 29022 (SAN); Penampang Distr., Togudon/Tunggol km 48 Jalan Tambunan/Penampang, Sumbing SAN 127744 (K, SAN).

\section{Schismatoglottis conoidea Engl.}

Schismatoglottis conoidea Engl., Bull. Soc. Tosc. Ortic. 4 (1879) 296 \& in Becc., Malesia 1 (1883) 285, pl. 22, figs 1-10 \& Pflanzenr. 55 (IV.23Da) (1912) 101. - Type: Malaysia, Sarawak, Matang, Jun 1866, O. Beccari P.B. 1791 (FI, holo; iso B).

Schismatoglottis caulescens Ridl., J. Straits Br. Roy. Asiat. Soc. 44 (1905) 182. - Type: Malaysia, Sarawak, Bidi, Jul 1903, H. N. Ridley s.n. (SING, holo).

Small herb c. 10-15 cm tall. Stem epigeal, erect to decumbent, sometimes physiognomically branched, to $6 \mathrm{~mm}$ diam. with internodes $0.5-1 \mathrm{~cm}$ long, 
pleionanthic. Leaves to 5 together clustered at the end of the stem; petiole (2-)3.5-10 cm long, sheathing in the lower $1 / 3-3 / 5$; wings of sheath fully attached, truncate at the apex; blade dark green and sometimes variegated with a central grey green line or irregularly spattered grey-green throughout, adaxially with minute verruculae on the surface when dry, elliptic to ovate, $7-10 \mathrm{~cm}$ long $\times 2-4.5 \mathrm{~cm}$ wide, the base acute to rounded (to subtruncate), the tip acute and slightly acuminate for c. $5 \mathrm{~mm}$; midrib abaxially prominent, adaxially impressed; primary lateral veins 4-6 on each side, alternating with lesser interprimaries and diverging at $45-70^{\circ}$, abaxially faintly prominent, adaxially faintly impressed; secondary venation fine and dense, nearly all arising from the midrib, a few from near the bases of the primary veins, adaxially rather obscure; tertiary venation obscure. Inflorescence solitary (occasionally two in series with a long time interval between them); peduncle subequalling the petioles, subtended by a cataphyll completely hidden by the subtending leaf sheath. Spathe 2-2.5 cm long, more or less spindle-shaped; lower spathe 2-2.5 cm long, 5-7 mm across, narrowly ovoid, differentiated from the limb by a weak constriction, green; limb lanceolate, $2-2.5 \mathrm{~cm}$ long, slender, white, subcylindric for $1.2-1.5 \mathrm{~cm}, 3-5 \mathrm{~mm}$ diam. distally narrowed to a $1 \mathrm{~cm}$ acumen, crumbling-deciduous. Spadix $3.5-4 \mathrm{~cm}$ long, sessile, narrowly more or less spindle-shaped; female zone adnate to the spathe for most of its length, $9 \mathrm{~mm}$ long; pistils subglobose, somewhat lax, c. $1 \mathrm{~mm}$ diam.; stigma subsessile, broad, discoid, papillate, faintly impressed centrally, c. $0.5 \mathrm{~mm}$ diam.; interpistillar staminodes a few scattered among the pistils, but much more concentrated in distal part of female zone, variable in shape within a spadix from truncate-filiform to apically inflated and irregularly polygonal, to c. $1 \mathrm{~mm}$ diam., slightly taller than the pistils; sterile interstice massive, c. $1 \mathrm{~cm}$ long, $5 \mathrm{~mm}$ diam. at base, slightly conoid, occupying whole of upper half of lower spathe chamber; staminodes flat-topped, crowded, irregularly polygonal, c. $1 \mathrm{~mm}$ across; male zone c. $1.5 \mathrm{~cm}$ long, slender, subcylindric, c. $3 \mathrm{~mm}$ diam., extending to tip of spadix; stamens crowded, truncate, dumbbell-shaped with elliptic slit-like pores; appendix absent but for a few terminal abortive anthers, or these absent altogether. Infructescence unknown. - Fig. 7.

Distribution - Malesia: endemic to Borneo (Sarawak); known from Matang and the vicinity of Bidi and Sarikei. A single disjunct collection from East Kalimantan (Kenangan) may belong to this species, but it is in fruit and its identity cannot at present be verified morphologically.

Habitat - Terrestrial in disturbed lowland forest at c. $200 \mathrm{~m}$ alt.

Notes - This species is highly distinctive with its slender erect stem, elliptic leaves, relatively large lower spathe, the relatively enormous sterile interstice and absence of an appendix. In the latter two respects it recalls $S$. wallichii (to which it is not closely allied). It would appear that the male zone and appendix are placed in a sequence reverse from the normal.

Engler's illustration (loc. cit.) of $S$. conoidea is extremely poor and misleading, giving the impression of a thick-set plant and depicting a tuber-like stem which is absent from the type.

Other specimens examined: BORNEO: SARAWAK: Sarikei, Bogner 1544 (K), $1576 \mathcal{E} 1584$ (both M); Cult. RBG Sydney Acc. No. 940455 ex Sarikei, Sebakul Recreation Park (orig. coll. Hay et al. 9300), Herscovitch s.n. (NSW, SAR). KALIMANTAN: East Kalimantan, Balikpapan, Kenangan, Soetisna 55 (BO, K).

\section{Schismatoglottis crinitissima $A$. Hay, sp. nov.}

A Schismatoglottide hottae Bogner \& Nicolson lamina folii majore ovato-sagittata, margine et superficiebus ambitu lepidotis, inflorescentia mascula cylindroidea differt. - TYPUS: Malaysia, Sabah, Tamburan Distr., Sunsuran, km 45 Jalan Tamburan/ Penampang, 23 Aug 1989, Asik Mantor SAN 127890 (K, holo; iso KEP, SAN). 


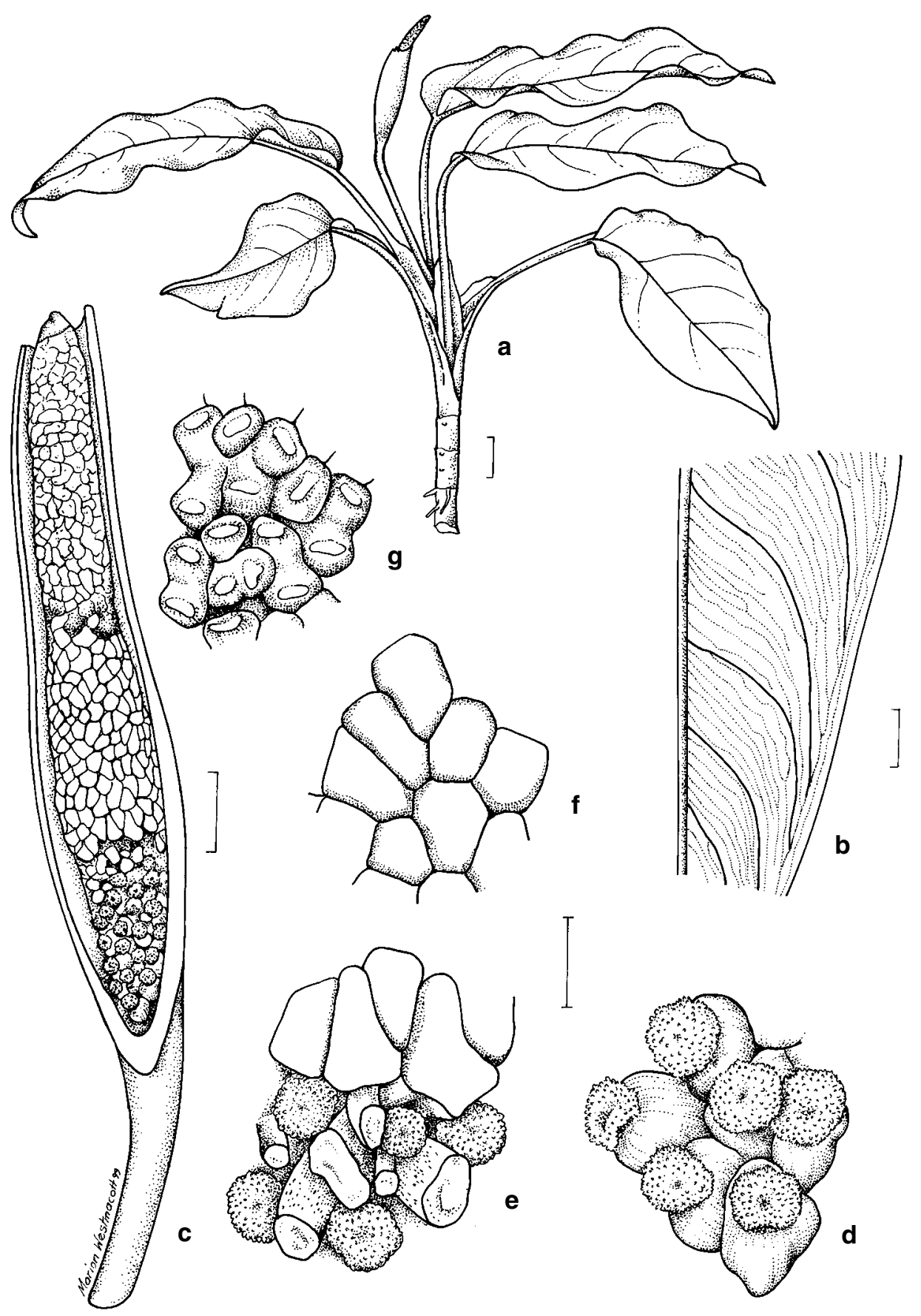

Fig. 7. Schismatoglottis conoidea Engl. a, Habit; b, Venation; c, Inflorescence; d, Pistils; e, Junction of female zone and interstice; f, Staminodes of interstice; g, Stamens (RBG Sydney Acc. No. 940455). Scale bars: $\mathrm{a}=1 \mathrm{~cm} ; \mathrm{b}=4 \mathrm{~mm} ; \mathrm{c}=3 \mathrm{~mm} ; \mathrm{d}-\mathrm{g},=1 \mathrm{~mm}$. 
[Schismatoglottis ferruginea auct. non Merr.: Mayo et al., The Genera of Araceae (1997) 184, fig. 49(ii)C \& 357, Pl. 117C.]

Herb to c. $30 \mathrm{~cm}$ tall. Stem suberect, condensed, c. $1 \mathrm{~cm}$ diam., clothed in old leaf remains, pleionanthic. Leaves few (c. 3) together; petiole dark blue-green, 10-24 cm long, densely clothed in white (rust-brown when dry) multicellular unbranched hairs 2-3 mm long, sheathing in the lower $1 / 8-1 / 4$ with the apex of the sheath extended into a tongue-shaped (sometimes longitudinally split) ligular part c. $1.5 \mathrm{~cm}$ long; blade narrowly ovato-sagittate, dark green adaxially, grey-green abaxially, $14-17 \mathrm{~cm}$ long $\times$ $6.5-9 \mathrm{~cm}$ wide, the apex acute and apiculate for $2 \mathrm{~mm}$, the base retuse to cordate (always some cordate-based leaves on a plant); adaxially with densely scattered hairs on the midrib and otherwise mainly between the veins, the margin ciliate and the abaxial surface densely hairy on the primary and secondary veins with scattered hairs on the lamina in between the veins; hairs on the blade similar to but shorter and thinner than those on the petiole; posterior lobes rounded, 2-3 cm long, somewhat spreading; primary lateral veins rather prominent abaxially, about 8 on each side of the midrib, alternating with lesser interprimaries and emitting one or two branches from half way or less from the midrib, diverging at $60-70^{\circ}$ then ascending to join a marginal or submarginal (see Notes) vein c. $1 \mathrm{~mm}$ from the margin; secondary veins moderately dense (c. $1 \mathrm{~mm}$ apart) to rather sparse (c. $2 \mathrm{~mm}$ apart - see Notes); tertiary venation forming a rather distinct reticulum or obscure (see Notes). Inflorescence solitary or two together; peduncle very short, c. $2 \mathrm{~cm}$ long and almost completely obscured by leaf bases. Spathe c. $3 \mathrm{~cm}$ long, yellowish cream; lower spathe more or less cup-shaped, $5 \mathrm{~mm}$ long, differentiated from the limb by a faint constriction; limb deciduous (?crumbling) $2.6 \mathrm{~cm}$ long in all, subcylindric level with male zone, then inflated over appendix, finally acuminate for $8 \mathrm{~mm}$. Spadix $2 \mathrm{~cm}$ long, sessile; female zone $4 \mathrm{~mm}$ (adnation, if any, unclear); pistils densely packed, subglobose, c. $0.5 \mathrm{~mm}$ diam., (covered with fine whitish crystals); stigma sessile, discoid, about as wide as ovary; interpistillar staminodes ?absent; sterile interstice c. $1 \mathrm{~mm}$ long, a whorl of flat-topped more or less lens-shaped and longitudinally aligned staminodes; male zone cylindric, $5 \mathrm{~mm}$ long $\times$ $2.5 \mathrm{~mm}$ thick; stamens mostly in partially adnate pairs with the connectives much elevated above the thecae and slightly capitate, c. $0.25 \mathrm{~mm}$ diam.; appendix ellipsoid, $1 \mathrm{~cm}$ long, $3 \mathrm{~mm}$ thick at the middle, blunt-tipped, composed of very slightly convextopped irregularly polygonal staminodes c. $1 \mathrm{~mm}$ diam. Fruiting spathe broadly urceolate, c. $1 \mathrm{~cm}$ long and wide.

Distribution - Malesia: endemic to Borneo (Sabah, Brunei and possibly Sarawak).

Habitat - Streamsides and on ridges in forest; 20-1300 m alt.

Notes - This species is unique in the genus in having multicellular hairs on both surfaces and the margin of the leaf blade, as well as on the petiole. Only the holotype has flowering structures present. The leaves of the two collections from Brunei (both from Ladan Hills Forest Reserve) are less densely hairy than, and have the secondary venation about twice as widely spaced as in the remaining specimens. Moreover the primary venation joins a submarginal vein some $1 \mathrm{~mm}$ within the margin, while in the remaining material the vein in which the primary veins unite is virtually on the leaf margin itself. The tertiary venation forms a rather conspicuous reticulum in the Sabah specimens, but is more or less obscure in the Brunei material. Altitudinal data is only provided on the holotype $(1300 \mathrm{~m})$ and on the Brunei collections which are both from low elevation. It is not clear whether the Brunei collections represent a distinct taxon, or merely a somewhat distinctive population.

The only record for Sarawak (Bogner 1543) is a specimen purchased in Sabak Market; it is not possible to be certain whether the plant originated in Sarawak or not. 
Schismatoglottis crinitissima is the hairiest known member (hence the specific epithet) of a group of species with conspicuous coarse white (drying brown) multicellular hairs on the leaves, including S. barbata, S. rubiginosa, S. ferruginea, S. pyrrhias and S. ciliata. Whether this grouping is natural is not clear: there is considerable variation in stamen and leaf sheath morphology. Schismatoglottis crinitissima can be differentiated from other coarsely hairy species by the presence of hairs not only on the petiole but also on the lamina margins and both adaxial and abaxial surfaces.

Other specimens examined: BORNEO: SARAWAK: Sabak market, Bogner 1543 (K). BRUNEI: Tutong Distr., Lamunin, Ladan Hills FR, Dransfield et al. 6871 (K) \& Sands et al. 5764 (K). SABAH: Tamburan Distr., G. Trusmadi, Asik Mantor SAN125582 (SAN).

\section{Schismatoglottis elegans $A$. Hay, sp. nov.}

A Schismatoglottide nervosa petiolo haud puberulo, folii lamina tenuior, spathae lamina coriacea, late aperta, reflexa, acuminata, interstitio sterile pistillodiis et staminodiis tecto, appendicis staminodiis minoribus differt. - TYPUS: Cult. RBG Sydney Acc. No. 940510 ex Malaysia, Sarawak, Niah National Park, Niah Caves area, along path from Niah town (orig. coll. Hay et al. 9359), Feb 1996, C. Herscovitch s.n. (SAR, holo; iso K, KEP, NSW, all + spirit).

[Schismatoglottis caulescens auctt. non Ridl. (1905): Ridl. in Gibbs, J. Linn. Soc. Bot. 42 (1914) 171; Beaman \& Beaman, Pl. Mt Kinabalu 3 (1998) 83].

Herb to $70 \mathrm{~cm}$ tall. Stem epigeal, erect to decumbent, physiognomically branched, freely rooting from the internodes, to $50 \mathrm{~cm}$ long, c. $2 \mathrm{~cm}$ diam., internodes to $1.5 \mathrm{~cm}$ long. Leaves to 10 together; petiole (10-) c. $25 \mathrm{~cm}$ long, sheathing in the lower $1 / 2$; wings of sheath fully attached, tapering; blade mid-green on both surfaces, elliptic to rather narrowly (oblong-)ovate, (13)15-18 cm long $\times(4.5) 7-9 \mathrm{~cm}$ wide, the base obtuse to rounded, the apex acute and acuminate for $2 \mathrm{~cm}$; midrib abaxially prominent near base (dry), with c. 12 primary lateral veins on each side, alternating with lesser interprimaries, frequently with a few branches from near the base, abaxially prominent (fresh), diverging at $45-60^{\circ}$; secondary venation rather obscure, arising from the midrib and the primary veins; tertiary venation obscure. Inflorescence solitary, sometimes up to three in quick succession alternating with foliage leaves (i.e. not forming a true synflorescence); peduncle not exserted from leaf bases. Spathe (5.6-) c. $13 \mathrm{~cm}$ long, greenish yellow; lower spathe narrowly ovoid, (1.6-)2.5 cm long, differentiated from the limb by a distinct constriction; limb broadly lanceolate, rather coriaceous, opening wide except for convolute base, at first overarching, then reflexed, finally more or less twisted and then disintegrating and deciduous, (3.6-) c. $10.5 \mathrm{~cm}$ long. Spadix sessile, whitish, to $9.5 \mathrm{~cm}$ long; female zone c. (1.7-)2.5 cm long, adnate to the spathe in the lower $1 / 3$; pistils more or less ovoid, with $2-3(-4)$ longitudinal lobes, crowded, c. $0.6 \mathrm{~mm}$ diam.; stigma small, button-like, narrower than the ovary, subsessile; interpistillar staminodes very occasional among the pistils, crowded into a row along the spathe/spadix adnation, stalked, clavate and flat-topped, c. $1 \mathrm{~mm}$ diam.; sterile interstice somewhat attenuate, c. $3 \mathrm{~mm}$ diam. in the middle (slightly wider at each end), (0.5-) c. $1 \mathrm{~cm}$ long, basally more or less covered with inflated abortive pistils (reduced stigmas), apically covered with sterile stamens; male zone (1.1-)1.3 cm long, cylindric, c. $5 \mathrm{~mm}$ diam.; stamens crowded, truncate, dumbbellshaped with the connective not elevated above the thecae, c. $1 \mathrm{~mm}$ across; appendix subcylindric, tapering in the upper $1 / 3$ to an acute point, $5 \mathrm{~cm}$ long, basally more or less isodiametric with top of male zone; staminodes of appendix more or less columnar, flat-topped, irregularly polygonal (drying with the stalk collapsed but the top remaining expanded and tending to cohere in groups), c. $0.5 \mathrm{~mm}$ diam. Infructescence unknown. 
Distribution - Malesia: endemic to Borneo (Sarawak, Sabah, Kalimantan); known certainly only from the type locality and, tentatively, on G. Kinabalu and G. Besar.

Habitat - At Niah growing out of crevices in limestone in wet to swampy lowland rainforest at c. $200 \mathrm{~m}$ alt.; at the other localities in rainforest between 800 and $1300 \mathrm{~m}$ alt.

Notes - This species is clearly closely allied to $S$. nervosa from limestone in southern Sarawak. It can be distinguished by the petiole without minute hairs, the leaf blade not glaucous and more or less elliptic, the wide-opening and somewhat coriaceous acuminate spathe limb (from which the specific epithet derives), the well-defined sterile interstice covered with neuter structures and the smaller appendical staminodes.

Gibbs 4100 from G. Kinabalu seems to differ only in somewhat smaller dimensions (given in parentheses in the description). The appendix is broken, which may have led Ridley to determine this plant as $S$. caulescens (=S. conoidea), which has the spadix fertile to the apex (or with a small apical cluster of staminodes). While it seems counter-intuitive that this plant, collected from the Kadamaian River, whose bed Gibbs (1914:25) described as 'choked with enormous blocks of granite', should be of the same taxon as a lowland limestone element, a morphological basis for distinguishing it as a different species is not apparent. Tamura $\mathcal{E}$ Hotta 265, also from Kinabalu, is also incomplete. Re-collection on G. Kinabalu is required. The two cited collections from G. Besar (Kalimantan) are also incomplete and lacking data on the substrate. Murata B-4027, however, agrees well in leaf, habit and spathe shape. These determinations should be regarded as provisional.

Other specimen examined: BORNEO: SABAH: Mt Kinabalu, Kadamaian R., Gibbs 4100 (BM); Ranau, Kpg Poring, NE of Ranau, Tamura \& Hotta 265 (KYO). SOUTH KALIMANTAN: G. Besar, Murata et al. B-4021 \& B-4027 (both KYO).

\section{Schismatoglottis ferruginea Merr.}

Schismatoglottis ferruginea Merr., J. Straits Branch Roy. Asiat. Soc. 85 (1922) 159. - Type: Malaysia, Sabah, Sandakan and vicinity, Nov 1920, M. Ramos 1675 (PNH, holo, presumed destroyed; iso K, L, P, US (photo MO)).

Small herb to c. $20 \mathrm{~cm}$ tall. Stem somewhat elongate, suberect, c. $5 \mathrm{~mm}$ diam. with internodes c. $5 \mathrm{~mm}$ long, pleionanthic. Leaves few together (c. 4); petiole shorter than the blade, 5-9 cm long, thickly clothed in coarse white (drying rust) multicellular hairs to $4 \mathrm{~mm}$ long, sheathing in the lower $1 / 4-1 / 3$, the sheath fully attached save for a bluntly bilobed ligular extension c. $5 \mathrm{~mm}$ long; blade rather variable in size and shape on any plant, but some leaves always and characteristically (narrowly) obovate (some elliptic or narrowly oblong-ovate) $10-16 \mathrm{~cm}$ long $\times 4-6 \mathrm{~cm}$ wide, mid-green adaxially, abaxially paler, the base narrowly but distinctly cordate with the posterior lobes reduced to auricles c. $0.5-1 \mathrm{~cm}$ long and sometimes overlapping each other, the tip acute and shortly acuminate for c. $1 \mathrm{~cm}$; abaxial side of blade densely hairy on the midrib and progressively more sparsely hairy on the higher order venation with few hairs between the veins; adaxial side and margins completely glabrous; midrib more or less flush with the lamina (dry); 6-9 primary lateral veins on each side diverging at $45-60^{\circ}$, alternating with lesser interprimaries; secondary veins not prominent, mostly arising from the midrib, a few from the bases of the primary veins; tertiary venation forming a rather faint tessellate reticulum abaxially. Inflorescence solitary, subtended by an abaxially hairy lanceolate cataphyll to $4 \mathrm{~cm}$ long; peduncle slender, hairy, weak, c. $4 \mathrm{~cm}$ long. Spathe $5 \mathrm{~cm}$ long; lower spathe ovoid, c. $8 \mathrm{~mm}$ long, hairy, differentiated from the limb by a clear but rather weak constriction; limb lanceolate, $3.5 \mathrm{~cm}$ long, deciduous at the constriction, very slightly reflexed, with scattered hairs abaxially, especially along the midline. Spadix details unknown. Infructescence unknown. 
Distribution - Malesia: endemic to Borneo (Sabah); known only from the vicinity of Sandakan.

Habitat - On boulders and terrestrial on rather dry slopes in mixed lowland forest at low elevation.

Notes - Merrill did not describe the spadix. The type was collected by Ramos, botanical collector with the Bureau of Science at Manila, Philippines, and presumably the top set of his Bornean collections was deposited at PNH and subsequently destroyed. Isotypes were distributed, but none has an intact inflorescence. A duplicate (at K) of Ramos 1713, also cited by Merrill in the protologue, has an inflorescence present from which the spathe shape is clear, but the spadix is unobservable owing to fungal decay and mounting glue. A.H.'s collection of this species was sterile and it has failed to flower in cultivation as yet. Hence the description remains incomplete.

Schismatoglottis ferruginea is strikingly similar to S. barbata (Sarawak) in the coarsely hairy petiole and the leaf shape tending to be widest distal to midway along the midrib. It differs in the not tufted habit, larger size, the distinctly cordate leaf blade base, the hairy and relatively long peduncle, the slender hairy spathe constricted near the base and, presumably from the shape of the spathe, the more or less narrowly tapering spadix.

Other specimens examined: BORNEO: SABAH: Cult. RBG Sydney Acc. No. 950371 ex Sandakan, Kebun Cina (orig. coll. Hay et al. 10034) (no voucher); Sandakan, Batu Lima, Ramos 1713 (K).

\section{Schismatoglottis grabowskii Engl.}

Schismatoglottis grabowskii Engl., Pflanzenr. 55 (IV.23Da) (1912) 121. — Type: Indonesia, Kalimantan, Mindai, Pramassawalai Mt., 17 Jun 1882, F. Grabowsky s.n. (B, holo).

Moderately robust herb to c. $45 \mathrm{~cm}$ tall. Stem condensed, more or less hypogeal (?becoming epigeal), c. $1.5 \mathrm{~cm}$ diam., pleionanthic. Leaves c. 5 together; petiole c. $37 \mathrm{~cm}$ long, sheathing in the lower quarter; wings of sheath fully attached to the petiole, tapering; blade ovato-sagittate, $19-26 \mathrm{~cm}$ long $\times 11-18 \mathrm{~cm}$ wide, the base cordate with somewhat angularly rounded posterior lobes to c. $7 \mathrm{~cm}$ long, the tip acute and rather abruptly acuminate for c. $1 \mathrm{~cm}$; midrib not prominent abaxially (dry), with c. 7 primary lateral veins on each side, alternating with lesser interprimaries and diverging at c. $45-70^{\circ}$; secondary venation more or less obscure on both surfaces, mostly arising from the midrib, some from the lower parts of the primary veins; tertiary venation obscure. Inflorescence ?solitary but to 3 in succession interspersed with foliage leaves [organisation not clear from available material]; peduncle not or hardly exserted from the subtending leaf bases and cataphylls; cataphylls lanceolate, to c. $4 \mathrm{~cm}$ long. Spathe 5-6 cm long; lower spathe more or less flask-shaped - rather broadly ovoid at the base, narrower and subcylindric in the upper part, c. $2-2.5 \mathrm{~cm}$ long, not constricted at interface with the spathe limb; limb oblong-lanceolate, 3-4 cm long, apiculate for $3 \mathrm{~mm}$, deciduous. Spadix sessile, $3.2-4.2 \mathrm{~cm}$ long, subcylindric; female zone obliquely inserted, c. $7 \mathrm{~mm}$ long, somewhat conoid, c. $4 \mathrm{~mm}$ diam. at top; pistils subglobose, c. $0.7 \mathrm{~mm}$ diam.; stigma discoid, sessile, about as wide as the ovaries, papillate; interpistillar staminodes few, scattered among the pistils, clavate, flat-topped, about twice the height of the pistils; sterile interstice ill-defined - some concentration of interpistillar staminodes and sterile stamens mixed with fertile elements at the interface of the two zones; male zone cylindric, c. $1 \mathrm{~cm}$ long $\times 3 \mathrm{~mm}$ diam., almost entirely within the lower spathe chamber; stamens more or less rectangular, truncate, c. $0.5 \mathrm{~mm}$ across, the connective thick and block-like, pores small, more or less slit-like, distant, with pollen extruded in filaments; appendix more than half the length of the whole spadix, cylindric, basally very slightly thicker than the male zone, ultimately tapering to an obtuse point; staminodes of appendix low, 
flat-topped, irregularly polygonal with sharp angles, c. $0.5 \mathrm{~mm}$ across. Fruiting peduncle hardly lengthening; fruiting spathe urceolate, c. $2 \mathrm{~cm}$ long (immature).

Distribution - Malesia: endemic to Borneo (SE Kalimantan).

Habitat - Rainforest at low elevation (few details available).

Notes - The relatively very long appendix, male zone within the lower spathe chamber, the more or less brick-shaped stamens with distant pores separated by a thick connective, pollen extruded in strands and the large discoid stigma indicate that S. grabowskii is closely related to S. asperata. Schismatoglottis grabowskii differs from $S$. asperata in the more deeply cordate base of the leaf blade, and correspondingly more extensive primary vasculature to the posterior lobes, the glabrous, non-alate petioles, the smaller inflorescence, the absence of a well-defined sterile interstice and the stigmas not contiguous. Schismatoglottis asperata is a western and northwestern Bornean species, while S. grabowskii is geographically disjunct in SE Borneo.

Other specimens examined: KALIMANTAN: East Kalimantan, Berau, Kostermans 21341 (BO, K, L); East Kalimantan, Kutei Reserve, Sangkima, Kondolo R., N of Samarinda, Reksodihardjo 43 (L).

\section{Schismatoglottis hottae Bogner \& Nicolson}

Schismatoglottis hottae Bogner \& Nicolson, Aroideana 2 (1979) 120; Mayo et al., The Genera of Araceae (1997) 184, pl. 49(ii), D. - Schismatoglottis cordifolia M. Hotta, Mem. Coll. Sci. Univ. Kyoto, ser. B, 32 (1966) 229 (non S. cordifolia Ridl. (1911), i.e. S. calyptrata (Roxb.) Zoll. \& Moritzi). - Type: Brunei, Seria Distr., Bukit Teraja, Teraja Forest Reserve, 21 Dec 1963, M. Hotta 12886 (KYO, holo; photo, K).

Small lithophytic herb to $17 \mathrm{~cm}$ tall. Stem very condensed and short, c. $3 \mathrm{~cm}$ long $\times 1 \mathrm{~cm}$ diam., clothed in old leaf remains, pleionanthic. Leaves several together (4-7) with roots emerging from among their bases; petiole 5-9 $\mathrm{cm}$ long, slender, about equalling the blade, very densely clothed in minute straight pale brown hairs, sheathing only at the extreme base with the sheath extended into a narrowly triangular abaxially pubescent bicarinate ligular portion $2-4 \mathrm{~cm}$ long; blade ovate to broadly ovate, matte dark green, slightly metallic and densely minutely hairy throughout adaxially, matte pale green, densely minutely hairy on all the venation and minutely tuberculate between the veins abaxially, drying dark brown, 9-12 cm long $\times 7-9 \mathrm{~cm}$ wide, the base retuse to cordate with rounded posterior lobes to $2 \mathrm{~cm}$ long, the apex broadly acute to obtuse and shortly apiculate; midrib not or hardly prominent abaxially and adaxially; primary lateral veins crowded, c. 13 on each side of the midrib, diverging at $45-60^{\circ}$, alternating with lesser interprimaries and very occasionally branching near the midrib, impressed adaxially, prominent abaxially; secondary veins abaxially prominent (due to hairs), arising from the midrib and the bases of the primary veins; tertiary venation obscure. Inflorescence solitary; peduncle very short, completely concealed within subtending leaf bases. Spathe c. $3.5 \mathrm{~cm}$ long, green to salmon pink and then veined with deeper pink; lower spathe ovoid, c. $1.1 \mathrm{~cm}$ long, differentiated from the limb by a slight constriction; limb 2.2-2.8 $\mathrm{cm}$ long, broadly lanceolate, apiculate for 2-3 mm, ?deciduous. Spadix $2.5 \mathrm{~cm}$ long, sessile; female zone obliquely inserted, c. $3 \mathrm{~mm}$ long; pistils densely packed; ovary subglobose, c. $1 \mathrm{~mm}$ diam.; stigma sessile, thickly discoid, almost as wide as the ovary; sterile interstice slightly wider than male and female zones, $2 \mathrm{~mm}$ long, c. 3 whorls of flat-topped irregularly polygonal staminodes c. $0.6 \mathrm{~mm}$ diam.; male zone cylindric, slightly attenuate corresponding to spathe constriction, c. $3 \mathrm{~mm}$ long; stamens somewhat laxly arranged, mostly in adnate pairs with the bluntly and narrowly pyramidal connective extended beyond the thecae; appendix cylindric-ellipsoid, more than half the length of the spadix, about twice the width of the male zone, c. $2 \mathrm{~cm}$ long $\times 6 \mathrm{~mm}$ thick, composed of flat-topped irregularly polygonal staminodes c. $1 \mathrm{~mm}$ diam. Infructescence unknown. 
Distribution - Malesia: endemic to Borneo (Brunei).

Habitat - Lithophytic on sandstone in kerangas and hill dipterocarp forest, $180-400 \mathrm{~m}$ alt.

Notes - This species appears allied to Schismatoglottis puberulipes, sharing the velvety hairs on the leaf, the solitary short-pedunculate inflorescence with inflated appendix. Both are lithophytes, S. puberulipes on limestone. Schismatoglottis puberulipes further differs in the relatively longer leaf, in having hairs confined to the petiole and abaxial midrib, a basal row of tongue-shaped staminodes below the female zone, a much larger sterile interstice, and truncate stamens in an obconic male zone.

As Schismatoglottis cordifolia was already occupied when Hotta (loc. cit.) first described this species using that name, the new binomial $S$. hottae was established for it by Bogner \& Nicolson (loc. cit.).

Other specimens examined: BORNEO: BRUNEI: Belait Distr., Ulu Ingei, Bukit Batu Patam, Boyce et al. 279 (K, L); Belait Distr., Labi Subdistr., Bukit Teraja, Johns 6872 (K).

\section{Schismatoglottis latevaginata Engl.}

Schismatoglottis latevaginata Engl., Pflanzenr. 55 (IV.23Da) (1912) 106; Alderw., Bull. Jard. Bot. Buitenzorg. III, 4 (1922) 345. - Type: Cult. Hort. Bogor. ex Borneo (XI.B.X.149), Jan/Feb 1906, A. Engler 4055 (B, holo). - Epitype: Cult. Hort. Bogor. ex Borneo (XI.B.X.149) (orig. coll. Nieuwenhuis 1968), C.R.W.K. van Alderwerelt van Rosenburgh 366 (BO spirit; designated here).

Small herb to c. $15 \mathrm{~cm}$ tall. Stem shortly epigeal, ?pleionanthic. Leaves few together; petiole to c. $14 \mathrm{~cm}$ long, sometimes red, longitudinally finely ridged, densely and minutely papillate, scabrid, sheathing in the lower $2 / 5-4 / 5$; wings of sheath fully attached, the margin parallel to the petiole except at the base, the tip a bifid rounded ligule $3 \mathrm{~mm}$ long; blade narrowly ovate, rather markedly asymmetric, c. $12.5-15 \mathrm{~cm}$ long $\times 6-7.5 \mathrm{~cm}$ wide, shining green adaxially and sometimes variegated with a greygreen band near each margin, paler and matte abaxially, the base narrowly cordate with posterior lobes c. $1.5 \mathrm{~cm}$ long, the tip acuminate for c. $2 \mathrm{~cm}$; midrib abaxially prominent, finely channelled and scabrid like the petiole, adaxially more or less flush with the lamina; primary lateral veins c. 13 on each side of the midrib, more or less regularly alternating with lesser interprimary veins and diverging at $45-70^{\circ}$; secondary venation arising mainly from the midrib, some from near the bases of the primary veins; tertiary venation forming a tessellate reticulum abaxially. Inflorescence ?solitary; peduncle length? Spathe 4.2-5.5 cm long, narrow; lower spathe narrowly ovoid, 1-1.5 cm long, yellowish flushed pale reddish brown, differentiated from the limb by a sharp constriction; limb 3.1-3.9 cm long, lanceolate, apically acuminate for c. $6 \mathrm{~mm}$, reddish brown, deciduousness not observed. Spadix sessile, $2.5-5.5 \mathrm{~cm}$ long, subcylindric; female zone slightly conoid, obliquely inserted but not adnate to the spathe, $0.8-1.4 \mathrm{~cm}$ long $\times 3 \mathrm{~mm}$ thick apically; pistils more or less cylindric in the lower part of the female zone, becoming ovoid distally, c. $0.5 \mathrm{~mm}$ diam., sometimes somewhat squashed level with the spathe constriction and there ?abortive; stigma sessile, button-like to discoid, slightly centrally impressed, papillate, about half as wide to as wide as the ovary; interpistillar staminodes absent from among the pistils, confined to a row along the insertion of the spadix, almost sessile and irregularly cuboidal to shortly stalked and flat-topped, about equalling the pistils in height; sterile interstice relatively robust, $4 \mathrm{~mm}$ long, basally isodiametric with female zone, strongly narrowed near the base or in the upper half corresponding with the spathe constriction, lower staminodes clavate and flat-topped, c. $0.7 \mathrm{~mm}$ diam., upper 2-3 whorls irregularly polygonal and resembling sterile anthers; male zone $0.8-1.6 \mathrm{~cm}$ long, subcylindric, c. 2.5-5 mm diam.; stamens crowded, truncate, dumbbell-shaped, 
c. $0.5 \mathrm{~cm}$ across, with the connective not elevated above the thecae; appendix $0.6-1.8 \mathrm{~cm}$ long, subcylindric, basally isodiametric with the male zone, the apex truncate to tapering; staminodes of appendix large, irregularly polygonal (mostly rhomboid or hexagonal), white, c. $0.8 \mathrm{~mm}$ diam. Fruit unknown.

Distribution - Malesia: endemic to Borneo (Sarawak, Kalimantan).

Habitat - Unknown.

Notes - The type and protologue are incomplete, as the inflorescence is past anthesis and only the female part of the spadix is represented, with only a decomposing basal fragment of the interstice remaining. Engler (loc. cit.) described the female inflorescence as lacking staminodes and the male and female zones contiguous. Both statements are incorrect. There is a row of staminodes at the base of the female zone, and at the apex, though this is somewhat unclear, there seems to be the remnant of a stout staminode. Dearden s.n. (cited below) has an immature inflorescence (which may account for the smaller overall size, subsessile interpistillar staminodes and truncate appendix), but it clearly has a sterile interstice of rather stout staminodes and a row of staminodes at the base of the female zone. The two specimens are almost identical in leaf, with broad wings to the leaf sheath ending in a short blunt ligular portion, scabrid, papillate petioles (not mentioned by Engler) and rather numerous, prominent, spreading primary veins. They differ only in the length of the nonsheathing portion of the petiole which is much shorter than the blade in the type and about three quarters of the blade's length in Dearden s.n. Alderwerelt (loc. cit.) provided a completed description of this species based on cultivated material of Nieuwenhuis 1968. He preserved material of this plant labelled with the number XI.B.X.149, the plant number corresponding with that noted by Engler on the type. In BOKR, material from bed XI.B.X. has specimens of plants numbered between 147 and 155 missing (or misplaced), and a sheet could not be found in BO either. However, Alderwerelt's spirit material is still present. This generally matches the inflorescence of Dearden s.n. closely (though it is in a more mature stage of development). Since the leaf of Dearden s.n. matches that of the type, it seems very likely that the plant Alderwerelt studied and preserved was the same one studied by Engler. Alderwerelt's spirit material is therefore designated as the interpretive epitype.

Other specimen examined: SARAWAK: Cult. Redlynch, Queensland ex Malaysia, Sarawak, without locality, Dearden s.n. (NSW, spirit only).

\section{Schismatoglottis multinervia M. Hotta}

Schismatoglottis multinervia M. Hotta, Mem. Coll. Sci. Univ. Kyoto, Ser. B, 32 (1966) 237, fig. 6, G-N. - Type: Sarawak, Mardi, at foot of Gunung Mulu, along Sg. Payau, 22 Mar 1964, M. Hotta 15297 (KYO, holo).

Herb to c. $30 \mathrm{~cm}$ tall. Stem epigeal, more or less condensed, c. $1 \mathrm{~cm}$ diam, pleionanthic. Leaves few (c. 4) together; petiole to c. $18 \mathrm{~cm}$ long, sheathing in the lower $1 / 3$, minutely and densely puberulent; wings of the sheath fully attached, persistent, tapering and finally narrowly truncate at the apex; blade adaxially dark green, abaxially paler and glaucescent, broadly and shortly oblong-ovate, the largest $13 \mathrm{~cm}$ long $\times 9 \mathrm{~cm}$ wide, the base cordate with rounded posterior lobes c. $1.7 \mathrm{~cm}$ long, the apex obtuse and not apiculate (but more or less damaged); midrib abaxially prominent, adaxially more or less flush with the lamina, with c. 16 primary lateral veins on each side, alternating with lesser interprimaries and diverging at c. $80^{\circ}$; secondary venation arising from the midrib and the basal parts of the primary veins; tertiary venation forming a rather obscure tessellate reticulum. Inflorescence solitary; peduncle short, not exserted from the leaf bases and cataphylls. Spathe $4 \mathrm{~cm}$ long; lower spathe ellipsoid, $1.5 \mathrm{~cm}$ long, differentiated from the limb by a somewhat weak constriction; limb c. $2.5 \mathrm{~cm}$ long, 
more or less ovate, green, inflated over the appendix and distally shortly acuminate, mode of dehiscence unknown. Spadix sessile, $2.8 \mathrm{~cm}$ long, weakly hourglass-shaped; female zone $1.3 \mathrm{~cm}$ long, adnate to the spathe in the lower half, the free part narrowly conoid, distally $3 \mathrm{~mm}$ diam. (dry); pistils crowded, subglobose, c. $1 \mathrm{~mm}$ diam.; stigma sessile, button-like, somewhat impressed centrally, about $1 / 2$ the diameter of the ovary; interpistillar staminodes very occasional among the pistils, otherwise confined to 1-2 irregular rows along the spathe/spadix adnation and crowded in the interstice, stipitate, broad- and flat-topped, slightly broader than and about the height of the pistils; sterile interstice c. $3 \mathrm{~mm}$ long, isodiametric with the top of the female zone (dry), composed mostly of crowded interpistillar staminodes, distally with some crowded abortive stamens; male zone obconic, $6 \mathrm{~mm}$ long, distally c. $5 \mathrm{~mm}$ diam.; stamens crowded, truncate, flat-topped, dumbbell-shaped, c. $1 \mathrm{~mm}$ across, the rims of the thecae cleft on the outer side; appendix more or less bullet-shaped, c. $8 \mathrm{~mm}$ long, slightly and abruptly wider than the male zone at the base, there c. $6 \mathrm{~mm}$ diam., the apex blunt; staminodes of appendix irregularly polygonal with sharp angles, flattopped, 0.5-1 mm diam. Fruit unknown.

Distribution - Malesia: endemic to Borneo (Sarawak); known only from the type.

Habitat - Terrestrial in moist clay under riparian forest, 50-100 m alt.

Notes - Schismatoglottis multinervia is evidently closely related to S. puberulipes, sharing the pleionanthic stem, puberulent petioles and abaxial main veins, closely spaced and wide-spreading primary veins, and robust sterile interstice. It differs in its larger overall size of the vegetative parts, apparently relatively longer internodes (little stem is present on the type), the much less conspicuous tessellate reticulum of tertiary veins, the relatively somewhat shorter interstice and apparently more slender inflorescence. In this latter aspect however, there is some difficulty in making a comparison, as the inflorescence of S. multinervia appears, from the dimensions given, to have been described from the dry state. In S. puberulipes, where in the fresh state the inflorescence is characteristically fat and squat, there is much lateral shrinkage on drying. It therefore seems possible that Schismatoglottis multinervia is no more than a robust aspect of $S$. puberulipes. Observation of fresh plants from the type locality is required. Ecologically the two species appear to be differentiated, S. puberulipes being found on limestone, however there are substrate data for only one specimen of each species.

\section{Schismatoglottis nervosa Ridl.}

Schismatoglottis nervosa Ridl., J. Straits Br. Roy. Asiat. Soc. 49 (1907) 50. — Type: Cult. Singapore Botanic Garden ex Malaysia, Sarawak, Bau, Jan 1907, H. N. Ridley s.n. (SING, holo - 2 sheets).

Rather robust herb to $50 \mathrm{~cm}$ tall, with somewhat pungently aromatic vegetative tissues. Stem epigeal, suberect to decumbent and then rooting on contact with ground, to c. $40 \mathrm{~cm}$ long $\times 1.5-4 \mathrm{~cm}$ thick; internodes to $2 \mathrm{~cm}$ long. Leaves few together (to c. 6); petiole $13-30 \mathrm{~cm}$ long, strongly longitudinally ridged (like celery) especially abaxially at the base, very minutely (strong lens required) and densely verruculate, sheathing in the lower $1 / 3-1 / 2$ with the wings tapering and fully attached; blade broadly ovate to oblong ovate, adaxially mid- to dark green and somewhat glossy, slightly bullate, $12-21 \mathrm{~cm}$ long $\times 6-10 \mathrm{~cm}$ wide, the base broadly rounded to slightly retuse, the tip broadly acute and shortly acuminate for c. $1 \mathrm{~cm}$; midrib abaxially very prominent (Bau specimens; not so at Gunung Gading — see Notes), adaxially flush with the lamina and centrally channelled; primary lateral veins abaxially prominent (Bau specimens; not so at Gunung Gading), numerous, 16-25 on each side of the midrib, alternating with lesser interprimaries or these occasionally arising on the bases of the primary veins, diverging at $60-90^{\circ}$ and gradually curving towards the tip before 
reaching the margin; secondary veins mostly arising from the midrib, occasionally from near the bases of the primary veins; tertiary venation forming a faint tessellate reticulum abaxially. Inflorescences 1-3 together, subtended by lanceolate cataphylls to $6 \mathrm{~cm}$ long; peduncle short, concealed by leaf bases and cataphylls at flowering, slightly exserted in fruit. Spathe subcylindric, c. $5.5 \mathrm{~cm}$ long, pale green; lower spathe c. $1.2 \mathrm{~cm}$ long, differentiated from the limb by a faint constriction; limb oblonglanceolate, c. $4.3 \mathrm{~cm}$ long, mucronate for $5 \mathrm{~mm}$, deciduous. Spadix sessile, subcylindric, subequalling the spathe; female zone more or less cylindric, $1.2 \mathrm{~cm}$ long $\times 3 \mathrm{~mm}$ thick; pistils very numerous and close-packed, irregularly rhomboid from above, c. $0.5 \mathrm{~mm}$ across; stigma sessile, minute, punctate; interpistillar staminodes confined to more or less a single ring at the base of the female zone, squat-columnar, irregularly polygonal from above, about the same size as the ovaries; sterile interstice absent (?or reduced to a whorl of incompletely abortive stamens); male zone contiguous with female zone or separated by a very short naked zone c. $2 \mathrm{~mm}$ long, cylindric, 1.4-1.8 cm long, $2 \mathrm{~mm}$ diam.; stamens close-packed, anthers truncate, the connective narrow and the thecae large, the whole butterfly-shaped from above and neighbouring anthers with their lobes interdigitating; pores impressed, C-shaped with the convex side innermost, the rims narrowly alate; appendix subcylindric, distally tapering to a blunt point, basally very slightly thicker than the male zone, $1.5-1.8 \mathrm{~cm}$ long; staminodes of appendix densely packed, flat-topped to slightly impressed, irregularly polygonal, c. $0.3 \mathrm{~mm}$ diam. Infructescence (immature) narrowly ovoid, $2 \mathrm{~cm}$ long on a $2.5 \mathrm{~cm}$ peduncle. - Fig. 8 .

Distribution - Malesia: endemic to Borneo (southern Sarawak).

Habitat - Terrestrial on stream banks in wet forest, or more or less lithophytic in humus pockets and ledges on limestone, 10-300 m alt.

Notes - This species can be distinguished by its robust, more or less elongate epigeal stem, the longitudinally ridged petioles with fully attached sheath wings, the broadly ovate to oblong-ovate strongly and densely ribbed leaf blade, the subcylindric spadix with the fertile zones contiguous, the basal ring of interpistillar staminodes, the very numerous and angular ovaries with minute stigmas, and the anthers with narrow connective and large flared thecal pores. In aspect this species bears some resemblance to $S$. brevicuspis Hook. f. (Malay Peninsula) differing in its larger size, the subcylindric spadix and contiguous fertile zones.

My collection from the base of Gunung Gading, cited below, had distinctly pungentaromatic vegetative tissues like some Homalomena species. It differs from the Bau specimens in not having a very prominent abaxial midrib, and in the male and female zones of the spadix being separated by a very short naked zone (c. $2 \mathrm{~mm}$ long). It matches the Bau collections very well in other respects and would appear to represent a variant population.

Ridley's description (loc. cit.) included a number of errors and inaccuracies, particularly in its implication that the fertile male zone extended to the tip of the spadix (the appendix is clearly visible in the type). Engler (1912) seems to have overlooked this species in his monograph.

Other specimens examined: BORNEO: SARAWAK: 1st Divn, Bau, Fairy Caves, c. 7 km from Bau, Boyce 793 (K); Bau, Brooke 10852 (BM, L); without locality, Brooks s.n. (1909) (BM); Cult. RBG Sydney Acc. No. 940556 ex Lundu, Gunung Gading (orig. coll. Hay et al. 9403), Herscovitch s.n. (NSW); Vicinity of Bau, Nicolson 1261 \& 1304 (both US). 


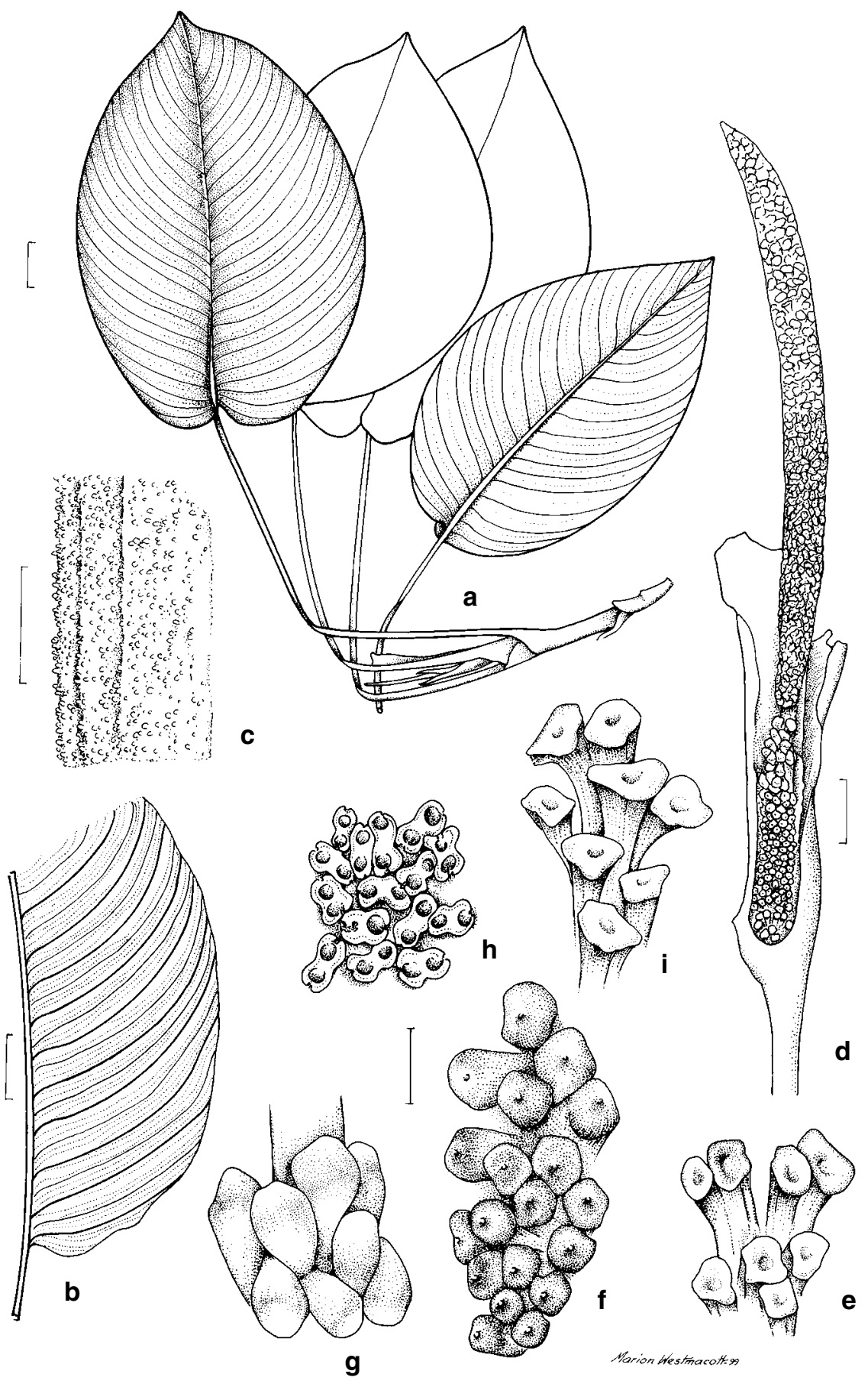

Fig. 8. Schismatoglottis nervosa Ridl. a, Habit; b, Venation; c, Petiole indumentum; d, Inflorescence; e, Basal interpistillar staminodes; $\mathbf{f}$, Pistils; $\mathbf{g}$, Abortive pistils of interstice; $\mathbf{h}$, Stamens; $\mathbf{i}$, Staminodes of appendix (RBG Sydney Acc. No. 940556). Scale bars: a, b, d = $2 \mathrm{~cm} ; \mathrm{c}, \mathrm{e}-\mathrm{i}=1 \mathrm{~mm}$. 


\section{Schismatoglottis patentinervia Engl., s. lat.}

Schismatoglottis patentinervia Engl., Pflanzenr. 55 (IV.23Da) (1912) 90. - Type: Indonesia, Borneo [?East Kalimantan], H. Hallier 3271 (BO, holo; iso B).

Herb to c. $40 \mathrm{~cm}$ tall. Stem suberect to decumbent, c. $1 \mathrm{~cm}$ diam., pleionanthic, internodes to c. $1.5 \mathrm{~cm}$ long. Leaves several together (to 8); petiole 5-12 cm long, green to suffused dark red, scabrid, minutely and densely puberulent with stiff short hairlike papillae, sheathing in the lower $1 / 3-4 / 5$; sheath membranous, tapering, completely attached to petiole; blade lanceolate to (oblong-)elliptic to narrowly obovate, $11-16 \mathrm{~cm}$ long $\times 2.5-6 \mathrm{~cm}$ wide, the base broadly acute to cuneate to slightly decurrent, the tip acute to obtuse and then apiculate for c. $1 \mathrm{~cm}$; midrib abaxially prominent and puberulent/scabrid like the petiole; primary lateral veins numerous and closely spaced, 15-20 on each side, alternating with lesser interprimaries (these and primary veins sometimes rather difficult to differentiate), diverging at (80-)90(-100) ${ }^{\circ}$, usually running more or less straight for much of the width of the blade then rather abruptly deflected towards the tip before joining the margin or upcurved rather gradually (variable within a population viz. Boyce 251); secondary venation mostly arising from the midrib, occasionally from near the bases of the primary veins; tertiary venation abaxially forming a more or less obscure tessellate reticulum, especially near the margin, adaxially obscure. Inflorescence solitary; peduncle short, concealed by leaf bases and subtending cataphyll(s) at flowering (slightly exserted later). Spathe $4.5-7 \mathrm{~cm}$ long, subcylindric; lower spathe 1-2.5 cm long, differentiated from the limb by a weak constriction; limb oblong-lanceolate, cream, 3.5-4 cm long, deciduous. Spadix sessile; female zone $0.8-1.7 \mathrm{~cm}$ long; pistils basally crowded, distally mostly rather laxly arranged, more or less subglobose, c. $0.5 \mathrm{~mm}$ diam.; stigma sessile, button-like, c. $1 / 3$ the diameter of the ovary; interpistillar staminodes restricted to an incomplete row around the base of the female zone (occasional among the pistils), more or less tongueshaped, c. $0.5 \mathrm{~mm}$ wide; sterile interstice naked, c. $0.5-1 \mathrm{~cm}$ long $\times 3-4 \mathrm{~mm}$ thick, with a few distant abortive pistils at the base, distally with an incomplete whorl of abortive stamens (occasionally contracted and more or less without a naked portion); male zone subcylindric, shortly obconic at the base, $0.8-1.5 \mathrm{~cm}$ long $\times 4-6 \mathrm{~mm}$ thick distally; stamens densely packed, truncate, dumbbell-shaped, c. $0.7 \mathrm{~mm}$ across, the connective somewhat mounded between the pores; appendix bullet-shaped, basally isodiametric with male zone, apically tapering to a blunt point, $1.1-1.5 \mathrm{~cm}$ long; staminodes of appendix irregularly polygonal, somewhat impressed, c. $0.5 \mathrm{~mm}$ diam. Fruiting spathe narrowly urceolate, c. $2 \mathrm{~cm}$ long.

Distribution - Malesia: endemic to Borneo (West and South Kalimantan, Sarawak, Brunei, Sabah).

Habitat - In lowland dipterocarp and mixed forest, often on steep soil banks, to $200 \mathrm{~m}$ alt.

Notes - The circumscription of this species has been qualified 's. lat.' as the cited specimens are all but three without inflorescence (including the type) and are placed under this species on the basis of habit and leaf characteristics only. Although these features are very distinctive, the distribution is highly fragmented, and it would seem entirely possible, in a genus which, especially in Borneo, has many species restricted to small geographical ranges, that further study would reveal more than one taxon in this grouping.

Schismatoglottis patentinervia is close to S. retinervia, sharing the epigeal habit tending to be decumbent, the more or less elliptic leaves with rather closely spaced, spreading primary venation, the solitary short-peduncled inflorescence, the (partly) naked interstice of the spadix bearing basal abortive ovaries. It differs in the scabrid, minutely pubescent petiole, generally larger size and more conspicuously spreading primary venation (though both species are somewhat variable in this respect), the less 
conspicuous reticulum of tertiary veins, the much less attenuate interstice and the much less conspicuously obconoid male zone.

In 1996 A.H. collected plants falling within this species at Kalabakan Virgin Jungle Reserve in Kinabatangan Distr., Sabah. There two distinct forms co-existed, one with rather broadly elliptic leaves growing as numerous more or less identical individuals together on steep slopes in forest, the other stenophyllous with the narrowly lanceolate leaf blades suffused dark red throughout and whitish beneath, growing on a vertical stream bank. Both were sterile at the time and unfortunately both subsequently failed in cultivation, though inflorescences were preserved of the former. The specimen made from a cultivated plant from Hay et al. 12024 differs from the two other fertile collections examined in the abbreviated interstice and in having a few somewhat clavate interpistillar staminodes scattered among the pistils.

Other specimens examined: BORNEO: SARAWAK: 4th Divn, Bintulu, along valley of Sg. Keyan, a branch of Ulu Sg. Kakus, Hirano \& Hotta 548 (KYO); BRUNEI: Belait Distr., Labi, Kg Teraja, path along Sg. Teraja, Boyce \& Jangarum 251 (AAU, GH, K, L, SAN). SABAH: Tambunan Distr., Crocker Range, km 64 on Kota Kinabalu-Tambunan rd, Beaman et al. 9335 (US); Cult. RBG Sydney Acc. No. 960564 ex Kinabatangan, Kalabakan Virgin Jungle Reserve (orig. coll. Hay et al. 12024), Herscovitch s.n. (NSW, spirit only); Tongod Distr., Ulu Sg. Kiwolotikan, Kambira SAN 117536 (SAN); Keningau Distr., Crocker Range area, mi 16, Kimanis Rd, Krispinus SAN 120565 (K, KEP, SAN). KALIMANTAN: South Kalimantan, Djaro Dam, Muara Uja, Dransfield \& Saerudin 2199 (BO); East Kalimantan, around Jelini, along Sg. Belayan, NW of Tabang, Murata et al. 1294 (BO).

\section{Schismatoglottis puberulipes Alderw.}

Schismatoglottis puberulipes Alderw., Bull. Jard. Bot. Buitenzorg III, 4 (1922) 200. - Type: Java, Cult. Hort. Bogor, XI.B.X.118, C.R.W.K. van Alderwerelt van Rosenburgh 286 (BOKR + BO spirit, lecto; selected here).

Small herb to c. $15 \mathrm{~cm}$ tall. Stem condensed, epigeal, slender, c. $2 \mathrm{~cm}$ long, $3 \mathrm{~mm}$ diam., pleionanthic. Leaves several together (to c. 6); petiole 5-14 cm long, slender, stiff, densely and minutely puberulent with short straight colourless hairs, sheathing in the lower $1 / 3-2 / 5$ (sometimes sheathing for the entire length in the leaf below an inflorescence); wings of sheath almost fully attached except for a blunt apical free portion c. $5 \mathrm{~mm}$ long, membranous, spreading, sometimes somewhat crisped, abaxially puberulent; blade variable in shape, broadly ovate to oblong-lanceolate, $8-14 \mathrm{~cm}$ long $\times 3.2-5.5 \mathrm{~cm}$ wide, very dark green adaxially, paler abaxially, sometimes distinctly bullate, the base slightly but distinctly cordate with rounded posterior lobes $1-2 \mathrm{~cm}$ long and overlapping each other or nearly so, the tip acute to obtuse, not acuminate; midrib abaxially prominent and pubescent like the petiole; primary lateral veins 11-16 on each side of the midrib, alternating with lesser interprimaries, diverging at $70-90(-100)^{\circ}$ (always some c. $90^{\circ}$ ) at first, then rather sharply acropetally deflected before reaching the margin, adaxially somewhat prominent near the midrib, abaxially puberulent near the midrib; secondary venation arising from both the midrib and the bases of the primary veins; tertiary venation forming a fine tessellate reticulum abaxially. Inflorescence solitary, subtended by a cataphyll usually with reduced but well-differentiated petiole and blade; peduncle very short, hidden within the leaf bases. Spathe c. $4 \mathrm{~cm}$ long; lower spathe greenish, ovoid, c. $1.5 \mathrm{~cm}$ long, differentiated from the limb by a distinct constriction; limb dirty white, broadly ovate, inflated over the appendix of the spadix, the tip apiculate, crumbling-deciduous somewhat above the constriction to about level with the top of the male zone. Spadix c. $2.8 \mathrm{~cm}$ long, stipitate for c. $1 \mathrm{~mm}$; female zone subcylindric, slightly conic; pistils crowded, subglobose, c. $1 \mathrm{~mm}$ diam.; stigma subsessile, button-like, papillate, about half the diameter of the ovary; interpistillar staminodes tongue-shaped, c. $1 \mathrm{~mm}$ wide, yellowish, confined to a single row around the base of the female zone; sterile interstice c. $4 \mathrm{~mm}$ long, about isodiametric with top of female zone (fresh), slightly 
thicker than top of female zone (dry), somewhat attenuate at junction with male zone, composed of irregularly polygonal more or less flat-topped staminodes c. $1 \mathrm{~mm}$ diam. (smaller distally and some thin L-shaped ?abortive staminodes sometimes present); male zone obconoid, c. $1 \mathrm{~cm}$ long, basally c. $2 \mathrm{~mm}$ diam., apically c. $4 \mathrm{~mm}$ diam.; stamens crowded, c. $0.5 \mathrm{~mm}$ diam., more or less dumbbell-shaped, truncate with broad elevated rims around the pores; appendix rather broadly ellipsoid, widest slightly above junction with male zone, c. $8 \mathrm{~mm}$ long $\times 4 \mathrm{~mm}$ wide, composed of irregularly polygonal more or less flat-topped staminodes c. $0.7 \mathrm{~mm}$ diam. Fruiting spathe broadly urceolate, c. $1.5 \mathrm{~cm}$ diam. - Fig. 9.

Distribution - Malesia: endemic to Borneo (Sarawak, ?Kalimantan).

Habitat - Lithophytic (on limestone at Niah) or on banks in wet forest to $450 \mathrm{~m}$ alt.

Notes - Schismatoglottis puberulipes was described from living material cultivated at Bogor Botanic Garden in 1919 and 1920, Alderwerelt making two specimens. Alderwerelt $317(\mathrm{BO})$ is less complete than the specimen selected as lectotype. Later clonotype material is deposited at SING.

Alderwerelt (loc.cit.) indicated that the plant was Bornean, but that precise details were lacking. While it seems reasonable to suppose it likely that the type plant originally came from Kalimantan, no further collections exist from Indonesian Borneo, all being from Sarawak.

Schismatoglottis puberulipes is very distinctive, but is superficially approached by $S$. hottae which differs in the much more prominently veined and puberulent leaf blade, the more conspicuously ligular leaf sheath, the absence of interpistillar staminodes, the longer appendix and in the elongate connective of the stamens. Schismatoglottis multinervia may be a synonym. It seems to differ little, apart from in its considerably more robust stature.

Other specimens examined: BORNEO: SARAWAK: Bintulu, Ulu Tubau, Ashton S.18179 (US); 3rd Divn, Belarga, Brooke 9107 (G); Cult. RBG Sydney Acc. No. 940520 ex Niah National Park, Batu Niah (orig. coll. Hay et al. 9369) Herscovitch s.n. (K, KEP, L, NSW, SAR, US); 4th Divn, Bintulu, eastern ridge of Bukit Kana, Hirano \& Hotta 1460 (KYO); Tau Range, Bukit Mayeng, Purseglove P5376 (L, NY)

\section{Schismatoglottis pyrrhias A. Hay, sp. nov.}

A Schismatoglottide hottae Bogner \& Nicolson stature valde majore, petiolo grosse puberulo, appendice cylindroidea differt. - TYPUS: Malaysia, Sarawak, 7th Divn, Belaga, Linau, Sg. Iban, 13 Nov 1982, B. Lee S. 45530 (US, holo; iso SAR).

Herb to c. $60 \mathrm{~cm}$ tall. Stem condensed, c. $2 \mathrm{~cm}$ diam., pleionanthic. Leaves c. 8 together; petiole to c. $40 \mathrm{~cm}$ long, dark purplish red and thickly covered in coarse more or less filamentous hairs c. $1 \mathrm{~mm}$ long, sheathing only at the extreme base, the wings of the sheath extended into a ligular narrowly triangular abaxially densely hairy portion c. $4 \mathrm{~cm}$ long; blade ovate to oblong ovate, $25-30 \mathrm{~cm}$ long $\times 12-14 \mathrm{~cm}$ wide, the base shallowly and narrowly or widely cordate, with posterior lobes to $3 \mathrm{~cm}$ long, the tip acute to obtuse and acuminate for c. $3 \mathrm{~cm}$; midrib abaxially prominent, adaxially flush with the lamina, with about 20 fine primary lateral veins on each side, alternating with lesser interprimaries and diverging at c. $60^{\circ}$; secondary venation arising from the midrib and mostly pinnately from the primary venation especially in the lower part of the blade; midrib, primary and secondary venation abaxially densely hairy like the petiole; tertiary venation obscure, glabrous. Inflorescence ?solitary, subtended by narrowly triangular cataphylls resembling the ligular sheath extension; peduncle c. $2.5 \mathrm{~cm}$ long, densely hairy; spathe at least $3 \mathrm{~cm}$ long (incompletely preserved); lower spathe $1.3 \mathrm{~cm}$ long, ?not differentiated from the limb by a constriction; limb incompletely preserved, ?somewhat persistent. Spadix $3 \mathrm{~cm}$ long, subcylindric, c. $4 \mathrm{~mm}$ thick (dry); female zone 


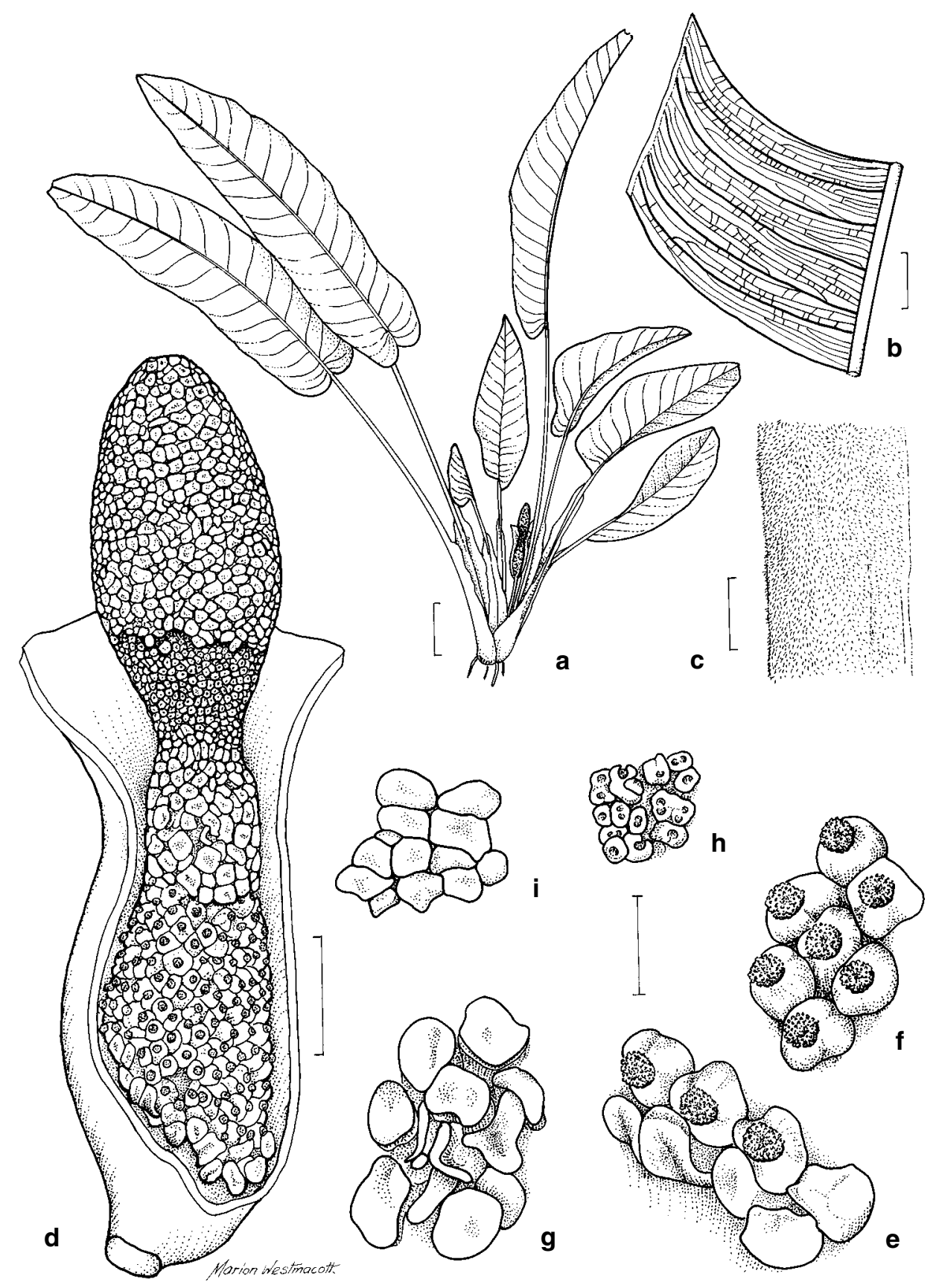

Fig. 9. Schismatoglottis puberulipes Alderw. a, Habit; b, Venation; c, Petiole indumentum; d, Inflorescence; e, Basal interpistillar staminodes; f, Pistils; g, Staminodes of interstice; h, Stamens; i, Staminodes of appendix (RBG Sydney Acc. No. 940520). Scale bars: $a=4 \mathrm{~cm} ; \mathrm{b}=4 \mathrm{~mm}$; $\mathrm{c}=1 \mathrm{~mm} ; \mathrm{d}=8 \mathrm{~mm} ; \mathrm{e}-\mathrm{i}=2 \mathrm{~mm}$. 
not adnate to the spathe, $8 \mathrm{~mm}$ long; pistils unobservable except stigmas; stigmas sessile, button-like to discoid, papillate, more or less contiguous, c. $0.5 \mathrm{~mm}$ diam.; interpistillar staminodes not observed; sterile interstice c. $2 \mathrm{~mm}$ long, c. 2 whorls of staminodes drying black; male zone c. $7 \mathrm{~mm}$ long; stamens mostly in rather loosely arranged adnate pairs with the connective elevated into narrowly pyramidal flattopped peaks about twice the height of the thecae, about $0.25 \mathrm{~cm}$ across; appendix pale orange, subcylindric, $1.3 \mathrm{~cm}$ long, apically abruptly tapering to a bluntly acute tip; staminodes of appendix irregularly polygonal, flat-topped and centrally impressed, c. $0.5 \mathrm{~mm}$ diam. Fruit unknown.

Distribution - Malesia: endemic to Borneo (Sarawak); known only from the type locality.

Habitat - Lithophytic on the face of a vertical rock cliff; substrate, vegetation and altitude not recorded.

Notes - The only material of this very distinctive species is not well preserved, the only inflorescence having been badly damaged. However, it is evident from the stamens (in adnate pairs with elevated connectives) and the coarsely hairy character of the leaves that S. pyrrhias is allied to S. hottae, S. ciliata and S. crinitissima. In this group the leaf sheath, extended into a short ligular portion, is somewhat intermediate in character between the fully attached sheath of most species and the very elongate ligular sheath of, for example, S. multiflora.

Schismatoglottis pyrrhias is evidently closest to $S$. hottae, sharing the dense hairy leaf venation as well as the more or less discoid stigma, short sterile interstice and the distinctive stamen form mentioned above. Schismatoglottis pyrrhias differs in its very much larger size in vegetative features, the much coarser indumentum, the larger inflorescence with a relatively shorter, subcylindric appendix with impressed staminodes and the relatively and actually longer female zone. The specific epithet, meaning 'redhead' alludes to the red, hairy petioles.

\section{Schismatoglottis retinervia Furtado}

Schismatoglottis retinervia Furtado, Gard. Bull. Straits Settlem. 8 (1935) 157; Beaman \& Beaman, Pl. Mt Kinabalu 3 (1998) 83. - Type: Malaysia, Sabah, Mt Kinabalu, Tenompok, 26 Mar 1932, C.X. Furtado sub J. E M. S. Clemens 29153 (SING, holo - 2 sheets; iso BO, BM, G, GH, K, L, NY).

Small, sometimes colony-forming herb to c. $20 \mathrm{~cm}$ tall. Stem creeping to sprawling and somewhat elongate, to c. $20 \mathrm{~cm}$ long, c. $0.5 \mathrm{~cm}$ diam., epigeal, rooting along its length, occasionally branching, pleionanthic, internodes $0.5-1 \mathrm{~cm}$ long. Leaves several together along the distal parts of the stem and clustered at the apex; petiole 8-12 cm long, sheathing in the lower $1 / 3-1 / 2$; wings of sheath fully attached to petiole, tapering, membranous; lamina very dark green adaxially, paler abaxially, elliptic and slightly falcate, $7-12 \mathrm{~cm}$ long $\times 2.5-4 \mathrm{~cm}$ wide, the base acute, the apex acute and slightly acuminate for c. 5-8 $\mathrm{mm}$; midrib abaxially prominent, adaxially flush with the lamina; primary lateral veins 8-9 on each side, mostly alternating with lesser interprimaries, diverging at $80-100^{\circ}$, then gradually up-curved more or less throughout their length to spreading most of the way across the lamina then abruptly upcurved (variable to some extent even on same stem), abaxially prominent in older leaves; secondary venation mostly arising from the midrib, occasionally from the base of the primary veins; tertiary venation forming a conspicuous tessellate reticulum abaxially. Inflorescence solitary; peduncle to c. $2 \mathrm{~cm}$ long, not or only slightly exserted from the leaf bases. Spathe creamy white, $2.5-3 \mathrm{~cm}$ long; lower spathe $1 \mathrm{~cm}$ long, ovoid, differentiated from the limb by a constriction; limb broadly ovate, c. $1.8 \mathrm{~cm}$ long, mucronate for $2-4 \mathrm{~mm}$, deciduous. Spadix white, $2.2 \mathrm{~cm}$ long, sessile; female zone 
$6 \mathrm{~mm}$ long, narrowly conoid; pistils somewhat lax, subglobose, $0.5 \mathrm{~mm}$ diam.; stigma sessile, button-like, c. $1 / 2$ the diameter of the ovary; interpistillar staminodes confined to a ring at base of female zone; sterile interstice attenuate, partly naked, 3-4 mm long, at the base an irregular whorl of abortive pistils, distally these scattered, finally a loose group of abortive stamens; male zone obconoid, $6 \mathrm{~mm}$ long, $1.5 \mathrm{~mm}$ diam. at base, $4 \mathrm{~mm}$ diam. distally; stamens crowded, dumbbell-shaped, more or less truncate with the connective slightly mounded between the thecae; pores each with a heavily flanged rim; appendix conic-ellipsoid $5 \mathrm{~mm}$ long and wide at the base, the tip acute, composed of irregularly polygonal, more or less flat-topped staminodes c. $0.75 \mathrm{~mm}$ diam. Fruiting spathe short-peduncled, erect, urceolate, c. $1 \mathrm{~cm}$ long.

Distribution - Malesia: endemic to Borneo (Sabah); known only from Mt Kinabalu.

Habitat - Terrestrial in mid-montane forest near streams (but not rheophytic) at c. $1200-1500 \mathrm{~m}$ alt.

Notes - The somewhat elongate sprawling habit, in which the plants may form clonal colonies, together with the membranous, elliptic leaves with spreading primary and conspicuously tessellate tertiary venation and the solitary inflorescence suggest affinity with species such as S. patentinervia Engl. and S. brevicuspis Hook. f. (Malay Peninsula).

Furtado (loc. cit.) noted that he had not seen mature flowering plants. This is apparently not true, since the type includes complete inflorescences at male anthesis. It would appear that the spathe hardly opens and that the inflorescence is held down among the leaf bases, and that this may have led Furtado to believe the inflorescences were immature.

Other specimens examined: BORNEO: SABAH: Cult. RBG Sydney Acc. No. 950386 ex Kinabalu National Park, Silau-Silau trail towards Liwagu R. (orig. coll. Hay 10049) (†, no voucher); Mt Kinabalu, Tenompok, towards Dallas, Kiah sub Clemens \& Clemens 29154 (BM, G, K); Kinabalu NP, along rd between HQ and Tenompok, Kokawa \& Hotta 3050 (KYO).

\section{Schismatoglottis scortechinii Hook. $\mathrm{f}$.}

Schismatoglottis scortechinii Hook. f., Fl. Brit. Ind. 6 (1893) 537; Ridl., Materials Fl. Mal. Pen. 3 (1907) 32, Fl. Mal. Pen. 5 (1925) 113; Engl. \& K. Krause, Pflanzenr. 55 (IV.23Da) (1912) 100. - Type: Malaysia, Perak, Scortechini 148 (K, holo; iso CAL).

Schismatoglottis kingii Engl. in Engl. \& K. Krause, Pflanzenr. 55 (IV.23Da) (1912) 97, fig. 62, J. - Type: Malaysia, Johor, King s.n. (CAL, holo).

Schismatoglottis marginata Ridl., J. Bot. 40 (1902) 36, Materials Fl. Mal. Pen. 3 (1907) 34; Engl. \& K. Krause, Pflanzenr. 55 (IV.23Da) (1912) 89; nom. illeg., non Schismatoglottis marginata Engl., Bull. Soc. Tosc. Ortic. 4 (1879) 298 [i.e. Piptospatha marginata (Engl.) N.E. Br., Bot. Mag. 51 (1895) descr. ad. t. 7410 (Borneo)]. — Type: Malaysia, Pahang, Tahan woods, Ridley s.n. (SING, holo)

Stem epigeal, pleionanthic, erect to decumbent or creeping, to c. $20 \mathrm{~cm}$ long, $1-2 \mathrm{~cm}$ thick, internodes $0.5-1 \mathrm{~cm}$ long, not freely rooting except when in contact with soil, renewal growth sometimes delayed by protracted inflorescence production. Leaves 1-5 per module; petiole 10-30 $\mathrm{cm}$ long, 5-7 mm thick with the margins narrowly but distinctly alate and the wing crisped (rarely hardly alate), rough and longitudinally slightly ridged, dull mid-green, sheathing in the lower $1 / 3$; wings of sheath persistent, membranous, the wing to c. $0.7 \mathrm{~cm}$ wide, spreading to slightly inrolled, fully attached except for the apex asymmetrically and bluntly ligular for c. $0.7 \mathrm{~cm}$, rarely the sheath tapering and fully attached throughout its length; blade c. 15-30 cm long $\times 5-10 \mathrm{~cm}$ wide, elliptic to oblong to ovate, widest at around the mid-point, grey-green to yellowgreen to mid-green, not glossy, variegated spattered, bivittate or vittate in shades of 
grey-green or yellow-green, the base acute to obtuse to weakly cordate; posterior lobes, if present, to c. $1.2 \mathrm{~cm}$ long; midrib abaxially prominent, with c. 10-15 abaxially prominent primary lateral veins on each side, diverging at $45-90^{\circ}$ with strongly acroscopic to flattened wide courses, 1-2 cm apart; interprimary veins present; secondary venation flush adaxially and abaxially, originating on the midrib and lower parts of the primary veins; tertiary venation inconspicuous. Inflorescences 1-8 together, with a strong sweet esteric odour at anthesis, turning dark brown in spirit; peduncle c. $5 \mathrm{~cm}$ long, c. $4 \mathrm{~mm}$ thick but thickening distally into the spathe base, erect at anthesis, then deflected. Spathe 6-10 cm long; lower spathe narrowly ovoid to rhomboid in outline, $2-3.5 \mathrm{~cm}$ long, $1-1.5 \mathrm{~cm}$ wide, green; limb separated from lower spathe by an abrupt constriction, membranous, pale grey-green at first, broadly oblong with the tip mucronate, opening cowl-like, sometimes more so at the base than the apex, revealing the whole appendix and the distal part of the male zone, then deciduous, turning dirty dark grey and dying as it falls. Spadix $5.5-9.9 \mathrm{~cm}$ long; female zone 1.5-2 cm long, more or less conic, c. $1 \mathrm{~cm}$ thick, obliquely inserted; pistils c. $1.5 \mathrm{~mm}$ high, c. $1 \mathrm{~mm}$ diam., pale green, stigmas sessile, very flat and contiguous, somewhat impressed centrally; interpistillar staminodes (absent from among the pistils to) few to frequent, scattered, slightly taller than the pistils, the tops button-like, irregularly rounded-polygonal, white, c. $0.5 \mathrm{~mm}$ diam.; sterile interstice torus-shaped, slightly thicker than both female and male zones, about 3-4 mm long, composed of two types of staminodes either of which may predominate or they are equally represented proximally a crowd of structures more or less identical with the interpistillar staminodes, distally a crowd (or ring) of structures more or less identical with the staminodes of the appendix (see below); male zone $0.6-1 \mathrm{~cm}$ long, 4-6 mm thick, cylindric, ivory, narrower than the female zone and markedly narrower than the lower part of the appendix, corresponding with the constriction of the spathe; male flowers (1-)2-3-staminate, the anthers trapezoid to triangular from above, terminal on slablike filaments, opening by apical pores; pollen white, extruded in very fine filaments; appendix very large, $3-6 \mathrm{~cm}$ long, $0.8-1 \mathrm{~cm}$ thick, subcylindric, tapering, rather blunttipped; staminodes columnar, flat-topped, sometimes centrally impressed, in groups of $2-5$, c. $1 \mathrm{~mm}$ diam., yellowish ivory to pale orange. Fruiting spathe declinate, urceolate, dehiscing from the base; fruits greyish.

Distribution - Malesia: endemic to Peninsular Malaysia.

Habitat - In lowland rain forest and lowland hill forest, mostly on the slopes of gulleys, to c. $900 \mathrm{~m}$ alt.

Notes - Schismatoglottis scortechinii is not closely related to other Peninsular Malaysian species, and not obviously close to any other species in the genus. Nevertheless there are similarities which suggest it is nearly related to Bornean species including S. asperata Engl. The petiolar epidermis is rough with protuberant epidermal cells which here and there agglomerate into minute multicellular pustules. Elaboration of the petiolar epidermis occurs also in $S$. asperata where there are very numerous minute multicellular spinules.

This species is variable within and between populations. For example, the species' entire range of leaf shape, variegation and venation pattern is found in the population A.H. collected from at Ayer Terjun, Sekayu Forest Reserve (Terengganu). Populations at Gombak and in Johor along the Kota Tingi-Mersing road have greyer leaves which are bright pink when young. The sterile interstice varies from being composed almost entirely of structures resembling interpistillar staminodes (recognised by their colour, diameter, height and reaction to alcohol) in the Gombak population, while in the Sekayu population the sterile interstice is composed either of structures resembling (by their different colour, lower height, greater diameter and darkening reaction to alcohol) staminodes of the appendix or a mixture of both kinds segregated 
longitudinally. While it is conventional to refer to interpistillar structures, interstice structures and structures of the appendix as staminodes in this group, this would appear to be labelling as identical, structures of somewhat differing homology.

Spirit material of this species characteristically blackens.

Schismatoglottis kingii is based on a sterile plant which appears to match S. scortechinii well in leaf shape, petiole/blade ratio and in the channelled petiole with adaxial crisped wing. S. marginata Ridl. is a rather narrow-leaved aspect of S. scortechinii and does not appear to differ significantly in any other respect.

Other specimens examined: PENINSULAR MALAYSIA: Penang, Sg. Ara, Baharuddin s.n. (USM); Selangor, Ulu Gombak Forest Reserve, Boyce 672 (K); Perak, Gopeng, base of G. Chanteh, Furtado s.n. (SING); Pahang, Bentong-Raub boundary, Furtado 33105 (B, BO, K, L, SING); Pahang, Bentong, Furtado 33112 (BO, K); Cult. RBG Sydney, Acc. No. 940093, 940096 ex Selangor, Gombak Valley, (orig. coll. Hay et al. 9049, 9052), both Herscovitch s.n. (NSW); Cult. RBG Sydney Acc. No. 940273, 940274 ex Johor, Kota Tinggi- Mersing Road, (orig. coll. Hay et al. 9205, 9206), both Herscovitch s.n. (NSW); Cult. RBG Sydney Acc. No. 940288, 940292, 940298, 940299, 940300, 940303, 940304, 940305, 940322, 940325 ex Terengganu, Ayer Terjun, Sekayu F.R., (orig. coll. Hay et al. 9220, 9224, 9230, 9231, 9232, 9235, 9236, 9237, 9254, 9257), all Herscovitch s.n. (NSW); Johor, G. Beridong, Holttum 10969 (SING); Johor, Labis, Sg. Juasseh towards Sg. Ulu Kemidak, Md. Shah 2304 (SING); Selangor, Ulu Gombak, Md. Nur 34216 (SING); Selangor, Kanching forest, 3 mi SE of Rawang, Melville 4752 (K); Perak, Bujong Malacca, Ridley s.n. (SING); Selangor, Klang Gates, Ridley s.n. (SING); Selangor, Kuala Lumpur, Weld Hill, Ridley s.n. (K); Perak, Gua Batu Puteh, Wray 1201 (CAL, SING);

\section{Schismatoglottis sejuncta $A$. Hay, sp. nov.}

In aspectu Schismatoglottidem asperatam simulans sed stigmate minore, interstitio nudo, connectivo tenuiore, appendice breviore differt. - TYPUS: Brunei Darussalam, Temburong Prov., Labu, Bukit Peradayan, 25 Jan 1964, M. Hotta 13585 (KYO, holo).

Herb c. $45 \mathrm{~cm}$ tall. Stem condensed, epigeal, rooting among the leaf bases, ?pleionanthic. Leaves few (c. 4) together; petiole c. $18 \mathrm{~cm}$ long, sheathing in the lower $1 / 3$, narrowly alate; wings of sheath fully attached, persistent, tapering; blade thinly membranous (dry), broadly oblanceolate c. $23 \mathrm{~cm}$ long $\times 9 \mathrm{~cm}$ wide, the base narrowly acute and decurrent, the tip broadly acute and rather abruptly acuminate for c. $2 \mathrm{~cm}$; midrib flush with the lamina with c. 17 primary lateral veins on each side, alternating with fine interprimaries and diverging at c. $60^{\circ}$; secondary venation arising mostly from the midrib, some from the bases of the lower primary veins; tertiary venation obscure. Inflorescences 3 together clustered low among the leaf bases; peduncle very short, completely concealed by the subtending leaf bases and cataphylls at anthesis, becoming slightly exserted (on one side) and c. $4 \mathrm{~cm}$ long afterwards. Spathe c. $5 \mathrm{~cm}$ long; lower spathe c. $1.5 \mathrm{~cm}$ long, ovoid, differentiated from the limb by a weak constriction; limb lanceolate, c. $3.5 \mathrm{~cm}$ long, apically mucronate for $5 \mathrm{~mm}$, mode of deciduousness not observed. Spadix ?sessile, c. $4.5 \mathrm{~cm}$ long; female zone $1 \mathrm{~cm}$ (?or more) long, ?not adnate to the spathe, subcylindric; pistils crowded, subglobose and somewhat flat-topped, c. $0.5 \mathrm{~mm}$ diam.; stigmas small, slightly raised, button-like, c. $0.2 \mathrm{~mm}$ diam.; interpistillar staminodes absent from among the pistils (base of female zone, where they might be predicted, unobservable); sterile interstice naked except for 3 irregular whorls of abortive stamens contiguous with base of male zone, $6 \mathrm{~mm}$ long $\times 2 \mathrm{~mm}$ diam., level with the spathe constriction; male zone narrowly obconoid, $1 \mathrm{~cm}$ long, distally $3 \mathrm{~mm}$ diam.; stamens crowded, truncate and flat-topped, c. $0.5 \mathrm{~mm}$ across, dumbbell-shaped with the connective rather thick; pores of thecae flanged and cleft on the outer side; appendix $1.2 \mathrm{~cm}$ long, subcylindric, distally tapering to a blunt point, the base slightly and abruptly thicker than the top of the male zone, c. $0.5 \mathrm{~mm}$ diam.; staminodes of the appendix irregularly polygonal, flattopped, c. $0.4 \mathrm{~mm}$ diam. Fruiting spathe urceolate, c. $2 \mathrm{~cm}$ long. 
Distribution — Malesia: endemic to Borneo (Brunei); known only from the type.

Habitat - Not specified; the type collected between 100 and $300 \mathrm{~m}$ alt.

Notes - In aspect Schismatoglottis sejuncta resembles narrower-leaved forms of $S$. asperata. Vegetatively it can be distinguished by the more membranous leaf blade and the glabrous petiole. The inflorescences also at first resemble those of $S$. asperata, being in small clusters held low among the leaf bases, and having subcylindric spathes with the lower spathe and more or less lanceolate limb differentiated by a weak constriction. Spathe limb dehiscence has not been observed, but the ragged edges of the lower spathe in one inflorescence, together with the evident affinity of this species with the diverse $S$. asperata group, suggest that it probably crumbles rather than being caducous. However in spadix details the species are readily distinguished, S. sejuncta having much smaller stigmas, no interpistillar staminodes (except possibly at the base of the female zone which is unobservable in the material to hand), a conspicuous naked interstice separating the fertile zones (from which the epithet derives), dumbbell-shaped anthers with conspicuous broad-flanged pores, and the appendix approximately equalling the male zone in length.

\section{Schismatoglottis multiflora group}

Shoot pleionanthic. Leaf sheath ligular. Spathe limb caducous. Spadix often held subhorizontal (apex of peduncle and/or base of female zone bent); appendix sometimes absent. Often rheophytic.

14 species, Borneo.

\section{Schismatoglottis bauensis A. Hay \& C. Lee, sp. nov.}

A Schismatoglottide monoplacenta staminodiis inter pistillis plusminusve deficientibus, ovario subcylindrico, interstitio neutro robustiore, antheris minoribus, appendice deficienti differt. - TYPUS: Malaysia, Sarawak, 1st Divn, Bau, Fairy Caves, c. 7 km from Bau, 10 Mar 1994, P.C. Boyce 790 (K, holo — 2 sheets; iso SAR (n.v.)).

Herb to c. $75 \mathrm{~cm}$ tall. Stem condensed, more or less creeping, c. 2-2.5 cm thick, bright red internally (?always), with internodes to c. $0.5 \mathrm{~cm}$ long, pleionanthic. Leaves to c. 8 together; petiole $30-55 \mathrm{~cm}$ long, tinged reddish towards the base (?always), drying rust-brown, sheathing only at the extreme base, the wings of the sheath extended into a bicarinate narrowly lanceolate ligular portion 15-22 cm long, this drying dark brown; blade ovate, $15-30 \mathrm{~cm}$ long $\times 7-15 \mathrm{~cm}$ wide, dark green adaxially, abaxially paler, the base obtuse (sometimes slightly decurrent), not at all cordate, the tip acute and acuminate for up to c. $3 \mathrm{~cm}$; midrib very prominent abaxially (dry), adaxially flush with the lamina, with 18-26 primary lateral veins on each side, irregularly alternating with interprimary veins and diverging at $60-70^{\circ}$; secondary venation rather obscure, arising from the midrib and from the bases of the primary veins; tertiary venation obscure. Inflorescences 1-4 together subtended by lanceolate cataphylls resembling the ligular leaf sheaths; peduncle to $10 \mathrm{~cm}$ long, not exceeding the cataphylls. Spathe $8 \mathrm{~cm}$ long; lower spathe $3.5 \mathrm{~cm}$ long, green, differentiated from the limb by a weak constriction level with the top of the interstice; limb $5 \mathrm{~cm}$ long, becoming white, caducous. Spadix $6.5 \mathrm{~cm}$ long, subcylindric; female zone $3 \mathrm{~cm}$ long, adnate to the spathe in the lower $2 / 3$, the free part slightly conoid, apically $4 \mathrm{~mm}$ diam.; pistils numerous and crowded, subcylindric, c. $0.4 \mathrm{~mm}$ diam.; stigma sessile, about the diameter of the ovary, button-like, papillate; interpistillar staminodes very few among the pistils, otherwise confined to a single row along the spathe/spadix adnation, about the height and diameter of the pistils, subcylindric, flat-topped; sterile interstice $6 \mathrm{~mm}$ long, white, somewhat obconoid, distally $6 \mathrm{~mm}$ diam.; staminodes of interstice 
crowded, irregularly polygonal, $0.5-1 \mathrm{~mm}$ diam., flat-topped; male zone $3 \mathrm{~cm}$ long, finger-like, basally isodiametric with top of interstice, tapering to a blunt point in the upper half; stamens somewhat lax, truncate, flat-topped, somewhat irregularly rectangular with the connective wide and the pores small on the narrower edges of the connective, $0.5-0.7 \mathrm{~mm}$ across; appendix absent. Fruiting spathe narrowly urceolate, $4 \mathrm{~cm}$ long. - Fig. 10.

Distribution - Malesia: endemic to Borneo (Sarawak); known only from the vicinity of Bau. One collection, doubtfully of this species, from West Kalimantan (see notes).

Habitat - Lithophytic in humus and litter pockets on limestone boulders and cliffs at c. $10 \mathrm{~m}$ alt.

Notes - Schismatoglottis bauensis is readily distinguished from Schismatoglottis monoplacenta, which it resembles strongly in habit, by the absence of an appendix. This species coexists with $S$. nervosa Ridl., which has rather similar ovate, multiveined leaves. However, in that species, the leaf sheath is fully attached, the petioles are ribbed rather like celery and minutely puberulent, and an appendix is present.

Burley et al. 3258, from West Kalimantan, differs in being finely and densely pubescent, while the plants from Bau are completely glabrous. The inflorescence on this specimen is immature, but the spadix is fertile to the apex, as in S. bauensis, which it also resembles in leaf. The Bau plants are on limestone. Substrate is not specified for this collection. It is provisionally attributed to this species, but more material is needed from this locality (see under other specimens examined).

Other specimens examined: BORNEO: SARAWAK: Bau, Lee s.n. (NSW spirit); 1st Divn, vicinity of Bau, $1 \mathrm{mi}$ W of Bau, Nicolson 1300 (US) $\mathcal{E} 1303$ (B, L, US). KALIMANTAN: West Kalimantan, G. Bentuang area, 5-10 km N of Masa Vill., $150 \mathrm{~km} \mathrm{NE}$ of Pontianak, Ridge SW of G. Bentuang, river bank nr Batu Besapih camp, Burley et al. $3258(\mathrm{GH})$.

\section{Schismatoglottis cyria P.C. Boyce}

Schismatoglottis cyria P.C. Boyce, Kew Bull. 49 (1994) 796, fig. 2. - Type: Brunei, Temburong Dist. Kuala Belalong, Sg. Engkiang, above Kuala Belalong, 6 May 1991, Argent $\mathcal{E}$ Mitchell 91/203 (E, holo; iso AAU, BRUN, K, L).

Robust herb to $1.2 \mathrm{~m}$ tall. Stem condensed, pleionanthic, c. $3 \mathrm{~cm}$ diam., pink internally. Leaves several together; petiole c. $1 \mathrm{~m}$ long, sheathing only at the extreme base; attached portion of sheath c. $4 \mathrm{~cm}$ long, ?with a ligular extension (see Notes); blade oblong-ovate, dark green adaxially, paler abaxially, to $44 \mathrm{~cm}$ long $\times 24 \mathrm{~cm}$ wide, the base truncate-rounded, shortly decurrent on the petiole, the tip abruptly acuminate for c. $4 \mathrm{~cm}$; midrib yellowish and somewhat prominent abaxially, adaxially somewhat impressed; primary lateral veins c. 18 on each side, abaxially prominent, adaxially impressed, diverging at c. $60-80^{\circ}$, alternating with lesser interprimary veins and occasionally with one or two subsidiary veins arising c. $1 / 4-1 / 3$ of the way along their length from the midrib; secondary venation fine and dense, mostly arising from midrib or from primary veins distal to insertion of subsidiary veins. Inflorescences 6 together, subtended by lanceolate cataphylls to $12 \mathrm{~cm}$ long; peduncle to $30 \mathrm{~cm}$ long. Spathe $12 \mathrm{~cm}$ long; lower spathe green, narrowly ovoid, $3 \mathrm{~cm}$ long, differentiated from the limb by a weak constriction; limb lanceolate, pale pink, $9 \mathrm{~cm}$ long including a $2 \mathrm{~cm}$ mucro, deciduous. Spadix sessile, c. $9 \mathrm{~cm}$ long, subcylindric (somewhat attenuate at junction of male and female zones); female zone $3 \mathrm{~cm}$ long, dorsally adnate to the spathe for c. $1.5 \mathrm{~cm}$; pistils ovoid, c. $0.5 \mathrm{~mm}$ diam., close-packed; stigma sessile, irregularly discoid, papillate, slightly narrower than ovary; interpistillar staminodes irregularly scattered within the female zone, distally crowded and forming part of the sterile interstice, basally forming a row along the spathe/spadix adnation, clavate, c. $0.5 \mathrm{~mm}$ diam., white-tipped, the filament brown; sterile interstice c. $5 \mathrm{~mm}$ long, 


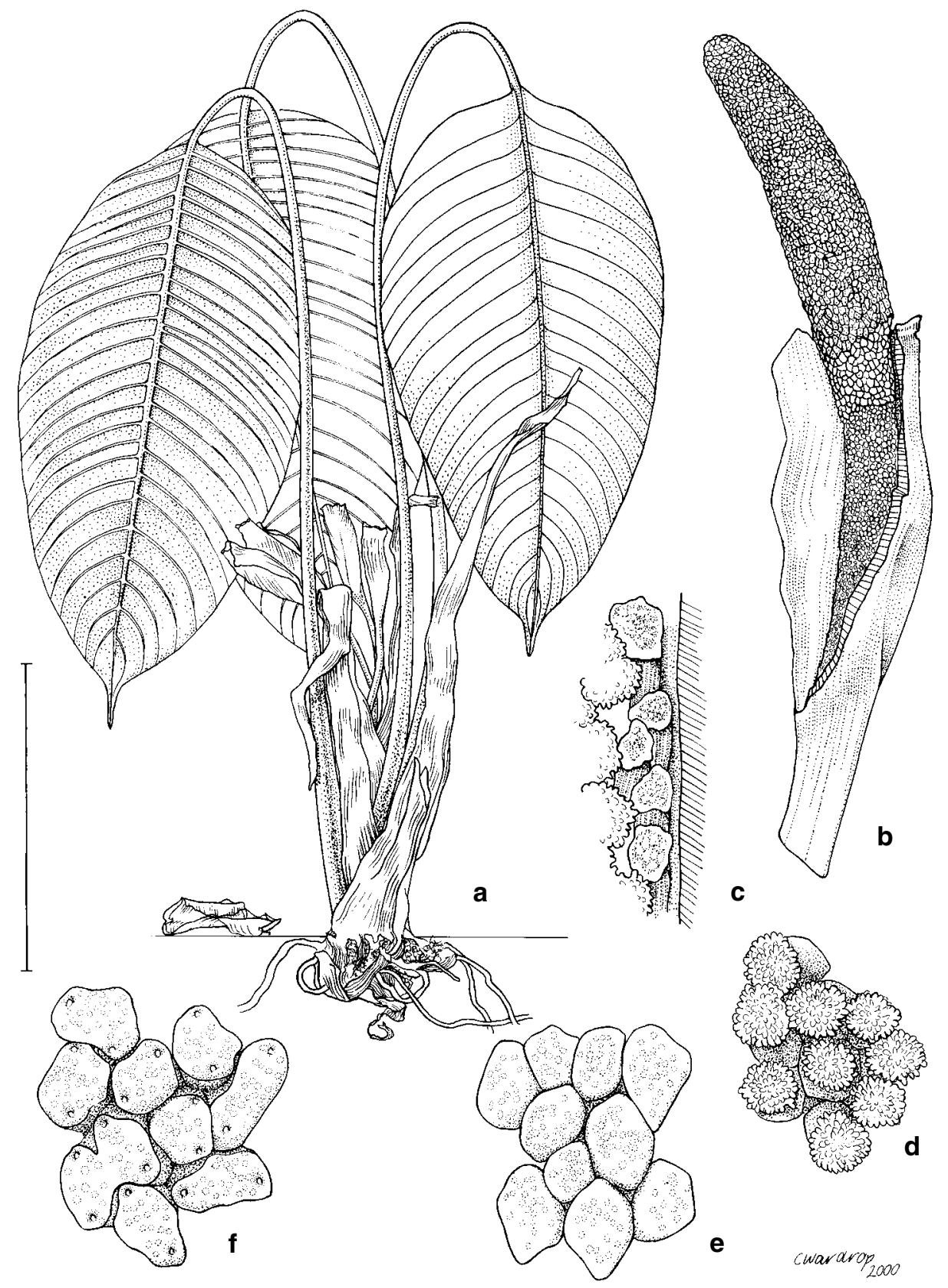

Fig. 10. Schismatoglottis bauensis A. Hay \& C. Lee. a, Habit; b, Inflorescence; c, Staminodes along spathe/spadix adnation; d, Pistils; e, Staminodes of interstice; f, Stamens (a: Boyce 790; b-f: Lee s.n.). Scale bar: $\mathrm{a}=12 \mathrm{~cm} ; \mathrm{b}=2 \mathrm{~cm} ; \mathrm{c}-\mathrm{f}=3 \mathrm{~mm}$. 
attenuate, c. $4 \mathrm{~mm}$ diam., the lower part formed of interpistillar staminodes (with a few interspersed pistils), the upper c. $2 \mathrm{~mm}$ formed of sterile stamens; male zone $2 \mathrm{~cm}$ long, $6 \mathrm{~mm}$ diam.; stamens close-packed, somewhat irregularly rectangular to dumbbell-shaped, occasionally in united pairs, c. $0.7 \mathrm{~mm}$ across (covered with white crystals in dry state); connective truncate, slightly raised above the tops of the thecae; apical pores conspicuously flanged; appendix $4.5 \mathrm{~cm}$ long, basally more or less isodiametric with male zone, tapering in the distal $2 \mathrm{~cm}$; appendix staminodes more or less rectangular, c. $0.7 \mathrm{~mm}$ across, densely packed, truncate.

Distribution - Malesia: endemic to Borneo (Brunei); known only from the type.

Habitat - On wet shaded shale cliff by river, c. $70 \mathrm{~m}$ alt.

Notes - In aspect and inflorescence morphology this species resembles S. monoplacenta M. Hotta, differing in its larger dimensions and 2-3 placentas in the ovary. Schismatoglottis monoplacenta has conspicuously ligular leaf sheaths. Schismatoglottis cyria was described (Boyce, loc. cit) as having the sheath very short and fully adnate to the petiole. However, all along the distal rim of the sheath of the $\mathrm{K}$ isotype, there is a break in the tissue, suggesting that an extended portion may be missing (this is not clear in the holotype due to the way it has been pressed).

Schismatoglottis is, like most striate-veined genera of Araceae, one in which the leaf blade is contained within some sheathing structure until its development is well advanced - either a long, fully adnate sheath, an extended ligular portion of the sheath, or, as in S. tecturata, the sheath is very short but the leaves develop within cataphylls. The sheath length described for S. cyria $($ c. $4 \mathrm{~cm})$ is far too short to contain a leaf as large as that of this species, and it seems highly probable that there is a long ligular sheath extension. The $\mathrm{K}$ isotype is accompanied by a habit photograph, but it is insufficiently close up to see whether any cataphyll or ligule remnants exist among the petioles.

\section{Schismatoglottis erecta $M$. Hotta}

Schismatoglottis erecta M. Hotta, Mem. Coll. Sci. Univ. Kyoto, Ser. B, 32 (1966) 233, fig. 5, A-F. - Type: Malaysia, Sarawak, 4th Divn, Bintulu, valley of Sg. Keyan, Ulu Sg. Kakus, 9 Nov 1963, M. Hirano \& M. Hotta 479 (KYO, holo).

Herb to c. $30 \mathrm{~cm}$ tall. Stem erect to decumbent, c. $5 \mathrm{~mm}$ diam., with internodes to $1.5 \mathrm{~cm}$ long, epigeal, pleionanthic. Leaves c. 6 along the stem; petiole to c. $11 \mathrm{~cm}$ long, slender, sheathing only at the extreme base, the wings of the sheath extended into a linearlanceolate ligular portion to $4 \mathrm{~cm}$ long; blade oblong-lanceolate to narrowly elliptic, 10-15 cm long $\times 2-3.5 \mathrm{~cm}$ wide, the base acute and somewhat decurrent, the apex acute and rather abruptly acuminate for c. $2 \mathrm{~cm}$; midrib abaxially prominent, adaxially grooved, with c. 8 primary lateral veins on each side, alternating with lesser interprimaries and diverging at c. $60^{\circ}$; secondary venation abaxially rather inconspicuous, adaxially more or less obscure, arising from the midrib; tertiary venation obscure. Inflorescence solitary; peduncle c. $6 \mathrm{~cm}$ long, slender, apically curved bringing the inflorescence subhorizontal. Spathe c. $5 \mathrm{~cm}$ long; lower spathe subcylindric, c. $2 \mathrm{~cm}$ long, differentiated from the limb by the abrupt inflation of the latter; limb c. $3 \mathrm{~cm}$ long, ellipsoid in the lower $2 / 5$ (corresponding to male zone of spadix), then abruptly and narrowly acuminate in the remainder, ?caducous (not observed). Spadix shorter than spathe, c. $3 \mathrm{~cm}$ long, more or less hourglass-shaped; female zone conoid, adnate to the spathe in the lower half, $1.5 \mathrm{~cm}$ long; pistils crowded, obovoid, c. $1 \mathrm{~mm}$ diam. (fresh; $0.5 \mathrm{~mm}$ diam. dry); stigma button-like, sessile, about $1 / 2$ the diameter of the fresh ovary; interpistillar staminodes confined to a row along the spathe/spadix adnation, about the height of the pistils, stipitate, flattopped, c. $1 \mathrm{~mm}$ diam.; sterile interstice obconoid, c. $5 \mathrm{~mm}$ long, composed of 
crowded, columnar staminodes c. $0.6 \mathrm{~mm}$ diam.; male zone obovoid, c. $1.7 \mathrm{~cm}$ long, distally $1 \mathrm{~cm}$ diam., apically rounded; stamens crowded, truncate with the connective thick and slightly raise above the thecae and deeply channelled across the top between the pores, c. $0.75 \mathrm{~mm}$ across, very bluntly rhomboid; pores paired at each end of the anther, bordered by raised rims; appendix absent. Infructescence unknown.

Distribution - Malesia: endemic to Borneo (Sarawak); known only from the type locality.

Habitat - Terrestrial on humus in dense forest, 50-100 $\mathrm{m}$ alt.

Notes - Schismatoglottis erecta is evidently allied, by its ligular sheath, absent appendix and paired pores on each end of the anther, to S. schottii and S. mayoana. Of those, it further resembles the former in the more or less erect, terrestrial habit. It differs from both in the distinctive tops of the anthers, with the connective somewhat raised and conspicuously grooved from theca to theca, and in the raised rims around the pores.

\section{Schismatoglottis gillianae P.C. Boyce}

Schismatoglottis gillianae P.C. Boyce, Kew Bull. 49 (1994) 793, fig. 1; Mayo et al., The Genera of Araceae (1997) 183, pl. 49(i), A, B. - Type: Brunei, Tutong, Sg. Tutong between Benutan and Balabau, 27 Mar 1990, M.C.E. Coode et al. 6313 (K, holo; iso BRUN, L).

Rather small pendent to suberect usually rheophytic herb to c. $40 \mathrm{~cm}$ long. Stem branched and tuft-forming, rooting among and below the leaf bases. Leaves several together; petiole $2.5-12.5 \mathrm{~cm}$ long, pale to olive green, sometimes tinged red, sheathing in the lower $1.5-2 \mathrm{~cm}$, the sheath extended into a free tapering ligular portion to $3.5 \mathrm{~cm}$ long, occasionally minutely and densely hairy abaxially, usually glabrous; blade narrowly oblanceolate, 1.5-3 times longer than the petiole, $9-35 \mathrm{~cm}$ long, 3-3.5 cm wide, the base decurrent, the apex acuminate for $1.5-4 \mathrm{~cm}$; midrib not or hardly raised on either surface (dry), drying conspicuous dark brown abaxially; primary lateral veins $4-8$ on each side, diverging at c. $30^{\circ}$, slender and not raised but conspicuously dark abaxially, adaxially somewhat obscure, alternating with more slender interprimary veins; secondary venation fine and rather dense, arising from the midrib. Inflorescence solitary; peduncle very short, 2-3.5 cm long, concealed by leafand cataphyll bases (elongating in fruit). Spathe 3-6 cm long, cream to white, sometimes flushed pink in the lower part; lower spathe narrowly ovoid, $1.5-2.5 \mathrm{~cm}$ long; limb lanceolate, caducous, $2.5-4.5 \mathrm{~cm}$ long. Spadix sessile, cream, somewhat shorter than the spathe, more or less subcylindric throughout (dry); female zone $1-2 \mathrm{~cm}$ long, partly adnate to the spathe dorsally; interpistillar and basal staminodes absent; ovaries squat, $1 \times 1 \mathrm{~mm}$; stigma sessile, discoid, slightly wider than ovary, c. $1.1 \mathrm{~mm}$ diam., papillate; sterile interstice $3.4 \mathrm{~mm}$ long narrowly obconoid, composed of somewhat lax oblong to somewhat polygonal staminodes; male zone c. 1-1.3 cm long; stamens polygonal-columnar, truncate, densely arranged, 1-1.5 $\mathrm{mm}$ diam.; appendix $1.2-3 \mathrm{~cm}$ long, tapering, distally somewhat flattened, composed of very densely arranged trapezoid to polygonal, centrally impressed staminodes. Fruiting peduncle to $8 \mathrm{~cm}$; fruiting spathe ovoid, c. $3.5 \mathrm{~cm}$ long.

Distribution - Malesia: endemic to Borneo (Brunei), with one doubtful record from Sarawak (see Notes).

Habitat - Rheophytic on rocks and in muddy stream banks, occasionally on forest floor; on Setap shales and Belait series sediments, to $120 \mathrm{~m}$ alt.

Notes - Schismatoglottis gillianae is distinguished from other species with ligular sheaths by the blade considerably longer than the petiole, the very short peduncle and 
the absence of interpistillar and basal staminodes in the female zone. Though the sheath is ligular, it is relatively short and attached to the petiole for about a third of its (the sheath's) length.

Boyce 254 has the sheath minutely and densely hairy abaxially. Other Brunei specimens are glabrous.

Clemens $\mathcal{E}$ Clemens 21937 no longer has an inflorescence (the field notes record the 'flower' as white), but resembles $S$. gillianae in habit, size and leaf shape. It has an irregular variegated band about the midrib adaxially; the abaxial leaf surface is rather more brown (dry) than other material of this species, and the primary veins diverge at a rather wider angle. This specimen too has the ligular sheath densely hairy abaxially. It falls well outside the rest of the known range for this species and it is ascribed to it only tentatively.

Other specimens examined: BORNEO: SARAWAK: Kapit, Upper Rejang River, Clemens \& Clemens 21937 (K). BRUNEI: Belait Dist., Labi, Kg Teraja, path along Sg. Teraja, Boyce et al. 254 (K, L); Temburong Dist., Sg. Temburong at Kuala Belalong, bank of Sg. Belalong, Boyce et al. 424 (K, L); Temburong Dist., Wong Nguan rapids, Coode et al. 6665 (K); Temburong, Selapon, banks of Sg. Selapon, Dransfield et al. 6920 (K); Temburong, Apo, Kuala Belalong, Sg. Belalong, Dransfield et al. 7041 (K); Temburong, Batu Apoi FR, Sg. Belalong, Poulsen 47A (K).

\section{Schismatoglottis josefii A. Hay, sp. nov.}

A Schismatoglottide mayoana Bogner \& M. Hotta statura valde minore, lamina folii anguste lanceolata, nervis primariis obscuris, pedunculo valde breviore, inflorescenctia valde minore, connectivo antherae crasso, thecis elevatis, appendice ellipsoidea differt. - TYPUS: Malaysia, Sarawak, Entabai, 3 Sep 1978, J. Bogner 1353 (M, holo).

Very small herb to $15 \mathrm{~cm}$ tall. Stem condensed, suberect, c. $3 \mathrm{~cm}$ long, c. $6 \mathrm{~mm}$ diam., pleionanthic. Leaves 5 together; petiole slender, to $7 \mathrm{~cm}$ long, shorter than the blade, sheathing only at the extreme base, but sheath extended into a tapering bicarinate ligular portion to $3.2 \mathrm{~cm}$ long; blade narrowly lanceolate, to $11.5 \mathrm{~cm}$ long $\times 1.1 \mathrm{~cm}$ wide, the base cuneate, the apex indistinctly acuminate for $1.2 \mathrm{~cm}$ including a $2 \mathrm{~mm}$ cylindric mucro; midrib prominent adaxially and abaxially; primary lateral veins extremely fine, adaxially impressed, abaxially almost indistinguishable from secondary veins (hand lens required), 3 on each side of midrib, subopposite, diverging at c. $30^{\circ}$; secondary venation adaxially obscure, abaxially very fine and dense, arising from the midrib. Inflorescence solitary, subtended by lanceolate cataphylls to $3 \mathrm{~cm}$ long; peduncle much shorter than the petioles and not exceeding the cataphylls, $2 \mathrm{~cm}$ long. Spathe $2 \mathrm{~cm}$ long, green; lower spathe subcylindric, $5 \mathrm{~mm}$ long, differentiated from the limb by a very weak constriction; limb $1.5 \mathrm{~cm}$ long, somewhat inflated over the appendix of the spadix, then acuminate for $6 \mathrm{~mm}$, ?caducous; female zone slender, $4 \mathrm{~mm}$ long, mostly adnate to the spathe; pistils crowded; ovary subglobose, c. $0.5 \mathrm{~mm}$ diam.; stigma sessile, about half the diameter of the ovary, button-like, very weakly 3-4lobed, papillate; interpistillar staminodes confined to a single row along each side of the spathe/spadix adnation, stalked, flat-topped, about the same height as the pistils; sterile interstice c. $1 \mathrm{~mm}$ long, somewhat wider than the female zone, 1-2 irregular whorls of centrally impressed sterile stamens; male zone $3 \mathrm{~mm}$ long $\times 1.7 \mathrm{~mm}$ thick; stamens crowded; anthers truncate, irregularly rectangular, c. $0.25 \mathrm{~mm}$ across, with the connective somewhat dilated and sometimes expanded on one side; thecae somewhat raised above the connective; appendix $5 \mathrm{~mm}$ long, ellipsoid-clavate, formed of flattopped irregularly discoid staminodes c. $0.5 \mathrm{~mm}$ across. Fruit unknown. - Fig. 11.

Distribution - Malesia: endemic to Borneo (Sarawak); known only from the type.

Habitat - Rheophytic on rocks in a stream; 50-100 m alt. 


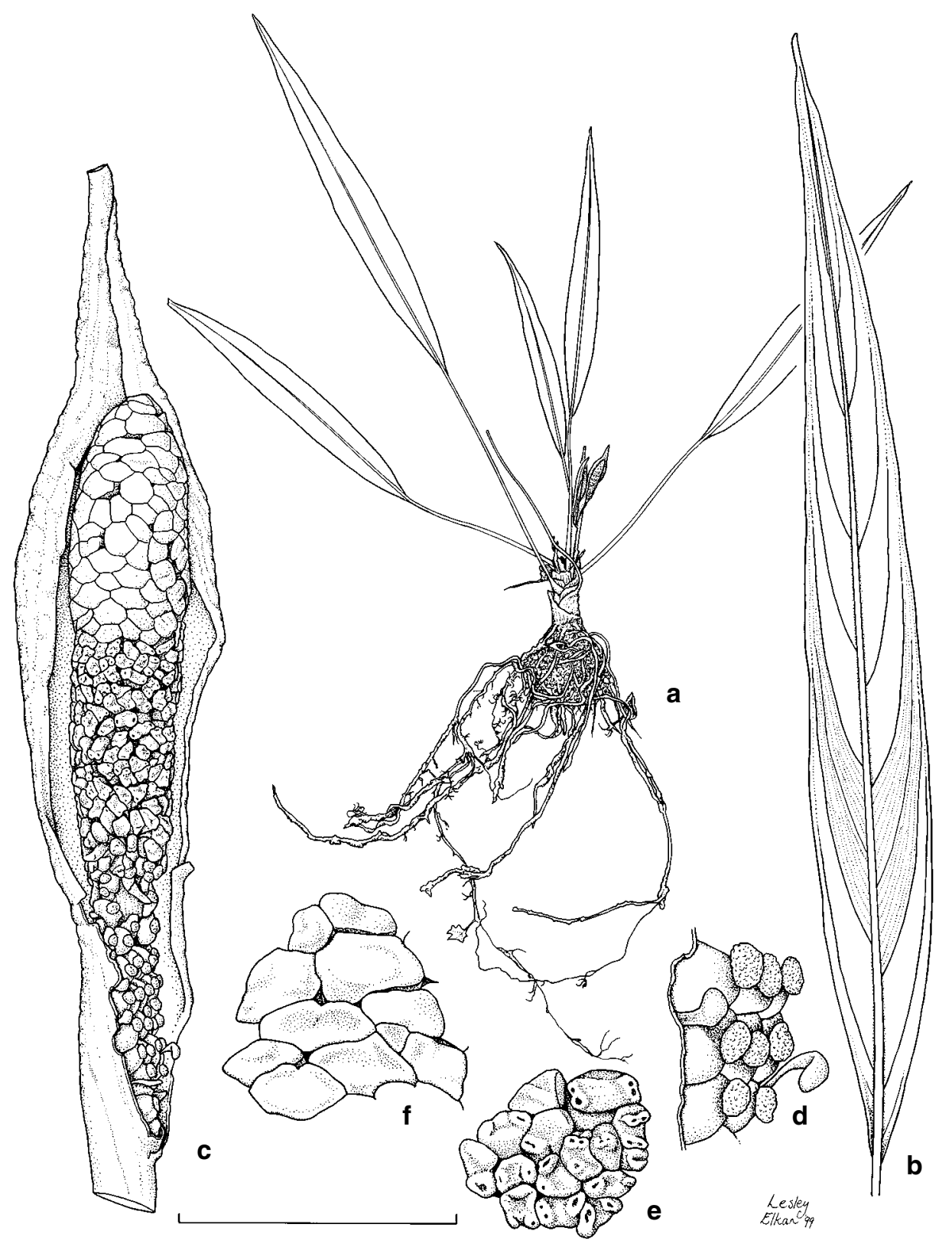

Fig. 11. Schismatoglottis josefii A. Hay. a, Habit; b, Leaf; c, Inflorescence; d, Pistils and interpistillar staminodes; e, Stamens; f, Staminodes of appendix (Bogner 1353). Scale bar: $a=8 \mathrm{~cm} ; \mathrm{b}=2 \mathrm{~cm}$; $c=5 \mathrm{~mm} ; \mathrm{d}-\mathrm{f}=2 \mathrm{~mm}$. 
Notes - In leaf this species rather resembles $S$. sarikeensis, sharing the dense secondary venation and primary venation hardly differentiated from it. Schismatoglottis sarikeensis differs in having the dorsal side of the male zone sterile and adnate to the spathe.

This species is named for Josef Bogner (Munich Botanic Garden), who has contributed much to knowledge of the Schismatoglottideae, in particular the rheophytic members of the tribe.

\section{Schismatoglottis mayoana Bogner \& M. Hotta}

Schismatoglottis mayoana Bogner \& M. Hotta, Acta Phytotax. Geobot. 34 (1983) 48. - Type: Malaysia, Sarawak, near Matang, 1979, J. Bogner 1606 (M, holo; iso K, KYO, M, US).

Schismatoglottis beccariana var. cuspidata Engl., Bull. Soc. Tosc. Ortic. 4 (1879) 297. - Type: Malaysia, Sarawak, Matang, O. Beccari P.B. 1648 (FI, holo; iso GH, K).

Schismatoglottis multiflora var. latifolia Ridl., J. Straits Br. Roy. Asiat. Soc. 49 (1907) 50. - Type: Malaysia, Sarawak, Matang, 21 Jun 1893, E.W. Bartlett 2 (SING, holo - 2 sheets).

Mostly lithophytic herb to c. $30 \mathrm{~cm}$ tall. Stem condensed, pleionanthic, c. $1-1.5 \mathrm{~cm}$ diam. Leaves few to several together, somewhat pendent; petiole 13-21 cm long, slender, sheathing only at the extreme base, but sheath extended into a tapering, papery dark brown ligular portion to $10 \mathrm{~cm}$ long; blade elliptic to narrowly (oblong-) ovate, slightly but distinctly asymmetric about the midrib, $14-21 \mathrm{~cm}$ long $\times 4-8 \mathrm{~cm}$ wide, the base cuneate, the tip acuminate for c. $3 \mathrm{~cm}$; midrib abaxially prominent; primary lateral veins hardly prominent abaxially, c. 12 on each side, diverging at c. $45^{\circ}$, alternating with lesser interprimary veins; secondary venation very fine and dense, arising from the midrib. Inflorescence large, solitary or two together; peduncle $1 / 3-1 / 2$ the length of the petiole, the apex bent and obliquely deflecting the spathe and spadix. Spathe c. $12 \mathrm{~cm}$ long; lower spathe green, spindle-shaped, $2.5 \mathrm{~cm}$ long, differentiated from the limb by a distinct constriction; limb lanceolate, white, mucronate for $2 \mathrm{~cm}$, incompletely opening at first, then caducous. Spadix sessile, c. $2 / 3$ the length of the spathe; female zone $2.5 \mathrm{~cm}$ long, adnate to the spathe for c. $1.7 \mathrm{~cm}$; pistils very numerous and crowded, narrowly ovoid to bottle-shaped, c. $0.5 \mathrm{~mm}$ diam.; stigma sessile, button-like, papillate; clavate interpistillar staminodes sparsely scattered among the pistils, more concentrated near junction of female zone and sterile interstice, and forming a basal row on each side along adnation of spathe and spadix; sterile interstice short, c. 2-3 mm long, 2-3 irregular whorls of staminodes resembling sterile stamens (i.e. different from interpistillar staminodes); male zone and appendix subcylindric, about twice the thickness of the top of the female zone, c. $6 \mathrm{~mm}$ diam.; male zone c. $2.5 \mathrm{~cm}$ long; stamens close-packed, truncate, more or less rectangular, c. $1 \mathrm{~mm}$ across, with the connective wide and about the height of the thecae, the thecae at the short ends, each with two minute pores, the top of the connective usually impressed along the long axis; appendix c. $2 \mathrm{~cm}$ long, blunt-tipped, composed of densely packed sterile, sometimes irregularly bent and twisted staminodes $1-2 \mathrm{~mm}$ across. Fruiting spathe narrowly urceolate, c. $3.5 \mathrm{~cm}$ long. - Fig. 12.

Distribution - Malesia: endemic to Borneo (Sarawak); known only from Matang and vicinity.

Habitat - On wet rocks in forest, to c. 200-800 m alt. Field notes on Brooke 9504 record it growing on forest floor.

Notes - This species strongly resembles S. multiflora Ridl. in its elliptic leaves with ligular sheaths and the rather large, long and long-pedunculate inflorescence. It differs 


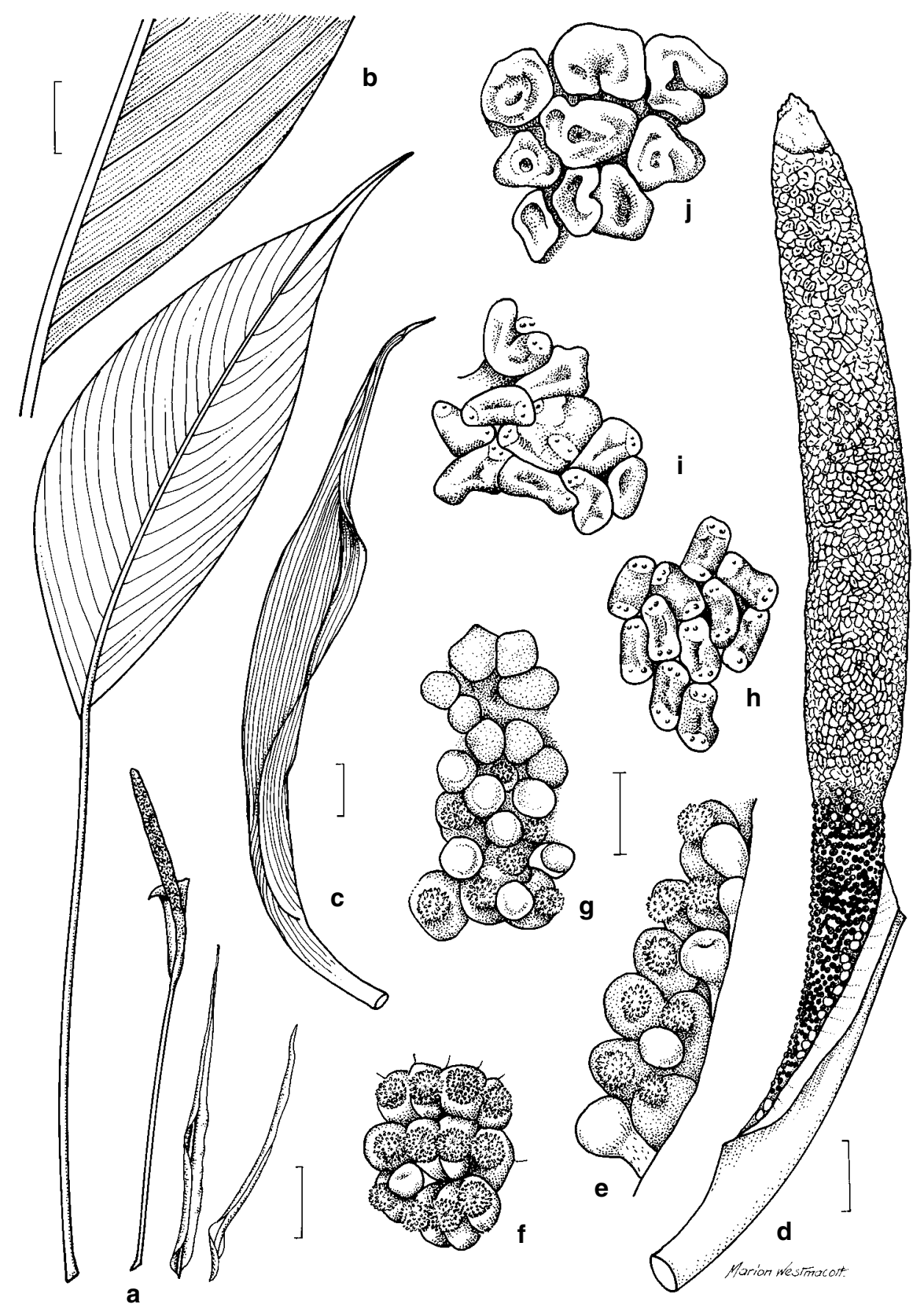

Fig. 12. Schismatoglottis mayoana Bogner \& M. Hotta. a, Detached leaf, inflorescence and cataphylls; b, Venation; c, Inflorescence; d, Spadix; e, Interpistillar staminodes along spathe/spadix adnation; $\mathbf{f}$, Pistils; $\mathbf{g}$, Transition from female zone to interstice; $\mathbf{h}$, Stamens; $\mathbf{i}$, Transition from male zone to appendix; j, Staminodes of appendix (RBG Sydney Acc. No. 940577). Scale bars: a $=2 \mathrm{~cm}$; b, $c=8 \mathrm{~mm} ; \mathrm{d}=5 \mathrm{~mm} ; \mathrm{e}-\mathrm{j}=1 \mathrm{~mm}$. 
in apparently not being truly rheophytic; it appears to be more of a lithophyte in wet places. It is a somewhat more delicate plant than $S$. multiflora, with more slender petioles and less vigorous growth. The leaf venation is similar to $S$. multiflora, but the secondary venation is more dense: about 2 secondary veins per millimetre vs 1.5 per millimetre in S. multiflora. The chief difference lies in the spadix, where there is a large appendix in S. mayoana, but none in S. multiflora - the male zone being continued to the apex; otherwise the inflorescences are extremely similar in general appearance.

Other specimens examined: BORNEO: SARAWAK: just outside Kubah National Park, above intake dam on Sg. Bungen, Boyce 772 (K); Matang, Brooke 9504 (L); Cult. RBG Sydney Acc. No. 940577 ex Matang (orig. coll. Hay et al. 9424), Herscovitch s.n. (NSW); Matang, Ridley s.n. (K).

\section{Schismatoglottis monoplacenta M. Hotta}

Schismatoglottis monoplacenta M. Hotta, Mem. Coll. Sci. Univ. Kyoto, Ser. B, 32 (1966) 227, fig. 2, A-H. - Type: Malaysia, Sarawak, Mardi, along Sg. Melinau, between Sg. Tutoh and Lubang Bungan, at foot of G. Mulu, 14 Mar 1964, M. Hotta 14404 (KYO, holo).

Herb to c. $60 \mathrm{~cm}$ tall. Stem condensed, c. $1.5 \mathrm{~cm}$ thick, pleionanthic. Leaves few together; petiole $20-30 \mathrm{~cm}$ long, sheathing at extreme base, but extended into a tapering papery ligular portion to $13 \mathrm{~cm}$ long; blade elliptic to oblong elliptic, somewhat coriaceous, c. $30 \mathrm{~cm}$ long $\times 13 \mathrm{~cm}$ wide, the base obtuse and slightly decurrent on the petiole, the tip acute and mucronate for c. $1.8 \mathrm{~cm}$; primary lateral veins c. 14 on each side of midrib, alternating with lesser interprimary veins; secondary venation fine and dense. Inflorescences 4 together, subtended by linear-lanceolate cataphylls to $8 \mathrm{~cm}$ long; peduncle c. $13 \mathrm{~cm}$ long. Spathe slender, c. $9 \mathrm{~cm}$ long; lower spathe narrowly ovoid, $3 \mathrm{~cm}$ long, differentiated from the limb by a weak constriction; limb lanceolate, c. $6 \mathrm{~cm}$ long, caducous. Spadix sessile, subcylindric, slightly attenuate at sterile interstice, c. $6.5 \mathrm{~cm}$ long, $6 \mathrm{~mm}$ diam; female zone $2.5 \mathrm{~cm}$ long, adnate to the spathe for half its length; pistils broadly ovoid; stigma sessile, discoid, slightly narrower than ovary; interpistillar staminodes scattered among pistils, white-tipped, brown-stalked, clavate with the top somewhat vertically compressed, arranged in a single row along the spathe/spadix adnation, not concentrated in distal portion of female zone; sterile interstice c. $3 \mathrm{~mm}$ long, composed of sterile stamens; male zone $2 \mathrm{~cm}$ long; stamens close-packed c. $1 \mathrm{~mm}$ across, rectangular-dumbbell-shaped; truncate with the connective slightly exceeding the thecae; appendix $2.1 \mathrm{~cm}$ long, cylindric, blunttipped; staminodes of the appendix somewhat smaller than the stamens, more or less rectangular from above. Fruiting spathe narrowly urceolate.

Distribution - Malesia: endemic to Borneo (Sarawak); known with certainty only from the type locality; specimens from G. Liang Gagang (a limestone area) in SE Kalimantan, may also be of this species.

Habitat - On limestone on moist gravelly slopes; altitudinal data lacking.

Notes - The distribution appears fragmented; however, it is not certain that the cited specimens are conspecific. Hallier 2792 is fertile, but the inflorescences are poorly preserved.

Hotta (1966) placed much significance on the single placenta in this species, suggesting that $S$. monoplacenta may represent an unrecognised supra-specific taxon. It seems however, that this species is closely allied to S. cyria where there are (2-)3 placentas. It is also apparent that the number of placentas may vary within species, such as in S. tecturata. Hotta (loc. cit.), in describing S. homalomenoidea and S. parviflora (here regarded as synonyms of $S$. tecturata), noted that though they both had single placentas, they were closely allied to $S$. beccariana $($ also $=S$. tecturata $)$. Evidently the number of placentas can vary either within species or at least between very closely allied species, and hence it does not seem warranted to attach great taxonomic significance to this feature in isolation. 
Other specimens examined: BORNEO: KALIMANTAN: East Kalimantan, G. Liang Gagang, Hallier 2792 (BO, K, L).

\section{Schismatoglottis multiflora Ridl.}

Schismatoglottis multiflora Ridl., J. Straits Br. Roy. Asiat. Soc. 44 (1905) 181; Engl., Pflanzenr. 55 (IV.23Da) (1912) 90; van Steenis, Rheophytes of the World (1981) 196. - Type: Malaysia, Sarawak, Matang, Jul 1903, H.N. Ridley 11582 (SING, holo; iso K)

Schismatoglottis bulbifera H. Okada, H. Tsukaya \& Y. Mori, Syst. Bot. 24 (1999) 62. - Type: Indonesia, West Kalimantan, Singkawang, G. Poteng, 12 Dec 1991, M. Kato et al. 30432 (TI, holo - n.v.; iso BO).

Rheophytic herb c. 30-60 cm tall, often forming vigorous clumping tufts. Stem condensed, c. $2 \mathrm{~cm}$ thick, pleionanthic. Leaves several together; petiole $7-25 \mathrm{~cm}$ long, sheathing only at the extreme base, but sheath extended into a papery brown tapering ligular portion 4-10 cm long; blade elliptic to (ob)lanceolate, 14-27 cm long, 2-9 $\mathrm{cm}$ wide, the base cuneate, the tip more or less acuminate; midrib abaxially prominent, often but not always with scattered bulbils on the sides; primary lateral veins (6-)10-16 on each side, diverging at $30-45^{\circ}$, more or less regularly alternating with lesser interprimary veins, abaxially prominent (not very well-defined in smallest specimens); secondary venation dense, arising from the midrib. Inflorescences large, in clusters of 2-5 subtended by narrow papery brown cataphylls similar to the ligular sheath extensions; peduncle 6-11 cm long, about half the length of the petioles in robust plants to exceeding the petioles in small plants. Spathe 8-11 cm long; lower spathe subcylindric, green, 2-2.5 cm long, differentiated from the limb by a constriction; limb more or less lanceolate, white, opening at first incompletely, then caducous. Spadix about $2 / 3$ the length of the spathe, $4-7 \mathrm{~cm}$ long, subcylindric; female zone c. $2 \mathrm{~cm}$ long, most adnate to the spathe; pistils very numerous and crowded, cylindric to bottle-shaped, c. $0.4 \mathrm{~mm}$ diam.; stigma sessile, button-like, about the same diameter as the ovary; clavate interpistillar staminodes irregularly and sparsely scattered among the pistils, usually more crowded at the junction of the female zone and sterile interstice, and forming a basal row on each side along the adnation of the spathe and spadix; sterile interstice c. $3 \mathrm{~mm}$ long, a few whorls of staminodes resembling sterile stamens (i.e. different from interpistillar staminodes); male zone about twice the thickness of the female zone and interstice, c. $5 \mathrm{~mm}$ diam. (dry), extending throughout the rest of the spadix though apically with somewhat smaller thecae and sometimes forming a small terminal cluster of sterile stamens; stamens more or less rectangular, c. $0.5-1 \mathrm{~mm}$ across, truncate, with marginal thecae reaching the top of the stamen on the two ends. Fruiting spathe narrowly urceolate, c. $3.5 \mathrm{~cm}$ long.

Distribution - Malesia: endemic to Borneo (Southern Sarawak and West Kalimantan).

Habitat - Rheophytic on rocks and in gravel by and in forest streams, to c. $500 \mathrm{~m}$ alt. (Yii S.55245 at $950 \mathrm{~m}$ ).

Notes - This species is remarkable in having no appendix; instead the male zone is very large, extending to the end of the spadix. In this respect, S. multiflora approaches the genus Piptospatha, from which it differs in the constricted spathe. Schismatoglottis multiflora is quite variable in plant size and leaf shape. There is considerable variation in the size of the stamens, from $0.5-1 \mathrm{~mm}$ across. This species can be confused with S. mayoana (q.v. for distinction).

Schismatoglottis bulbifera was erected on the basis of the bulbiliferous leaves of plants collected in West Kalimantan. Bulbiliferous leaves occur sporadically in S. multiflora in Sarawak, and there does not appear to be any other feature that can be used to distinguish S. bulbifera from S. multiflora. The authors did not contrast S. bulbifera with any species in the protologue, though they allied it with $S$. homalomenoidea 
( = S. tecturata). The basis for that is not clear, as neither the shoot organisation nor that of the spadix of $S$. bulbifera resembles $S$. tecturata. Okada et al. (1999) made valuable observations on the development of the bulbils, which appear to arise from the cortex of the midrib and burst through the epidermis as they develop into epiphyllous shoots.

Other specimens examined: BORNEO: SARAWAK: G. Bakat, Tebakang area, Awa \& Paie S.45834 (SAN, SAR, US); 18 mi S of Kuching, Penrissen Rd, Sg. Retien, Bogner 1367 (M) \& 1368 (US); Matang, by intake dam, Bogner 1430 (K); Sg. Kambang, 27 mi from Kuching, Bogner 1453 (M, US); Mt Santubong, Sg. Tambak, Bogner 1520 (M); Mt Santubong, Bogner 1597 (M); 1st/9th Divn border, rd to Serian, Baan Gong Sikog waterfall, c. $2 \mathrm{~km}$ from Kg Sikog, Boyce 788 (K); G. Buri, Ulu Simunjan, Chai S.36703 (K, KEP, L, SAR, US); Bau, G. Kawa, 1st Divn, George S.38277 (K); cult. RBG Sydney Acc. No. 940529 ex Kg Sentah, nr Kuching (orig. coll. Hay et al. 9379), Herscovitch s.n. (NSW); cult. RBG Sydney Acc. No. 940565 ex Matang (orig. coll. Hay et al. 9412), Herscovitch s.n. (NSW spirit only); G. Buri, 75th mile, 1st/2nd Divn boundary, Martin \& Ismawi S. 36866 (L); Matang FR, Nicolson 1265 (B, K, L, US); Matang, Ridley s.n.(K) G. Merubong, Ulu Sg. Sluba, Padawan, 1st Divn, Yii S.51392 (US); 1st Divn, Sarawak/Kalimantan Border, G. Siruruh, Yii S. 55245 (US). KALIMANTAN: West Kalimantan, G. Bentuang area, $5-10 \mathrm{~km}$ N of Masa vill., $150 \mathrm{~km}$ NE of Pontianak, Burley et al. 2939 (E, GH, L).

\section{Schismatoglottis nicolsonii A. Hay, sp. nov.}

A Schismatoglottide mayoana inflorescentia tota breviore, interstitio neutro deficienti, staminibus et staminodiis valde minoribus differt. - TYPUS: Malaysia, Sarawak, Bako National Park, path to Telok Paku, 7 Aug 1961, D.H. Nicolson 1308 (US, holo; iso $\mathrm{K}, \mathrm{L})$.

Herb to c. $30 \mathrm{~cm}$ tall. Stem condensed, more or less creeping, c. $1.2 \mathrm{~cm}$ diam., pleionanthic. Leaves c. 7 together; petiole $18-26 \mathrm{~cm}$ long, sheathing only at the extreme base with the wings extended into a bicarinate narrowly lanceolate ligular portion to c. $10 \mathrm{~cm}$ long drying red-brown; blade broadly lanceolate to narrowly ovate, c. $15-25 \mathrm{~cm}$ long $\times 4-9 \mathrm{~cm}$ wide, dull dark green adaxially, the abaxial side drying brown, the base acute, the tip acute then acuminate for $2 \mathrm{~cm}$ and with a cylindric mucro to $2 \mathrm{~cm}$ long; midrib adaxially grooved and abaxially very prominent (dry) with 14-16 primary lateral veins on each side alternating with fine interprimaries and diverging at c. $60^{\circ}$; secondary venation fine and very dense, adaxially obscure, mostly arising from the midrib; tertiary venation obscure. Inflorescences 1 or 2 together; peduncle less than half the length of the petioles, $5-9 \mathrm{~cm}$ long, subtended by cataphylls resembling the ligular sheath extensions. Spathe reddish, $5.5-7.5 \mathrm{~cm}$ long; lower spathe $1.5-2 \mathrm{~cm}$ long, differentiated from the limb by a weak constriction; limb 4-5.5 cm long, oblonglanceolate, apiculate for $5 \mathrm{~mm}$, ?caducous. Spadix sessile, $3.5-5.5 \mathrm{~cm}$ long, subcylindric; female zone 1.5-1.7 cm long, adnate to the spathe in the lower $2 / 3$, somewhat conic in the free part, apically $2 \mathrm{~mm}$ diam. (dry); pistils crowded; ovary more or less globose, c. $0.4 \mathrm{~mm}$ diam.; stigma sessile, button-like, c. $0.25 \mathrm{~mm}$ diam.; interpistillar staminodes confined to a basal row along the spathe/spadix adnation, shortly stalked, clavate, round-topped (slightly laterally flattened), c. $0.5 \mathrm{~mm}$ wide; sterile interstice absent; male zone cylindric, basally slightly thicker than the top of the female zone, c. $3 \mathrm{~mm}$ diam.; stamens crowded, small, c. $0.3 \mathrm{~mm}$ across, truncate, dumbbell-shaped, with the connective slightly exceeded by the thecae; thecae each with two separate minute apical pores with thick rims; appendix basally isodiametric with top of the male zone, in the distal half tapering to an acute point; staminodes of appendix flat-topped, irregularly polygonal, small, c. $0.3 \mathrm{~mm}$ diam. Fruit unknown. - Fig. 13.

Distribution - Malesia: endemic to Borneo (Sarawak); known only from Bako National Park.

Habitat - Lithophytic in shade of primary lowland dipterocarp forest and by waterfalls; Bogner 1441 records the substrate as sandstone. No altitude data recorded. 


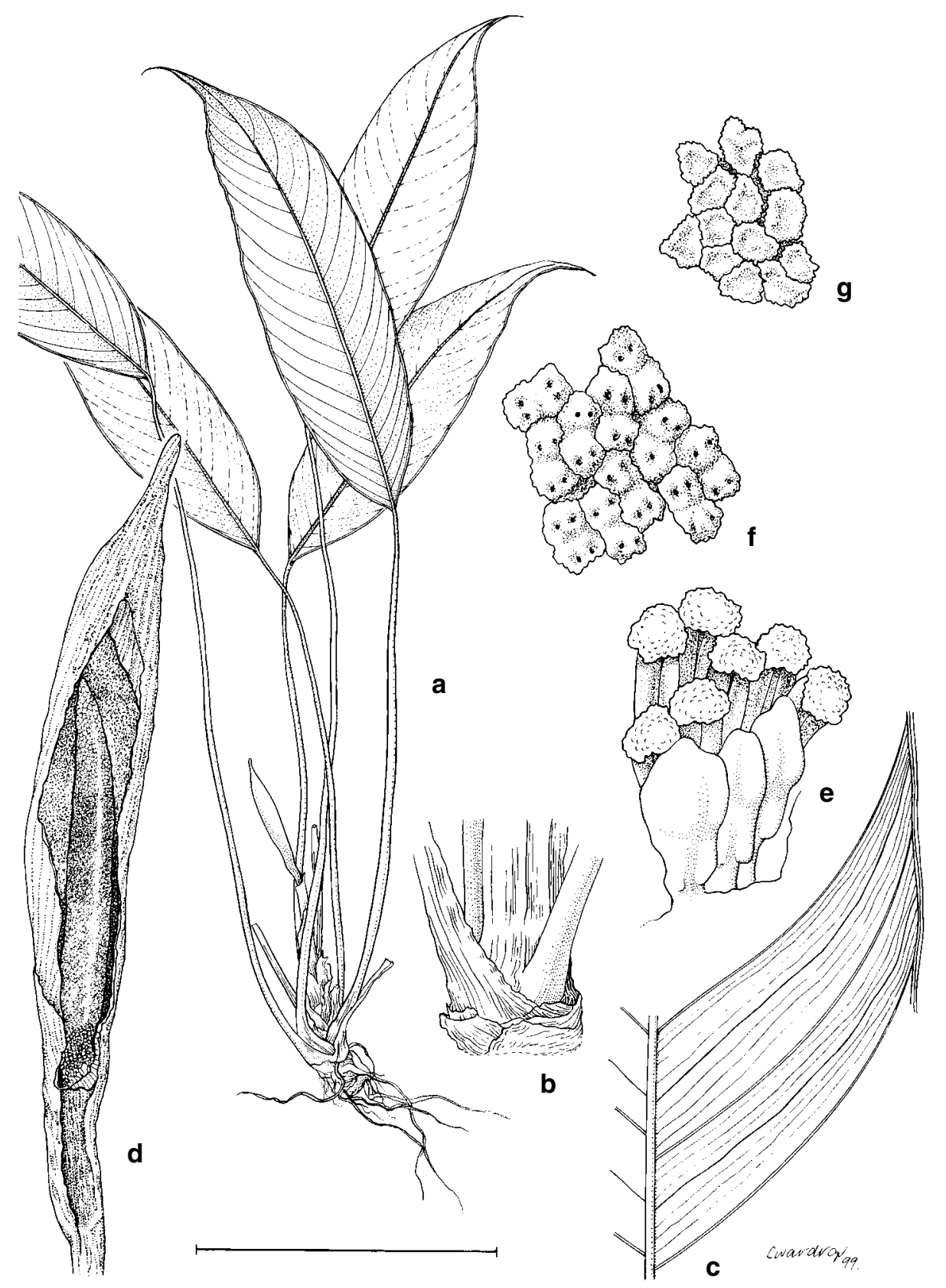

Fig. 13. Schismatoglottis nicolsonii A. Hay. a, Habit; b, Leaf bases; c, Venation; d, Inflorescence; e, Basal interpistillar staminodes and pistils; f, Stamens; g, Staminodes of appendix (Nicolson 1308). Scale bar: $\mathrm{a}=12 \mathrm{~cm} ; \mathrm{b}, \mathrm{c}=3 \mathrm{~cm} ; \mathrm{d}=2 \mathrm{~cm}$; $-\mathrm{g}=1.5 \mathrm{~mm}$. 
Notes - This species is clearly closely allied to S. mayoana. They share the ligular leaf sheath and very fine and dense secondary venation, the thecae of the stamens each with two pores, and the presence of an appendix. Both are (entirely or usually) lithophytic. Schismatoglottis nicolsonii differs in the smaller size of the inflorescence, the absence of a sterile zone between the fertile zones and the much smaller stamens and appendical staminodes.

Schismatoglottis nicolsonii is named for D.H. Nicolson (US), collector of the type and mentor of contemporary Malesian Arologists.

Other specimens examined: BORNEO: SARAWAK: Bako National Park, nr Telok Asam, Bogner 1441 (M, US); Bako National Park, Lintang path, Nicolson 1324 (US); Bako National Park, Sg. Delima, Nicolson 1334 (US); Bako National Park, Telok Tajor, Purseglove 4946 (L).

\section{Schismatoglottis platystigma M. Hotta}

Schismatoglottis platystigma M. Hotta, Mem. Coll. Sci. Univ. Kyoto, Ser. B, 32 (1966) 229, fig. 3, A-H. - Type: Brunei, Temburong Dist., eastern slope of Bukit Bangar, 19 Jan 1964, M. Hotta 13132 (KYO, holo).

Herb to c. $40 \mathrm{~cm}$ tall. Stem condensed, creeping, ?pleionanthic, c. $8 \mathrm{~mm}$ diam. Leaves few together, ?interspersed with cataphylls (unclear from dried material); petiole to c. $40 \mathrm{~cm}$ long, sheathing only at the extreme base; sheath ?ligular; leaf blade coriaceous, adaxially dark green to yellow green (fide Hotta, loc. cit.) sometimes with a central grey-green band about the midrib, abaxially pale green, oblong-elliptic to narrowly ovate, $18-33 \mathrm{~cm}$ long, 7-12 cm wide, the base (sometimes very) narrowly cordate, the tip acuminate for $2-3 \mathrm{~cm}$; posterior lobes c. $2 \mathrm{~cm}$ long, usually overlapping in the sinus, rounded; midrib not prominent on either surface, primary lateral veins 8-12 on each side of the midrib, slender, adaxially more or less obscure; secondary venation more or less obscure abaxially, adaxially somewhat prominent (dry), fine and dense, arising from the midrib. Inflorescence solitary or two together, subtended by straw-coloured papery cataphylls to $4 \mathrm{~cm}$ long; peduncle slender, c. 3-5 cm long. Spathe greenish white to pale green, the limb sometimes speckled red-brown; lower spathe narrowly ovoid, differentiated from the limb by a weak constriction $1.5-2.5 \mathrm{~cm}$ from the base. Spathe limb slender, ?not opening wide, apically beaked for c. $8 \mathrm{~mm}$, deciduous after anthesis. Spadix sessile, shorter than the spathe, c. 3-5 cm long, subcylindric throughout, c. 3-4 mm diam. (dry); female zone 0.4-1 cm long, dorsally adnate to the spathe for half to all its length; staminodes absent; ovary squat, stigma sessile, flat but slightly impressed centrally, discoid, as wide as or slightly wider than ovary, c. $0.5 \mathrm{~mm}$ diam.; male and female zones separated by a sterile zone $3-5 \mathrm{~mm}$ long of tightly packed staminodes; male zone 1.1-1.7 cm long, composed of dense, low, irregularly shaped stamens with the filament and connective widely dilated and sometimes confluent into irregularly shaped synandria c. $0.6-1 \mathrm{~mm}$ diam.; thecae more or less spherical, very prominent on the expanded connective margins; appendix apricot, 1-1.9 cm long, blunt-tipped, composed of flat-topped staminodes, these becoming more closely-packed and confluent at the appendix apex. Fruiting spathe urceolate, c. $1.7 \mathrm{~cm}$ long.

Distribution - Malesia: endemic to Borneo (Brunei, Temburong district).

Habitat - On slopes and ridges, and on dry rocks in mixed dipterocarp forest floor over Setap shales, to $210 \mathrm{~m}$ alt.

Notes - The type material differs in the somewhat larger inflorescence dimensions and in the female zone being adnate to the spathe for only half its length. Hotta (loc. cit.) also described the leaves as green to yellow-green, whereas those of other material cited here are adaxially distinctly dark green and variegated about the midrib. However, the distinctive sessile, very broad stigma and the remarkable low, dilated 
anthers with marginal spherical thecae are highly characteristic. This species bears some resemblance to $S$. tecturata in shoot organisation (though this is not completely clear from material to hand) and inflorescence shape. However, S. platystigma differs in the larger, usually cordate-based leaves, the deciduous upper spathe, the female zone partly adnate to the spathe, the absence of staminodes below the female zone, the robust sterile interstice, as well as the above-mentioned characters of the stigma and stamens. Moreover, S. platystigma is not rheophytic, evidently found in well-drained and sometimes dry sites.

At present, this species appears to have a very restricted distribution.

Other specimens examined: BORNEO: BRUNEI: Temburong Distr., Sg. Temburong at Kuala Belalong, Boyce 446 (K, L); Temburong Distr., en route Kg Biang to Bukit Biang, Hotta 13321 (KYO); Temburong Distr., Amo, below jct Temburong and Belalong Rs, Johns 6979 (K).

\section{Schismatoglottis pudenda $A$. Hay, sp. nov.}

A Schismatoglottide roseospatha inflorescentia femina et inforescentia mascula conubialiter intra spatham inferiorem contentis, appendice longa differt. - TYPUS: Malaysia, Sarawak, Simanggang, 1978, J. Bogner s.n. (K, holo).

Herb to c. $25 \mathrm{~cm}$ tall. Stem? Leaf number unknown; petiole shorter than the blade, c. $9 \mathrm{~cm}$ long, sheathing only at the extreme base [probably with long ligular portion - the apex of the attached portion broken away]; blade coriaceous, adaxially variegated about the midrib with a narrow irregular band of grey-green, narrowly lanceolate, $25 \mathrm{~cm}$ long $\times 2.5 \mathrm{~cm}$ wide, widest slightly less than half way from the base, very gradually tapering distally and proximally, the base decurrent, the tip apiculate for c. $4 \mathrm{~mm}$, the margins slightly revolute (dry); midrib abaxially and adaxially prominent, with 4 abaxially prominent, adaxially impressed primary lateral veins on each side, alternating with lesser interprimaries and diverging at c. $30^{\circ}$; secondary and tertiary venation more or less obscure. Inflorescence ?solitary; peduncle?; spathe $5.5 \mathrm{~cm}$ long; lower spathe $3.5 \mathrm{~cm}$ long, narrowly ovoid, differentiated from the limb by a distinct constriction; limb $2 \mathrm{~cm}$ long, oblong, finally acute and apiculate for $3 \mathrm{~mm}$, caducous. Spadix $5 \mathrm{~cm}$ long, sessile, slender subcylindric; female zone $1.4 \mathrm{~cm}$ long $\times 4 \mathrm{~mm}$ thick, almost completely adnate to the spathe; pistils depressed subglobose, somewhat lax, c. $1 \mathrm{~mm}$ diam. (the basal ones becoming slightly narrower); stigma sessile, discoid, papillate, c. $0.7 \mathrm{~mm}$ diam.; interpistillar staminodes scattered among the pistils and forming an incomplete row along the spathe/spadix adnation, subcylindric to narrowly clavate, more or less round-tipped, slightly taller than the pistils; male zone contiguous with the female but for an incomplete whorl of more or less sterile anthers (reduced thecae), held completely or almost completely (4/5) within the lower spathe chamber, more or less cylindric, c. $1.6 \mathrm{~cm}$ long, $2.5 \mathrm{~mm}$ diam.; stamens crowded, truncate, more or less dumbbell-shaped, with the thecal rims raised slightly above the connective, c. $1 \mathrm{~mm}$ across; appendix $2 \mathrm{~cm}$ long, cylindric, basally isodiametric with the male zone, the tip acute; staminodes of the appendix flat-topped, irregularly polygonal, c. $0.7 \mathrm{~mm}$ diam. Fruit unknown.

Distribution - Malesia: endemic to Borneo (Sarawak); known only from Simanggang.

Habitat - Not known but probably rheophytic.

Notes - This species is known only from fragmentary material, but has very distinctive coriaceous narrowly lanceolate leaves in which the secondary and finer venation is more or less obscure. The most distinctive feature however, is the male zone not segregated from the female by the spathe constriction, which it usually is in this genus (hence the specific name, meaning disgraceful). 
The attached part of the leaf sheath is extremely short and the apex in both specimens is broken. It is not possible to tell how much has broken off, but the very narrow leaves suggest that the species is rheophytic and most rheophytic Schismatoglottis have long ligular leaf sheaths.

Other specimen examined: BORNEO: SARAWAK: without locality, Bogner 1572 (M).

\section{Schismatoglottis roseospatha Bogner}

Schismatoglottis roseospatha Bogner, Aqua-planta 88 (1988) 96 (3 un-numbered plates). - Type: Malaysia, Sarawak, Gaad River, [without date] J. Knüppel \& H. Linke, s.n. (M, holo; iso $\mathrm{K}, \mathrm{KYO}$ ).

Small rheophytic herb c. $30 \mathrm{~cm}$ tall. Stem condensed, creeping, to $25 \mathrm{~cm}$ long, $0.5-1 \mathrm{~cm}$ diam., pleionanthic. Leaves several together; petiole (6-)15-24 cm long, sheathing only at the extreme base, but sheath extended into a tapering lanceolate bicarinate marcescent ligular portion to $4 \mathrm{~cm}$ long; blade narrowly elliptic, c. 9-22 cm long $\times 1.5-4.5 \mathrm{~cm}$ wide, the base cuneate with the margins uniting on the adaxial side of the petiole, the tip acuminate for c. $5 \mathrm{~cm}$ including a $6 \mathrm{~mm}$ long mucro; midrib prominent abaxially, hardly raised adaxially, with 8-10 primary lateral veins on each side alternating with lesser interprimaries and diverging at c. $45^{\circ}$; secondary venation fine and dense, arising from the midrib. Inflorescences 2-4 together subtended by lanceolate cataphylls c. $6 \mathrm{~cm}$ long and mucronate (reduced petiole) well below the apex; peduncle subequalling to somewhat exceeding the petioles. Spathe $\mathrm{c} .7 \mathrm{~cm}$ long; lower spathe green to olive, narrowly ovoid, somewhat curved at the base, $2.2 \mathrm{~cm}$ long, differentiated from the limb by a rather abrupt constriction; limb more or less ovate, opening rather inflated about the male portion of the spadix, distally conoid and mucronate for c. $1 \mathrm{~cm}$. Spadix shorter than the spathe, c. $4.5 \mathrm{~cm}$ long, stipitate for $1-2 \mathrm{~mm}$ with the stipe very obliquely inserted on the spathe; female zone narrowly conoid, $1.5-2 \mathrm{~cm}$ long, $6 \mathrm{~mm}$ diam. at base, distally $3 \mathrm{~mm}$ diam.; interpistillar staminodes confined to an oblique basal ring, stalked with the top expanded, flat, centrally impressed, c. $1 \mathrm{~mm}$ diam.; pistils crowded, the distal ones sometimes squashed by the spathe constriction; ovary ovoid, c. $0.5 \mathrm{~mm}$ diam.; stigma almost sessile, discoid, papillate, $0.4 \mathrm{~mm}$ diam.; sterile interstice broadly obconoid, basally isodiametric with apex of female zone, distally isodiametric with base of male zone, c. $4 \mathrm{~mm}$ long, c. 4 whorls of sterile stamens; male zone $2-2.5 \mathrm{~cm}$ long, subcylindric, $5 \mathrm{~mm}$ diam., extending to the apex of the spadix, blunt-tipped, white; stamens rectangulardumbbell-shaped, truncate with the connective very slightly raised above the tops of the thecae; appendix absent. Fruit unknown.

Distribution - Malesia: endemic to Borneo (Sarawak).

Habitat - Rheophytic on rocks fringing streams at low elevation.

Notes - Schismatoglottis roseospatha is most similar to the more robust and common, also rheophytic $S$. multiflora Ridl., sharing the ligular leaf sheath, more or less cylindric spadix and the absence of an appendix. It differs in the shorter inflorescence, gaping inflated spathe limb, shortly stipitate spadix, wider pistils and flat-topped interpistillar staminodes confined to a basal ring. Similar species also include $S$. schottii Bogner \& Nicolson and S. erecta M. Hotta. The former differs in the expanded ovoid male zone and much shorter peduncle, and is not rheophytic. The latter has the male zone clavate and the stem elongate; it appears also not to be rheophytic.

Burtt 12958 has the spathe limb white, while in the type it is pink, but they appear structurally almost identical.

Other specimens examined: BORNEO: SARAWAK: Sg. Lelang, Kg Klubong, Bogner 1365 (M); Kapit Distr., Sg. Bena area, Burtt 12958 (E, M); Gat, Clemens \& Clemens 5813 (NY). 
46. Schismatoglottis sarikeensis (Bogner \& M. Hotta) A. Hay \& Bogner, comb. nov.

Hottarum sarikeense Bogner \& M. Hotta, Bull. Mus. Natl. Hist. Nat., B, Adansonia 5 (1983) 27, Pl. 1-3; Mayo et al., Genera of Araceae (1997) 188, Pl. 51, F-J. - Type: Cult. Botanischer Garten München ex Malaysia, Sarawak, nr Sarikei, Sep 1978, J. Bogner 1553 (KYO, holo; iso K, M, P, US).

Rheophytic? herb to c. $20 \mathrm{~cm}$ tall. Stem condensed, $0.5-0.8 \mathrm{~cm}$ diam. Leaves several together; petiole $6-12 \mathrm{~cm}$ long, slender, adaxially canaliculate especially in distal part, sheathing only at extreme base, the wings extended into a very narrowly triangular ligular portion 4-7 cm long, green tinged red, drying brown; blade very narrowly elliptic, $10-14 \mathrm{~cm}$ long $\times 1-2.5 \mathrm{~cm}$ wide, adaxially glossy dark green, paler abaxially, the base cuneate, the apex acuminate to caudate for $1.5-3 \mathrm{~cm}$; midrib abaxially prominent, adaxially flush with the lamina to slightly impressed, with 5-6 extremely fine (barely differentiated from secondary venation) primary lateral veins on each side, diverging at c. $45^{\circ}$; secondary venation faintly prominent adaxially, fine and dense; tertiary venation obscure. Inflorescence solitary; peduncle 7-8 cm long. Spathe slightly nodding (down-curved in lower part), 5-6 cm long; lower spathe narrowly ovoid, slightly down-curved, green, 1.5-2 cm long, differentiated from the limb by a constriction; limb white, caducous, more or less lanceolate, somewhat inflated over the spadix, thence narrowed into a beaked tip. Spadix subcylindric, 3-3.5 cm long; female zone 1-1.2 cm long, adnate to the spathe, c. $3 \mathrm{~mm}$ diam.; pistils subglobose, c. $1 \mathrm{~mm}$ diam.; stigma sessile, discoid, c. $0.4 \mathrm{~mm}$ diam., papillate; interpistillar staminodes absent from among the pistils, confined to a row along the spathe/spadix adnation, stipitate, weakly clavate, slightly exceeding the pistils; sterile interstice confined to about 2 irregular whorls of sterile stamens at the base of the male zone; male zone c. $1 \mathrm{~cm}$ long, wider than the female zone, c. $0.5 \mathrm{~cm}$ diam.; stamens crowded, truncate, flat-topped, rather irregular in shape and size, ellipsoid to dumbbell-shaped from above, c. $0.5 \mathrm{~mm}$ across, partially to completely connate into groups of 2-3; appendix bullet-shaped, basally isodiametric with top of male zone, distally tapering and finally narrowly obtuse, c. $0.5 \mathrm{~cm}$ long; staminodes of appendix columnar, flattopped, faintly impressed, c. $0.5 \mathrm{~mm}$ diam., often united to the top into curved or sinuous groups. Fruiting spathe narrowly urceolate.

Distribution - Malesia: endemic to Borneo (Sarawak); known only from the locality from which the type plant was collected.

Habitat - Not recorded.

Notes - Schismatoglottis sarikeensis clearly belongs in the S. multiflora group, with its ligular leaf sheath and caducous spathe limb. Those species are generally rheophytic, though the habitat for $S$. sarikeensis was not recorded. Within this group, the rheophytic species have condensed stems - as does this species, whereas the nonrheophytic species, such as $S$. schottii, have more elongate stems.

This species was originally placed in the genus Hottarum on account of its basal placentation. It has since become evident that basal placentation is found in species of Schismatoglottideae with truncate stamens having a variety of affinities and that Hottarum, defined by this placentation and stamen type, is heterogeneous (Bogner \& Hay, 2000 - this volume).

The leaf venation is remarkable for the extreme reduction of the primary venation so that it is almost not differentiated from the secondary - indeed the primary veins are virtually impossible to recognise in the dry plant.

Other specimen examined BORNEO: SARAWAK: Cult. Bot. Gart. München ex Sarikei, Bogner 1530 (K). 


\section{Schismatoglottis schottii Bogner \& Nicolson}

Schismatoglottis schottii Bogner \& Nicolson, Aroideana 2 (1979) 120. - Piptospatha acutifolia Engl., Pflanzenr. 55 (IV.23Da) (1912) 128, fig. 76. - Schismatoglottis acutifolia (Engl.) M. Hotta, Mem. Coll. Sci. Univ. Kyoto, Ser. B, 32 (1966) 233 (non S. acutifolia Engl.). - Type: Indonesia, Kalimantan, Sungei Doho [?= Long Deho], 1896 [?1897], Nieuwenhuis 1585 (BO, holo; iso B).

Small herb to c. $25 \mathrm{~cm}$ tall. Stem slender, somewhat elongate, ?erect, pleionanthic, c. $3 \mathrm{~mm}$ diam. (dry), internodes c. $4 \mathrm{~mm}$ long. Leaves c. 4 together; petiole to $7 \mathrm{~cm}$ long, shorter than the blade, slender, sheathing only at the extreme base but with the sheath extended into a linear-lanceolate ligular portion to $6 \mathrm{~cm}$ long; blade narrowly elliptic to lanceolate, $13-16 \mathrm{~cm}$ long $\times 2-4.5 \mathrm{~cm}$ wide, the base cuneate, the tip gradually to abruptly acuminate for $1.5 \mathrm{~cm}$ including a $3-4 \mathrm{~mm}$ cylindric mucro; midrib abaxially somewhat prominent, not raised adaxially; primary lateral veins c. 8 on each side of midrib, alternating with lesser interprimary veins and diverging at c. $60^{\circ}$; secondary veins fine and dense, arising from the midrib. Inflorescence $1-2$ together, subtended by lanceolate cataphylls to $3.5 \mathrm{~cm}$ long and mucronate (reduced petiole) near base; peduncle very slender, c. $5 \mathrm{~cm}$ long apically rather sharply bent to bring the spathe and spadix subhorizontal. Spathe green, c. $3 \mathrm{~cm}$ long; lower spathe very narrowly subcylindric-obconoid, c. $1.3 \mathrm{~cm}$ long, $2.5 \mathrm{~mm}$ diam. (dry), differentiated from the limb by a weak constriction; limb inflated over spadix apex then abruptly narrowly acuminate for $1 \mathrm{~cm}$, caducous. Spadix c. $2 \mathrm{~cm}$ long, sessile; female zone 1.2-1.4 cm long, adnate to the spathe in the lower half, very narrowly obconoid, to $2 \mathrm{~mm}$ diam. (dry) at apex; pistils crowded, ovary subglobose, longitudinally somewhat 4-ribbed, c. $0.5 \mathrm{~mm}$ diam.; stigma sessile, discoid, papillate, c. $0.3 \mathrm{~mm}$ across; interpistillar staminodes more or less mushroom-shaped, confined to a single oblique basal row along each side of the spathe/spadix adnation; sterile interstice c. $1.5 \mathrm{~mm}$ long $\times 2 \mathrm{~mm}$ wide, two or three irregular whorls of sterile stamens; male zone clavate, c. $6 \mathrm{~mm}$ long $\times 4 \mathrm{~mm}$ wide; stamens crowded, rectangular-dumbbell-shaped, truncate with the connective slightly mounded between the thecae and the margins slightly raised; pores conspicuous, paired at each end of the stamen; appendix absent. Fruiting spathe more or less narrowly urceolate.

Distribution - Malesia: endemic to Borneo (Central Kalimantan).

Habitat - Terrestrial on damp steep slopes in montane forest c. $1000 \mathrm{~m}$ alt.

Notes - The ligular sheath and lack of an appendix suggest affinity to S. multiflora Ridl., S. roseospatha Bogner and S. erecta M. Hotta. Of these, S. schottii is clearly closest to $S$. erecta, sharing the non-rheophytic habit, somewhat elongate stem, inflated and abruptly acuminate spathe and clavate male zone. It differs from $S$. erecta in the smaller inflorescence, rather larger pistils and less conspicuous sterile interstice.

This species, originally described in Piptospatha as P. acutifolia Engl., was combined in Schismatoglottis as S. acutifolia (Engl.) M. Hotta (Hotta, 1966). However that binomial was already occupied by S. acutifolia Engl., and the new name S. schottii was therefore established by Bogner \& Nicolson (loc. cit.).

Other specimen examined: BORNEO: KALIMANTAN: Central Kalimantan, Bukit Raya, Upper Samba R., c. 10 km NNW of Tumbang Tosah, Mogea 3914 (L).

\section{Schismatoglottis calyptrata group}

Shoot usually hapaxanthic. Leaf sheath fully attached and persistent. Spathe limb caducous. Sometimes rheophytic.

Throughout the Old World range of the genus. 39 species in Malesia. 


\section{Schismatoglottis ahmadii $A$. Hay, sp. nov.}

A Schismatoglottide calyptrata habitu rheophytico, folii nervis numerosis prominentibus, ovariis majoribus, appendice parva differt. - TYPUS: Cult. RBG Sydney Acc. No. 960570 ex Maliau Basin, Gunung Rara FR, 2.5 km upstream from main Maliau Falls (orig coll. Hay, Ahmad et al. 12060), Aug 1998, Herscovitch s.n. (holo SAN; iso NSW).

[Schismatoglottis calyptrata auctt. non (Roxb.) Zoll. \& Moritzi: Beaman \& Beaman, Pl. Kinabalu 3 (1998) 82, p.p. quoad mult. specim. cit.]

Herb c. (10-)20-50 cm tall. Stem condensed, more or less hypogeal, hapaxanthic, $1-2 \mathrm{~cm}$ thick, clump-forming. Leaves few together; petiole (6-)12-48 cm long, glabrous, sheathing in the lower $1 / 3-3 / 5$; wings of sheath fully attached, tapering; blade rather tough, elliptic to ovato-sagittate, mid-green, sometimes variegated with a single greygreen central stripe or spattered grey-green throughout, (6-)10-29 cm long $\times 3.5-16 \mathrm{~cm}$ wide, the base obtuse to more or less truncate (usually) to somewhat cordate with posterior lobes spreading and up to $5 \mathrm{~cm}$ long, the tip acute to broadly acute and acuminate for $1.5 \mathrm{~cm}$; midrib abaxially prominent; primary lateral veins adaxially somewhat impressed, abaxially prominent usually even when dry (and then usually straw-coloured), c. 10 on each side of the midrib, alternating with lesser interprimaries and diverging at c. $45-60^{\circ}$, occasionally giving off branches similar in thickness to the interprimary veins; secondary venation adaxially obscure, arising from the midrib and frequently from the lower parts of the primary veins; tertiary venation adaxially obscure, abaxially forming a rather distinct tessellate reticulum. Inflorescences 1-8 together, subtended by short cataphylls $2-8 \mathrm{~cm}$ long, these often but not always bearing reduced but well-differentiated petiole and blade; peduncle about half the length of the petiole at anthesis but inflorescences first exposed when peduncle very short and this elongating further in fruit; spathe 4-7 cm long; lower spathe green, narrowly ovoid, 1-2 cm long, differentiated from the limb by an abrupt constriction; limb white, broadly ovate, inflated over the appendix then abruptly acuminate for 1-1.5 cm, caducous. Spadix sessile, more or less hourglass-shaped, c. 3-4 cm long; female zone c. $2 \mathrm{~cm}$ long, adnate to the spathe for about $1 / 2$ its length, c. $4 \mathrm{~mm}$ diam. in the middle, distally attenuate; pistils subglobose, somewhat lax in the lower part of the female zone, more so in the attenuate part, c. $1 \mathrm{~mm}$ diam.; stigma sessile, button-like, papillate, about $1 / 2$ the diameter of the ovary; interpistillar staminodes scattered among the pistils, about equalling to slightly taller than the pistils, stalked with spreading flat tops c. $0.6 \mathrm{~mm}$ across; sterile interstice ill-defined, a partly naked distal portion of the female zone with scattered interpistillar staminodes and some ?abortive (small stigmas) ovaries; male zone obconic (occasionally widest slightly below the tip), c. $1 \mathrm{~cm}$ long, c. $3 \mathrm{~mm}$ thick at base, $6 \mathrm{~mm}$ thick at top; stamens crowded, dumbbellshaped with the connective very slightly elevated above the thecae, c. $1 \mathrm{~mm}$ across (fresh); appendix more or less hemispherical, to 3-7 mm long; staminodes of appendix columnar, irregularly polygonal with rounded angles, more or less flat-topped to somewhat rounded, whitish, very slightly taller than the stamens, c. $0.6 \mathrm{~mm}$ diam. Fruiting spathes ellipsoidal, to $4 \mathrm{~cm}$ long on erect peduncles. - Fig. 14.

Distribution - Malesia: endemic to Borneo (western and southern Sabah, northern Sarawak).

Habitat - Facultatively rheophytic on rocks in streams and on forest floor; c. 300-1500 m alt.

Notes - This species is very similar in spadix details to $S$. calyptrata, but differs in the usually smaller size of the inflorescence, the larger more globose ovaries, the more conspicuously flat-topped interpistillar staminodes and the usually smaller appendix. The fruiting peduncle in S. calyptrata is declinate but erect in S. ahmadii. In leaf 


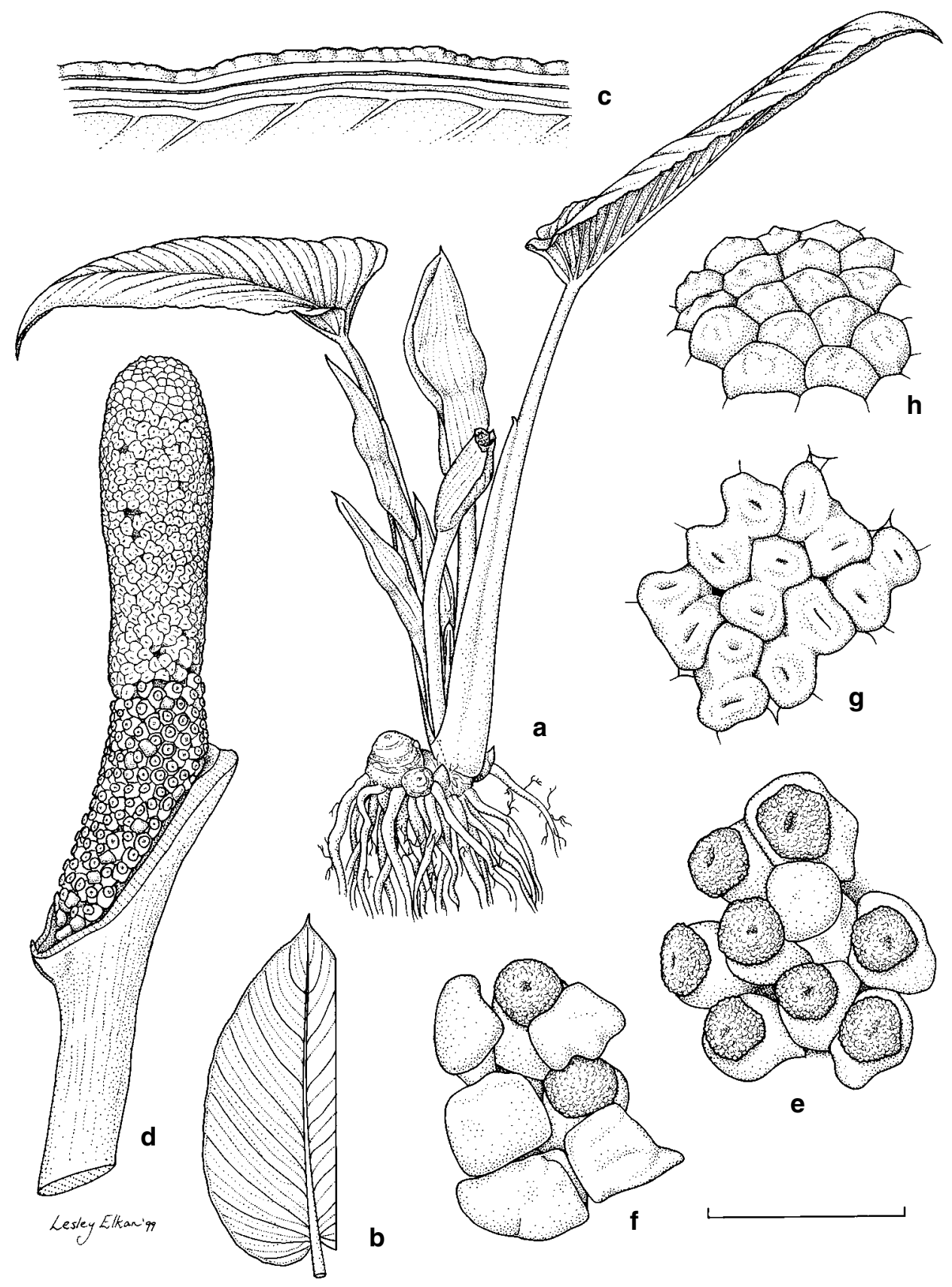

Fig. 14. Schismatoglottis ahmadii A. Hay. a, Habit; b, Leaf; c, Marginal venation; d, Inflorescence; e, Pistils and interpistillar staminode; $\mathbf{f}$, Transition between female and male zones (inverted); g, Stamens; h, Staminodes of appendix (RBG Sydney Acc. No. 960570). Scale bar: a, b $=4 \mathrm{~cm}$; $\mathrm{c}=2.5 \mathrm{~mm} ; \mathrm{d}=1 \mathrm{~cm} ; \mathrm{e}-\mathrm{h}=2 \mathrm{~mm}$. 
however, the species are readily distinguishable, $S$. ahmadii having usually a much less cordate base, and more numerous, closely spaced, tough primary veins. Schismatoglottis ahmadii is often rheophytic, but not obligately so; S. calyptrata never is and has softer leaves with fewer primary veins. Daim Andau 715 is an exceptionally small flowering specimen whose vegetative dimensions are given above in parentheses; the notes record that this species is edible.

The only records from Sarawak are unfortunately without precise locality.

This species is named for Ahmad bin Sappan (Forest Research Centre, Sepilok) who generously (and with the utmost patience and good humour) assisted A.H. in the field in Sabah in 1996.

Other specimens examined: BORNEO: SARAWAK: without locality, Bogner 1528 (K), 1549 (K) E 1561 (US). SABAH: Kota Merudu, Ulu Sg. Sungei 2, Aban SAN 94330 (K, SAN); Keningau Distr., Kitau, Amin SAN 95330 (K); Ranau Distr., Sg. Bambangan, Amin E Jarius SAN 116539 (K, KEP, SAN); Ranau, Tenompok, Amin et al. SAN 123499 (K, KEP, SAN); Ranau Distr., Poring, Amin SAN 118860 (SAN); Kinabalu, Kg Nalumad, Daim Andau 715 (KEP); Kota Belud, S of Sayap on NW side of Mt Kinabalu, Beaman et al. 9769 (US); Without locality, Burbidge s.n. (K); Mt Kinabalu, Eastern shoulder, Singh's plateau, Chew et al. RSNB 1026 (K); Mesilau R., Chew et al. RSNB 4899 (K, SAN); Ranau Distr., Mount Kinabalu, Dallas, Clemens \& Clemens 26024 (BM, G, K, L, NY) \& 26025 (BM, G, K) \& 29183 [coll. by Furtado] (BM, G, K, L, NY) \& 29184 [coll. by Furtado] (BM, BO, G, K, NY) \& 29188 [coll. by Furtado] (BM, BO, K, NY); Mt Kinabalu, Tenompok, Clemens \& Clemens 28647 (BM) \& 29185 (BM, G, L, NY); Cult. RBG Sydney Acc. No. 841545 ex Tenom, Kallang Falls (orig. coll. Wallace \& Forlonge 84/216), Herscovitch s.n. (NSW); Kinabalu NP, Liwagu trail NW of HQ, Kokawa 6192 (KYO); Kinabalu NP, along rd from HQ to Tenompok, Kokawa \& Hotta 3106 \& 3107 (both KYO); Kinabalu NP, along Sg. W Mesilau, Kokawa \& Hotta 4378 \& 4397 (both KYO); Kinabalu NP, along Sg. E \& W Mesilau [sic], Kokawa \& Hotta 4444 (KYO); Kinabalu NP, between Mesilau camp and Kundassan, Kokawa \& Hotta 4508 (KYO); Kinabalu NP, Sosopodon \& Sg. Liwagu, Kokawa \& Hotta 4629 \& 4644 (both KYO); Kinabalu NP, en route Poring Hot Springs to Langanan waterfall, Kokawa \& Hotta 4750, 4751, 4752 \& 4920 (all KYO); Kinabalu NP, along Sg. Mamut, nr Poring, Kokawa \& Hotta 4871, 4874 \& 4886 (all KYO); Tambunan Distr., Rafflesia FR, km 68 Tambunan Rd, Madana \& Ismail SAN 111204 (SAN); Ranau Distr., OMRD area, Matin SAN 122298 (E, K); Ranau Distr., between Sg. Kipungit \& Sg. Langanan, Meijer SAN 119148 (SAN); Ranau Distr., Sg. Kepungit, Kinabalu National Park, Meijer SAN 134592 (SAN); Ranau Distr., about 1/2 mi E of Kg Takulan, Shea \& Aban SAN 77210 (SAN); Beaufort Distr., Bukit Bendira, Sundaling SAN 80169 (L, SAN)

\section{Schismatoglottis bifasciata Engl.}

Schismatoglottis bifasciata Engl. Pflanzenr. 55 (IV.23Da) (1912) 107, fig. 66; Alderw. Bull. Jard. Bot. Buitenzorg III, 4 (1922) 224 \& 345. - Type: Cult. Hort. Bogor. XI.B.X.114 ex Borneo, Feb 1906, A. Engler 4042 (B, holo).

Herb to c. $40 \mathrm{~cm}$ tall. Stem (not observed) ?hypogeal, hapaxanthic, condensed; petiole c. $30 \mathrm{~cm}$ long, sheathing in the lower $1 / 3$; wings of sheath fully attached, persistent distally tapering; blade broadly triangular-ovato-sagittate, c. $25-30 \mathrm{~cm}$ long $\times 13-18 \mathrm{~cm}$ wide, the base divided into two rounded-triangular posterior lobes c. $8 \mathrm{~cm}$ long, the apex broadly acute and shortly and abruptly acuminate for c. $1 \mathrm{~cm}$; midrib abaxially somewhat prominent, with c. 6 primary lateral veins on each side, irregularly alternating with lesser interprimary veins, diverging at c. $50-60^{\circ}$ and frequently branched with 1-3 subsidiary veins; secondary venation arising from the primary veins and midrib; tertiary venation obscure. Inflorescences ?grouped; peduncle at least $10 \mathrm{~cm}$ long. Spathe 6.5-9 cm long; lower spathe ovoid, 2.5-c. $4 \mathrm{~cm}$ long, differentiated from the limb by an abrupt constriction; limb more or less ovate, 4-5 cm long, caducous. Spadix 5.5-8.5 cm long, subcylindric (very slightly hourglass-shaped); female zone $1.5-3 \mathrm{~cm}$ long, adnate to the spathe in the lower $1 / 3$, somewhat conoid with the apex c. $4 \mathrm{~mm}$ diam.; pistils crowded, shortly cylindric, sometimes becoming lax in the distal part of the zone and then somewhat ovoid, c. $0.7 \mathrm{~mm}$ diam.; stigma sessile, 
broad - about as wide as the ovary and laterally more or less contiguous, papillate; interpistillar staminodes scattered among the pistils, stipitate, clavate with more or less rounded heads, about 1.5 times the height of the pistils, somewhat concentrated at junction with male zone; sterile interstice absent or ill-defined (then consisting of lax distal pistils and interpistillar staminodes); male zone exserted from lower spathe, short, weakly obconoid, c. $1 \mathrm{~cm}$ long $\times 5-6 \mathrm{~mm}$ diam. at the top; stamens crowded, truncate, dumbbell-shaped with conspicuous round pores slightly elevated above the connective, c. $0.5 \mathrm{~mm}$ across; appendix bluntly cylindric, about half the length of the whole spadix, basally slightly broader than the top of the male zone, c. $7 \mathrm{~mm}$ diam.; staminodes of appendix flat-topped, irregularly polygonal with rounded angles, c. $0.6 \mathrm{~mm}$ diam. Fruit unknown.

Distribution - Malesia: endemic to Borneo (Kalimantan).

Habitat - Unknown.

Notes - Schismatoglottis bifasciata resembles S. trivittata, differing principally in the relatively much longer appendix and more slender inflorescence. In those respects it approaches $S$. trifasciata and S. motleyana, differing in having the male zone completely exserted from the lower spathe. As noted elsewhere, members of this group of variable species are difficult to differentiate at the extremes of their variation and S. bifasciata, known only from two cultivated collections, is a linking element.

The type is fragmentary and consists of a leaf and three (only one complete) inflorescences. No provenance data (beyond 'Borneo') are available for the type of $S$. bifasciata, and the specimen is not exactly matched by any other wild-collected material.

A second plant was cultivated at Bogor - XI.B.X.61, originally collected by Nieuwenhuis (no. 1311). It was apparently not seen by Engler, but Alderwerelt (loc. cit.) studied it, and preserved material (Alderwerelt 370 (BOKR + BO spirit)).

\section{Schismatoglottis bogneri A. Hay, sp. nov.}

$\mathrm{Ab}$ aliis speciebus Schismatoglottidis Philippinarum antheris connectivo producto differt. - TYPUS: Philippines, Luzon, Ifugao Prov., nr Banaue, 22 Jun 1983, J. Bogner 1629 (M, holo; iso K).

Robust to moderately robust herb. Stem ?hypogeal, ?hapaxanthic. Petiole $15-60 \mathrm{~cm}$ long, sheathing in the lower $1 / 3-3 / 5$; wings of sheath fully attached, persistent, tapering; blade lanceolate to cordato-sagittate, $16-32 \mathrm{~cm}$ long $\times 4.5-21 \mathrm{~cm}$ wide, the apex acuminate to obtuse and then apiculate, the base narrowly obtuse to truncate to cordate, with the posterior lobes, if present, to $8 \mathrm{~cm}$ long; midrib with c. 9-16 closely spaced abaxially prominent primary lateral veins on each side, irregularly alternating with lesser interprimaries and sometimes emitting subsidiary veins, diverging at c. $30-60^{\circ}$; secondary venation arising from the midrib and primary venation; tertiary venation inconspicuous. Inflorescences several together; peduncle 5-7 cm long, at anthesis more or less concealed within the cataphylls. Spathe 6-7 cm long, slender; lower spathe c. $2 \mathrm{~cm}$ long, narrowly cylindric; limb 4-5 cm long, lanceolate and somewhat inflated, caducous, acuminate-tipped. Spadix sessile, $3.5-5.5 \mathrm{~cm}$ long; female zone subcylindric-spindle-shaped, adnate to spathe in lower $1 / 3$; pistils subglobose, crowded, c. $0.5 \mathrm{~mm}$ diam.; style c. $0.25 \mathrm{~mm}$ long; stigma punctate; interpistillar staminodes few, scattered among the pistils, squat, more or less equalling the height of the pistils, flat-topped, more or less as wide as the ovary; sterile interstice ill-defined, a few irregular whorls of close-packed sterile stamens (not interpistillar staminodes), narrowed for c. $2 \mathrm{~mm}$, then broadening and becoming fertile; male zone cylindric, 1.8-2.2 cm long, c. $5 \mathrm{~mm}$ diam.; stamens crowded, dumbbell-shaped, with the connective extended, tongue-like, c. $1 \mathrm{~mm}$ long, erect or pressed into pore of 
adjacent theca; appendix short, 4-5 mm long, conic; appendical staminodes flattopped, irregularly polygonal, c. $0.6 \mathrm{~mm}$ across. Fruiting spathe narrowly urceolate, c. $4 \mathrm{~cm}$ long.

Distribution - Malesia: endemic to the Philippines (from a few scattered localities on Luzon and Mindoro).

Habitat - Mostly not noted, presumably in forest; Bogner 1629 from 1500 m alt. Santos 5278 from roadside at edge of primary forest.

Notes - There is an extremely broad range in leaf shape, and it is apparent from Bogner's collections that a high level of variability may be found in the same population or populations in close proximity to one another. Loher 7034 has incomplete inflorescences bearing only the female zone of the spadix. This specimen has rather numerous flat-topped interpistillar staminodes, of the type found in S. bogneri. The leaves agree well with this species. The specimen clearly has a new leaf emerging from the apex of the shoot following flowering, indicating that the shoot is pleionanthic. Santos 5278, from Mindoro, differs in having the appendix somewhat enlarged, the interpistillar staminodes numerous and, in addition to being scattered among the pistils, crowded in the lower half of the interstice which is composed in its upper half of sterile stamens. This latter specimen possibly represents a narrowly distinct species.

This species is named for Josef Bogner (Munich Botanic Garden) whose extensive collections of Schismatoglottis and other Araceae in Malesia have included many rare and newly discovered species.

Other specimens examined: Luzon, Ifugao Prov., Banaue, Bogner 1630 (M); Luzon, Rizal Prov., Makiling, Loher 7034 (K); Luzon, Nueva Vizcaya, Dupax, McGregor BS 11248 (K, US); Oriental Mindoro, Puerto Galera, nr Visayan Fall, Santos 5278 (US).

\section{Schismatoglottis calyptrata (Roxb.) Zoll. \& Moritzi}

Schismatoglottis calyptrata (Roxb.) Zoll. \& Moritzi in Moritzi, Syst. Verz. (1846) 83; Schott, Prodr. Syst. Aroid. (1860) 321; Engl. in DC., Monogr. Phan. 2 (1879) 352; Náves, Noviss. App. (1882) 291; Schumann \& Lauterb., Fl. Deutsch. Schutzgeb. Südsee (1901) 213; Usteri, Beitr. Kentnn. Philip. Veg. (1905) 130; Ridl., Materials Fl. Mal. Pen. (1907) 31 \& J. Straits Branch Roy. Asiat. Soc. 57 (1910) 112 \& Fl. Mal. Pen. 5 (1925) 111; Engl. \& K. Krause, Nova Guinea 8 (1910) 251 \& in Engl., Pflanzenr. 55 (IV.23Da) (1912) 114; Koord., Exkurs.-Fl. Java 1 (1911) 260; Merr., Interpr. Herb. Amboin. (1917) 129 \& Enum. Philipp. Fl. Pl. (1922) 181; Alderw., Bull. Jard. Bot. Buitenzorg III, 4 (1922) 212 \& 343; Koord., Fl. Tjibodas 6 (1922) 35 \& Exkurs.-Fl. Java 4 (1923) 192 fig. 390; Ochse, Veg. Dutch E. Ind. (1931) 60; Henderson, Mal. Wildfl. Monoc. (1954) 231, fig. 137A; Bakh.f., in Backer, Bekn. fl. Java 17 (1957) 33; Bakh.f., \& Koster, Blumea 12 (1963) 67; Backer \& Bakh.f., Fl. Java 3 (1968) 116; Chin, Gard Bull. Sing. 35 (1982) 182; Peekel, Fl. Bismarck Archip. (1984) 70, fig. 116; Borrell, Checklist Fl. Kairiru Isl. (1989) 157, un-numbered fig.; Hay, Aroids of Papua New Guinea (1990) Pl. 16a, b \& Sandakania 7 (1996) 11. - Calla calyptrata Roxb., Fl. Ind. 3 (1832) 514. - Homalomena calyptrata (Roxb.) Kunth, Enum. Pl. 3 (1841) 57. - [Colocasia? humilis Hassk., Flora 25 (2), Beibl. 1 (Jul 1842) 10; Tijdschr. Ned. Ind. 4 (2) (1842) 237, nom. superfl. pro Schismatoglottis calyptrata (based on Arisarum esculentum Rumph., Herb. Amboin. 5 (1747) t. 111, fig. 1) ]. — [Colocasia? humilis var. major Hassk., Tijdschr. Nat. Gesch. \& Physiol. 9 (Aug/Sep 1842) 160; Hassk., Cat. Hort. Bot. Bog. (1844) 56, nom. superfl. pro var. typ.]. - Zantedeschia calyptrata (Roxb.) C. Koch, Ind. Sem. Hort. Berol. App. (1854) 9. - [Schismatoglottis calyptrata var. concolor Hallier f., Bull. Herb. Boiss. (1898) 620; Ridl., Materials Fl. Mal. Pen. 3 (1907) 31; Engl., Pflanzenr. 55 (IV.23Da) (1912) 115; Ridl., Fl. Mal. Pen. 5 (1925) 111, nom. superfl. pro var. typ.]. - Type: Arisarum esculentum Rumph., Herb. Amboin. 5 (1747) t. 111, fig. 1. (lecto; selected by Hay, 1996). - Epitype: Indonesia, Maluku, Ambon, Zippelius s.n., (L; designated here). 
Colocasia? humilis var. minor Hassk., Flora 25 (2), Beibl. 1 (1842) 10; Tijdschr. Nat. Gesch. \& Physiol. 9 (Aug/Sep 1842) 160. - Neotype: Indonesia, Java, West Java, Preanger, Tjampaka, Panjairan, 22 Jun 1923, J.J. Smith 930 (L; designated here).

Colocasia? humilis var. picta Hassk., Cat. Hort. Bot. Bog. (1844) 56 [nom. nud.]. - Schismatoglottis picta [Hassk. ex] Schott, Oesterr. Bot. Zeit. 8 (1858) 317; Schott, Prod. syst. Aroid. (1860) 320; Teijsm. \& Binn., Natuur. Tijdschr. Ned. Ind. 27 (1864) 25; Engl., in A. \& C. DC., Monogr. phan. 2 (1879) 350; Engler, Bot. Jahrb. Syst. 25 (1898) 19; Koord., Exkurs.-Fl. Java 1 (1911) 260; Engl, in Engl \& K. Krause, Pflanzenr. 55 (IV.23Da) (1912) 114; Alderw, Bull. Jard. Bot. III, 4 (1922) 224. - Schismatoglottis calyptrata var. picta (Schott) Hallier f., Ann. Jard. Bot. Buitenzorg 14 (1897) 269; Ridl., Materials. Fl. Mal. Pen. (1907) 31 \& Fl. Mal. Pen. 5 (1925) 111. - Type: Indonesia, West Java, Hasskarl s.n. (L, holo [barcode L 0235802]). — Epitype: Schott Ic. no. 3077-3078 (W; designated here (fiche 46: $c 1-c 2$ in the microfiche edition)).

Schismatoglottis longipes Miq., Bot. Zeit. 14 (1856) 565; Miq., Fl. Ind. Bat. 3 (1856) 214; Schott, Prod. syst. Aroid. (1860) 321; Hook. f., Fl. Brit. India 6 (1893) 538. - Type: Indonesia, Java, Zollinger 813. (L, holo; iso K, G, P).

Schismatoglottis riparia Schott, Ann. Mus. Bot. Lugduno-batavum 1 (1864) 281. — Type: Indonesia, Java, Zippelius s.n. (L, holo [barcode L 0041972]).

Colocasia neoguineensis ('neo-guineensis') Linden ex André, Ill. Hort. 27 (1880) 68 \& Ill. Hort. 28 (1881) 60, fig. c. - Schismatoglottis neoguineensis (André) N.E. Brown, Gard. Chron 24 (1885) 776; Schumann \& Lauterb., Fl. Deutsch. Schutzgeb. Südsee (1901) 213 'novo-guineensis'; Engl., Araceae Exsiccat. \& Illustratae No. 256 \& Pflanzenr. 55 (IV.23Da) (1912) 113 ('novo(neo)-guineensis'). - Schismatoglottis calyptrata var. flavidomaculata Hallier f., Ann. Bot. Gard. Buitenzorg 14 (1897) 260. — Schismatoglottis calyptrata var. maculata f. flavidomaculata (Hallier f.) Hallier f., Bull. Herb. Boiss. 6 (1898) 621. - Type: Ill. Hort. 27 (1880) t. 380 (lecto; selected here). — Epitype: Cult. RBG Kew ex Hort. Linden, Dec 1885, N.E. Brown s.n. (K; designated here).

[Schismatoglottis ovata sensu auctt. non Schott: Engl. in Schumann \& Hollrung, Fl. Kaiser Wilhelms Land (1889) 20; Schumann \& Lauterb., Fl. Deutsch. Schutzgeb. Südsee (1901) 213].

Schismatoglottis calyptrata var. albidomaculata Hallier f., Ann. Bot. Gard. Buitenzorg 14 (1897) 260, [nom. nud.]. - Schismatoglottis calyptrata var. maculata Hallier f., Bull. Herb. Boiss. 6 (1898) 621. - [Schismatoglottis calyptrata var. maculata f. albidomaculata Hallier f., Bull. Herb. Boiss. 6 (1898) 621, nom. superfl. pro f. typ.]. - [Schismatoglottis calyptrata var. albidomaculata Hallier f. ex Ridl., Materials Fl. Mal. Pen. 3 (1907) 31, nom. superfl. pro Schismatoglottis calyptrata var. maculata Hallier f.]. - Type: Cult. Hort. Bogor, of unknown origin, ? H. Hallier, (BO?, not found).

Schismatoglottis calyptrata f. grandifolia Engl., Bot. Jahrb. Syst. 25 (1898) 18; Schismatoglottis calyptrata var. concolor f. grandifolia Engl., Pflanzenr, 55 (IV.23Da) (1912) 116. - Type: Indonesia, Sulawesi, Minahassa Prov., Pahoe-oere, May 1895, S.H. Koorders $16141 \beta$ (B十, holo; iso BO - n.v., L).

Schismatoglottis calyptrata var. dahlii Engl., Bot. Jahrb. Syst. 25 (1898) 19; Engl., Notizbl. Bot. Gart. Berl.-Dahlem 2 (1898) 99; Schumann \& Lauterb., Fl. Deutsch. Schutzgeb. Südsee (1901) 213. — Schismatoglottis calyptrata var. concolor f. dahlii Engl., Pflanzenr, 55 (IV.23Da) (1912) 116. - Type: New Ireland, Ralum, Lowon, Feb 1897, F.O. Dahl, (B十, holo).

Schismatoglottis calyptrata var. concolor f. glaucescens Hallier f., Bull. Herb. Boiss. (1898) 620; Engl., Pflanzenr. 55 (IV.23Da) (1912) 116. - Type: Cult. Hort. Bogor ex Sumatera, Deli (orig. coll. Jaheri), ? H. Hallier (BO?, not found). 
Schismatoglottis calyptrata var. concolor f. olivacea Hallier f., Bull. Herb. Boiss. (1898) 620; Engl., Pflanzenr. 55 (IV.23Da) (1912) 116. - Type: Cult. Hort. Bogor ex Sumatera, Deli (orig. coll. Jaheri), ? H. Hallier (BO?, not found).

[Schismatoglottis calyptrata var. bivittata Hallier f., Bull. Herb. Boiss. 6 (1898) 621, nom. nud.]

Schismatoglottis calyptrata var. celebica Koord., Fl. Celebes (1898) 303. - Type: Indonesia, Sulawesi, S.H. Koorders $17158 \beta$ (BO, holo).

? (see Notes) Schismatoglottis bitaeniata Engl., Bot. Jahrb. Syst. 37 (1905) 124 \& Pflanzenr. 55 (IV.23Da) (1912) 95, fig. 60. - Type: Indonesia, North Sulawesi, Tomohon, G. Lokon, 16 May 1894, K.F. E P.B. Sarasin 233 (B, holo).

Schismatoglottis cordifolia Ridl., J. Straits Branch Roy. Asiat. Soc. 57 (1911) 112. - Type: Malaysia, Perak, Temangoh Woods, H.N. Ridley s.n. (SING, holo).

? (see notes) Schismatoglottis emarginata Engl., Pflanzenr. 55 (IV.23Da) (1912) 93, fig.59; Alderw., Bull. Jard. Bot. Buitenzorg III, 4 (1922) 222. - Type: Pflanzenr. 55 (IV.23Da) (1912) fig. 59 (lecto; selected by Alderwerelt, 1922 — see below). Epitype: Cult. Hort. Bogor., XI.B.X.15 of unknown origin, C.R.W.K. van Alderwerelt van Rosenburgh 297 (BOKR + BO spirit).

Schismatoglottis djamuensis Engl., Bot. Jahrb. Syst. 49 (1912) 99 \& Pflanzenr. 55 (IV.23Da) (1912) 93. - Type: Papua New Guinea, Djamu, April 1908, R. Schlechter 17568 (B, holo).

Schismatoglottis hellwigiana Engl., Nova Guinea 8 (1912) 806 \& Pflanzenr. 55 (IV.23Da) (1912) 102. - Type: Papua New Guinea, 'Kaiser-Wilhelmsland' [Morobe Province, Huon Peninsula, Sattelberg], 14 Jan 1889, F. Hellwig 251 (B, holo; iso BO).

Schismatoglottis tenuifolia Engl., Nova Guinea 8 (1912) 807 \& Pflanzenr. 55 (IV.23Da) (1912) 113; Alderw., Bull. Jard. Bot. Buitenzorg III, 4 (1922) 208. — Type: Indonesia, West New Guinea, Noord River, Sep 1909, L.S.A.M. von Römer 326 (U, holo — n.v.; iso BO).

Schismatoglottis nieuwenhuisii Engl., Bot. Jahrb. Syst. 48 (1912) 95 \& Pflanzenr. 55 (IV.23Da) (1912) 112, fig. 69; Alderw., Bull. Jard. Bot. Buitenzorg III, 4 (1922) 215. - Type: Indonesia, SE Kalimantan, Hayup, May 1908, H. Winkler 2129 ( B†, lecto; isolecto $\mathrm{BM}, \mathrm{BO}, \mathrm{L}, \mathrm{P}$; selected here).

Schismatoglottis acutangula Engl., Pflanzenr. 55 (IV.23Da) (1912) 110; Alderw., Bull. Jard. Bot. Buitenzorg III, 4 (1922) 219. — Type: Cult. Hort. Bogor. ex West New Guinea, Feb 1906, A. Engler ?s.n. (B十, holo). - Neotype: Cult. Hort Dahlem, Oct 1911, Anon., s.n. (B; designated here).

Schismatoglottis picta f. bivittata Engl., Pflanzenr. 55 (IV.23Da) (1912) 114. - Type: Indonesia, Sulawesi, Minahassa, Pahoe oere, S.H. Koorders $16142 \beta$ (BO, holo - n.v.) Schismatoglottis picta f. robusta Engl., Pflanzenr. 55 (IV.23Da) (1912) 114; Alderw., Bull. Jard. Bot. Buitenzorg III, 4 (1922) 224. - Type: Cult. Hort. Bogor. ex Java, Krumbung, Feb 1906, A. Engler ?s.n. (Bt, holo). - Neotype: Cult. Hort. Bogor XI.B.X.60, C.R.W.K. van Alderwerelt van Rosenburgh 287 (BOKR + BO spirit; designated here).

Schismatoglottis calyptrata var. concolor f. minor Engl., Pflanzenr, 55 (IV.23Da) (1912) 116. - Type: Singapore, Bukit Timah, Dec 1905, A. Engler, (B十, holo).

Schismatoglottis calyptrata var. ornata Ridl. ex Engl. \& K. Krause, Pflanzenr. 55 (IV.23Da) (1912) 116; Ridl., Fl. Mal. Pen. 5 (1925) 111. — Type: Malaysia, Selangor, Pahang Track, H.N. Ridley s.n. (CAL, holo - n.v.; iso SING).

Schismatoglottis calyptrata f. minor Engl. in Engl. \& K. Krause, Pflanzenr. 55 (IV.23Da) (1912) 116. - Type: Singapore, Bukit Timah, Engler s.n. (B十, holo). 
Schismatoglottis klossii Ridl., Trans. Linn. Soc. Bot. 9 (1916) 239. — Type: Indonesia, West New Guinea, Mt Carstenz, Camps III to IV, Feb 1913, C. Boden Kloss s.n. (BM, holo).

Schismatoglottis dorensis Gibbs, Phytog. Fl. Arfak Mts (1917) 201. - Type: Indonesia, West New Guinea, Manokwari, Jan 1914, L.S. Gibbs 6167 (K, holo; iso BM).

Schismatoglottis ruttenii Alderw., Bull. Jard. Bot. Buitenzorg III, 4 (1922) 211. — Type: Cult. Hort. Bogor XI.B.X.69 ex Maluku, Ceram (orig. coll. Rutten), C.R.W.K. van Alderwerelt van Rosenburgh 300 (BOKR + BO spirit, lecto; selected here).

Schismatoglottis calyptrata f. multimargarita Alderw., Bull. Jard. Bot. Buitenzorg III, 4 (1922) 212. - Type: Indonesia, Sumatera, Deli, Sibolangit, 26 Nov 1917, J.A. Lörzing 5441 (BO + BO spirit, holo; iso K, L)

Schismatoglottis pseudocalyptrata Alderw., Bull. Jard. Bot. Buitenzorg. III, 4 (1922) 212. - Type: Cult. Hort. Bogor. XI.B.X.19 ex Borneo (orig. coll. Nieuwenhuis 266), C.R.W.K. van Alderwerelt van Rosenburgh s.n. (BOKR + BO spirit, holo)

Schismatoglottis calyptratoides Alderw., Bull. Jard. Bot. Buitenzorg III, 4 (1922) 213. - Type: Cult. Hort. Bogor. XI.B.X.165 (origin unknown), C.R.W.K. van Alderwerelt van Rosenburgh 337 (BOKR + BO spirit, holo).

Schismatoglottis maculata Alderw., Bull. Jard. Bot. Buitenzorg III, 4 (1922) 218. - Type: Indonesia, SE Kalimantan, Hayup, May 1908, H. Winkler 2129 (BO, holo; iso Bt, BM, L, P).

Schismatoglottis acutangula f. staminodiifera Alderw., Bull. Jard. Bot. Buitenzorg III, 4 (1922) 220. - Type: Cult. Hort. Bogor XI.B.X.146 ex West New Guinea, Mt Alkmaar (orig. coll. Djibdja), C.R.W.K. van Alderwerelt van Rosenburgh 322 (BO + BO spirit, lecto; selected here; photo LAE).

? (see notes) Schismatoglottis vanvuurenii Alderw. ('Vanvuureni'), Bull Jard. Bot. Buitenzorg III, 4 (1922) 221. - Type: Cult. Hort. Bogor [bed and plant number not indicated] ex Sulawesi, Mt Taloang (orig. coll. L. van Vuuren s.n.), C.R.W.K. van Alderwerelt van Rosenburgh s.n. (BO + BO spirit, holo).

? (see notes) Schismatoglottis sublaxiflora Alderw. Bull. Jard. Bot. Buitenzorg III, 4 (1922) 222. - Type: Cult. Hort. Bogor XI.B.X.67 ex Sulawesi, Mt. Siseh (orig. coll. L. van Vuuren s.n.), C.R.W.K. van Alderwerelt van Rosenburgh 316 (BOKR + BO spirit, holo).

Schismatoglottis parvifolia Alderw., Bull. Jard. Bot. Buitenzorg III, 4 (1922) 342. — Type: Cult. Hort. Bogor XI.B.X.125 ex New Guinea, Mt Alkmaar (orig. coll. Djibdja), C.R.W.K. van Alderwerelt van Rosenburgh 367 (BOKR + BO spirit, holo).

Schismatoglottis potamophila Alderw., Bull. Jard. Bot. Buitenzorg III, 4 (1922) 343. - Type: Indonesia, West New Guinea, by Prauwenbivac, 24 Aug 1920, H.J. Lam 886 (BO + BO spirit, holo; photo LAE).

Schismatoglottis angustifolia Alderw., Bull. Jard. Bot. Buitenzorg III, 4 (1922) 344. - Type: Indonesia, West New Guinea, by Pionierbivac, 28 Jul 1920, H.J. Lam 710 (BO, holo).

Schismatoglottis muluensis M. Hotta, Mem. Coll. Sci. Univ. Kyoto, Ser. B, 32 (1966) 235, fig. 6, A-F. - Type: Malaysia, Sarawak, Mardi, western ridge of Gunung Mulu, 17 Mar 1964, M. Hotta 14623 (KYO, holo).

Stoloniferous herb forming colonies, or clump-forming, $15-60 \mathrm{~cm}$ tall. Stems hypogeal, hapaxanthic, 1-2 cm diam. Petiole smooth, c. 5-50 cm long (often less), sheathing for c. $1 / 3$ its length; wings of sheath fully attached, persistent, tapering or, especially in diminutive forms, shortly and bluntly ligular at the apex; blade usually dull midgreen, sometimes variegated with 1-2 bands or irregularly spotted grey-green to yellowish green, c. 7-35 cm long, widest at the base or c. $1 / 3$ along its length, c. $4-18 \mathrm{~cm}$ wide, mostly cordate to sagittate, sometimes oblong-lanceolate with the base cordate 
to (rarely) emarginate with posterior lobes rounded to rather sharply triangular and c. (0-)1-10 cm long; midrib somewhat abaxially prominent, with primary lateral veins 6-15 per side, irregularly alternating with lesser interprimaries, diverging at $45-70^{\circ}$, nearly always raised adaxially towards the midrib, marginally impressed, entirely raised abaxially, mostly not branched but occasionally with 1 or 2 branches especially in the lower part of the blade; secondary venation arising mostly from the midrib, sometimes from the bases of the primary veins; tertiary venation inconspicuous. Inflorescences 1-8 together, with a strong esteric odour at female anthesis; exposed part of peduncle 2-14 cm, erect at anthesis, then deflected. Spathe 3.5- c. $12 \mathrm{~cm}$ long; lower spathe narrowly ovoid, c. half the length of the whole spathe, green, often minutely longitudinally ridged and asperous; limb differentiated from lower spathe by an abrupt constriction corresponding to the base of the male zone of the spadix, at female anthesis much inflated, narrowing and turbinate, the apex conspicuously mucronate, completely surrounding the spadix and gaping ventrally or with the margins loosely overlapping, creamy to pale greenish-yellow, caducous immediately after female anthesis. Spadix c. 3/4 the length of the spathe, narrowly hourglass-shaped; female zone about half the length of the whole spadix, sessile, somewhat to markedly obliquely inserted to partially adnate to spathe, c. 5-8 mm diam. below, distally tapering to c. 3-4 mm diam.; pistils pale green, close-packed, c. $1 \mathrm{~mm}$ tall, c. $0.5 \mathrm{~mm}$ diam., flask-shaped and close-packed below, distally becoming more widely spaced and subglobose, finally rather widely scattered and squashed by the constricting spathe; stigmas button-like, papillate, raised on a short style; interpistillar staminodes white, mostly conspicuously taller than pistils, few in number, scattered, stalked, clavate, rarely absent in very small forms; sterile zone between male and female zones absent save sometimes for a relative concentration of interpistillar staminodes amongst the distal pistils; male zone narrowly obconic, approximately half the length of the female zone, distally c. $0.5-1 \mathrm{~cm}$ diam., ivory; anthers dumbbell-shaped from above, c. $0.5 \times 1 \mathrm{~mm}$, with thecae apically impressed, the connective shorter than to very slightly elevated above the thecae; appendix bullet-shaped to hemispherical, basally nearly always somewhat wider than apex of male zone, creamy yellow; staminodes of appendix columnar, irregularly polygonal, flat- to slightly round-topped, c. $0.5 \mathrm{~mm}$ diam. Fruiting spathe declinate, urceolate.

Distribution - Tropical southwestern China to Indo-China east to Vanuatu; Malesia: throughout except for extremely seasonal areas.

Habitat - In lowland and lower montane rainforest (occasionally reaching upper montane forest) and forest margin in both wet and well-drained sites, from sea level to c. $1700 \mathrm{~m}$ alt.

Notes - This species is distinguished from others in this group by its hapaxanthic, hypogeal stems and stoloniferous, often colony-forming terrestrial habit, the clustered inflorescences on rather short peduncles which elongate and become declinate in fruit, the strongly hourglass-shaped spadix with a poorly defined interstice positioned level with the top of the lower spathe chamber, the scattered (sometimes very few, occasionally absent) interpistillar staminodes about equalling to more usually somewhat exceeding the pistils, the dome-shaped appendix slightly and abruptly wider than the top of the male zone. Typically, local 'populations' are strikingly uniform, and frequently seem rather sharply differentiated from adjacent ones. This may well be a result of the colonial habit of this species enabling the formation of very extensive, long-lived clonal 'superindividuals'.

Overall, this species is extremely variable in leaf shape and size and in inflorescence size - nowhere more so than in New Guinea (extreme dimensions in parentheses in the description), where it is very common and the only species of this genus represented. There, the most diminutive forms have been called S. klossii, S. dorensis, 
S. hellwigiana, S. hellwigiana var. subcordata and S. parvifolia. Though all those are described from Irian Jaya, similarly small plants are recorded from localities scattered throughout New Guinea at a wide variety of altitudes. In these the leaf is elliptic with an obtuse to very slightly cordate base, and as little as $5.5 \mathrm{~cm}$ long. Robust forms with dramatically variegated, spattered leaves have been called S. neoguineensis (a form extending to the Bismarck Archipelago, Solomon Islands and Vanuatu). The most robust forms have ovato-sagittate leaves as much as $40 \mathrm{~cm}$ long. The very small forms tend to have reduced numbers of interpistillar staminodes which often do not exceed the pistils in height, unlike in the more robust forms. There is a complete set of intermediates including the types of all other names applied to Schismatoglottis in New Guinea, and no evidence has been found from amongst the herbarium material examined that there is ecological differentiation (e.g. to substrate or vegetation type) of any of them. Whether there is biological differentiation by pollinators remains to be discovered. Schismatoglottis calyptrata is common and variable, but not to the same extent, throughout most of the rest of Malesia. However, this species is surprisingly uncommon in Borneo, though there are a number of geographically and ecologically (where known) restricted segregate species there, such as Schismatoglottis ahmadii, S. lingua, S. venusta and S. viridissima.

A few specimens occur in the Malay Peninsula which are intermediate between this species and S. wallichii (e.g. Hay et al. 9159). In the latter species, the sterile and male zones of the spadix are in reverse order to that in $S$. calyptrata, so that there is no appendix (though there may be a very small terminal cluster of staminodes at the spadix apex). In the intermediate specimens, the male zone is longer than in $S$. calyptrata s. str. and is separated from the female by a narrow zone of staminodes of the type found in the appendix of S. calyptrata and the sterile zone in S. wallichii s. str. The appendix is much shorter, and the distal portion of the spadix is rather narrowly clavate: i.e. intermediate between the more or less cylidrical spadix of $S$. wallichii and the abruptly clavate one of $S$. calyptrata and without the slight but abrupt difference in width between the male zone and appendix of the latter species. Occasional specimens are also found in which the structure of the spadix is typical for S. calyptrata except for a very short sterile zone between the male and female zones; these have been determined as $S$. calyptrata, but if hybridization has taken place with $S$. wallichii, they may suggest that some introgression is occurring. Cytological investigation and experimental crossing are required to confirm whether or not these species are genetically isolated. The descriptions of both $S$. calyptrata and S. wallichii presented here are based on material judged to be broadly 'typical'.

Calla calyptrata Roxb. was based on material cultivated at Calcutta and obtained from Ambon. It was lectotypified by Hay (1996), where it was noted that an epitype was required, as both the elements from which the lectotype could be selected are somewhat ambiguous. The designated specimen is the only complete material seen from Ambon and it conforms with the sense in which the name Schismatoglottis calyptrata is widely used.

Hasskarl's publications in Flora (1842a) and Tijdschr. Nat. Gesch. \& Physiol. (1842b), cited above, appear to have been published in reverse order to that in which they seem to have been written. C. humilis var. major, designated variety $\alpha$, appears in Hasskarl (1842 b; Aug/Sept), but not in Hasskarl (1842a; July), where only var. minor appears, designated variety $\beta$. It is evident that Hasskarl considered var. major the 'type' form from which var. minor was segregated, and not another variety in addition to an implicit var. humilis. We conclude therefore that var. major is a superfluous name for the nomenclaturally typical variety. That, in turn, is a superfluous name for Calla calyptrata, as they are both based on the above-cited plate in Rumphius' Herbarium Amboinense. 
Although C. humilis Hassk. is a synonym of Schismatoglottis calyptrata, it cannot be deemed completely clear if var. minor is actually Schismatoglottis too. No element was cited that could serve as type, the description is very sparse and it is not indicated from where the plant is supposed to have originated. No herbarium material bearing this name has been located at Leiden. Hasskarl (1842a \& b), in discussing the varieties of Colocasia humilis, was clear about the specific character of the clavate appendix which does not accord with Colocasia in the current sense at all. It does however, accord with Schismatoglottis calyptrata, though also with other Schismatoglottis species (though not in Java). Hasskarl (1842a) also mentions capitate interpistillar staminodes as a character of C. humilis var. minor - another characteristic in accord with S. calyptrata, particularly when combined with the additional specific character of being stoloniferous (cf. Hay 1996). It therefore seems highly likely, though not certain, that Colocasia humilis var. minor is Schismatoglottis calyptrata, and we have found nothing to suggest it might be anything else. It is not a name in use.

Besides the issue of its identity, Colocasia humilis var. minor Hassk., though erected under an illegitimate species name, is valid (Tokyo Code Art. 55.2). A new type is therefore needed. Smith 930 is designated neotype here; it conforms to Hasskarl's description in its small size and somewhat hastate, rather narrowly lanceolate and acuminate leaf blade (though it is not variegated).

No material was cited in the protologue of Colocasia neoguineensis and so the accompanying plate is selected as lectoype. It is not detailed however, and in interpretive epitype is required. Material studied and preserved by Brown at Kew in 1885 when he made the combination in Schismatoglottis, which was obtained from Linden and matches the description of $C$. neoguineensis, is therefore designated as the epitype.

Schismatoglottis calyptrata var. albidomaculata was first published by Hallier (loc. cit.) as a nomen nudum. A year later he reduced it to the first of two validly published forms of a new variety maculata. The second, f. flavidomaculata, included Schismatoglottis neoguineensis. One of these forms has to be regarded as the nomenclaturally typical (and hence superfluous) one, and the first is taken here. Ridley, apparently unaware of Hallier's 1898 reduction of var. albidomaculata to a forma in var. maculata, validated S. calyptrata var. albidomaculata, citing a specimen of his own. Schismatoglottis calyptrata var. albidomaculata Ridl. could be regarded as an altogether new, valid and legitimate variety. However, since Ridley clearly cites Hallier as the originating authority, the name can be regarded as a superfluous renaming of $S$. calyptrata var. maculata Hallier $\mathrm{f}$.

Engler (1912) attributed Schismatoglottis calyptrata var. bivittata to Hallier, and considered his own S. picta f. bivittata to be based on it. However, the former was not valid - there being no description, and is thus not the basionym. Schismatoglottis picta f. bivittata is therefore typified with the material cited by Engler and not with material linked to Hallier's trinomial.

Engler cited two syntypes of S. emarginata in the protologue, Nieuwenhuis 393 (BO) from Bochang and Amdjah 420 (BO) - Borneo, without specific locality. Alderwerelt (loc. cit.) pointed out that the protologue and the illustration do not agree with the specimens Engler cited. Both specimens are sterile (Amdjah 420 with a fruiting spathe), while the description and illustration include flowering parts. Both the description and illustration are of a stoloniferous plant with a central band of variegation along the midrib. The cited specimens do not show these features either. Engler (loc. cit.) indicated that he had seen cultivated material in addition to the cited specimens, though he did not specify what, and apparently none was preserved and annotated with the name at the time. Years later, Alderwerelt found at Bogor two living plants cultivated under this name, one of which (XI.B.X.15) matched the illustration and 
original description of $S$. emarginata. On the basis of this living plant and its resemblance to the protologue, he provided a more exhaustive description (preserving a specimen in the Gardens Herbarium here designated the epitype). He also indicated that Nieuwenhuis 393 \& Amdjah 420, though inadequate for certain identification, were probably referable to S. irrorata Engl. (= S. motleyana Schott s. lat.). From this it is concluded that he effectively lectotypified S. emarginata with Engler's illustration. Unfortunately, the plant on which the illustration was allegedly based is of unknown original provenance (even as to island). Schismatoglottis emarginata belongs in the group around the widespread $S$. calyptrata which includes a number of narrow segregates whose definition sometimes relies on geographic location and substrate preference to support slight morphological differences. Schismatoglottis emarginata differs only slightly from typical S. calyptrata (in the rather somewhat more numerous primary lateral veins relative to the size of the leaf blade - cf. the Sulawesi elements S. bitaeniata, S. sublaxiflora and S. vanvuurenii here also placed in synonymy with S. calyptrata). It is at present impossible to evaluate as no exactly matching material exists of known provenance. It is therefore placed provisionally in the synonymy of S. calyptrata.

The holotype of Schismatoglottis acutangula, a species described from sterile material cultivated at Bogor and collected from there by Engler in 1906, is not at B. It presumably was destroyed during the war. Alderwerelt (loc. cit.) expressed some doubt about whether the plant he subsequently described in full under this name was the same cultivated plant that Engler had seen. He appears to have been right to doubt it, as Alderwerelt's plant was cited as originally collected from Mt Alkmaar by Djibdja, who accompanied Versteeg there in 1907 (van Steenis-Kruseman, 1950), the year after Engler had visited Bogor. That material is therefore not used as a neotype. The specimen so-designated is one determined with this name by Engler, made from a plant growing at the Berlin Botanic Garden in 1911. It is not clear whether this plant was obtained from Bogor during Engler's visit. However, it matches the protologue quite closely.

The type of Schismatoglottis bitaeniata, a Sulawesi element, does not seem to be distinguishable from $S$. calyptrata s. lat. in inflorescence, though the leaf is somewhat distinctive, combining a cuspidate tip, finely crispate margin, rather reduced posterior lobes and unusually closely parallel primary lateral veins. Bornean Schismatoglottis ahmadii and other species are also extremely similar to $S$. calyptrata in inflorescence but have rather minor differences in leaf and are recognised here as segregate species. However, in those instances there is evidence of ecological differentiation. This may, of course, transpire to be the case with S. bitaeniata, in which case it would reasonably be pulled out of the synonymy of $S$. calyptrata, but there are no ecological data available at present. This particular form is quite widely cultivated (usually as Schismatoglottis picta, under which name it is illustrated in Graf (1978: 320)). Schismatoglottis sublaxiflora and $S$. vanvuurenii, also from Sulawesi and provisionally regarded as synonyms of S. calyptrata, are elements rather similar to $S$. bitaeniata.

The identity of Schismatoglottis nieuwenhuisii appears to have been somewhat confused. It was discussed by Alderwerelt (loc. cit.) who noted that of the two specimens cited by Engler in the protologue, one, Nieuwenhuis 1485, collected by Jaheri (who was cited as the collecting locality) and grown at Bogor, was a Homalomena. The second was a Schismatoglottis preserved directly from the wild (Winkler 2129). Alderwerelt was also of the opinion that Engler had used, though did not cite, other material cultivated at Bogor to form the basis of his diagnosis of S. nieuwenhuisii and the figure which appeared in Pflanzenreich. Alderwerelt therefore decided to redefine S. nieuwenhuisii on this basis. He not only rightly excluded the Homalomena element from S. nieuwenhuisii, but also, unseen, the only other element Engler cited (the Berlin 
duplicate of Winkler 2129), basing the redefined S. nieuwenhuisii on a cultivated plant XI.B.X.160. Having rearranged things to his liking, Alderwerelt used the Bogor duplicate of Winkler 2129 (incorrectly cited as 2199), an isosyntype of S. nieuwenhuisii, as the holotype of a new species Schismatoglottis maculata Alderw. In order to establish an identity for $S$. nieuwenhuisii, it does not seem useful or acceptable, for the purpose of lectotypification, to go down Alderwerelt's very speculative path, after over a decade and a half had elapsed (Engler visited Bogor in 1906), given all the opportunities that exist for the misplacement of plant labels, of specifying what other material growing in the Bogor gardens Engler might have seen and used to formulate his concept. Where there is this much confusion, and in a case where the name can hardly be deemed to be in current use, it seems preferable to take a mechanical approach rather than to try to fathom and make a tenuous case for what the author may have really meant in the event that the cited materials do not agree well with the description. In that case S. nieuwenhuisii is to be lectotypified by the Berlin duplicate of Winkler 2129 [evidently Engler's inclusion of material of a Homalomena was a mistake; besides which the epithet nieuwenhuisii is already occupied in that genus]. However, the Berlin duplicate, which was the only one cited by Engler, appears to have been destroyed in WWII. The other duplicates of Winkler 2129 are not syntypes and therefore the lectotype itself cannot be selected from among them, but as duplicates they have a strong, if mechanical, link with the name $S$. nieuwenhuisii, and they are therefore here designated as isolectotypes. The specimens concerned conform uncontroversially with S. calyptrata. As Schismatoglottis niewenhuisii and S. maculata were based on different duplicates of Winkler 2129, they are not homotypic and S. maculata is to be regarded as legitimate.

The holotype of Schismatoglottis klossii is mounted on a sheet which includes a second, virtually identical specimen labelled as having been collected on Mt Carstenz at Camp III in Dec 1912. Ridley's citation states 'Camps III to IV...', which agrees exactly with the label associated with the specimen cited as holotype here.

Alderwerelt made two specimens from the type plant of Schismatoglottis ruttenii Alderw., either of which could be selected as lectotype. The second, Alderwerelt 323, is in $\mathrm{BO}$ (+ BO spirit).

Alderwerelt also made two specimens from the type plant of Schismatoglottis acutangula f. staminodiifera Alderw., either of which could be selected as lectotype. The second, Alderwerelt 295, is in BOKR (+ BO spirit).

Selected other specimens examined [a large number of collections are cited, as this species is both extremely widespread and extremely variable]: MALAY PENINSULA: Penang, Sg. Ara, Baharuddin s.n. (USM); Belum FR, waterfall of Kejor R, Baharuddin s.n. (USM); Perak, Bukit Larut, Boyce 687 (K); Penang, Waterfall, Curtis 2828 (K, SING); Trengganu, Bukit Bauk Forest Reserve, Hardial Singh 5 (SING); Selangor, Langat, Ulu Lui, Hassan-Kasim s.n. (SING); Cult. RBG Sydney, Acc. No. 940058 ex Perlis, Bukit Bintang, nr Kangar (orig. coll. Hay et al. 9013), Herscovitch s.n. (NSW); Cult. RBG Sydney Acc. No. 940086, 940100 ex Selangor, Gombak Valley (orig. coll. Hay et al. 9042, 9056), both Herscovitch s.n. (NSW); Cult. RBG Sydney Acc. No. 940125 ex Perak, foothills of G. Bubu (orig. coll. Hay et al. 9129), Herscovitch s.n. (NSW); Cult. RBG Sydney Acc. No. 940151 ex Negeri Sembilan, Jaram Toi Recreation Area (orig. coll. Hay et al. 9155), Herscovitch s.n.(NSW); Cult. RBG Sydney Acc. No. 940181, 940182, 940183, 940184 ex Perak, Bukit Larut (orig. coll. Hay et al. 9087, 9088, 9089, 9090), all Herscovitch s.n. (NSW); Cult. RBG Sydney Acc. No. 940285, 940306, 940307 ex Terengganu, Ayer Terjun, Sekayu F.R., (orig. coll. Hay et al. 9217, 9238, 9239), all Herscovitch s.n. (NSW); Cult. RBG Sydney Acc. No. 940339 ex Pahang, The Gap, Semangoh Pass (orig. coll. Hay et al. 9272), Herscovitch s.n. (NSW); Cult. RBG Sydney Acc. No. 940340, 940359 ex Pahang, Bukit Fraser, (orig. coll. Hay et al. 9273, 9292), Herscovitch s.n. (NSW); Kelantan, Gua Musang, Henderson 22683 (BO); Pahang, Kuala Tembeling, Holttum 20536 (SING); Johor, G. Pulai, Maxwell 81-8 (AAU, SING); Kelantan, Kuala Relai, Mohd. Nur 10227 (SING); Negeri Sembilan, Perhentian Tinggi, Ridley s.n. (SING); Perak, Scortechini 622a (CAL, K, NSW, SING). SINGAPORE: Bukit Timah, Ridley s.n. (SING). SUMATERA: North Sumatera, Sibolangit Nature Reserve, Alston 14468 (BM); Aceh, Lawe 
Sigala, nr Kutacane, Alston 14666 (BM); North Sumatera, N Tapanuli, Lumban Djulu, L. Toba, Alston 15322 (BM, L); West Sumatera, Padang, Sg Bulu, Beccari P.S. 943 (K); Lampung, Sebesi Island, Docters van Leeuwen-Reijnvaan 5135 \& 5292 (both BO); Jambi, Kerinci Seblat National Park, up Manjunto R. from Lempur Vill., Hay et al. 13032 (NSW); Jambi, Lubuk Pasang — Lempur, Hay et al. 13058 (NSW); Cult. RBG Sydney Acc. No. 970523 \& 970324 ex West Sumatera, Lembah Anai Forest Reserve, (orig. coll. Hay et al. 13096 \& 13097), both Herscovitch s.n. (BO, NSW); West Sumatera, around Rafflesia reservation at Batang Palupuh, N of Bukit Tinggi, Hotta 25011 (KYO); West Sumatera, Bukit Gajabuih, Ulu Gadut, c. 15 km E of Padang, Hotta 25420 (KYO), 25852 (BO, KYO) $\mathcal{E} 26036$ (BO); West Sumatera, along valley of Ulu Gadut, c. $15 \mathrm{~km}$ E of Padang, Hotta 25784, 25789, 25798, 26036, 26111, 26119 \& 26151 (all KYO); West Sumatera, around Anai waterfall, W of Padangpanjiang, Hotta 26156 (KYO); West Sumatera, Air Sirah Plot, nr pass of Padang-Solok rd, Hotta 26451 \& 26479 (both KYO); West Sumatera, small valley nr Batusangkar, Hotta 26596 (KYO); West Sumatera, K. Putih, E of Padang, Hotta $\mathcal{E}$ Okada 295, 305, 312, 315, 327 \& 488 (all KYO); West Sumatera, Setia Mulia (Bot. Gard. Of Andalas Univ.), c. $20 \mathrm{~km} \mathrm{~W}$ of Padang, Hotta \& Okada 595 (KYO); West Sumatera, Pinang-Pinang Plot, Ulu Gadut, c. $15 \mathrm{~km}$ E of Padang, Hotta \& Okada 688 (KYO); West Sumatera, Padang, Lolo, Sg. Lareh, Hotta \& Okada 1691 (BO); West Sumatera, en route from Base Camp to G. Kambot, c. 15 km E of Padang, Hotta \& Tamin 248 \& 258 (both KYO); West Sumatera, Setia Mulia, Bot. Gards of Andalas Univ. c. $20 \mathrm{~km}$ E of Padang, Hotta et al. 1008, 1049b $\mathcal{E} 1057 b$ (all KYO), 1054 \& 1061 (both BO \& KYO); West Sumatera, en route from Base Camp to Pinang Pinang Plot, Ulu Gadut, c. 15 km E of Padang, Hotta et al. 1091 (KYO); West Sumatera, en route from base Camp to Bukit Lantik, Ulu Gadut, c. $15 \mathrm{~km}$ E of Padang, Hotta et al. 1109 (KYO); Lampung, Mt Tanggamus, Jacobs 8269 (L); West Sumatera, Kab. Padang Pariaman, Sipisang, 40 km n of Padang, from Anak Air Pinyangek to Batang Pinang, Okada et al. 1332 (BO); North Sumatera, Asahan, vicinity of Loemban Ria, Rahmat Si Boeea 8130 (US); Jambi, Mengopeh, Rutten-Kooistra 40 (U); Aceh, G. Leuser Nature Reserve, Ketambe, valley of Lau Alas, nr tributary of Lau Ketambe, c. $35 \mathrm{~km}$ NW of Kutacane, de Wilde $\mathcal{E}$ de Wilde-Duyfjes 12282 \& 14524 (both L); Aceh, G. Leuser Nature Reserves, Ketambe Rsearch Station and vicinity, Alas R. valley, c. 35 km NNW of Kutacane, de Wilde $\mathcal{E}$ de Wilde-Duyfjes 18617 (L); Aceh, Kloët nature reserve, S Kloët, along the Krung Lembang, c. $20 \mathrm{~km}$ upstream, E of Kandang, de Wilde $\mathcal{E}$ de Wilde-Duyfjes 19664 (L); Aceh, Middle Alas R. (Lae Sauraya) area, c. $15 \mathrm{~km}$ N of Gelombang, S of Bengkomg R., de Wilde $\mathcal{E}$ de Wilde-Duyfjes 20306-A (L); Tapanuli, Dolok Simanukmanuk, Yoshida 461 (KYO). JAVA: West Java, cult. Bogor Botanic Gardens, Alston 15406 (BM); East Java, Mount Wilis, Kediri, Backer 11364 (BO); West Java, Buitenzorg, Tjilendek, Bakhuizen f. 3731 (U); Java, Batavia, Buitenzorg, Bakhuizen f. 345 (L); West Java, Batavia, Pasir Honje, Leuwiliang, Bakhuizen f. 5497 (L, BO); West Java, Mount Geulis, Bakhuizen f. 5977 (L); West Java, Mount Gede-Pangrango, Gegerbintang, Blaembergen 442 (BO); Java, Mount Seribu?, Blume s.n.(L); West Java, Tjibodas, Boerlage s.n. (L); West Java, Tjibeureum, Boerlage s.n. (L); Java, Cult. RBG Kew, Brown s.n. (K); Java, RBG Kew, Brown s.n. (K); Java, Tjibodas, Danser 5713 (L); West Java, Tjibodas, Pasanggrahan, Danser 5746 (L); Java, Mount Salak, Danser 7798 (L); East Java, Ranu Darungan, Groot \& Wehlburg 268 (BO); Java, Engler 123 (BM, G, K, L, P); Java, Culta in Hort. Bot. Univ. Breslau, Engler 255 (K, P); West Java, Buitenzorg, Tjiapus, Hallier 551a. (BO); West Java, Buitenzorg, Pamaragan, Hallier 552a. (L); West Java, Buitenzorg, Baranangsiang, Hallier 552b. (L); West Java, Buitenzorg, Mantarena, Hallier 552d. (BO, K); West Java, Tjibodas, Hallier 552e. (BO); West Java, Mount Gede, Tjibodas, c. 1425 m altitude, Hallier $552 f(=272)$ (BO, L); West Java, Buitenzorg, Kampung Batu, Tapak, Hallier s.n. (BO, L); West Java, Buitenzorg, Tjiapus, Hallier s.n. (BO); Java, Hasskarl s.n. (K); West Java, Mount Salak, Tegalankap, Hochreutiner 1995 (G); Java, Junghuhn s.n. (L); West Java, Mount Mandalagiri, Kaur 338 (BO); Java, Mount Muriah, above Tjolo, Kern 8489 (BO, L); West Java, Takoka, Tjiandjur, Koorders $14977 \beta(\mathrm{BO})$; West Java, Tjiampea, Buitenzorg, Koorders $31486 \beta$ (BO); West Java, Tjibodas, Tjiputri, Tjiandjoer, Koorders $31682 \beta$ (BO); Central Java, Mount Telomojo, Ambarawa, Koorders $35962 \beta$ (BO); Java, Besoeki, Kalibendo, Koorders $42964 \beta$ (L); West Java, Dago, Koorders 44243 $\beta$ (BO); West Java, Buitenzorg, Kuntze 4332 (NY); West Java, Sagaranten, Kuntze 5125 (NY); West Java, Tjibodas, Kooper s.n. (U); Java, Kuhl \& van Hasselt s.n. (L); West Java, Mount Mandalagiri, Garut, Lam 335 (BO); East Java, Mount Wilis, Lörzing 910 (BO); West Java, Tjibodas, Lörzing 1717 (BO); Java, Lotzy s.n. (L); West Java, Hutan Pasir Sintok, Mount Gede, Tjibodas, Meijer 2630 (L); West Java, Mount Salak, Kota Batu, Monchi s.n. (BO); Central Java, en route from Baturaden to G. Slamet, Murata et al. J-859 (KYO); West Java, Cibinon, Jalan Cikureup, nr Bogor, Murata et al. J-1652 (KYO); West Java, Tjibodas Botanic Garden, Nicolson 893 (BO); West Java, Tjibodas Botanic Garden, Nicolson 896 (BO, US); West Java, Tjibodas, Mount Gede, Noerta 13371 (L); West Java, Tjibodas, Sapii 75 (BO); West Java, Tjibodas, Sapii 2001 (BO); West Java, Preanger, Tjampaka, Tjibeber, Smith 930 (L); West Java, Buitenzorg, Sindang Barang, Soegandi 205 (BO); Cult. 
Hort. Bogor., Teijsmann s.n. (L); Java, Teijsmann 14072 (BM); West Java, Nirmala Estate, Mount Halimun area, van Balgooy \& Wiriadinata 2875 (L); Central Java, Pati, Kalangan, Waitz s.n. (L); Java, Waitz s.n. (L); West Java, Telaga Warna, Puncak, Yuzammi 399001 (NSW); West Java, Mount Bunder, near Kawah Ratu, Yuzammi 399009 (NSW); Central Java, W Mount Slamet, Panjuran Tujuh, Batu Raden, Purwokerto, Yuzammi 399035 (NSW); Central Java, Grojokan Sewu, Balai Kambang, Tawangmangu, Yuzammi 399041 (NSW); West Java, Hutan Lindung Darajat, Kampung Pasir Hayam, Desa Sukamulya, Talegong, Garut, Yuzammi 399058 (NSW). NUSA TENGGARA: Bali, G. Pala, Sarip 287 (BO). BORNEO: SARAWAK: Cult. RBG Sydney Acc. No. 942727 (ex cult. Hort. Leiden Acc. No. 932733) ex Lanjak-Etimau Park, between Sg. Mujok and Ulu Sg. Ensirieng (orig. coll. Vogel s.n.) Herscovitch s.n. (K, L, NSW, SAR). SABAH: Kinabalu, Lumu, Furtado sub Clemens $\mathcal{E}$ Clemens 29186 (BM, G, K); West Coast Residency, Pinosuk Plateau, nr Kundassang, de Vogel 8015 (L); Kinabalu NP, between HQ and Kg Kundassan, Kokawa 6156 (KYO); Kinabalu NP, between HQ and power station, Kokawa \& Hotta 3131 (KYO); Kinabalu National Park, between Sosopodon and NP HQ, Kokawa \& Hotta 5149 \& 5152 (both KYO). KALIMANTAN: East Kalimantan, Kutai, nr Lahum, Endert 1849 (B, BO, K, L); East Kalimantan, W. Kutei, Kombeng, Endert 5123 (BO); East Kalimantan, N of Sangkulirang, Sg. Kerajaan,. Kostermans 6226 (BO, L); Central Kalimantan, Bukit Raya, c. 10 km NNW of Tumbang Tosah, Mogea 3905 (L); Eastern part of Samarinda, Murata et al. 176 (L), 177 (BO, L), 250 (L) \& 253 (BO, L); East Kalimantan, c. 15 km NE of P.T. Kutai Timber Co. camp, Tabang, Murata et al. B-929 (KYO); East Kalimantan, foot of G. Batukenye, along Sg. Belayan, NW of Tabang, Murata et al. B-1495 \& B-1506 (both KYO); South Kalimantan, G. Besar, Murata et al. 3976 (KYO). PHILIPPINES: Mindanao, Davao Prov., Mt McKinley, Edaño PNH 1101 (GH); Mindanao, Davao Prov., Mainit, Mt Apo, Edaño PNH 1332 (GH); Samar, Mt Sarawag, Edaño PNH 15279 (GH); Samar, Mt Sarawag, Edaño PNH 15312 (BM, GH, K, L, SING); Mindanao, So. Cotabato, Koronodakal, Lamlisi vill., Miasong, Tupi, Mt Matutum, Gaerlan et al. PPI 5307 (K); Luzon, Tabayas Prov., Merrill 4192 (K); Mindanao, Davao, Prov., Compostela, Barrio Marapat, Nicolson 702 (US); Mindanao, Baracatan, W side of Mt Apo, Nicolson 724 \& 725 (both US); Mindanao, Agusan Prov., Esperanza, Sianib, along Labao Ck., Nicolson 738 (US); Catanduanes, San Miguel, Tagbac Barrio, Nicolson 792 \& 793 (both US); Luzon, Batangas Prov., Mt Macolod, Quisumbing BS 78165 (NY); Samar, Catubig R., Ramos BS 24247 (BM, US); Alabat Isl., Ramos \& Edaño BS 48340 (NY, UC). SULAWESI: Tanggari, N of Tondano, Alston 15759 (BM); Taratara, nr Tomohon, Alston 16165 (BM); Winowangan, 4 km E of Menado, Alston 16201 (BM); Tanggari, Alston 16222 \& 16224 (both BM); Sonder, Alston 16229 (BM); Popontollen, nr Tumpaan, Alston 16505 (BM); Central Sulawesi, Palu-Oti rd, c. 57 km N of Palu, van Balgooy 3591 (BO, GH, L); Masamba, NW of Tetaki, Eyma 1543 (BO, L); Central Sulawesi, Mt Nokilaki, along Sg. Pehuia, Meijer 9600 (BO, L); SW Sulawesi, NE of Makassar, Karaenta FR, Meijer 10978 (L); Central Sulawesi, Sopu valley, c. 80 km SSE of Palu, de Vogel 5581 (L); Manado, Tonsealama, Wisse 83 (BO). MALUKU: Buru, N Buru, Wae Ili, van Balgooy 4619 (L); Ternate, Ake Bobotja, Beguin 851 (BO); Halmahera, Galela, Beguin 2246 (BO); Sula Mangoli, Wai Tamila, Bloembergen 4722 (BO); Aru, P. Kobroor, Namadoeboele, Buwalda 5180 (BO, L); W Ceram, Boeria, Wae Bekai, Eyma 2500 (BO, K, L); Halmahera, Weidamo, Idjan/Mochtar 193 (L); N Seram, Kg Posahari, Kornassi 1559 (BO); Buru, W Buru, Wae Kose, Wae Nibe, Wood Industry base camp 1, Mogea \& Ismail 5123 (BO). NEW GUINEA: IRIAN JAYA: South New Guinea, Sg. Aendoea, by Oeta, Aet 510 (BO); Idenberg River, Bernhard Camp, Brass 12391 (BO, GH, L); Mamberamo, Albatross Bivac, Docters van Leeuwen 11214 (BO); Maroeni Ck, nr Andai, SW of Manokwari, Koster BW13552 (L); by Prauwenbivac, Lam 431 (BO); Bernhard bivac, Meijer Drees 623 (BO); Tafelberg Reserve, 2 km N of Manokwari, Nicolson 1584 (BO, K, LAE, SING); Biak, Bisimsar R., 20 km ENE of Mokmer, Nicolson 1598 (K); Vogelkop Peninsula, side rd $1.2 \mathrm{~km}$ from Steenkool to Temboeni, van Royen 4012 (L); Hollandia, Cycloop Mts, Ifar-Ormoe, van Royen \& Sleumer 6078 (BO, GH); Vogelkop Peninsula, Aifat R. valley, path from Sururem to Son vill., van Royen \& Sleumer 7512 (BO, K, L); W of Hollandia, N of Simboro Strait of Lake Sentani, Sigafoos 95 (GH); Noord R., Versteeg 1083 (U); Beriat, c. $12 \mathrm{~km} \mathrm{~S}$ of Teminaboean, Versteegh BW 4909 (L, LAE); Warmare valley, 20 km SW of Manokwari, Versteegh BW 12574 (L); Fak-Fak R., N from Fak-Fak, Vink BW12150 (BO, GH, K, LAE); Fakfak, Mimika Timur, rd to Mapurujaya, Widjaja 2618 (BO). PAPUA NEW GUINEA: Cult. RBG Kew Acc. No. 246-70.02301 ex West Sepik Prov., Kilifas (orig. coll. Sands 1266), anon. s.n. (K); West New Britain, Wide Bay, Bateson 125 (K); Central Prov., Dieni, Ononge Rd, Brass 3843a (NY); Western Prov., Fly R., 528 mi camp, Brass 7017 (GH); Western Prov., Palmer R., 2 mi below jct Black R., Brass 7360 (GH, L); Milne Bay Prov., Peria Ck, Kwagira R., Brass 24091 (GH, K, LAE) \& 24309 (GH); Central Prov., Koitaki, Carr 12053 (NY) \& 12495 (K, L, NY); Central Prov., Boridi, Carr 14340 (BM, NY); Central Prov., Isuarava, Carr 15455 (BM, NY); Morobe Prov., Gizan, Conn et al. 30 (L, LAE); Gulf Prov., nr Kerema, Craven \& Schodde 691 (L); Gulf Prov., nr Ihu, Craven E Schodde 745 
(GH, K, L, LAE); East Sepik Prov., Wewak, along trail beyond Boys Town, Croat 52757 (LAE, MO); East Sepik Prov., along small river S of Boys Town, Croat 52780 (LAE, MO); Morobe Prov., along rd to Sangkwep, SE of Lae, c. $10 \mathrm{~km}$ beyond Sankwep R., Croat 52809 (LAE, MO); Telefomin, Hak valley, above Nenem R. opp. Community School, Frodin \& Morren 3453 (K); Triton Bay, Le Guillou s.n. (P); Morobe Prov., 3 mi S of Garagos R. bridge on Lae-Bulolo rd, Hartley 11018 (K, LAE); East New Britain, Rabaul, Herre 164 (NY); Cult. RBG Sydney Acc. No. 902298 ex Madang Prov., Omuru (orig. coll. Wheatley $\mathcal{E}$ Hay 043), Herscovitch s.n. (BO, K, L, LAE, NSW); Cult. RBG Sydney Acc. No. 902523 \& 902585 both ex West Sepik Province, Vanimo, (orig. coll. Hay ex Dearden 6026 \& 6014), both Herscovitch s.n. (BO, K, L, LAE, NSW); Cult. RBG Sydney Acc. No. 902650 ex Morobe Prov., Garasa, (orig. coll. Wheatley \& Hay 117), Herscovitch s.n. (K, L, LAE, NSW); Morobe Prov., Huon Peninsula, c. 3 mi S of Pindiu, between Masba Ck and Kua R., Hoogland 8931 (GH, K, LAE); East Sepik Prov., nr Ambunti, Hoogland \& Craven 10084 (GH); Madang Prov., Saidor, Long Island, nr Matafuna Bay, LAE 50176 (L, LAE); Manus Island, Wili R. between Pelikawa \& Dremsel, LAE 53753 (GH, K, L, LAE); West New Britain, Fulleborn Harbour, LAE 58196 (GH, K, LAE) \& 58199 (E, GH, K, LAE); Madang Prov., Gogol, Lauterbach 977 \& 1015 (both WRSL); Sepik, Ledermann 7891a \& 10152 (both K); West New Britain Prov., nr Cape Hoskins, Galilo Vill., NGF 6445 (GH, K, LAE); West New Britain, W Nakanai, Malalia nr Cape Hoskins, NGF 6518 (BO, GH, L, LAE); East New Britain, Pomio, Tomo timber area nr Fulleborn Harbour, NGF 12324 (GH, LAE); North Solomons Prov., Pavairi, NGF 31262 (K, LAE); Morobe Prov., Wampit, NGF 35659 (BO, K, LAE); Madang Prov., Long Island, nr Matafuna Point, NGF 43652 (GH, K, L, LAE); Morobe Prov., Bumbu logging area, 7 mi $\mathrm{N}$ of Lae, Nicolson 1390 (K, LAE); Central Prov., Sogeri Plateau, between Subitana and Javereri, headwaters of Kemp Welsh R., Nicolson 1435 (LAE, US); East New Britain, Kerevat R. road, 6 mi beyond prison, Nicolson 1503 (K, LAE); New Ireland, Lamekol, Peekel 44 (BO, L); East Sepik Prov., Wewak-Angoram area, nr Balam Vill. On the But-Kauk rd W of Wewak, Pullen 1334 (GH, LAE); New Ireland, Namatanai, Hans Meyer Range, Danfu R. valley c. $8 \mathrm{~km}$ W \& upstream of the Danfu bridge nr Manga, Sands 786 (K); West Sepik Prov., Amanab, Bewani Mts, nr Kilifas on R. Yenabu, Sands 1254 (K); Central Prov., Laloki River, Rouna Falls, Schodde 2932 (GH, K, L, LAE); North Solomons Prov., Bougainville, c. $10 \mathrm{mi}$ W of Buin, Aku vill., Schodde 4034 (GH, LAE); North Solomons Prov., Buka, Skotolan, Waterhouse 40-B (K); North Solomons Prov., Bougainvile, Siwai, Waterhouse 288-B (K). SOLOMON ISLANDS: NW Guadalcanal, Mt Mambulu, BSIP 8020 (K, LAE); Paro, Guppy 204 (K). VANUATU: Malekula, Tisbel, Hallé RSNH 6358 (K).

\section{Schismatoglottis canaliculata Engl.}

Schismatoglottis canaliculata Engl., Pflanzenr. 55 (IV.23Da) (1912) 112; Alderw., Bull. Jard. Bot. Buitenzorg III, 4 (1922) 209. - Type: Cult. Hort. Bogor. XI.B.X.16, ex Borneo, Jan/Feb 1906, A. Engler 4048 (B, holo). - Epitype: Cult. Hort. Bogor. XI.B.X.16, C.R.W.K. van Alderwerelt van Rosenburgh 305 (BOKR + BO spirit; designated here).

Herb to c. $25 \mathrm{~cm}$ tall. Stem (not observed) ?hypogeal, ?hapaxanthic. Leaves ?several together; petiole c. $20 \mathrm{~cm}$ long, about as long as the blade, sheathing in the lower $1 / 4-1 / 2$; wings of sheath persistent, fully attached, tapering; blade triangular-cordato-sagittate, c. $20 \mathrm{~cm}$ long $\times 9 \mathrm{~cm}$ wide, the tip acute and acuminate for c. $2 \mathrm{~cm}$, the base widely cordate with rounded posterior lobes c. $3 \mathrm{~cm}$ long; midrib more or less flush with the blade (dry) with c. 7 primary lateral veins on each side, regularly alternating with lesser interprimaries and diverging at c. $45^{\circ}$; secondary venation arising from the midrib and from the bases of the primary veins; tertiary venation obscure. Inflorescences 2 ?or more together; peduncle c. $10 \mathrm{~cm}$ long. Spathe (incomplete), length?; lower spathe ovoid, c. $3 \mathrm{~cm}$ long, apparently differentiated from the limb by a weak constriction; limb?. Spadix subcylindric, $6 \mathrm{~cm}$ long; female zone $2.5 \mathrm{~cm}$ long, adnate to the spathe in the lower $2 / 5$, the free part faintly conoid, apically c. $5 \mathrm{~mm}$ diam.; pistils crowded, narrowly ovoid, c. $0.6 \mathrm{~mm}$ diam.; stigma raised on a very short style, broadly button-like, about as wide as the ovary; interpistillar staminodes scattered among the pistils, long-stalked, narrowly clavate, about twice the height of the pistils; sterile interstice absent; male zone contiguous with female zone, subcylindric, slightly attenuate in the middle, held half within the lower spathe chamber, $1.1 \mathrm{~cm}$ long, $6 \mathrm{~mm}$ diam. at the top; stamens crowded, truncate, dumbbell-shaped, the thecae with 
conspicuous round pores and slightly elevated above the connective, c. $0.6 \mathrm{~mm}$ across; appendix subcylindric, basally isodiametric with top of male zone, distally tapering to a blunt point, $2.4 \mathrm{~cm}$ long; staminodes of appendix flat-topped, irregularly polygonal with rounded angles, c. $0.6 \mathrm{~m}$ diam. Fruit unknown.

Distribution - Malesia: known only from cultivation at Bogor, said to be from Borneo.

Habitat - Unknown.

Notes - The holotype of Schismatoglottis canaliculata consists of a leaf and a separate young infructescence, and the protologue was correspondingly incomplete. A completed description was given by Alderwerelt (loc. cit.) who made a preserved collection including complete inflorescence. However, he expressed some doubt concerning whether he was looking at the same plant as that which Engler described. It transpires that the two elements have the same plant number (16), and since the leaves of each closely match (notwithstanding their rather undistinctive venation and sagittate shape), it seems plausible to conclude that the two collections were indeed made from the same plant. Alderwerelt's more complete specimen is therefore designated the epitype.

Schismatoglottis canaliculata is clearly very closely allied to the highly variable $S$. motleyana. It falls outside the presently known range of variation of that species in its relatively thickly cylindric spadix and in the well-developed posterior lobes of the leaf. In these respects it resembles S. bifasciata, but in that species the male zone is exserted from the lower spathe chamber. The combination of a subcylindric spadix with the male zone held partly within the lower spathe chamber and sagittate leaves is found also in S. trifasciata, which differs from S. canaliculata in the much more elongate, attenuate spadix. As this group contains several species which are rather difficult to differentiate at the extremes of their variation, it may well transpire, with further collecting, that $S$. canaliculata will become impossible to differentiate from $S$. motleyana, but for the present it is maintained as a distinct species.

\section{Schismatoglottis clarae A. Hay, sp. nov.}

$\mathrm{Ab}$ aliis speciebus Schismatoglottidis in habitu hapaxanthico, folii lamina oblonga, ad basin haud cordata, lamina spathae caduca, interstitio neutro robusto differt. — TYPUS: Cult. Royal Botanic Gardens Sydney Acc. No. 940465 ex Malaysia, Sarawak, 7th Divn, $2.3 \mathrm{~km}$ past bridge over Kemena River, towards Sibu on Bintulu-Sibu Road (orig. coll. Hay et al. 9311), Oct/Nov 1997, C. Herscovitch s.n. (NSW + NSW spirit 5717D, holo; iso $\mathrm{K}, \mathrm{KEP}, \mathrm{SAR})$.

Robust herb to c. $75 \mathrm{~cm}$ tall. Stem hypogeal, clump-forming, hapaxanthic, c. $2 \mathrm{~cm}$ diam. Leaves c. 3 together; petiole to $60 \mathrm{~cm}$ long, sheathing in the lower $1 / 3-1 / 2$, wings of sheath tapering, fully attached; blade oblong-lanceolate to narrowly obovate, 26-37 cm long $\times 7-13 \mathrm{~cm}$ wide, dark green adaxially, paler below, the base acute to rounded, not at all cordate, the tip acute and acuminate for c. $2 \mathrm{~cm}$; midrib not prominent, with c. 11 primary lateral veins on each side, alternating with lesser interprimaries, diverging at $45-60^{\circ}$ (wider angle towards middle of blade), soon rather abruptly deflected towards the tip before joining the margin; secondary veins rather obscure, arising from the midrib; tertiary veins forming a tessellate reticulum visible on the adaxial side (dry), abaxially obscure. Inflorescences to 5 together; peduncle to $13 \mathrm{~cm}$ long, erect, declinate after anthesis, cataphylls hidden in subtending leaf sheath. Spathe c. $8 \mathrm{~cm}$ long; lower spathe ovoid, $3 \mathrm{~cm}$ long, green, differentiated from the limb by a distinct constriction; limb ovate, whitish, caducous, c. $5 \mathrm{~cm}$ long, acuminate for $1 \mathrm{~cm}$. Spadix c. $7 \mathrm{~cm}$ long, sessile; female zone $2.2 \mathrm{~cm}$ long, adnate to the spathe for $1 \mathrm{~cm}$, subcylindric (slightly conic in upper 1/3), $8 \mathrm{~mm}$ diam.; pistils crowded, subglobose, $1 \mathrm{~mm}$ diam.; stigma sessile, button-like, papillate, c. $0.5 \mathrm{~mm}$ diam.; interpistillar staminodes scattered among the pistils, more or less irregularly polygonal, slightly convex-topped, c. $0.5 \mathrm{~mm}$ 
diam.; sterile interstice $8 \mathrm{~mm}$ long, stout, slightly conic, $5 \mathrm{~mm}$ diam., with the staminodes squashed by the spathe constriction; staminodes crowded, irregularly polygonal, c. $0.8 \mathrm{~mm}$ diam.; male zone slightly and rather abruptly thicker than sterile zone, $7 \mathrm{~mm}$ diam. at base, slightly obconic, $1.6 \mathrm{~cm}$ long; stamens very crowded, more or less dumbbell-shaped with the connective mounded between the thecae, c. $1 \mathrm{~mm}$ across; pores more or less elliptic; appendix bullet-shaped, $2.4 \mathrm{~cm}$ long, the base slightly but abruptly wider than top of male zone, c. $1 \mathrm{~cm}$ diam., the tip acute; staminodes of appendix flat-topped, irregularly polygonal, frequently in small connate groups, c. $0.75 \mathrm{~mm}$ diam. Fruiting spathe narrowly urceolate, to c. $4 \mathrm{~cm}$ long.

Distribution - Malesia: endemic to Borneo (Sarawak); restricted to the vicinity of Bintulu.

Habitat - In disturbed or secondary forest in clay loam on slopes, c. $150 \mathrm{~m}$ alt.

Notes - This species is distinguished from other hapaxanthic species allied to S. calyptrata by its robust elongate leaf blade with the base not at all cordate, the low interpistillar staminodes, the stout sterile interstice and the bullet-shaped appendix.

Schismatoglottis clarae is named for Clare Herscovitch who has been of invaluable assistance to A.H.'s research over many years.

Other specimens examined: BORNEO: SARAWAK: locality as for type, Boyce 733 (K); Bintulu, Ulu Segan, Wright S.27960 (K, US).

\section{Schismatoglottis convolvula P. C. Boyce}

Schismatoglottis convolvula P. C. Boyce in Mayo et al., Genera of Araceae (1997) 346, fig. 49(I), E. - Type: Malaysia, Sarawak, 1st Divn, Kuching, mile 38 Padawan Rd, Bukit Manok, 22 Oct 1979, J. Mamit S. 42102 (SAR, holo; iso K, L, US).

Sprawling small herb to c. $20 \mathrm{~cm}$ tall. Stem very slender and elongate, c. $30 \mathrm{~cm}$ long, c. $1 \mathrm{~mm}$ diam. (dry), with internodes to $4 \mathrm{~cm}$ long, decumbent and rooting sparsely along much of its length, apparently hapaxanthic and regenerating from the base. Leaves distant, c. 9 together; petiole c. $4 \mathrm{~cm}$ long, minutely scabrid with dense epidermal papillae (strong lens required), sheathing in the lower $1 / 2-3 / 5$; wings of sheath fully attached but then torn by elongation of subsequent internode, tapering; blade narrowly ovato-sagittate, c. $6.5 \mathrm{~cm}$ long $\times 3 \mathrm{~cm}$ wide, the base cordate with rounded posterior lobes c. $8 \mathrm{~mm}$ long, the apex acute; midrib slightly abaxially prominent, minutely scabrid like the petiole, with 5 primary lateral veins on each side diverging at c. $60^{\circ}$; interprimary veins hardly differentiated; secondary veins almost all arising from the midrib; tertiary venation forming a faint tessellate reticulum abaxially. Inflorescence solitary; peduncle hidden within sheath of last leaf on the stem. Spathe c. $3.5 \mathrm{~cm}$ long; lower spathe narrowly obovoid, $1 \mathrm{~cm}$ long, differentiated from the limb by a distinct constriction; limb more or less ovate, white, c. $2.5 \mathrm{~cm}$ long, ?deciduous. Spadix details unknown; pistils subglobose, c. $0.7 \mathrm{~mm}$ diam.; stigma sessile, buttonlike, c. $0.3 \mathrm{~mm}$ diam.

Distribution - Malesia: endemic to Borneo (Sarawak); known only from the type.

Habitat - Near stream on limestone hill; altitude not specified.

Notes - This species is remarkable for its very elongate slender sprawling habit. In that respect it is reminiscent of S. brevipes (Malay Peninsula) and S. ovata (Sumatera), the latter also having scabrid petioles and internodes. Both of these species are more robust and thick-stemmed than $S$. convolvula however, and they both are allied to $S$. rupestris and other species in a group which appears to be absent from Borneo. Unfortunately most of the spadix is lacking, making confirmation of its relationship to S. calyptrata and allies difficult. However, other than the sprawling habit, it appears to belong to that group in aspect, and there is no sign of renewal growth of the shoot following flowering. 


\section{Schismatoglottis decipiens $A$. Hay, sp. nov.}

A Schismatoglottide motleyana tota inflorescentia mascula e spatha inferiora exserta, interstitio neutro subnudo differt; a Schismatoglottide trivittata nervis primariis paucioribus, appendice quam inflorescentiae masculae apice haud crassiore, in substrato ultramafico crescenti differt. - TYPUS: Cult. RBG Sydney Acc. No. 960586 ex Malaysia, Sabah, Tongod Distr., Gunung Tingkar (orig. coll. Hay et al. 12003), Herscovitch s.n. (SAN, holo; iso K, NSW).

Herb to c. $30 \mathrm{~cm}$ tall. Stem condensed, hypogeal, hapaxanthic, clump-forming, 1-2 cm diam. Leaves c. 4 together; petiole $28-32 \mathrm{~cm}$ long, sheathing in the lower $2 / 5$; wings of sheath fully attached, tapering; blade ovato-sagittate to narrowly sagittate, variegated with a central grey-green band and/or bold and irregularly distributed grey-green blotches, $14-23 \mathrm{~cm}$ long $\times 5-12.5 \mathrm{~cm}$ wide, the base cordate with rather acutely rounded posterior lobes $2-5 \mathrm{~cm}$ long, the apex acute and acuminate for c. $2 \mathrm{~cm}$; midrib not or hardly prominent abaxially (dry), with c. 5 primary lateral veins on each side, alternating with lesser interprimaries and diverging at $45-70^{\circ}$ (usually the angle widest on veins c. $1 / 3$ of the way from the base of the midrib); secondary veins arising from the midrib and from the lower $1 / 3-1 / 2$ the length of the primary veins especially in the proximal half of the blade; tertiary venation more or less obscure or forming a faint tessellate reticulum abaxially. Inflorescences to 4 together; peduncle 5-12 cm long, subtended by short lanceolate cataphylls, the first of which may have a reduced but well-differentiated petiole and blade. Spathe 6.5-8.5 cm long; lower spathe 1.6-3 cm long, narrowly ovoid, differentiated from the limb by a constriction; limb oblonglanceolate, c. $5 \mathrm{~cm}$ long, apiculate, caducous. Spadix c. $7.5 \mathrm{~cm}$ long, subcylindric (weakly hourglass-shaped); female zone 1.2-2 cm long, adnate to the spathe in the lower $1 / 2,7 \mathrm{~mm}$ diam. in the middle, distally somewhat conoid; pistils depressed subglobose, crowded, longitudinally c. 4-lobed, c. $1 \mathrm{~mm}$ diam.; stigma sessile, buttonlike, papillate, c. $0.5 \mathrm{~mm}$ diam.; interpistillar staminodes few, scattered among the pistils, subcylindric (narrowly clavate), about twice the height of the ovary; sterile interstice 6-8 mm long, slightly attenuate, c. $3 \mathrm{~mm}$ diam., naked except for scattered abortive (reduced stigmas) pistils, distally with an irregular whorl of sterile anthers at the base of the male zone; male zone narrowly obconoid, $1-1.7 \mathrm{~cm}$ long, c. $8 \mathrm{~mm}$ diam. at the top; stamens crowded, truncate, more or less dumbbell-shaped with the connective conspicuously thick but not exceeding the thecae in height; pores deeply cleft on the outer edge; appendix more or less cylindric, $1.7-3 \mathrm{~cm}$ long, very slightly thicker shortly above the base than the top of the male zone, c. $8 \mathrm{~mm}$ diam., the tip obtuse; staminodes of appendix irregularly polygonal and flat-topped, with rounded edges before anthesis (edges sharp after anthesis), rather irregular in size within the same spadix, c. 0.5-1 mm diam. Fruiting spathe narrowly urceolate, c. $4.5 \mathrm{~cm}$ long.

Distribution - Malesia: endemic to Borneo (Sabah).

Habitat - Terrestrial on slopes and rocky sites in forest over ultramafic substrate at c. $100-400 \mathrm{~m}$ alt.

Notes - Schismatoglottis decipiens is closely allied to S. trivittata, S. motleyana and other allied species with hapaxanthic stems, fully attached leaf sheaths and caducous spathe limbs. At first sight (hence the specific epithet) it appears to connect $S$. trivittata with S. motleyana. However, it has a unique combination of features in the male zone exserted from the lower spathe chamber, the conspicuous partly naked interstice, the broad flat connective of the stamens, the appendix barely and not abruptly wider than the male zone, and the leaves with rather few primary lateral veins and a large number of secondary veins arising from them (a characteristic generally, though not entirely, otherwise associated with species with larger leaves). 
Other specimens examined: BORNEO: SABAH: Lahad Datu Distr., Segama R., nr Lakanan R., Beaman et al. 10103 (US); Sandakan Distr., Porog, Bidu Bidu Hills, Meijer 41246 (SAN); Sandakan Distr., Telupid, Kg Bauto, Dewol Sundaling SAN 92427 (K, KEP, L, SAN).

56. Schismatoglottis ecaudata $A$. Hay, sp. nov.

A Schismatoglottide calyptrata appendice deficienti differt; a Schismatoglottide wallichii interstitio neutro deficienti differt. - TYPUS: Indonesia, Sumatera, North Sumatera, Medan-Brastagi rd, km 59-61, 21 Feb 1932, W.N. E C.M. Bangham 1151 (K, holo).

Herb c. $20 \mathrm{~cm}$ tall. Stem hypogeal, stoloniferous, hapaxanthic, c. $1 \mathrm{~cm}$ diam. Leaves c. 5 together; petiole to $14 \mathrm{~cm}$ long, sheathing in the lower 1/3; wings of sheath fully attached, persistent, tapering; blade narrowly sagittate, c. $13 \mathrm{~cm}$ long $\times 4 \mathrm{~cm}$ wide, the base weakly and narrowly cordate with posterior lobes c. $1 \mathrm{~cm}$ long, the apex acute and acuminate for c. $1.5 \mathrm{~cm}$; midrib abaxially more or less flush with the lamina, adaxially slightly prominent, with c. 7 primary lateral veins on each side, alternating with lesser interprimaries and diverging at c. 45-60'; secondary venation arising from the midrib and the bases of the primary veins, especially in the proximal part of the blade; tertiary venation obscure. Inflorescence solitary; peduncle c. $8 \mathrm{~cm}$ long, exserted from the subtending leaf base. Spathe $5.5 \mathrm{~cm}$ long; lower spathe ovoid, $2 \mathrm{~cm}$ long, differentiated from the limb by a strong constriction; limb more or less ovate, $3.5 \mathrm{~cm}$ long, somewhat inflated over the male zone of the spadix, thence elongate-acute, ?caducous. Spadix sessile, more or less hourglass-shaped, $4 \mathrm{~cm}$ long; female zone $2.3 \mathrm{~cm}$ long, adnate to the spathe in the lower $2 / 5$, the free part conoid and distally $2 \mathrm{~mm}$ diam.; pistils crowded; ovaries subcylindric to subglobose, c. $0.6 \mathrm{~mm}$ diam.; stigma sessile, discoid, about the diameter of the ovary, papillate; interpistillar staminodes scattered among the pistils, stipitate, clavate with wide rounded tops c. $0.5-1 \mathrm{~mm}$ diam., white, about the height of the pistils; sterile interstice poorly defined, a slight concentration of interpistillar staminodes in about 2 irregular whorls corresponding with the spathe constriction; male zone narrowly obovoid, $1.5 \mathrm{~cm}$ long $\times 6 \mathrm{~mm}$ diam. at the widest point; stamens crowded, truncate with the connective hardly raised above the thecae, strongly hourglass-shaped, c. $1 \mathrm{~mm}$ across, the thecae with conspicuous rims to the pores, terminal stamens with conspicuously longer filaments than the rest; appendix absent. Fruit unknown.

Distribution - Malesia: endemic to Sumatera (North Sumatera); known only from the type.

Habitat — In disturbed lower montane forest at c. $1200 \mathrm{~m}$ alt.

Notes - Schismatoglottis ecaudata evidently belongs in the Schismatoglottis calyptrata group, with its hapaxanthic shoot, fully attached persistent leaf sheath, and conspicuously hourglass-shaped stamens. The mode of spathe limb dehiscence is unknown but would be predicted to be caducous. Schismatoglottis ecaudata is distinguished from almost all species of that group by the absence of an appendix (from which derives the epithet) - a state it shares with $S$. wallichii. In turn it differs from that species by the absence of a well-defined sterile interstice.

As this species is known only from a single collection with one inflorescence, it is possible that it is an exappendiculate abnormality in $S$. calyptrata, which it otherwise closely resembles. However, we have never otherwise come across a deformity of this kind in the numerous specimens and living plants we have examined, and therefore treat it as a distinct species here.

\section{Schismatoglottis edanoi $A$. Hay, sp. nov.}

A Schismatoglottide samarensis statura valde majore, spadice cylindroideo differt. - TYPUS: Philippines, Samar, Mt Sarawag, 3 Dec 1951, G.E. Edaño PNH 15317 (GH, holo; iso L). 
Robust herb. Habit and shoot organisation unknown; vegetative cataphylls linear lanceolate, to $35 \mathrm{~cm}$ long. Petiole to c. $65 \mathrm{~cm}$ long, sheathing in the lower half; blade cordato-sagittate, c. $40 \mathrm{~cm}$ long (estimated - specimen fragmentary) $\times$ c. $26 \mathrm{~cm}$ wide; posterior lobes c. $12 \mathrm{~cm}$ long, rounded; midrib with c. 15 (est.) primary lateral veins on each side diverging at c. $60^{\circ}$; interprimary veins well developed; secondary venation finely striate; tertiary venation inconspicuous. Inflorescence arrangement unknown; peduncle c. $25 \mathrm{~cm}$ long, subtended by a reduced leaf with a blade c. $17 \mathrm{~cm}$ long. Lower spathe c. $5 \mathrm{~cm}$ long, narrowly ovoid; limb caducous, unknown. Spadix sessile, $9 \mathrm{~cm}$ long; female zone $2.5 \mathrm{~cm}$ long, c. $7 \mathrm{~mm}$ thick, partly adnate to spathe in lower half; pistils crowded; ovaries ovoid-cylindric, c. $1 \mathrm{~mm}$ diam.; interpistillar staminodes extremely sparse (only one found), stipitate, clavate, exceeding the pistils; style very short, c. $0.25 \mathrm{~mm}$ long; stigma button-like, slightly wider than style; male zone contiguous with female, $3.5 \mathrm{~cm}$ long, more than half within the lower spathe chamber, slightly constricted at and below the level of spathe constriction, above this c. $1 \mathrm{~cm}$ diam.; appendix cylindric, the same width as the upper part of the male zone, $2.8 \mathrm{~cm}$ long, c. $1 \mathrm{~cm}$ diam., the end blunt; appendical staminodes flat-topped, very numerous, c. $0.5 \mathrm{~mm}$ diam.

Distribution - Malesia: endemic to the Philippines; known only from the type locality (Samar).

Habitat — In forest on ridge top at c. $150 \mathrm{~m}$ alt.

Notes - Evidently related to Schismatoglottis samarensis, also endemic to Samar, $S$. edanoi is distinguished by its much greater overall size and proportionally more elongate inflorescence with cylindric appendix.

Schismatoglottis edanoi is named for the late Gregorio E. Edaño, Filipino collector with the Bureau of Science, Manila, collector of the type.

\section{Schismatoglottis eymae $A$. Hay, sp. nov.}

$\mathrm{Ab}$ aliis speciebus Schismatoglottidis habitu rheophytico, caudice pleionanthico, vagina omnino cum petiolo connata, folii lamina lanceolata, interstitio neutro crasso staminodiis dense tecto, appendice crassa cylindroidea differt. - TYPUS: Indonesia, Central Sulawesi, Menado, Poso, river beyond Bujungtaripa, 22 Aug 1938, P.J. Eyma 3489 (L, holo; iso BO, U).

Herb c. 11-40 cm tall. Stem condensed, more or less epigeal, 1-2 cm diam., pleionanthic. Leaves several together, crowded; petiole 5-30 cm long, sheathing in the lower c. 1/3; wings of sheath fully attached, narrow, tapering; blade lanceolate to narrowly elliptic and then somewhat rhomboid, $7-21 \mathrm{~cm}$ long $\times 1.5-6 \mathrm{~cm}$ wide, the base acute to obtuse and then shortly decurrent, the apex acute and acuminate for $1-3 \mathrm{~cm}$; midrib abaxially somewhat prominent, with 5-9 primary lateral veins on each side, alternating with lesser interprimaries and diverging at $30-45^{\circ}$; secondary venation adaxially obscure, arising from the midrib; tertiary venation obscure. Inflorescence solitary or two together, produced severally in close sequence alternating with foliage leaves; peduncle 3-12 cm long, subtended by very narrowly lanceolate persistent/marcescent cataphylls 4-16 cm long. Spathe 3-5.5 cm long, subcylindric; lower spathe 1-1.5 cm long, narrowly ovoid, differentiated from the limb by a weak constriction; limb more or less lanceolate, $2-4 \mathrm{~cm}$ long, slightly inflated over the appendix and thence acuminate for $0.8-1 \mathrm{~cm}$, ?caducous. Spadix sessile, $2.5-4 \mathrm{~cm}$ long, subcylindric; female zone $0.8-1.5 \mathrm{~cm}$ long, adnate to the spathe in the lower $1 / 2-2 / 3$, the free part narrowly conic and apically $1.5-2 \mathrm{~mm}$ thick corresponding with the spathe constriction; pistils crowded, subglobose, $0.4-0.6 \mathrm{~mm}$ diam.; stigma button-like, about half the diameter of the ovary, elevated on a very short style; interpistillar staminodes very few or none among the pistils otherwise confined to an irregular row along the 
spathe/spadix adnation, shortly stipitate, flat-topped, about the height and diameter of the pistils; sterile interstice well-defined, about $3 \mathrm{~mm}$ long, slightly and abruptly thicker than the top of the female zone, 1.5-3 mm diam., 4-5 compacted whorls of flattopped sterile stamens c. $1 \mathrm{~mm}$ across and drying dark brown; male zone more or less cylindric, $0.7-1 \mathrm{~cm}$ long $\times 2-3 \mathrm{~mm}$ thick; stamens crowded, truncate, strongly dumbbell-shaped, c. $1 \mathrm{~mm}$ across, the connective not raised above the thecae, but the thecae with a narrow raised rim; pores slit-like, C-shaped; appendix 1-1.8 cm long, cylindric, blunt-tipped, the base slightly and abruptly thicker than the male zone, c. 3-4 mm diam.; staminodes of appendix flat-topped and somewhat impressed centrally, c. $0.6 \mathrm{~mm}$ diam. Fruiting peduncle not much elongated; fruiting spathe urceolate, c. 1-1.5 cm long.

Distribution - Malesia: endemic to Sulawesi (Central Sulawesi).

Habitat - On the type not specified other than the reference to a river cited above. The paratype was collected from between rocks in a regularly inundated stream bed in disturbed forest over raised coralline limestone at c. $60 \mathrm{~m}$ alt.

Notes - This species is known from only two collections which differ markedly in size (particularly vegetatively). The upper and lower dimensions in the description are taken from these respective specimens. In its broadly lanceolate, somewhat rhomboid leaf blades with strong primary venation departing the midrib at a low angle, and fully attached leaf sheaths, the robust aspect of this species (represented by the type) bears superficial resemblance to the Sumateran S. okadae. Schismatoglottis eymae differs however, in the interstice being completely covered in staminodes and in the thick, relatively long appendix which is distinctly broader than the male zone. The more delicate and narrower-leaved paratype rather resembles Philippine S. luzonensis, but differs in the robust interstice and subcylindric appendix.

The specific epithet commemorates the collector of the type, P.J. Eyma, who made extensive expeditions in Sulawesi, Maluku and West New Guinea, and who died in a Japanese prisoner-of-war camp in Sumatera in 1945.

Other specimen examined: SULAWESI: Central Sulawesi, NE of Luwuk, on rd from Kayutanyu to Siuna, Coode 5819 (BO, K, L).

\section{Schismatoglottis gamoandra M. Hotta}

Schismatoglottis gamoandra M. Hotta, Mem. Coll. Sci. Univ. Kyoto, ser. B, 32 (1966) 237, fig. 7, A-G. - Type: Malaysia, Sarawak, 4th Divn, Bintulu, along Sg. Latai, small branch of Ulu Sg. Kakus, 7 Nov 1963, M. Hirano \& M. Hotta 817 (KYO, holo).

Small herb to c. $15 \mathrm{~cm}$ tall. Stem hypogeal, creeping, condensed near soil level, more elongate below, ?pleionanthic. Leaves c. 5 together in a rosette; petiole to c. $6 \mathrm{~cm}$ long, sheathing in the lower $1 / 4$, narrowly alate above the sheath, the wing crisped or not; wing of sheath fully attached, broad, apically truncate; blade narrowly ovato-sagittate, 8-11 cm long $\times 3.5-5.5 \mathrm{~cm}$ wide, dark green adaxially, paler abaxially, the apex acute, the base narrowly and rather shallowly cordate with posterior lobes 1-1.5 cm long; midrib adaxially somewhat prominent (dry) less so abaxially, with 5-8 primary lateral veins on each side, alternating with lesser interprimaries and diverging at c. $60^{\circ}$; secondary venation rather sparse, arising mostly from the midrib; tertiary venation forming a conspicuous tessellate reticulum abaxially and adaxially (dry). Inflorescences 1-2 together subtended by short broad cataphylls; peduncle to c. $4 \mathrm{~cm}$ long. Spathe c. $5 \mathrm{~cm}$ long; lower spathe c. $2 \mathrm{~cm}$ long, green, narrowly ovoid, c. $1 \mathrm{~cm}$ diam., differentiated from the limb by an abrupt constriction; limb ovate, inflated over the male zone and appendix of spadix, white, c. $3 \mathrm{~cm}$ long, caducous. Spadix $3.6 \mathrm{~cm}$ long, narrowly hourglass-shaped; female zone $1.6 \mathrm{~cm}$ long, adnate to the spathe in the lower c. $2 / 3$, narrowly spindle-shaped; pistils somewhat lax; ovary subglobose, c. $1 \mathrm{~mm}$ diam.; 
stigma sessile, button-like, papillate, c. $0.3 \mathrm{~mm}$ diam.; interpistillar staminodes absent from among the pistils, confined to a row along the spathe-spadix adnation and concentrated in the sterile interstice, subsessile, truncate, drying scale-like, c. $1.3 \mathrm{~mm}$ across; sterile interstice $5 \mathrm{~mm}$ long covered with lax interpistillar staminodes, distally attenuate to c. $2 \mathrm{~mm}$ diam.; male zone obconic, distally c. $4 \mathrm{~mm}$ diam.; stamens large, c. $1.3 \mathrm{~mm}$ across, truncate, apparently connate, with the dome-like apices of the thecae elevated above the connective and opening through very conspicuous, large apical pores c. $0.6 \mathrm{~mm}$ diam.; appendix more or less hemispheric; staminodes irregularly polygonal with sharp angles and flat tops, c. $0.8 \mathrm{~mm}$ diam. Fruiting spathe narrowly urceolate, c. $3 \mathrm{~cm}$ long.

Distribution - Malesia: endemic to Borneo (Sarawak); known only from the type locality near Bintulu.

Habitat - Not specified on the type specimen. Hotta (loc.cit.) notes 'on clayey soil of the basin of moist valley'; altitude and vegetation unknown.

Notes - This species has highly distinctive large stamens with very robust, apically dome-like thecae opening through very large pores. It appears that the stamens are connate, with faint suture lines marking their union (however, this may merely be due to compression), and that the two pollen sacs on either side of the connective are confluent with each other. At present there is preserved only one dried inflorescence of this species - precluding destructive sampling and examination in greater detail, and more material needs to be collected in order to observe and interpret the male zone more confidently.

The stem organisation is also not clear from the type: there is no sign of renewal growth after flowering; however, the rather long but condensed rhizome suggests prolonged growth and hence pleionanthy.

\section{Schismatoglottis lingua $A$. Hay, sp. nov.}

A Schismatoglottide calyptrata habitu rheophytico sylvam 'kerangas' incolanti, folii lamina producta oblongo-lanceolata, inflorescentia magna unica, pedunculo dimidium petioli superanti; spadice robustiore, appendice crassa differt. - TYPUS: Cult. RBG Sydney Acc. No. 960523 ex Malaysia, Sabah, Maliau Basin Field Centre (orig. coll. Hay et al. 12098) C. Herscovitch s.n. (SAN, holo; iso NSW).

Herb to $65 \mathrm{~cm}$ tall. Stem condensed, clump-forming, hypogeal, hapaxanthic, c. $1.5 \mathrm{~cm}$ thick. Leaves 2-3 together; petiole $27-50 \mathrm{~cm}$ long, sheathing in the lower $1 / 4-1 / 3$, held very erect; wings of sheath broad, tapering and apically narrowly truncate, fully attached to the petiole, overlapping and more or less forming a pseudostem; blade oblong-lanceolate, c. $30 \mathrm{~cm}$ long $\times 7 \mathrm{~cm}$ wide, dark to mid-green and slightly glossy adaxially, paler abaxially, the base shortly cordate to auriculate, the apex acute and slightly acuminate; midrib somewhat prominent in the lower part abaxially (dry; prominent throughout abaxially when fresh), adaxially flush with the lamina to slightly raised; primary lateral veins c. 10 on each side of the midrib alternating with lesser interprimaries and diverging at c. $60-90^{\circ}$, when widely diverging then somewhat abruptly ascending to join the margin; secondary venation mostly arising from the midrib, some from the base of the primary veins; tertiary venation indistinct. Inflorescence solitary; peduncle more than half the length of the petiole, $18-25 \mathrm{~cm}$ long. Spathe 9-11 cm long; lower spathe green, narrowly ovoid, 4-5.5 cm long, differentiated from the limb by a distinct constriction; limb broadly ovate, $5-6.5 \mathrm{~cm}$ long, pale green, inflated over the appendix and then acuminate for $1.5 \mathrm{~cm}$, caducous. Spadix sessile, $6.5-8.5 \mathrm{~cm}$ long, hourglass-shaped; female zone $3.5-5 \mathrm{~cm}$ long, adnate to the spathe in the lower $1 / 2,4-6 \mathrm{~mm}$ diam. in the middle, attenuate distally to c. $2 \mathrm{~mm}$ diam.; pistils subglobose to somewhat columnar, basally more or less crowded, distally lax to very 
lax, c. $1 \mathrm{~mm}$ diam.; stigma sessile, discoid, somewhat narrower than the ovary, c. $0.6 \mathrm{~mm}$ across, papillate; interpistillar staminodes scattered among the pistils, stipitate, clavate with flat tops, about twice the height of the ovaries, c. $0.6 \mathrm{~mm}$ across; sterile interstice ill-defined, mostly naked with a few ?abortive pistils to mainly covered in pistils squashed by the spathe constriction; male zone obconic, c. $1.7 \mathrm{~cm}$ long, c. $3 \mathrm{~mm}$ wide at the base, $8 \mathrm{~mm}$ wide at the top; stamens crowded, c. $0.5 \mathrm{~mm}$ across, hourglassshaped, the connective thin and not elevated above the thecae; thecae with slightly elevated rims cut at the outer edge by a narrow slit; appendix hemispheric to squatcylindric and apically broadly obtuse, at the base slightly but abruptly wider than the top of the male zone, $1-1.5 \mathrm{~cm}$ long $\times 0.9-1.2 \mathrm{~cm}$ diam.; staminodes of appendix whitish, columnar, flat-topped and irregularly polygonal with rounded edges, $0.5-1 \mathrm{~cm}$ diam. Fruiting spathe narrowly urceolate, to $5 \mathrm{~cm}$ long. - Fig. 15.

Distribution - Malesia: endemic to Borneo (southern Sabah).

Habitat - Stream banks in kerangas forest at $960 \mathrm{~m}$ alt.

Notes - In spadix structure this species is very similar to S. calyptrata, differing chiefly in the larger dimensions and heavier appendix. However, it can be very easily differentiated by the solitary long-pedunculate inflorescence, with the rims of the staminal thecae elevated well above the connective, the very erect petioles with bases joined by the wings of the sheath into something resembling a pseudostem, and by the very elongate, tongue-shaped leaves from which the epithet is derived. Although it does not grow in streams, the three collections are all from stream banks, and one of A. H.'s was in conjunction with obligate rheophytes such as Dipteris lobbiana. A.H.'s collections were both from kerangas forest; it is not clear what vegetation type the third collection (cited below) was from.

Other specimens examined: BORNEO: SABAH: Cult. RBG Sydney Acc. No. 960575 ex Maliau Basin Feld Centre (orig. coll. Hay et al. 12111) Herscovitch s.n. (NSW, SAN); Nabawan Distr., Syt. Benawood [sic], Sg. Maadun, Krispinus SAN 119368 (K, SAN).

\section{Schismatoglottis longifolia Ridl.}

Schismatoglottis longifolia Ridl. J. Bot. 40 (1902) 37 \& Materials Fl. Mal. Pen. 3 (1907) 34 \& J. Straits Branch Roy. Asiat. Soc. 57 (1910) 113 \& Fl. Mal. Pen. 5 (1925) 114; Engl., Pflanzenr. 55 (IV.23Da) (1912) 89, fig. 58; Hay, Sandakania 7 (1996) 26, fig.2G. — Type: Malaysia, Perak, Bukit Larut, King's Collector 1967 (K, lecto; selected by Hay, loc. cit.).

Clump-forming herb to $50 \mathrm{~cm}$ tall. Stem hypogeal, hapaxanthic, to c. $2 \mathrm{~cm}$ diam. Leaves c. 5 together; petiole c. $25-40 \mathrm{~cm}$ long, smooth, somewhat flattened adaxially, with the angles rounded to acute, sheathing in the lower c. 1/2; wings of sheath tapering, fully attached except for c. 1-2 mm distal ligular portion; blades dull to slightly glossy rich mid-green, not variegated, c. (17-)21-40 cm long, (3-)5-8 cm wide at widest point, oblanceolate, the base attenuate to narrowly rounded, the apex shortly acuminate and mucronate for c. $1.5-2 \mathrm{~cm}$, the mucro solid; primary venation c. 6-8 per side, diverging at an angle of c. $35-45^{\circ}$, flush adaxially, barely prominent abaxially, interprimary veins irregularly present, secondary and tertiary venation inconspicuous and flush with the lamina. Inflorescences several to c. 12 together, on very slender, wiry, suberect peduncles c. 12-25 cm long (elongating in fruit), nodding from the apex of the peduncle. Spathe to (3-)5-6 cm long incl. the c. $1 \mathrm{~cm}$ long mucro; lower spathe $1.5-2 \mathrm{~cm}$ long, narrowly ovoid, c. $0.8 \mathrm{~cm}$ diam. at anthesis, mid-green, differentiated from spathe limb by a rather weak constriction; limb narrowly lanceolate, clasping and slightly gaping at anthesis, then deliquescent-deciduous, pale yellowish green. Spadix equalling laminar portion of spathe in length; female zone $1 / 3-1 / 2$ the length of the spadix, adnate for c. $2 / 3$ its length to the spathe, c. $5 \mathrm{~mm}$ thick; interpistillar staminodes few amongst the ovaries, mainly concentrated into a somewhat 


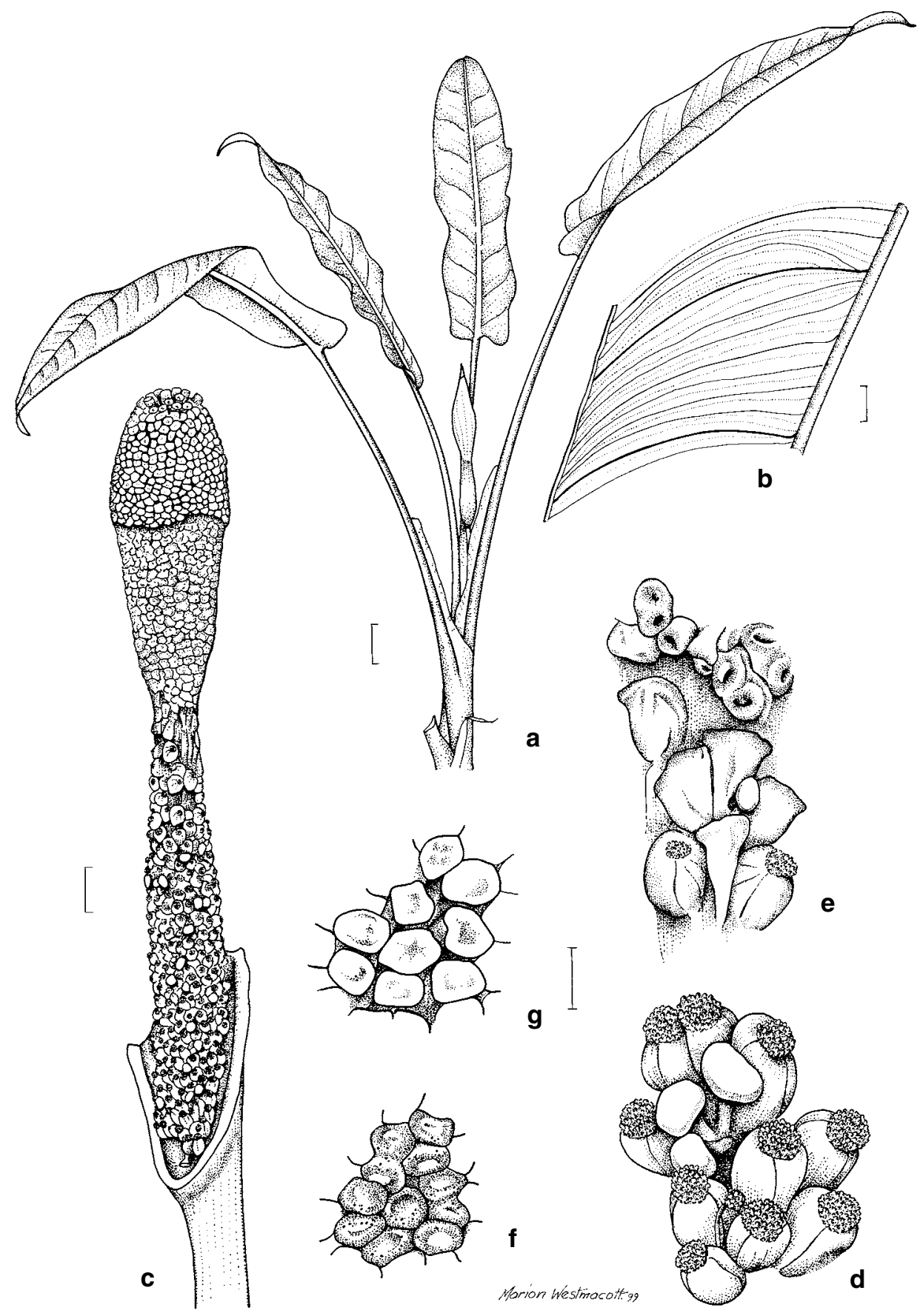

Fig. 15. Schismatoglottis lingua A. Hay. a, Habit; b, Venation; c, Spadix; d, Pistils with interpistillar staminodes; e, Interface of female and male zones; $\mathbf{f}$, Stamens; $\mathbf{g}$, Staminodes of appendix (RBG Sydney Acc. No. 960575). Scale bars: $\mathrm{a}=2 \mathrm{~cm} ; \mathrm{b}, \mathrm{c}=4 \mathrm{~mm} ; \mathrm{d}-\mathrm{g}=1 \mathrm{~mm}$. 
interrupted single row along the spathe/spadix adnation and at the apex of the female zone forming a c. $2 \mathrm{~mm}$ long sterile interstice, slender-stalked, apically narrowly clavate, a little higher than the pistils; pistils globose, rather distant, c. $1 \mathrm{~mm}$ diam.; stigma button-like, sessile, c. $0.3 \mathrm{~mm}$ diam.; male zone cylindric, c. $1 \mathrm{~cm}$ long, $5 \mathrm{~mm}$ thick; stamens close-packed, some with filaments partially united forming dimerous to trimerous male 'flowers', others solitary; anthers more or less dumbbell-shaped from above with the connective forming a slight dome between the thecae; thecae opening through large apical slit-like pores (becoming gaping at dehiscence); pollen dusty; appendix c. $1.5 \mathrm{~cm}$ long tapering-cylindric to very narrowly ovoid, c. $5 \mathrm{~mm}$ thick at base, composed of very close-packed columnar flat-topped staminodes c. $0.7 \mathrm{~mm}$ diam. Fruiting spathe narrowly campanulate, nodding; fruit green.

Distribution - Malesia: disjunct between the Malay Peninsula, (Perak), and a few localities in Borneo (Brunei and Sarawak).

Habitat - In lowland rain forest and lowland hill forest, and regrowth, sometimes near streams, occasionally in swampy areas, to c. $250 \mathrm{~m}$ alt.

Notes - A very distinctive species easily recognised by the nodding inflorescences on (for this genus) very long slender peduncles. Although it does sometimes grow along streams, it is by no means confined to that habitat and in spite of its rather narrow leaf blades, it is not a rheophyte.

Bogner (pers. comm.) has observed that Sarawak material has basal placentation, while material from the Malay Peninsula has parietal placentation.

Other specimens examined: MALAY PENINSULA: Perak, Tanjong Pondok, Burkill \& Hanif 13246 (K, SING); Perak, Bukit Larut, Hay et al. 9063 (UPM); cult. RBG Sydney Acc. No. 940121 ex Perak, foothills of G. Bubu, (orig. coll. Hay et al. 9125 (†); Perak, Taiping Hill, Henderson 10253 (SING); Perak, Taiping, along rd to Maxwell's Hill, Nicolson 1069 (SING); Perak, Kuala Temangoh, Ridley 14307 (SING); Perak, G. Hijau, Ridley s.n. (SING); 'Perak Hills', Ridley s.n. (K); Perak, Maxwell's Hill, Ridley s.n. (SING); Perak, Relau Tujor, Wray 1784 (CAL), 2193 (CAL, SING). BORNEO: SARAWAK: $1^{\text {st }}$ Divn, just outside Kubah NP, above intake dam on Sg. Bungen, Boyce 770 (K); Serian, Brooke 9605 (L); BRUNEI: Luang Kolom, Bernstein JHB228 (K); Brunei Muara, Lumapas, Bukit Lumapas, Bygrave et al. 46 (K); Belait Distr., Labi, Sg. Rampayoh, Coode et al. 7297 (K); Tutong Distr., Ukong, Andulau FR, Bukit Besong, Dransfield et al. 1146 (K); Belait Distr., Labi, Sg. Rampayoh, Dransfield et al. $1283(\mathrm{~K})$.

\section{Schismatoglottis longispatha W. Bull}

Schismatoglottis longispatha W. Bull, Retail List (1881) 20, un-numbered fig. on p. 6; Rodigas, Ill. Hort. 29 (1882) 159, pl. 466; Engl., Pflanzenr. 55 (IV.23Da) (1912) 105. - Type: W. Bull., Retail List (1881) 6, un-numbered fig. Epitype: Cult. Hort. Bull ex Borneo, 12 Jan 1881, N. E. Brown s.n. (K; designated here).

Diminutive stoloniferous colony-forming herb to c. $20 \mathrm{~cm}$ tall. Stem condensed, hypogeal, hapaxanthic, c. $0.5 \mathrm{~cm}$ diam., emitting subterranean stolons to c. $40 \mathrm{~cm}$ long. Leaves 1-2 together (to 3 in cultivation); petiole 6-15 cm long, sheathing in the lower c. $1 / 2$; wings of sheath fully attached, tapering but apically obtuse; blade oblong ovate, dull mid-green, spattered with grey-green or with a central grey-green band, or not variegated, c. $11 \mathrm{~cm}$ long $\times 4.5 \mathrm{~cm}$ wide, the base obtuse to emarginate, the tip broadly acute and rather abruptly acuminate for c. $1 \mathrm{~cm}$; midrib more or less flush with the lamina (dry), with c. 6 primary lateral veins on each side, alternating with lesser interprimaries and diverging at c. $50^{\circ}$; secondary venation adaxially obscure, abaxially faint, arising from the midrib, a few from the lower parts of the primary veins; tertiary venation obscure. Inflorescence solitary; peduncle c. $4 \mathrm{~cm}$ long, subtended by a cataphyll its own length or by a foliage leaf. Spathe to c. $12 \mathrm{~cm}$ long, slender; lower spathe very narrowly ovoid, green, to $4.5 \mathrm{~cm}$ long, differentiated from the limb by a weak constriction; limb narrowly lanceolate, hardly opening, to c. $8 \mathrm{~cm}$ long. 
Spadix 7.5-10.5 cm long, slender, subcylindric; female zone c. 2-3.5 cm long, almost completely adnate to the spathe; pistils subglobose to more or less rhomboid through squashing together, c. $1 \mathrm{~mm}$ diam.; stigma sessile, button-like, papillate, c. $0.5 \mathrm{~mm}$ diam.; interpistillar staminodes scattered among the pistils subglobose to squatcylindric, shorter than to subequalling the pistils in height, c. $0.5 \mathrm{~mm}$ diam., more crowded at apex of female zone; sterile interstice more or less absent, but interface of fertile zones somewhat lax; male zone cylindric, c. $1 / 4-1 / 3$ held within the lower spathe chamber, c. $2 \mathrm{~cm}$ long $\times 3 \mathrm{~mm}$ thick; stamens somewhat crowded, each ostensibly a single theca, with a large round to ellipsoid pore (some dimerous, but unclear whether these are single complete stamens or two connate stamens), c. $0.5 \mathrm{~mm}$ diam.; appendix slender and elongate, basally isodiametric with male zone, tapering to a fine point, to $4.5 \mathrm{~cm}$ long; staminodes of appendix rounded, low, the bases sometimes stretched parallel to long axis of spadix, c. $0.5 \mathrm{~mm}$ diam. Fruit unknown.

Distribution - Malesia: endemic to Borneo (Sarawak).

Habitat - Disturbed area of secondary lowland rainforest at low elevation.

Notes - The slender, elongate proportions of the spadix suggest that this species is allied to $S$. trifasciata. However, it is distinguished from it, and most other Schismatoglottis species by the apparently monomerous anthers. A somewhat similar state is apparently found in S. winkleri (q.v.) and (less so) in S. gamoandra (q.v.) where the pollen sacs are confluent, but in that case within each theca. In the latter species the stamens themselves also appear to be connate. The homology needs to be investigated anatomically.

Other specimen examined: BORNEO: SARAWAK: Cult. RBG Sydney Acc. No. 940533 ex Kg Sentah, nr Kuching (orig. coll. Hay et al. 9383), Herscovitch s.n. (K, NSW, SAR).

\section{Schismatoglottis luzonensis Engl.}

Schismatoglottis luzonensis Engl., Pflanzenr. 55 (IV.23Da) (1912) 88; Merr., Enum. Philipp. Fl. Pl. 1 (1922) 182 [non S. luzonensis Engl., op. cit.: 121; i.e. S. plurivenia Alderw.]. - Type: Philippines, Luzon, Rizal Prov., Montalban, Mar 1906, Merrill BS 5047 (PNH, holo, presumed destroyed). - Neotype: Catanduanes, Ramos E Edaño BS 75547 (NY, SING, UC; designated here).

Very small to small rheophytic herb. Shoots pleionanthic. Petiole 8-20 cm long, sheathing in the lower $1 / 3-1 / 2$; blade narrowly lanceolate to elliptic, rarely oblong ovate, $7-17 \mathrm{~cm}$ long $\times 1.2-4 \mathrm{~cm}$ wide, the apex narrowly acute to shortly acuminate, the base tapering to (rarely) obtuse, asymmetric; midrib with $2-4$ rather distant primary lateral veins on each side, diverging at c. $45-60^{\circ}$ and running distally to the margins. Inflorescence solitary or if two or three together then these interspersed with foliage leaves; peduncle c. $1 / 3$ the length of the petioles. Spathe $2-3 \mathrm{~cm}$ long, constricted at c. $1 / 3$ from the base; limb turbinate, distally acuminate, caducous. Spadix sessile, somewhat shorter than the spathe; female zone $7 \mathrm{~mm}$ long, adnate to the spathe in the basal 1/2; ovaries ovoid, c. $0.5 \mathrm{~mm}$ diam.; stigma sessile, globose; sterile interstice ill-defined, the spadix axis bearing either sparse pistils or stamens at level of spathe constriction, c. $1.5 \mathrm{~mm}$ diam.; male zone otherwise obconic, c. $7 \mathrm{~mm}$ long, to $3 \mathrm{~mm}$ diam. at apex; appendix conical to hemispherical, c. $3 \mathrm{~mm}$ long, occasionally to $5.5 \mathrm{~mm}$. Fruiting spathe c. $1 \mathrm{~cm}$ long, asymmetric cup-shaped.

Distribution - Malesia: endemic to and widespread in the Philippines.

Habitat - Rheophytic on rocks in forest streams at low elevation to c. $300 \mathrm{~m}$ alt.

Notes - This species exhibits strong rheophytic stenophylly in specimens collected explicitly from rocks in streams. Mendoza PNH 98593 has unusually wide leaves in the duplicates at L and US (but that at $\mathrm{K}$ is stenophyllous) and is described as having been 
collected on a river bank. It is possible that there is some element of facultative stenophylly in this species, according to microhabitat. Fenix BS 24952 is also unusually broad-leaved and bears some resemblance to $S$. calyptrata, but the specimens show evidence of renewal growth, which does not occur in the shoots of that species. Most specimens have a rather characteristic dark straw colour.

Interpretation fo the application of this name, in the abscence of its type, is based on Engler's description and subsequent determinations by Merrill. The designated neotype is a well-preserved representative comforming with Engler's concept.

Other specimens examined: PHILIPPINES: Panay, Capiz Prov., Agsaman R., Edaño BS 46139 (UC); Luzon, Camarines Sur, Kamugong R., Edaño BS 75855 (BO, NY); Mindanao, Bukidnon Subprov., vicinity of Tanculan, Fenix BS 24952 (K, US); Luzon, Quezon Prov., Guinayangan, Hinakaan, Mendoza PNH 98593 (K, L, US); Catanduanes, Ramos BS 30543 (K, US); Bohol, Ramos BS 42664 (BO, K, UC); Panay, Capiz Prov., Jamindan, Ramos E Edaño BS 30875 (NY, SING).

\section{Schismatoglottis merrillii Engl.}

Schismatoglottis merrillii Engl., Pflanzenr. 55 (IV.23Da) (1912) 89; Merr., Enum. Philipp. Fl. Pl. 1 (1922) 182. - Type: Luzon, Benguet Prov., Sablang, Nov 1910, Fenix BS 12679 (B, lecto; isolecto BM, K, PNHt, US; selected here).

Schismatoglottis ramosii Engl., Pflanzenr. 55 (IV.23Da) (1912) 98; Merr., Enum. Philipp. Fl. Pl. 1 (1922) 182. - Type: Luzon, Benguet Prov., Sablang, Nov 1910, Fenix BS 12679 (PNHt, lecto; isolecto B, BM, K, US; selected here).

Schismatoglottis rizalensis Engl., Pflanzenr. 55 (IV.23Da) (1912) 100. - Type: Luzon, Rizal Prov., Ahern's collector 3351 (B, holo; K, US iso).

Moderately robust herb. Stem ?becoming epigeal, ?pleionanthic. Petioles $18-42 \mathrm{~cm}$ long, sheathing in the lower half; wings of sheath fully attached, tapering; blade elliptic to ovate, $16-25 \mathrm{~cm}$ long x 4.5-10 cm wide; tip acuminate for c. $2 \mathrm{~cm}$; base broadly acute to obtuse, rarely very slightly cordate; midrib abaxially somewhat prominent, with c. 10-12 primary lateral veins on each side, these alternating with well-defined interprimary veins, diverging at c. 30-45 . Inflorescences several together; peduncle short at anthesis, extending to c. $15 \mathrm{~cm}$ in fruit. Spathe $3.5-4 \mathrm{~cm}$ long, constricted at c. $1 / 4$.. of the way from the base; limb white, turbinate, distally acuminate, caducous. Spadix 2.3-3 cm long, sessile; female zone c. $1 \mathrm{~cm}$ long, partly adnate to the spathe; interpistillar staminodes absent; interface between male and female zones occupied by a short (c. $1.5 \mathrm{~mm}$ ) zone of staminodes resembling sterile stamens (i.e. not resembling the clavate interpistillar staminodes of related species); male zone obconic, c. $1 \mathrm{~cm}$ long x $5 \mathrm{~mm}$ wide at top; appendix bluntly conic, c. $1 \mathrm{~cm}$ long; appendical staminodes flat-topped. Fruiting spathe c. $2.5 \mathrm{~cm}$ long, subcylindric, asymmetric.

Distribution - Malesia: endemic to the Philippines (Luzon).

Habitat - On cliffs and ledges along forest streams at low altitude.

Notes - Different duplicates of Fenix BS 12679 were cited by Engler as syntypes of S. merrillii and S. ramosii (at B and PNH respectively, the latter presumed lost). The other syntype of $S$. merrillii (Vanoverbergh 420) was at PNH and is presumed lost; a duplicate survives at B. The other syntype of S. ramosii (Ramos BS 13023) was at PNH and is also presumed lost; a duplicate has not been located. There seems little alternative but to interpret $S$. ramosii indirectly through duplicates of Fenix BS 12679, which are selected as isolectotypes, with the lost PNH duplicate as lectotype. S. merrillii can be interpreted directly through the Berlin duplicate of this same collection, which was cited by Engler and which is therefore selected as lectotype.

Whether this species is distinct from S. plurivenia is not clear. They differ chiefly in leaf shape, which does not intergrade between the two, on the basis of the material available. This requires re-evaluation in the field. 
This species is somewhat similar to $S$. calyptrata, differing in the ovate leaf, the more numerous primary and interprimary veins, the ring of staminodes at the base of the male zone and the absence of interpistillar staminodes within the female zone. It is not wholly clear from the available material if the stems are pleionanthic, and this feature needs to be re-examined in the field.

Other specimens examined: PHILIPPINES: Luzon, Abra Prov., Massisiat, Alcasid et al. PNH 1642; Benguet Prov., Baguio, Elmer 8690 (BO, E, G, K, L, WRSL); Montalban, Loher 2453 (K); Arambibi, Morong, Loher 2454 (K); Quezon Prov., Hinakaan, Mendoza PNH 97931 (K, L); Luzon, Bontoc Prov., Vanoverbergh 420 (B).

\section{Schismatoglottis mindanaoana Engl.}

Schismatoglottis mindanaoana Engl., Pflanzenr. 55 (IV.23Da) (1912) 103; Merr., Enum. Philipp. Fl. Pl. 1 (1922) 182. - Types: Mindanao, Lake Lanao, Strong BS 1225; Batuan Sub-province, Agusan R., Merrill BS 7320; Davao Prov., Todaya (Mt Apo), Elmer 11753 (none found; all presumed destroyed). - Neotype: Mindanao, Agusan Prov., Cabadbaran (Mt Urdaneta), Elmer 13489 (US, neo; isoneo BO, G, GH, K, L, NY, U, UC; designated here).

Very diminutive herb. Stem shortly creeping, ?pleionanthic, to c. $3 \mathrm{~mm}$ diam. Petiole 2-9 cm long, sheathing in the lower $1 / 4$, the adaxial margins minutely crispate; leaf blade dull dark green adaxially, paler and glaucescent abaxially; oblong elliptic to slightly obovate, c. $4.8 \mathrm{~cm}$ long $\times 1.5-3 \mathrm{~cm}$ wide; apex acute and minutely apiculate, the base obtuse to truncate to narrowly and shallowly cordate; midrib with 2-4 primary lateral veins diverging at $45-60^{\circ}$ and then curved acropetally and distally joining the margin; secondary and tertiary venation forming a distinct tessellate pattern abaxially. Inflorescence solitary or two in succession; peduncle c. $2 \mathrm{~cm}$ long. Spathe $1.5 \mathrm{~cm}$ long, constricted at about midway along its length, the limb turbinate and thence acuminate, caducous by male anthesis, white. Spadix c. $9 \mathrm{~mm}$ long, sessile; female zone $2 \mathrm{~mm}$ long, partly adnate to spathe; pistils subglobose, ?without interpistillar staminodes, c. $0.4 \mathrm{~mm}$ diam.; stigma sessile, punctiform; male zone contiguous with female, c. $7 \mathrm{~mm}$ long, c. $1.5 \mathrm{~mm}$ diam., half inside and half projecting from the mouth of the lower spathe after the limb has fallen, slightly attenuated at midpoint corresponding with spathe constriction; appendix hemispherical, $1.5 \mathrm{~mm}$ long, slightly wider than male zone; staminodes narrowly ovoid, pointed. Fruiting spathe c. $5 \mathrm{~mm}$ long, cup-shaped.

Distribution - Malesia: endemic to the Philippines (Mindanao).

Habitat - Lithophytic in forest and on forest river banks (but not rheophytic) to $500 \mathrm{~m}$ alt.

Interpretation of the application of this name, in the absence of any of its syntypes, is based on Engler's description and subsequent determinations by Merrill. The designated neotype is a well-preserved representative conforming with Engler's concept.

Other specimens examined: PHILIPPINES: Mindanao, Surigao Prov., Mt Kabatuan, Mendoza $\mathcal{E}$ Convocar PNH 10503 (GH, L); Surigao Prov. (no specific locality) Wenzel 3227 (G, GH, K, NY, UC).

\section{Schismatoglottis modesta Schott}

Schismatoglottis modesta Schott, Ann. Mus. Lugd.-Bat. 1 (1863) 125; Engl. in A. \& C. DC., Monogr. Phanerogam. 2 (1879) 351 \& in Becc., Malesia 1 (1883) 288; Hallier f., Bull. Herb. Boiss. 6 (1898) 613; Engl., Pflanzenr. 55 (IV.23Da) (1912) 351. — Type: Indonesia, Kalimantan, without locality, P.W. Korthals s.n. (L, holo; iso K).

Small herb to c. $20 \mathrm{~cm}$ tall. Stem ?epigeal (see notes), c. $2 \mathrm{~mm}$ thick with internodes to $8 \mathrm{~mm}$. Leaves 3-4 together; petiole c. $11 \mathrm{~cm}$ long, sheathing in the lower $1 / 3$; wings of sheath fully attached, tapering; blade ovato-sagittate, c. $9 \mathrm{~cm}$ long $\times 4 \mathrm{~cm}$ wide, the 
base cordate with rounded posterior lobes to $1 \mathrm{~cm}$ long, the apex acute and acuminate for c. $1 \mathrm{~cm}$ finally with an up to $6 \mathrm{~mm}$ long filamentous mucro; midrib slightly prominent adaxially, with 5-6 primary lateral veins on each side, irregularly alternating with lesser interprimaries and diverging at c. $80^{\circ}$; secondary venation mostly arising from the midrib, some from near the bases of the primary veins; tertiary venation obscure. Inflorescence solitary; peduncle about half the length of to subequalling the petiole. Spathe incompletely known; lower spathe $1.5-2 \mathrm{~cm}$ long, narrowly ovoid, differentiated from the limb by a constriction; limb not known. Spadix c. $3 \mathrm{~cm}$ long, narrowly hourglass-shaped; female zone c. $1.5 \mathrm{~cm}$ long, adnate to the spathe in the lower c. $1 / 4$, c. $3 \mathrm{~mm}$ diam. in the middle, distally tapering to $1.5 \mathrm{~mm}$ diam.; pistils somewhat lax proximally, the distal ones very lax, ovoid, somewhat upward-facing, c. $0.6 \mathrm{~mm}$ diam.; stigma elevated on a very short style, button-like, c. $0.2 \mathrm{~mm}$ diam.; interpistillar staminodes very few, scattered among the pistils, clavate, stalked, slightly taller than the pistils; interstice attenuate, c. $2 \mathrm{~mm}$ diam., naked except for a few scattered abortive pistils, the top of the interstice occupied by 1-2 irregular whorls of staminodes at the base of the male zone, these ?scale-like and diagonally upward-facing, sitting just outside the lower spathe chamber; male zone narrowly obconoid, $7 \mathrm{~mm}$ long $\times 3.5 \mathrm{~mm}$ wide at the top; stamens crowded, truncate more or less dumbbell-shaped, c. $0.6 \mathrm{~mm}$ across, with the connective slightly elevated into a peak on one side between the thecae; appendix conoid, $6 \mathrm{~mm}$ long, the base slightly and abruptly wider than the top of the male zone, c. $5 \mathrm{~mm}$ diam.; staminodes of the appendix columnar, rounded-topped, the apical ones extended somewhat to make the tip sharply acute. Fruit unknown.

Distribution - Malesia: endemic to Borneo (southern Kalimantan); known with certainly only from the type, which is of imprecise provenance.

Habitat - Unknown.

Notes - Though one of the earliest Bornean species described in this genus, it remains poorly known. The habit is not clear from the type, in which there is a short piece of elongate stem suggesting that this may be epigeal in nature. However, side shoots in hypogeal species may sometimes have long internodes between the point of origin and the ground surface. The most distinctive feature, besides the very small size, of the plant, is the short zone of apparently large scale-like staminodes at the base of the male zone. An attempt has not been made to examine these in detail as this would entail damaging the only inflorescence on the holotype.

Engler (1883, 1912) included a Beccari collection P.B. 946 (FI) in S. modesta. This specimen has not been examined during this revision.

67. Schismatoglottis moodii $A$. Hay, sp. nov.

A Schismatoglottide calyptrata statura valde majore, folii lamina hasto-sagittata, inflorescentia femina ad spatham haud adnata, appendice crasse et brevissime cylindroidea differt. - TYPUS: Cult. Haleiwa, Hawaii ex Malaysia, Sabah, Tenom Distr., near Tenom Agricultural Research Station (orig. coll. Mood M 854), J. Mood s.n. (NSW, holo).

Robust herb to $80 \mathrm{~cm}$ tall. Stem epigeal, $1-1.5 \mathrm{~cm}$ diam., clump-forming. Leaves $2-3$ together; petiole c. $60 \mathrm{~cm}$ long, sheathing in the lower 1/4; wings of sheath fully attached, tapering; blade broadly hasto-sagittate, $35 \mathrm{~cm}$ long $\times 21 \mathrm{~cm}$ wide, the base deeply divided into 2 acutely rounded somewhat out-turned posterior lobes c. $15 \mathrm{~cm}$ long, the apex obtuse and shortly acuminate for c. $1.5 \mathrm{~cm}$; midrib somewhat prominent adaxially (dry), with c. 11 primary lateral veins on each side, alternating with lesser interprimaries and diverging at 60-90 $0^{\circ}$, occasionally branched especially in the lower part of the blade; secondary venation mostly arising from the primary veins, a smaller 
proportion arising from the midrib; tertiary venation obscure. Inflorescence usually solitary; peduncle more than $20 \mathrm{~cm}$ long, stout. Spathe $12-15 \mathrm{~cm}$ long; lower spathe narrowly ovoid, 4-5 cm long, differentiated from the limb by a distinct constriction; limb 7-9 cm long, more or less ovate, inflated over the appendix then acuminate for $2.5-3 \mathrm{~cm}$, caducous. Spadix 8-10 cm long, narrowly hourglass-shaped; female zone 5-6 cm long (including the ill-defined interstice), obliquely inserted, otherwise not adnate to the spathe, narrowly conoid, the upper $7 \mathrm{~mm}$ exserted from the mouth of the lower spathe chamber, $1.1 \mathrm{~cm}$ diam. at the middle, tapering to $5 \mathrm{~mm}$ diam. at the top; pistils crowded, narrowly ovoid, $1 \mathrm{~mm}$ diam., in the attenuate upper part of the female zone becoming lax and depressed (almost flattened) subglobose and to $2 \mathrm{~mm}$ diam.; stigma sessile, button-like, c. $0.5 \mathrm{~mm}$ diam.; interpistillar staminodes few scattered among the pistils, long- and slender-stalked, clavate, about twice the height of the pistils; interstice comprising the attenuate upper $1.3 \mathrm{~cm}$ of the female zone with flattened lax ?fertile pistils; male zone conoid, $1.8 \mathrm{~cm}$ long, basally isodiametric with the top of the female zone/interstice, apically $1.2 \mathrm{~cm}$ diam.; stamens crowded, truncate, dumbbellshaped with the connective thin and slightly elevated between the thecae; rims of pores broadly cleft on the outer edges; appendix shortly cylindric, $1.7 \mathrm{~cm}$ long, apically very broadly obtuse/truncate, the base slightly and abruptly wider than the top of the male zone, $1.5 \mathrm{~cm}$ diam.; staminodes of the appendix flat- and slightly depressedtopped, irregularly polygonal, c. $1 \mathrm{~mm}$ diam. Fruit unknown. - Fig. 16.

Distribution - Malesia: endemic to Borneo (Sabah); known only from the type collection.

Habitat - Terrestrial in secondary forest along a stream at $230 \mathrm{~m}$ alt.

Notes - This species resembles $S$. trusmadiensis (q.v.) in the hasto-sagittate leaf blade. It differs in the much more robust stature, the female zone not adnate to the spathe, the shortly cylindric appendix, taller interpistillar staminodes and the narrower connective.

Schismatoglottis moodii is named for John Mood (Hawaii) who has built an important living collection of Aroids and Gingers, bringing several new species to light.

68. Schismatoglottis motleyana (Schott) Engl.

Schismatoglottis motleyana (Schott) Engl., Pflanzenr. 55 (IV.23Da) (1912) 102. - Apatemone motleyana Schott, Gen. Aroid. (1858) t. 57; Prodr. Syst. Aroid.(1860) 318; Engl. in A. \& C. DC., Monogr. Phanerogam. 2 (1879) 355. - Type: Malaysia, Sabah, Labuan, T. Motley s.n. (K, holo; 2 sheets).

Schismatoglottis pulchra N. E. Br., Ill. Hort. 31 (1884) 73, t. 520 \& Gard. Chron. Ser. 2, 24 (1885) 361, fig. 76; Hallier f., Bull. Herb. Boiss. 6 (1898) 611; Engl., Pflanzenr. 55 (IV.23Da) (1912) 105. - Type: Cult. RBG Kew from a plant obtained from Borneo by the Compagnie Continentale d'Horticulture, Gand, May 1884, N.E. Brown s.n. (K, holo - see Notes)

[Schismatoglottis decora W. Bull, Retail List (1884) 16; N.E. Br., Gard. Chron (1884) 711, nom. subnud.]

Schismatiglottis winkleri Engl., Bot. Jahrb. Syst. 48 (1912) 94 \& Pflanzenr. 55 (IV.23Da) (1912) 101. - Type: Indonesia, SE Kalimantan, between Lumo Sibak and Mt. Benangin, Aug 1908, H. Winkler 3214 (B, holo).

Schismatoglottis irrorata Engl., Pflanzenr. 55 (IV.23Da) (1912) 109, fig. 68 . - Type: Cult. Hort. Bogor., Jan/Feb 1906. A. Engler 4061 (B, holo).

Schismatoglottis diversicolor Alderw., Bull. Jard. Bot. Buitenzorg III, 4 (1922) 205. - Type: Cult. Hort. Bogor. XI.B.X.119 ex Borneo (orig. coll. Nieuwenhuis 1078), C.R.W.K. van Alderwerelt van Rosenburgh 313 (BOKR + BO spirit, lecto; selected here). 

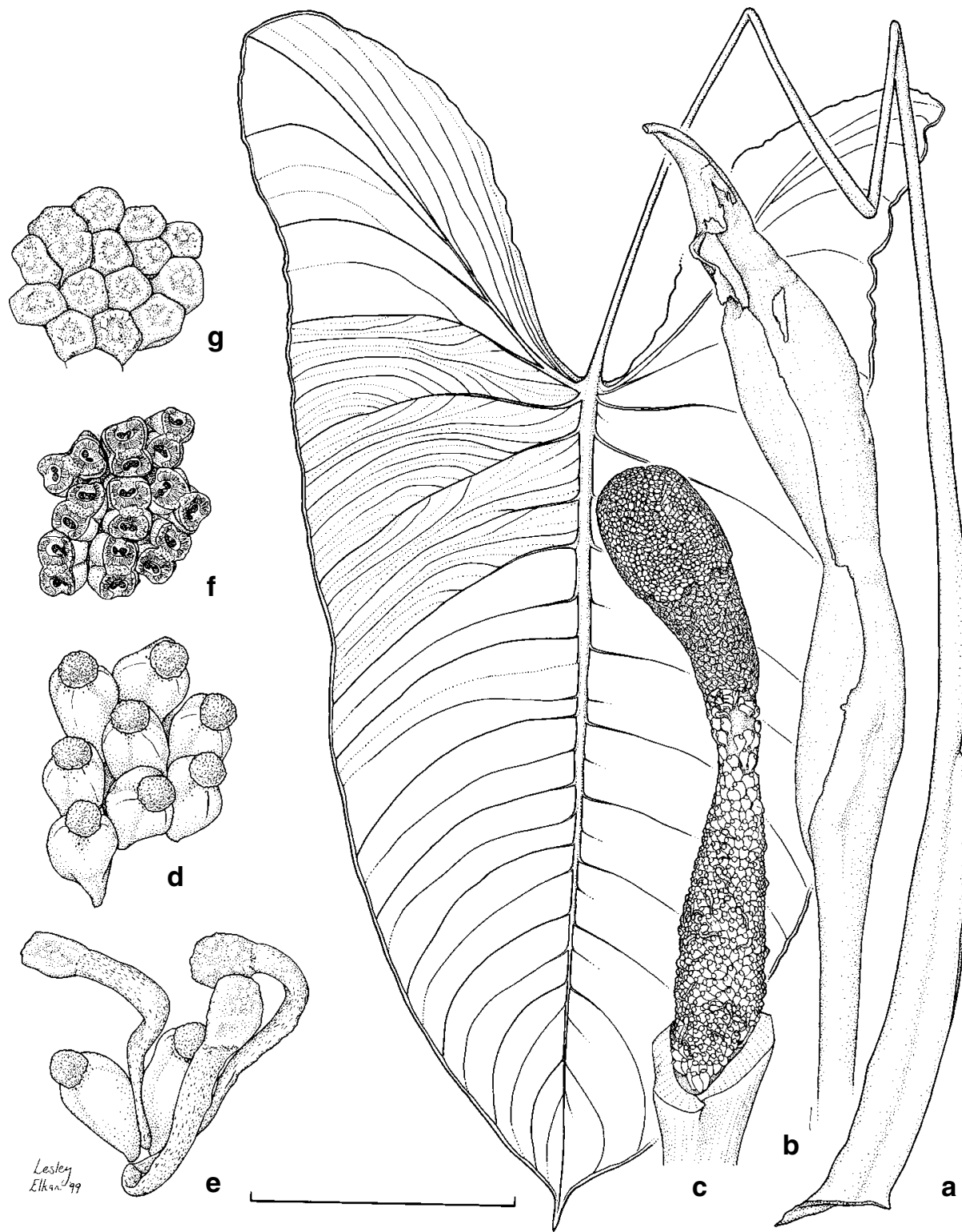

Fig. 16. Schismatoglottis moodii A. Hay. a, Leaf; b, Inflorescence; c, Spadix; d, Pistils; e, Interpistillar staminodes; $\mathbf{f}$, Stamens; $\mathbf{g}$, Staminodes of appendix (Mood M854). Scale bar: $\mathrm{a}=8 \mathrm{~cm} ; \mathrm{b}, \mathrm{c}=4 \mathrm{~cm}$; $\mathrm{d}-\mathrm{g}=5 \mathrm{~mm}$. 
Herb (15-)20-50 cm tall. Stem condensed, hapaxanthic, stoloniferous and colonial to loosely to tightly clump-forming, c. $1 \mathrm{~cm}$ diam. Leaves (2-)4-6 together; petiole (6-)7.5-48 cm long, glabrous to faintly scabrid with minute epidermal papillae, sheathing in the lower $1 / 4-1 / 2$; wings of sheath fully attached, tapering to subparallel (except at base) and then apically obtuse; blade ovate to narrowly to broadly oblongovate to more or less narrowly triangular, $10-28 \mathrm{~cm}$ long $\times 4-10 \mathrm{~cm}$ wide, mid-green adaxially, paler abaxially, sometimes variegated with grey-green spattering throughout or a grey-green band about the midrib, the base acute to truncate to shallowly cordate with posterior lobes to $2.5 \mathrm{~cm}$ long, the tip acute and acuminate for c. $1.5-4 \mathrm{~cm}$; midrib not or hardly prominent abaxially (dry), with 5-13 primary lateral veins on each side, alternating with lesser interprimaries and diverging at $30-60^{\circ}$, occasionally with 1 or $2(-3)$ branches in the lower part of the blade; secondary venation arising mostly from the midrib, some from the primary veins; tertiary venation obscure. Inflorescences 1-3 together; peduncle 4-11 cm long, the first subtending cataphyll sometimes with a reduced petiole and blade. Spathe (4-)8-12.5 cm long, slender; lower spathe (1.5-)3-5 cm long, green, narrowly ovoid, differentiated from the limb by a weak constriction; limb whitish to greenish-yellow to pink, oblonglanceolate, occasionally subulate, (2.5-)4.5-7.5 cm long, opening slightly, caducous. Spadix (3-)6-10.5 cm long, distinctly shorter than to subequalling the spathe, subcylindric; female zone (0.9-)2-4 cm long, adnate to the spathe in the lower c. $1 / 2$, subcylindric to slightly conoid in the free part, (3-)5-8 $\mathrm{mm}$ wide, if conoid then tapering to 3-6 mm diam. at the apex; pistils subglobose to subcylindric, $0.5-0.75 \mathrm{~mm}$ diam.; stigma sessile, discoid to button-like, papillate, c. $0.5 \mathrm{~mm}$ diam.; interpistillar staminodes scattered among the pistils, slightly exceeding to twice the height of the pistils, short- to long-stalked, clavate with rounded (to flat-topped) heads c. $0.5-0.75 \mathrm{~cm}$ across; sterile interstice completely absent to ill-defined (some concentration of usually short interpistillar staminodes intermixed with fertile elements); male zone subcylindric to very narrowly obconoid, (1-)1.5-3 cm long, $3-8 \mathrm{~mm}$ thick, $1 / 4-3 / 5$ held within the lower spathe chamber and there somewhat attenuate if the remainder thick; stamens crowded, truncate with the connective not or hardly raised between the thecae or the thecae sometimes confluent, dumbbell-shaped to almost circular in outline (when thecae confluent and then mixed states always present), $0.8-1 \mathrm{~mm}$ across; appendix cream to yellow to pink, basally isodiametric with, to slightly (c. $1 \mathrm{~mm}$ ) and abruptly wider than the top of the male zone, (1-)2.2-3.7 cm long, cylindric to narrowly conoid, the tip obtuse to bluntly acute; staminodes of appendix flat- to round- to somewhat pointed-topped, irregular polygonal to almost circular, 0.3-0.8 mm diam. Fruiting spathe narrowly urceolate, $1.5-6 \mathrm{~cm}$ long. - Fig. 17.

Distribution - Malesia: endemic to Borneo (Sarawak, Brunei, Sabah, where common and widespread); Schismatoglottis winkleri was based on a collection from SE Kalimantan, S. diversicolor was based on a cultivated plant collected by Nieuwenhuis in Kalimantan and S. irrorata (see Notes) was also presumably based on material originally from Kalimantan; Meier 2247 is from East Kalimantan, but no further specimens seen from Indonesian Borneo.

Habitat - Terrestrial (rarely lithophytic) on secondary and mature rainforest floor and in disturbed sites (e.g. rubber plantations) over a variety of substrates; sea level to c. $1400 \mathrm{~m}$ alt.

Notes - As interpreted here, Schismatoglottis motleyana is a highly variable species. It is characterised, within the $S$. calyptrata group, by a slender subcylindric spadix without a sterile interstice (though occasionally there may be a concentration of interpistillar staminodes at the interface of the two fertile zones), a slender cylindric to very narrowly obconoid male zone held partly within the lower spathe chamber and a subcylindric to very narrowly conoid appendix. However, these are features shared 


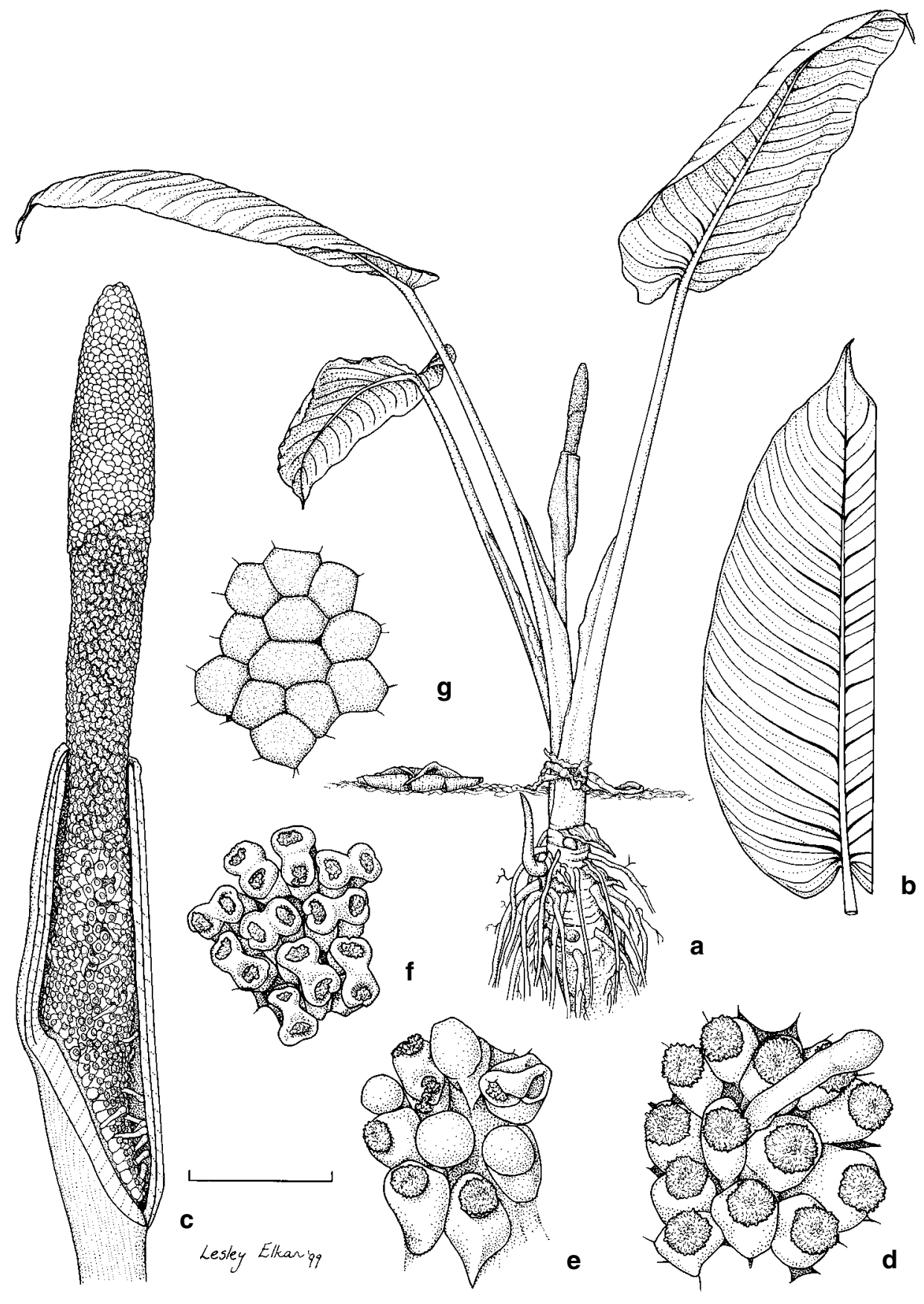

Fig. 17. Schismatoglottis motleyana (Schott) Engl. a, Habit; b, Leaf blade; c, Spadix; d, Pistils; e, Interface of female and male zones; $\mathbf{f}$, Stamens; $\mathbf{g}$, Staminodes of appendix (RBG Sydney Acc. No. 940519). Scale bar: $a, b=5 \mathrm{~cm} ; c=1 \mathrm{~cm} ; \mathrm{d}-\mathrm{g}=1.5 \mathrm{~mm}$. 
with $S$. trifasciata, another highly variable species, in this case with a very wide range of leaf shape, venation pattern and petiolar ornamentation (see under that species for discussion). The two species can be distinguished by the length/width ratios of the spadix (measured from dried specimens; width taken at the base of the appendix), which are around 40:1 in S. trifasciata (range 30:1 - 50:1) and around 15:1 in S. motleyana (range 10:1 - 22:1 (- 26:1)). Plants with the high extreme ratio in S. motleyana, which are unusual, approach the low extreme ratio in S. trifasciata, and so these two species can be difficult to separate at the extremes of their variation. Schismatoglottis canaliculata (q.v.) differs slightly in its relatively thicker inflorescence and leaves with more well-developed posterior lobes.

The type of $S$. motleyana represents the diminutive extreme in plant size, and the lower dimensions in parentheses in the description are taken from it (remaining dimensions are from spirit and fresh material which may exaggerate the differences, especially in measurements of thickness). It does not, however, seem to differ morphologically from the remainder of the species circumscribed here. Schott's illustration of Apatemone motleyana (Ic. 914; fiche 47:b8 in the microfiche edition) omitted the characteristic longstalked interpistillar staminodes, which are indeed present in the type. The type of S. pulchra represents a more robust aspect of the species, with a rather larger inflorescence in which the appendix is abruptly wider at the base than at the top of the male zone. Two collections corresponding more closely with the type of S. pulchra, in terms of appendix shape, Burbidge s.n. and Lobb 144, have extremely short inflorescences comparable in length with that of the type of S. motleyana. However, they are both from cultivated plants and conceivably they are abnormal: they are not closely matched by any other material of verifiable provenance. Specimens from N. Sarawak, Labuan and Brunei are generally stoloniferous, while elsewhere in the range the plants are loosely to tightly clump-forming.

The holotype sheet of Schismatoglottis pulchra contains two collections. The first is the holotype itself. The second is material of the same species (as S. decora) obtained from William Bull in October 1884; this does not have type status. The two elements are clearly identifiable, differentiated by Brown's annotations.

Schismatoglottis winkleri is based on a specimen which agrees with $S$. motleyana, but appears widely geographically disjunct from the rest of the range. It is unusual in the large proportion of stamens in which the thecae are confluent, emptying through a single large pore. However, a number of other collections show also this in varying degree, from a few abnormal stamens near the interface with the appendix, to occasional to numerous stamens with confluent thecae throughout the male zone. Such plants occur scattered through the range of the species, and this characteristic does not seem to be correlated with any other.

Schismatoglottis irrorata was described by Engler (1912) from a plant cultivated at Bogor attributed to Borneo. It would seem likely that the plant originated in Indonesian (then Dutch) Borneo, though the provenance does not seem to be traceable. An inflorescence was figured (loc.cit.), but only vegetative material remains of the type. The leaf and the inflorescence drawing clearly fall within a broad concept of S. motleyana. Okada (1992) made a cytotaxonomic study of populations of S. irrorata in Kalimantan. Whether the voucher specimens from this study are in fact $S$. motleyana in the sense here has not been verified during this revision.

Other specimens examined: BORNEO: without locality (ex Hort. Veitch), Burbidge s.n. (K); [cult. Hort. Bogor. without locality, Hallier s.n. (G,M)]; without locality, Lobb 144 (K). SARAWAK: Entabai, Bogner 1354 (M, US) \& 1355 (M, US); Sarikei, Bogner 1546 (K) \& 1586 (M); Bakelalan, Brooke 10499 (L); Gat, Upper Rejang R., Clemens \& Clemens 5731 \& 6128 (both NY); Cult. RBG Edinburgh Acc. No. 67/2479 ex 5th Divn, long Rapata, between Bakalong \& G. Murud (orig. coll. Burtt $\mathcal{E}$ Martin 5533), Davis C6046 (E); Miri, Setap rd, Ulu Luak, Othman Haron $S 21342$ (K, L); Cult. RBG 
Sydney Acc. No. 920739 ex Kapit (orig. coll. Dearden s.n.), Herscovitch s.n. (NSW); Cult. RBG Sydney Acc. No. 940454 ex Sarikei, Sebakul Recreation Park (orig. coll. Hay et al. 9299), Herscovitch s.n. (NSW); Cult. RBG Sydney Acc. No. 940456 ex Sarikei, Sebakul Recreation Park, (orig. coll. Hay et al. 9301), Herscovitch s.n. (K, KEP, L, NSW, SAR); Cult. RBG Sydney Acc. No. 940469 ex Bintulu, $2.3 \mathrm{~km}$ past bridge over Kemena R. towards Sibu on Bintulu-Sibu Rd (orig. coll. Hay et al. 9315), Herscovitch s.n. (K, KEP, L, NSW, SAR); Cult. RBG Sydney Acc. No. 940474, 940475 [NSW spirit only] \& 940480 ex Bintulu, Universiti Pertanian Malaysia Research Forest area (orig. coll. Hay et al. 9321, 9322 \& 9327), all Herscovitch s.n. (K, KEP, L, NSW, SAR); Cult. RBG Sydney Acc. No. 940491 ex Bintulu, Sg. Sebian (orig. coll. Hay et al. 9338) Herscovitch s.n. (NSW); Cult. RBG Sydney Acc. No. 940513 ex Niah National Park, Niah Caves area, en route from Niah town (orig. coll. Hay et al. 9362), Herscovitch s.n. (K, KEP, L, NSW, SAR); Cult. RBG Sydney Acc. No. 940519 ex Niah National Park, Batu Niah (orig. coll. Hay et al. 9368) Herscovitch s.n. (K, KEP, L, NSW, SAR); Cult. RBG Sydney Acc. No. 940547 ex Lundu, G. Gading (orig.coll. Hay et al. 9394), Herscovitch s.n. (NSW); 4th Divn, Bintulu, Sg. Kakus, along Sg. Minah, c. 1 km E of Minah Camp, Hirano \& Hotta 316 (KYO); 4th Divn, Bintulu, along Sg. Latai, a small branch of Ulu Sg. Kakus, Hirano \& Hotta 816 (KYO). BRUNEI: Belait Distr., Rampayoh, Sg. Rampayoh, c. 2 km from Labi rd, Atkins et al. 434 (K, KEP); Belait Distr., Labi, Kg Teraja, path along Sg. Teraja, Boyce 239 (AAU, B, BO, G, K, L) $\mathcal{E} 240$ (K) $\mathcal{E} 259$ (K, L); Belait Distr., Labi, Mendaram Waterfall, Boyce 267 (AAU, K, L) E 270 (K, L, SAN); Tutong Distr., Ukong, Andulau FR, Bukit Besong, Dransfield et al. 1147 (K); Belait Distr., Labi, valley of Sg. Rampayoh, Dransfield et al. 1277 (K); Temburong Distr., Batu Apoi, Selapon, Bukit Belitan, Sg. Sinupoi, Dransfield et al. 7485 (K); Belait Distr., Labi, Wong Kadir, nr Menaram, Coode et al. (K). SABAH: Penampang Distr., Crocker Range, km 49.5 on Kota Kinabalu-Tambunan rd, Beaman et al. 10449 (K, US); Kinabalu, Tenompok, Clemens \& Clemens 28552 (BM) \& 29143 (BM, NY); Cult. RBG Sydney Acc. No. 841549 ex Tenom, Kalang Falls (orig. coll. Wallace $\mathcal{E}$ Forlonge 84/222), Herscovitch s.n. (NSW); Cult. RBG Sydney Acc. No. 950364 ex Ulu Dusun (orig. coll. Hay et al. 10027), Herscovitch s.n. (K, KEP, L, NSW, SAN); Cult. RBG Sydney Acc. No. 950377 \& 960541 ex Medai Falls (orig. coll. Hay et al. 10040 \& 12177), both Herscovitch s.n. (K, KEP, L, NSW, SAN); Cult. RBG Sydney Acc. No. 950384, 950385 \& 950387 ex Kinabalu National Park Headquarters, Silau-Silau trail towards Liwagu R. (orig. coll. Hay 10047, 10048 \& 10050), all Herscovitch s.n. (NSW); Cult. RBG Sydney Acc. No.960513 ex Maliau Basin, G. Rara Forest Reserve, $2.5 \mathrm{~km}$ above main Maliau Falls (orig. coll. Hay et al. 12096), Herscovitch s.n. (K, NSW, SAN); Cult. RBG Sydney Acc. No. 960515 \& 960565 both ex Tibau Forest Station area (orig. coll. Hay et al. 12142 \& 12028), both Herscovitch s.n. (NSW); Sukau Distr., Bod Tai, Kiew \& Lim RK4143 (NSW, SING); Kinabalu NP, along rd between HQ and Tenompok, Kokawa \& Hotta 3049 (KYO); Kinabalu NP, between Mesilau \& Kundassan, Kokawa \& Hotta 4481 (K, KYO, US); Penampang Distr., km 45 from Tunggol, Penampang-Tamburan [rd], Krispinus SAN 131434 (SAN); Ranau Distr., Mesilau, East Kinabalu, Meijer SAN 38078 (K, L, SAN); Kinabalu NP, Ranau, along trail between Poring and Langanan Water Fall, Tamura $\mathcal{E}$ Hotta $211 \mathcal{E} 232$ (both KYO). KALIMANTAN: East Kalimantan, Nunukan, N of Takukan, Meier 2247 (BO).

\section{Schismatoglottis niahensis $A$. Hay, sp. nov.}

A Schismatoglottide motleyana statura majore, caudice epigeo, crasso, erecto, inflorescentia valde robustiore, interstitio sterile breve staminibus abortivis instructa, appendice conoidea obtusa differt. - TYPUS: Cult. RBG Sydney Acc. No 940512 ex Malaysia, Sarawak, Niah National Park, Niah Caves area (orig. coll. Hay et al. 9361), Nov 1997, C. Herscovitch s.n. (SAR, holo; iso K, KEP, L, NSW).

Robust herb c. $70 \mathrm{~cm}$ tall. Stem erect, suckering, pleionanthic, to c. $30 \mathrm{~cm}$ tall $\times 5 \mathrm{~cm}$ diam.; internodes c. $2 \mathrm{~cm}$ long. Leaves few together; petiole c. $40 \mathrm{~cm}$ long, sheathing in the lower $1 / 3-2 / 3$; wings of sheath tapering, fully attached; blade sagittate, mid-green adaxially, paler below, $28-35 \mathrm{~cm}$ long $\times 13-22 \mathrm{~cm}$ wide, widest at or near base, the base cordate with rounded posterior lobes $7-9 \mathrm{~cm}$ long; midrib flush with the lamina (dry), stout and broad, with c. 13 rather stout, adaxially pale green primary lateral veins on each side, irregularly alternating with lesser interprimaries, sometimes branched especially in the lower part of the anterior lobe, diverging at c. $70^{\circ}$ and almost straight for most of the way to the margin before deflecting distally; secondary venation rather obscure adaxially and abaxially, arising from the midrib and the primary veins; tertiary venation obscure. Inflorescences to 4 together, subtended by short cataphylls except the first subtended by a cataphyll reaching to half way along the spathe and 
bearing a reduced petiole and blade; peduncle 13-15 cm long. Spathe 11-15 cm long; lower spathe $4-5.5 \mathrm{~cm}$ long, narrowly ovoid, differentiated from the limb by a sharp constriction; limb ovate, 7-10 cm long, slightly inflated over the appendix, finally acuminate for c. $2 \mathrm{~cm}$, caducous. Spadix c. $9 \mathrm{~cm}$ long, narrowly hourglass-shaped; female zone $3.8 \mathrm{~cm}$ long, adnate to the spathe in the lower $1.2 \mathrm{~cm}, \mathrm{c} .8 \mathrm{~mm}$ diam. in the middle, distally conoid and apically $3 \mathrm{~mm}$ diam.; pistils crowded, narrowly cylindric (especially near the base of the female zone - distally somewhat lower and thicker) c. $0.5 \mathrm{~mm}$ diam.; stigma sessile, button-like, about the same diameter as the ovary; interpistillar staminodes scattered among the pistils, more crowded in the distal part of the female zone, long-stalked, apically abruptly clavate and flat-topped, c. 1.5 times the height of the ovary; sterile interstice $2-3 \mathrm{~mm}$ long, slightly obconic, 3-4 whorls of sterile stamens drying very dark brown, lying level with the mouth of the lower spathe; male zone obconic, c. $2.8 \mathrm{~cm}$ long, distally c. $1 \mathrm{~cm}$ diam.; stamens densely crowded, c. $0.5 \mathrm{~mm}$ across, dumbbell-shaped with large round pores and the connective slender and raised into a short broadly triangular point somewhat offcentre; appendix more or less bullet-shaped, at the base slightly but abruptly wider than the top of the male zone, c. $1.2 \mathrm{~cm}$ diam., then somewhat tapering and finally obtuse; staminodes of appendix columnar, flat-topped and irregularly polygonal with rounded angles, c. $0.5 \mathrm{~mm}$ diam. Infructescence unknown.

Distribution - Malesia: endemic to Borneo (Sarawak); known only from the type collection near Niah.

Habitat - On steep slopes at the base of limestone bluffs surrounded by swampy forest at c. $200 \mathrm{~m}$ alt.

Notes - This species is distinctive in Borneo in being the only species allied to S. motleyana to have pleionanthic epigeal stems. Schismatoglottis motleyana and immediately associated species are themselves allied to $S$. calyptrata and its more immediate allies - where the appendix is subhemispheric. This broader group is characterised by attached leaf sheaths and caducous spathe limbs. Almost all species of this wider group have hapaxanthic hypogeal stems, but in the Philippines S. plurivenia and S. merrillii represent the epigeal pleionanthic stem state. Bornean S. gamoandra, which appears to belong to this group also, seems to have a hypogeal pleionanthic stem, though this needs to be confirmed by recollecting this species which is known only from its type.

\section{Schismatoglottis pectinervia $A$. Hay, sp. nov.}

$\mathrm{Ab}$ aliis speciebus Schismatoglottidis caudice hapaxanthico, lamina folii oblanceolata, nervis primariis et interprimariis numerosissimis, pedunculo breve, interstitio neutro subnudo differt. - TYPUS: Brunei, Temburong District, Batu Apoi Forest Reserve, Sungei Batu, 10 Jun 1991, A. D. Poulsen 139 (K, holo; iso AAU, BRUN).

Herb to $35 \mathrm{~cm}$ tall. Stem condensed, more or less hypogeal, hapaxanthic, c. $1 \mathrm{~cm}$ diam. Leaves 2-4 together; petiole 15-21 cm long, sheathing in the lower $1 / 4-1 / 3$; wings of sheath tapering, fully attached to petiole; blade broadly oblanceolate, semi-glossy mid- to dark green adaxially, paler abaxially, c. $30 \mathrm{~cm}$ long $\times 7 \mathrm{~cm}$ wide at widest point, the base cuneate to decurrent, the tip acute and acuminate for $1.5 \mathrm{~cm}$; midrib abaxially very prominent; primary lateral veins not prominent, numerous, c. 20 on each side of the midrib, alternating with lesser interprimaries, diverging at $80-90^{\circ}$ and more or less gradually and evenly curving up to meet the margin; secondary venation arising from the midrib; tertiary venation rather indistinct. Inflorescence ?solitary, subtended by several lanceolate strongly keeled cataphylls to $5 \mathrm{~cm}$ long; peduncle short, concealed by leaf bases and cataphylls. Spathe $4.5 \mathrm{~cm}$ long, subcylindric; lower spathe pale green, c. $1.5 \mathrm{~cm}$ long, differentiated from the limb by a very weak constriction; limb $3 \mathrm{~cm}$ long, oblong-lanceolate, creamy white, ?caducous. Spadix subequalling the spathe, 
sessile; female zone $1.2 \mathrm{~cm}$ long, conoid, obliquely inserted; pistils crowded at base of zone, distally increasingly lax, more or less subglobose, strongly longitudinally 4-lobed, c. $0.7 \mathrm{~mm}$ diam.; stigma elevated on a very short style, button-like, about $1 / 4$ the diameter of the ovary; interpistillar staminodes restricted to base of female zone, absent from among the pistils, more or less mushroom-shaped, about as wide as the ovary; sterile interstice very attenuate, c. $1 \mathrm{~cm}$ long (upper and lower limits somewhat indeterminate owing to lax arrangement of and intergradation between abortive and fertile elements), mostly naked, in the lower half with scattered longitudinally (with respect to spadix) stretched partly abortive pistils and in the upper half with scattered partly abortive anthers; male zone $8 \mathrm{~mm}$ long, obconic in the lower part, the rest cylindric, c. $3 \mathrm{~mm}$ diam.; stamens crowded (except at base of zone), thickly hourglass shaped, c. $0.8 \mathrm{~mm}$ across, the connective slender and very slightly raised between the large $(0.2 \mathrm{~mm}$ diam.) impressed pores; appendix subcylindric, apically tapering to a blunt point, the base isodiametric with male zone, $1.2 \mathrm{~cm}$ long; staminodes of appendix more or less flat-topped, irregularly polygonal, c. $0.7 \mathrm{~mm}$ diam. Infructescence unknown.

Distribution - Malesia: endemic to Borneo (Brunei).

Habitat - Terrestrial in forest on river banks or on steep rocky slopes near streams, over Setap shales, to $70 \mathrm{~m}$ alt.

Notes - The shoot organisation appears to consist of hapaxanthic modules: no new leaves are observable subsequent to the inflorescence on any of the plants represented in the two collections seen, and the type has the stem physiognomically branched with the older axis aborted. The only flowering specimen, which has a solitary inflorescence, appears to be in bud, and the number of cataphylls present would suggest that there may be subsequent inflorescences which had not yet emerged when the specimens were made.

The distinguishing features of the new species are the putatively hapaxanthic stems, the oblanceolate leaf blades with attached sheath and very numerous primary and interprimary veins (to which the specific epithet, from pecten, a comb, alludes), the very prominent midrib, the short-pedunculate inflorescence, the basal staminodes and the naked interstice with scattered semi-abortive pistils and anthers.

Other specimen examined: BORNEO: BRUNEI: Temburong Distr., Sg. Temburong at Kuala Belalong, bank of Sg. Belalong, Boyce et al. 434 (BRUN, K).

\section{Schismatoglottis plurivenia Alderw.}

Schismatoglottis plurivenia Alderw., Bull. Jard. Bot. Buitenzorg III, 4 (1922) 209. - Schismatoglottis luzonensis Engl., Pflanzenr. 55 (IV.23Da) (1912) 121 (non Engl., op. cit.: 88). - Type: Philippines, Luzon, Bataan Prov., Lamao R., Mt Mariveles, Jun 1904, Borden 1243 (B, holo; iso NY, US).

[Schismatoglottis latifolia auct. non Miq.: Engl., Pflanzenr. 55 (IV.23Da) (1912) 117, p.p. quoad specim. cit. Philipp.; Merr., Enum. Philipp. Fl. Pl. 1 (1922) 102 (both as 'var. viridis Engl.' i.e. nom. superfl. pro var. typ.); Elmer, Leafl. Philipp. Bot. 10 (1938) 3634.]

Alocasia merrillii Engl. \& K. Krause, Bot. Jahrb. Syst. 54, Beibl. 118 (1916) 124; K. Krause \& Engl., Pflanzenr. 71 (IV.23E) (1920) 79 [non Schismatoglottis merrillii Engl.]. - Type: Philippines, Mindanao, Zamboanga Distr., Merrill 8072 (B, holo).

Schismatoglottis cardiophylla Quisumb. \& Merr., Philipp. J. Sci. 37 (1928) 136. — Type: Philippines, Luzon, Tayabas (Quezon) Prov., Casiguran, 11 Jun 1905, Ramos E Edaño BS 45387 (PNH, presumed destroyed, holo; iso K, NY, UC, US). 
Robust herb to c. $70 \mathrm{~cm}$ tall Stem pleionanthic, at first flowering when hypogeal, then becoming rather shortly epigeal, erect to creeping to c. $25 \mathrm{~cm}$ long, c. $3 \mathrm{~cm}$ diam. Petiole 20-50 cm long, sheathing in the lower half; blade cordato-sagittate, $22-38 \mathrm{~cm}$ long $\times 12-25 \mathrm{~cm}$ wide; posterior lobes about a quarter of the length of the anterior lobes, rounded, sometimes almost overlapping; midrib with c. 12 primary lateral veins on each side, diverging at $60-80^{\circ}$, alternating with somewhat thinner interprimary veins and sometimes directly bearing subsidiary veins of similar thickness to the interprimaries, especially near the base of the anterior lobe; primary, interprimary and subsidiary venation prominent abaxially; secondary venation finely striate, forming a rather inconspicuous tessellate pattern with the tertiary venation on the abaxial side. Inflorescences several to c. 12 together, interspersed with lanceolate cataphylls; peduncles much shorter than petioles, to c. $7 \mathrm{~cm}$ long at flowering. Spathe c. $6-8 \mathrm{~cm}$ long, constricted at about $1 / 3$ of the way from the base; lower spathe narrowly ovoid; limb turbinate then acuminate. Spadix sessile, to c. $5 \mathrm{~cm}$ long, considerably shorter than the spathe; female zone c. $2 \mathrm{~cm}$ long, adnate to the spathe in the lower c. $1 / 3$; interpistillar staminodes sparse to absent; pistils bottle-shaped, close-packed, c. 0.25 mm diam.; style very short; stigma punctiform; male zone c. $1.5 \mathrm{~cm}$ long, sterile in the lower c. $2 \mathrm{~mm}$, contiguous with the female zone or separated by a very short naked zone c. $1.5 \mathrm{~mm}$ long, obconic, distally c. $5 \mathrm{~mm}$ diam.; appendix bluntly conic to subhemispheric, as thick as to slightly wider than the male zone at the base; appendical staminodes more or less flat-topped. Fruiting spathe c. $4 \mathrm{~cm}$ long, asymmetric, subcylindric.

Distribution - Malesia: Philippines, widespread; extending via the Talaud Islands south of Mindanao, to Central Sulawesi.

Habitat - Lowland rainforest, especially in wet ravines and river banks, to c. $600 \mathrm{~m}$ alt.

Notes - Engler misapplied the name Schismatoglottis latifolia (= S. rupestris) to material of this species. Schismatoglottis plurivenia is significantly different from and not closely allied to $S$. rupestris which is characterised by the leaf sheath soon degrading and falling away, a basal ring of staminodes on the spadix, and a large, mostly naked zone between the female and the cylindric male zones of the spadix. The spathe limb is narrowly lanceolate, clasping and rots away after anthesis, falling with the defunct part of the spadix still enclosed. Schismatoglottis plurivenia has the sheath persistent, no basal staminodes, no (or a very short) naked zone between the female and the obconic male zones. Here the spathe limb is inflated and turbinate at female anthesis, thence caducous, exposing the still functional male zone and appendix.

Schismatoglottis plurivenia can be distinguished from the closely allied S. calyptrata (q.v.) by the more robust proportions, the numerous abaxially prominent primary, interprimary and subsidiary veins and by the pleionanthic shoots.

Schismatoglottis plurivenia is a new name given by Alderwerelt to the second of two species Engler separately named S. luzonensis in his monograph of 1912. Alocasia merrillii Engl. \& K. Krause precedes S. plurivenia, but the epithet merrillii is already occupied in Schismatoglottis. How a well preserved specimen (as the type of $A$. merrillii is) of this species could be described in detail as a species of Alocasia by such authorities as Engler and Krause seems inexplicable.

Other specimens examined: SULAWESI: Central Sulawesi, E of Tongoa, Johansson et al. 41 (L); Talaud Islands, Talaud, Karakelang, Pasir Malep, E of Lobo, Lam 2999 (L); Talaud Islands, Talaud, Salibaka, SE slope of G. Ajambana, Lam 3060 (K, L). PHILIPPINES: Luzon, Camarines Sur, Mt Isarog, Naga City, Barbon et al. PPI 8277 (US); Palawan, Mt Apis, Ebalo \& Conklin 1314 (GH); Palawan, Brooke's Point, Mt Mantalingahan, Edaño PNH 372 (GH); Negros Oriental, Cuernos de Negros, Edaño PNH 7330 (GH); Mindanao, Davao Prov., Mt Mansamuga, Edaño PNH 11115 (GH); Negros Occidental, Mt Katugasan, Edaño PNH 21837 (L); Luzon, Camarines Sur, Ponawa R., 
Edaño BS 76404 (BO, NY); Palawan, Imolmod, Edaño BS 77359 (NY); Luzon, Sorsogon Prov., Irosin, Edaño \& Gutierrez PNH 37749 (L); Luzon, Sorsogon Prov., Irosin (Mt Bulusan), Elmer 14739 (BO, G, GH, K, L, NSW, NY, U, US); Luzon, Laguna Prov., Los Baños (Mt Maquiling), Elmer 17829 (BO, G, GH, K, L, NSW, NY, U, UC, US); Luzon, Pampango Prov., Mt Abu, Foxworthy BS 2015 (US); Luzon, Zambales Prov., Mt Pinatubo, Fox PNH 4808 (GH); Luzon Central, Limutan, Loher 2452 (K); Samar, Laquilacon, McGregor BS 43819 (K, NY, UC); Luzon, Cavite Prov., Mendez Nunes, Mangubat BS 1323 (NY, US); Luzon, Albay Prov., Guinobatan, Banao, Mendoza PNH 18503 (L); Mindanao, Butuan Sub-Province, Agusan R., Merrill 7275 (BO, K, L, US); Luzon, Laguna Prov., Los Baños , cult. at College of Agriculture, Nicolson 692 (US); Luzon, Laguna Prov., Molawin Ck path, between colleges of Agriculture and Forestry, Nicolson 754 (US); Luzon, Sorsogon Prov., Mt Bulusan, along path around lake Bulusan, Nicolson 773 (US); Luzon, Manila, Perrottet s.n. (P); Luzon, Camarines Prov., Paracale, Ramos \& Edaño BS 33783 (NY, SING); Luzon, Camarines Prov., Mt Bagacay, Ramos $\mathcal{E}$ Edaño BS 33830 (NY, SING); Luzon, Laguna Prov., Los Baños, Robinson BS 6736 (NY); Luzon, Manila, Stewarts Garden, Steiner PNH 36479 (SING); Luzon, Sorsogon Prov., Mt Bulusan, Sulit PNH 2788 (GH); Oriental Mindoro, Mansalay, Mt Yagaw (E slope), Sulit \& Conklin PNH 16886 (GH, L); Leyte, Wenzel 285 (E, G, GH, US) \& 508 (BM); Mindanao, Lanao Prov., Vicinity of Malabang, Zwickey $120(\mathrm{GH})$.

72. Schismatoglottis pumila Hallier f. ex Engl.

Schismatoglottis pumila Hallier f. ex Engl., Pflanzenr. 55 (IV.23Da) (1912) 111. - Type: ?Cult. Hort. Bogor. ex Borneo, without date, H. Hallier 1355 (BO, holo; iso B). - Epitype: Cult. Hort. Bogor, without date or collector (NSW440421; designated here - see below).

Small herb to c. $25 \mathrm{~cm}$ tall. Stem condensed, hypogeal, stoloniferous, hapaxanthic, c. $5 \mathrm{~mm}$ diam. Leaves 4 together; petiole longer than the blades, 20-25 cm long, sheathing in the lower c. $1 / 4$; wings of sheath fully attached, tapering; blades narrowly cordato-sagittate, 12-17 cm long $\times 5-7 \mathrm{~cm}$ wide, the base shallowly cordate with spreading rounded posterior lobes c. $2 \mathrm{~cm}$ long, the apex acute and acuminate for c. $2 \mathrm{~cm}$, finally with a more or less filamentous mucro c. $1.5 \mathrm{~cm}$ long; midrib slightly prominent adaxially (dry), more or less flush abaxially, with 5-7 primary lateral veins, alternating with lesser interprimaries and diverging at c. $60^{\circ}$; secondary venation arising mostly from the midrib in the upper half of the blade, from the primary venation and the midrib in the lower half; tertiary venation obscure. Inflorescences 1 or 2 together; peduncle not much exserted from the sheath of the subtending leaf at anthesis, elongating somewhat afterwards. Spathe $4.5 \mathrm{~cm}$ long; lower spathe narrowly spindle-shaped, $2 \mathrm{~cm}$ long, differentiated from the limb by a rather gradual constriction; limb ovate, $2.5 \mathrm{~cm}$ long, inflated over the appendix then acuminate for $1 \mathrm{~cm}$, deciduous (almost certainly caducous). Spadix sessile, $3 \mathrm{~cm}$ long; female zone $1.4 \mathrm{~cm}$ long, $2 \mathrm{~mm}$ thick, subcylindric, adnate to the spathe in the lower c. $1 / 2$; pistils crowded, narrowly ovoid, c. $0.3 \mathrm{~mm}$ diam.; stigma elevated on a short style, discoid, about the same width as the ovary; interpistillar staminodes scattered among the pistils, stalked, clavate, flattopped, about the height of the pistils, c. $0.5 \mathrm{~mm}$ diam.; sterile interstice well-defined, $6 \mathrm{~mm}$ long, cylindric, $2 \mathrm{~mm}$ diam. (dry), covered in crowded staminodes, the basal ones resembling interpistillar staminodes, the distal ones resembling sterile anthers; male zone $8 \mathrm{~mm}$ long, obconic, distally $3 \mathrm{~mm}$ diam.; stamens crowded, dark purple, truncate, more or less dumbbell-shaped, with the thecae slightly elevated above the connective, c. $0.5 \mathrm{~mm}$ across; appendix c. $4 \mathrm{~mm}$ long, more or less conoid, abruptly wider at the base than the top of the male zone, $4 \mathrm{~mm}$ diam., the apex acute; staminodes of appendix flat-topped, irregularly polygonal to almost circular in outline, c. $0.3 \mathrm{~mm}$ diam. Fruiting peduncle c. $12 \mathrm{~cm}$ long. Fruiting spathe narrowly ovoid, $3 \mathrm{~cm}$ long.

Distribution - Malesia: not known with certainty, but allegedly from Borneo.

Habitat - Unknown. 
Notes - Schismatoglottis pumila is allied to S. calyptrata and S. modesta. It differs from both in the apically acute conoid appendix, and in the long and well-defined sterile interstice of the spadix, which is held within the lower spathe chamber.

Engler indicated (loc. cit.) that the plant was in cultivation at Bogor. This is not mentioned on the type's label, which simply says 'Borneo... Hallier 1355'. It is not clear whether the specimen was collected by Hallier in Borneo, preserved directly and part of the same collection cultivated, or whether Hallier collected the specimen from a cultivated plant.

Although Schismatoglottis pumila was described from fertile material, the holotype no longer has flowering parts present, except for a detached lower spathe. However there is deposited at NSW a specimen from a plant cultivated at Bogor under this name. It matches Engler's description in detail. When and by whom this specimen (and material of other Schismatoglottis cultivated at Bogor) was sent to NSW is unknown (apparently early 20th Century), but it would appear to be clonotype material. It is therefore designated the epitype.

\section{Schismatoglottis pusilla Engl.}

Schismatoglottis pusilla Engl., Bot. Jahrb. Syst. 1 (1881) 184; Engl., Pflanzenr. 55 (IV.23Da) (1912) 103, fig. 64; Merr., Enum. Philipp. Fl. Pl. 1 (1922) 182. — Type: Philippines, Leyte, Jagor 1018 a (B, holo).

[Schismatoglottis irosinensis Elmer, Leafl. Philipp. Bot. 10 (1938) 3632, nom. inval., descr. angl. — Based on Elmer 14594 (sheets seen at BM, G, K, L, U, UC, US).]

[Schismatoglottis hastata Elmer, Leafl. Philipp. Bot. 10 (1939) 3701, nom. inval., descr. angl. — Based on Elmer 17828 (sheets seen at GH, NY).]

Small herb c. 15-25 cm tall. Stem hypogeal, ?stoloniferous, ?pleionanthic, condensed. Petiole 6-20 cm long, sheathing in the lower $1 / 4$; leaf blade dark green and variegated grey in bivittate or spattered pattern adaxially, abaxially pale, subglaucous, $8-17 \mathrm{~cm}$ long $\times 3-4 \mathrm{~cm}$ wide (see note below); posterior lobes narrow, 1-3 cm long, often somewhat out-turned, round-tipped; anterior lobe widest mostly at or slightly distal (rarely proximal) to midway along midrib, acuminate for up to c. $3 \mathrm{~cm}$; midrib with c. 6-10 primary lateral veins on each side diverging at c. $60^{\circ}$, then ascending rather abruptly slightly more than half way towards the margin; interprimaries not strongly differentiated from secondary venation, these together with tertiary venation forming a fine but distinct tessellate pattern abaxially. Inflorescence mostly solitary, rarely 2 together; peduncle short, c. $3 \mathrm{~cm}$ long. Spathe (1.8-)2.5-3 cm long, the lower $1 / 3-1 / 2$ narrowly obconic, thence the limb inflated, turbinate and distally acuminate, white. Spadix (1-)1.5 cm long, sessile; female zone very slender, c. $6 \mathrm{~mm}$ long; ovaries subglobose, c. $0.5 \mathrm{~mm}$ diam.; interpistillar staminodes absent; stigma sessile, punctiform; male zone contiguous with female, slightly to rather strongly obconic, c. $6-7 \mathrm{~mm}$ long, $1 / 2-3 / 4$ contained within the lower spathe after limb dropped following female anthesis; appendix c. $4 \mathrm{~mm}$ long, bluntly conic to bullet-shaped, about the same width as the top of the male zone; lower appendical staminodes flat-topped, more distal ones becoming pointed. Fruiting spathe asymmetrically urceolate, c. $2 \mathrm{~cm}$ long.

Distribution - Malesia: endemic to the Philippines (Luzon, Panay, Catanduanes).

Habitat - Wet places in forest floor, 350-1000 m alt.

Notes - The provenance of the holotype is taken from Engler (loc. cit.). The label does not indicate where the specimen came from at all, though there may have been an additional sheet with more extensive notes which did not survive war-time damage in Berlin. 
Most specimens show a great range in leaf size and the leaf dimensions given here are those of the largest leaves on fertile shoots. In many instances the lower leaves are progressively smaller, suggesting that the specimens are seedlings flowering for the first time. It is perhaps curious that this should so frequently be the case.

The holotype is somewhat atypical in the small size of the leaves and the rather reduced hemispheric appendix, in which it approaches $S$. mindanaoana, to which S. pusilla is evidently allied. Schmatoglottis pusilla is distinguished from it by the larger size, usually conic appendix and terrestrial habit with condensed stem. All specimens have variegated leaves, while those of $S$. mindanaoana are not variegated. They share the dark green adaxial side of the leaf blade, the sub-glaucous abaxial side and the distinct tessellate pattern formed by the secondary and tertiary venation on the leaf underside; in reproductive features they share, inter alia, the male zone held mostly within the lower spathe and the pointed appendical staminodes.

One duplicate (at K) of Elmer 14594 appears to show a rolled (i.e. new) leaf inserted subsequent to the inflorescence, indicating that renewal growth takes place after flowering and that therefore the stems are pleionanthic. However, the exact relationship of the parts is not entirely clear in the dried and mounted specimen. Other material sheds little light on this matter, which needs further observation.

Since they are deposited in mutually exclusive sets of herbaria, the first two collections listed below would appear to be the same collection with the second and third numerals transposed on some labels. Elmer (loc. cit). cited the first as the basis for of the invalid S. irosinensis.

Other specimens examined: PHILIPPINES: Luzon, Sorsogon Prov., Irosin (Mt Bulusan), Elmer 14594 (BM, G, K, L, U, UC, US); Luzon, Sorsogon Prov., Irosin (Mt Bulusan), Elmer 15494 (BO, GH, NSW, NY); Luzon, Laguna Prov., Los Baños (Mt Maquiling), Elmer 17828 (GH, NY); Panay, Capiz Prov., Jamindan, Ramos \& Edaño BS 31202 (K, US); Catanduanes, Masangasibaki, Ramos E Edaño BS 75285 (NY); Panay, Antique Prov., Mt Balingaso, 10 km NE of Libertad, Sands \& Vendivil 3270 (K); Luzon, Sorsogon Prov., Mt Bulusan, Sulit PNH 2691 (GH, K, L); Luzon, Sorsogon Prov., Mt Bulusan, Sulit PNH 3621 (GH).

\section{Schismatoglottis samarensis $A$. Hay, sp. nov.}

A Schismatoglottide hastata inflorescentia majore, venulis obscuris, appendicis staminodiis ad apicem truncatis differt. - TYPUS: Philippines, Samar, Loquilocon, Apr-May 1948, Sulit PNH 6043 (GH, holo).

Small herb c. $25 \mathrm{~cm}$ tall. Stem ?erect to trailing, pleionanthic, rather condensed, to c. $15 \mathrm{~cm}$ long, $1 \mathrm{~cm}$ diam. Petioles c. 14-22 cm long, sheathing in the lower $2 / 5$; blades narrowly hastato-sagittate, to $25 \mathrm{~cm}$ long; anterior lobe c. 8-10 cm wide, widest c. $1 / 4$ the way along the midrib; posterior lobes to c. $3 \mathrm{~cm}$ long, rather narrowly rounded to squared off; midrib with c. 6 primary lateral veins on each side diverging at c. $45^{\circ}$; interprimary veins well defined; secondary venation finely striate; tertiary venation inconspicuous. Inflorescence solitary or in series each with an associated foliage leaf; peduncle c. $9 \mathrm{~cm}$ long. Spathe c. $5 \mathrm{~cm}$ long, constricted at c. $1 / 3$ from the base; limb lanceolate, acuminate, caducous. Spadix c. $3.5 \mathrm{~cm}$ long, sessile; female zone $1 \mathrm{~cm}$ long, 1/2 adnate to the spathe; interpistillar staminodes absent; pistils bottle-shaped, c. $0.5 \mathrm{~mm}$ diam.; style more or less lacking, stigma punctiform; male zone contiguous with female, $1.2 \mathrm{~cm}$ long, $1 / 2$ within the lower spathe after the limb has fallen, the rest exposed, slightly constricted level with spathe constriction, otherwise shallowly obconic, to c. $4 \mathrm{~mm}$ diam.; appendix conic, $1 \mathrm{~cm}$ long, slightly wider at the base than the top of the male zone; appendical staminodes flat-topped. Fruiting spathe asymmetrical urceolate, c. $2 \mathrm{~cm}$ long.

Distribution - Malesia: Philippines — endemic to (Samar). 
Habitat — In primary rainforest at c. $100 \mathrm{~m}$ alt.

Notes - This species has in common with $S$. pusilla the male zone partly occupying the lower spathe and the conic appendix and contiguous male and female zones lacking staminodes. It differs in the much larger inflorescence, the appendical staminodes not being pointed and the tertiary venation not forming a conspicuous tessellate pattern on the abaxial side of the leaf.

Other specimen examined: PHILIPPINES: Samar, Mt Comerol, May 1969, Gutierrez et al. PNH 117017 (L).

\section{Schismatoglottis silamensis $A$. Hay, sp. nov.}

A Schismatoglottide calyptrata (Roxb.) Zoll. \& Moritzi foliis coriaciis, inflorescentiae feminae staminodiis numerosissimis quam pistillis brevioribus; interstitio neutro pistillis abortivis et staminibus abortivis composito differt. - TYPUS: Cult. RBG Sydney Acc. No. 950379 ex Malaysia, Sabah, Lahad Datu, Gunung Silam (orig. coll. Hay et al. 10042), C. Herscovitch s.n. (SAN, holo; iso K, NSW).

Small herb c. 15-20 cm tall. Stem condensed, more or less epigeal, hapaxanthic, tightly but weakly clump-forming, c. $1 \mathrm{~cm}$ diam. Leaves c. 4 together; petiole 5-8 cm long, sheathing in the lower $2 / 5-2 / 3$; wings of sheath almost fully attached, broad, more or less parallel to petiole, the apex truncate or forming a short bifid rounded ligular portion c. $4 \mathrm{~mm}$ long; blade oblong-ovate to narrowly ovate, coriaceous, adaxially mid-green variegated with irregular blotches in three shades of green, abaxially paler, $11-15 \mathrm{~cm}$ long $\times 4.5-6.5 \mathrm{~cm}$ wide, the base very shallowly cordate to cordate with rounded posterior lobes to $2 \mathrm{~cm}$ long, the apex acute and shortly acuminate for c. $1.5 \mathrm{~cm}$; midrib abaxially prominent near the base, with c. 6 primary lateral veins on each side, alternating with fine interprimaries and diverging at $45-60^{\circ}$; secondary veins arising from the midrib and a few from near the bases of the primary veins; tertiary venation more or less obscure. Inflorescence solitary or 2 together; peduncle short, concealed within subtending leaf bases and cataphyll. Spathe 5-6.5 cm long; lower spathe narrowly ovoid, c. $2.5 \mathrm{~cm}$ long, differentiated from the limb by a constriction; limb oblong-lanceolate, somewhat inflated over the appendix, then acute, caducous. Spadix $4.7 \mathrm{~cm}$ long, sessile, more or less hourglass-shaped; female zone c. $2.2 \mathrm{~cm}$ long, more or less spindle-shaped, adnate to the spathe in the lower c. $3 / 5$, c. $6 \mathrm{~mm}$ diam. in the middle, distally slightly conoid and $4 \mathrm{~mm}$ diam. at the top; pistils depressed subglobose, strongly longitudinally c. 4-lobed, rather lax, c. $1 \mathrm{~mm}$ diam.; stigma sessile, button-like, papillate, c. $0.5 \mathrm{~mm}$ diam.; interpistillar staminodes very numerous, outnumbering and filling the spaces between the pistils at least in the lower c. $2 / 3$ of the female zone, clavate-prismatic, flat-topped, shorter than the pistils, more or less absent from the upper, attenuate part of the female zone; sterile interstice c. $5 \mathrm{~mm}$ long $\times 4 \mathrm{~mm}$ diam., composed in the lower part of 2-3 lax irregular whorls of abortive pistils (reduced or absent stigmas) and above of 2-3 irregular whorls of sterile anthers; male zone obconic, the basalmost part within the lower spathe chamber, c. $8 \mathrm{~mm}$ long, the base isodiametric with the interstice, the apex c. $7 \mathrm{~mm}$ diam.; stamens crowded, truncate, dumbbell-shaped with the connective equalling the rims of the thecae in height; rims of thecae deeply cleft at each end of the anther, c. $0.75 \mathrm{~mm}$ across; appendix $1.3-1.5 \mathrm{~cm}$ long, basally slightly and abruptly wider than the top of the male zone (fresh - not apparent dry), clavate, the tip very broadly obtuse to obtuse; staminodes of the appendix flat-topped, irregularly polygonal (post-anthesis with somewhat concave sides and tending to clump in groups of c. 4 ), c. $0.75 \mathrm{~mm}$ across. Fruit unknown.

Distribution - Malesia: endemic to Borneo (Sabah); known only from the type locality.

Habitat - On rocks on (dry) stream bank in rather dry mixed lower montane forest on ultramafic substrate at c. $500 \mathrm{~m}$ alt. 
Notes - Schismatoglottis silamensis is allied to S. calyptrata, S. motleyana, S. trivittata and S. trifasciata - variable species which tend to approach each other at the extremes of their variation. In this widespread alliance, S. silamensis is distinguished by the short interpistillar staminodes occurring in very large numbers in the female zone, the rather well-defined sterile interstice composed of abortive pistils and anthers, and its coriaceous leaves which have rather unusual variegation in three shades of green. It represents a local endemic segregate on ultramafic substrate.

\section{Schismatoglottis subundulata (Zoll. ex Schott) Nicolson}

Schismatoglottis subundulata (Zoll. ex Schott) Nicolson, Smithsonian Contrib. Bot. 1 (1969) 61. - 'Aglaonema sp. (si nova A. subundulatum Zoll.)', Zoll., Syst. Verzeich. 1 (1854) 76. - Aglaonema subundulatum Zoll. ex Schott, Syn. Aroid. (1856) 123; Miq., Fl. Ind. Bat. 3 (1856) 217; Schott, Prodr. Syst. Aroid. (1860) 306; Engl. in A. \& C. DC., Monogr. Phanerogam. 2 (1879) 443 \& Pflanzenr. 64 (IV.23Dc) (1915) 34. - Type: Indonesia, SW Sulawesi, near Maros, 14 Jun 1847, H. Zollinger 1075 (P, ?holo).

Schismatoglottis celebica Engl., Bot. Jahrb. Syst. 25 (1898) 19 \& Pflanzenr. 55 (IV.23Da) (1912) 90, fig. 55. - Type: Indonesia, SW Sulawesi, near Maros, 14 Jun 1847, H. Zollinger 1075 (P, lecto; selected here).

Herb c. 20-30 cm tall. Stem condensed, more or less epigeal, c. $1 \mathrm{~cm}$ diam., pleionanthic. Leaves few to c. 18 together, crowded; petiole 10-15 cm long, sheathing in the lower $1 / 3-1 / 2$; wings of sheath fully attached, narrow, tapering; blade lanceolate to narrowly elliptic, $8-17 \mathrm{~cm}$ long $\times 1-4.5 \mathrm{~cm}$ wide, the base acute and slightly decurrent to rounded to occasionally emarginate, the apex acute and acuminate for c. $2 \mathrm{~cm}$; midrib slightly prominent abaxially, with 3-9 primary lateral veins on each side, alternating with lesser, in varying degree conspicuous interprimaries and diverging at 45-60 ${ }^{\circ}$ secondary venation adaxially obscure, arising from the midrib; tertiary venation obscure. Inflorescence solitary; peduncle slender, exserted, c. $3 \mathrm{~cm}$ long. Spathe c. $3.5 \mathrm{~cm}$ long; lower spathe 7-9 mm long, narrowly cylindric, differentiated from the limb by a slight constriction; limb c. $3 \mathrm{~cm}$ long, more or less lanceolate, white, ?caducous. Spadix sessile, subcylindric (very narrowly obconoid), c. $2.5 \mathrm{~cm}$ long; female zone c. $6 \mathrm{~mm}$ long, slender, subcylindric, adnate to the spathe in the lower $1 / 3$; pistils subglobose, more or less crowded in the proximal $2 / 3$, lax in the distal $1 / 3$ of the zone, c. $0.4 \mathrm{~mm}$ diam. (dry); stigma small, c. $0.25 \mathrm{~mm}$ diam., elevated on a very short style abruptly differentiated from the top of the ovary, button-like; interpistillar staminodes absent from among the pistils, confined to an incomplete row along the spathe/spadix adnation, clavate, flat-topped, shortly stipitate, about the diameter and height of the pistils; sterile interstice c. $2 \mathrm{~mm}$ long, occupied by robust more or less sessile, more or less rhomboid staminodes c. $1.5 \mathrm{~mm}$ diam. and partially to completely connate in the distal part of the interstice; male zone $1 \mathrm{~cm}$ long, narrowly obconic, distally c. $3 \mathrm{~mm}$ diam.; stamens crowded, truncate, dumbbell-shaped, c. $1 \mathrm{~mm}$ across, the connective not elevated, the thecae with narrowly alate somewhat raised rims; appendix c. $5 \mathrm{~mm}$ long, bluntly conoid, slightly and abruptly wider at the base than the top of the male zone, c. $4 \mathrm{~mm}$ diam.; staminodes of appendix ivory, upward facing especially in the distal part of the appendix, columnar, elongate, c. $2 \mathrm{~mm}$ long $\times 0.3 \mathrm{~mm}$ diam., the tips rounded to erose. Fruiting peduncle not much elongated; fruiting spathe urceolate, c. $1 \mathrm{~cm}$ long.

Distribution - Malesia: endemic to Sulawesi (South Sulawesi); in the vicinity of Maros and Bantimurung.

Habitat - Lithophytic near streams, or actually rheophytic, on limestone at low elevation. 
Notes - The cited type of Aglaonema subundulatum is a Zollinger specimen in the Drake Herbarium now incorporated into the general herbarium at P. No duplicates have been found in other herbaria. The specimen is annotated with that name in Zollinger's hand and is quite possibly the holotype. Zollinger's own set of his collections found its way to Paris, though the initials H.Z., said to identify his private set (van Steenis-Kruseman, 1950: 595), are not present.

According to Nicolson (1969), Schismatoglottis celebica was also based on a Zollinger collection, a duplicate of the type of Aglaonema subundulatum, also at P, but not identified by Zollinger to species (A.H. has seen this specimen and it is determined by Zollinger as Aglaonema; Engler has determined it as Schismatoglottis celebica). Since the type of $A$. subundulatum is not annotated by Engler, it would appear that these two names, though apparently based on the same collection, are not homotypic. Schismatoglottis celebica had a Warburg collection as the second syntype; that specimen has not been located at B and was presumably destroyed during the war. The duplicate of Zollinger 1075 at P, annoted with 'Schismatoglottis celebica Engl., n.sp.' is therefore designated the lectotype of that name.

Engler noted that the very long staminodes of the appendix were one of the most distinctive features of this species, which he illustrated as S. celebica. These are not apparent in the type of $S$. subundulata, as the appendix has evidently been broken off. Unfortunately the rest of the spadix is very mouldy and detail is obscured. However it does appear that there is at least one very large staminode in the interstice. Engler did not illustrate or describe an interstice for S. celebica, but more recently collected complete material combines the long staminodes of the appendix, with very bulky and distinctive staminodes in the interstice, and in turn matches very closely the type of $S$. subundulata in vegetative features. However, a further anomaly is in the spathe, which in the more recently collected material is quite slender, where it appears to be distinctly inflated in the type. This may be no more than a reflection of different stages of maturity, but in view of these various aspects of ambiguity, it may transpire, with further collection, that there is more than one taxon within the concept of S. subundulata proposed here. Militating against that however, is the very restricted geographic distribution of the collections concerned, and their common specialised ecology, even Zollinger noting on the type 'Ad rupes Cataractar.'.

Other specimens examined: SULAWESI: SOUTH SULAWESI: Bantimurung and vicinity, Buwalda 3706 (BO, K, L); Maros, Bantimurung Park, Chin 3394 (L); Bantimurung, between Makassar and Maros, van Steenis 10423 (BO, L).

\section{Schismatoglottis trifasciata Engl. complex}

Schismatoglottis trifasciata Engl., Pflanzenr. 55 (IV.23DA) (1912) 106, fig. 65; Alderw., Bull. Jard. Bot. Buitenzorg III, 4 (1922) 225. - Type: Cult. Hort. Bogor. ex Borneo (orig. coll. Nieuwenhuis 1991), Jan/Feb 1906, A. Engler s.n. (Bt, holo; iso BO). - Epitype: Cult. Hort. Bogor. XI.B.X.68, C.R.W.K. van Alderwerelt van Rosenburgh 332 (BOKR + BO spirit; designated here).

Schismatoglottis colocasioidea M. Hotta, Mem. Coll. Sci. Univ. Kyoto, ser. B, 32 (1966) 238, fig. 7, H-N. - Type: Malaysia, Sarawak, Mardi, foot of Gunung Mulu, along Sg. Payau, 22 Mar 1964, M. Hotta 15310 (KYO, holo).

Herb, sometimes robust, c. 30-70 cm tall. Stem condensed, hypogeal, hapaxanthic, clump-forming, to c. $2.5 \mathrm{~cm}$ diam. Leaves few to several together; petiole (14-) c. 20-50 cm long, sometimes suffused purplish or blackish, very finely velvety hairy to scabrid with minute and dense papillae to glabrous, more or less terete to D-shaped in cross section and narrowly alate on the angles, sheathing in the lower $1 / 3-2 / 3(-9 / 10-$ Poulsen 143 , p.p.); wings of sheath fully attached, tapering; blade sagittate to oblong-ovate to 
ovate, adaxially shining to matt mid-green, sometimes variegated with 2 irregular grey-green bands about midway between the midrib and margin, paler abaxially, $16-15 \mathrm{~cm}$ long $\times 7-26 \mathrm{~cm}$ wide, the base acute to retuse to narrowly to broadly cordate and then with somewhat acute posterior lobes up to $12 \mathrm{~cm}$ long; midrib abaxially prominent (fresh; not so when dry) with (like the primary veins) the same variable surface texture as the petiole; primary lateral veins 5-13 on each side of the midrib, alternating with fine to robust (almost equalling primary veins) lesser interprimaries and diverging at $45-80^{\circ}$, unbranched or with 1-3 branches especially in the lower half of the blade; secondary venation arising from the midrib and sometimes from the primary veins - especially in forms with branched primary veins; tertiary venation obscure. Inflorescences (1-)2- c. 8 together; peduncle 8-20 cm long exserted from the leaf bases and cataphylls at anthesis, elongate and more or less declinate in fruit. Spathe 9-16.5 cm long, slender; lower spathe narrowly ovoid, $2.5-5 \mathrm{~cm}$ long, green to blackish (when the petiole so), differentiated from the limb by a distinct constriction; limb 6.2-12.5 cm long, lanceolate, whitish, loosening but hardly opening at anthesis, caducous. Spadix 6.5-11(-15.2) cm long, slender subcylindric, usually c. $3 / 4$ (but occasionally subequalling) the length of the spathe; female zone 2-4 cm long, adnate to the spathe in the lower $1 / 2-3 / 4,6-8(-10) \mathrm{mm}$ diam. in the middle, distally slightly conoid to (3-)4(-6) mm diam. at the top; pistils subglobose to bottle-shaped to subcylindric, $0.5-0.7 \mathrm{~mm}$ diam.; stigma sessile, discoid, papillate, c. $0.5 \mathrm{~mm}$ diam.; interpistillar staminodes densely to sparsely scattered among the pistils, sometimes also in a complete to much-broken row along the spathe/spadix adnation, about equalling to twice the height of the pistils, short- to long-stalked, narrowly to broadly clavate, round- to flat-topped; sterile interstice absent, occasionally a few shorter staminodes concentrated at the top of the female zone but then intermixed with fertile elements; interface of female and male zones or lower part of male zone sometimes (when spadix relatively thick) attenuated by spathe constriction, or more usually isodiametric with rest of male zone; male zone 2-3.5 cm long $\times 3-4(-6) \mathrm{mm}$ thick, about $1 / 3$ (rarely only the extreme base) held within the lower part of the spathe chamber, cylindric (unless lower part attenuate by spathe constriction), ivory white; stamens crowded, truncate, dumbbell-shaped, with the connective not elevated above the thecae, c. $0.5 \mathrm{~mm}$ across; appendix $2.5-4.5(-7.2) \mathrm{cm}$ long, usually basally isodiametric with male zone and then subcylindric, tapering to a fine or blunt point, occasionally slightly wider that top of male zone at base, occasionally wider (to $5 \mathrm{~mm}$ diam.) above the base, thence tapering; staminodes of appendix with rounded to pointed tips, densely arranged, c. 0.3-0.5 (-0.7) $\mathrm{mm}$ diam. Fruiting spathe narrowly urceolate, to c. $5 \mathrm{~cm}$ long.

Distribution - Malesia: endemic to northwestern and northern Borneo (Sarawak, Brunei, Sabah). The cultivated plant on which S. trifasciata was based was presumably collected in (?East) Kalimantan, but no other material from there has been found during this revision.

Habitat - Terrestrial on rainforest floor, sea level to c. $1200 \mathrm{~m}$ alt.

Notes - The isotype of $S$. trifasciata is fragmentary and inadequate. Later material evidently preserved by Alderwerelt from the same plant that Engler described is therefore designated epitype.

Schismatoglottis trifasciata is highly polymorphic. Recalling the situation in the also highly polymorphic Alocasia longiloba Miq. (Hay 1998), in parts of the range sharply differing forms of $S$. trifasciata co-exist and apparently maintain their identity behaving as locally discrete topospecies. Hence this species has been qualified as a complex. The problem usual in Malesian Araceae - undersampling - makes unproductive a rigorous analysis of variation which might otherwise enable the recognition of very narrowly defined, morphologically 'cryptic' species. However, a discursive, anecdotal account of the variation may be of some use. 
Leaf form is the most variable morphological aspect of this species (as in Alocasia longiloba). The form corresponding to the type of $S$. colocasioidea has sagittate leaf blades with numerous primary veins, which are often branched, and strong interprimary veins; secondary veins frequently arise from the primary veins; the petiole is velvety hairy and sometimes suffused purple, more or less terete in crosssection and not alate (Dearden s.n.). So far, this form is confined to Sarawak. The appendix is usually whitish. A rather similar, but less robust form occurs in eastern Sabah (e.g. at Sepilok, Sabah); however, though this has similar leaf venation, the petiole is scabrid rather than hairy and often suffused blackish (RBG Sydney 960542). The appendix is orange, as it is in all the Sabah specimens A.H. has seen living.

At the other extreme is a form with oblong-ovate, acute- to obtuse-based leaves with fewer primary veins, weaker interprimary veins, fewer secondary veins arising from the primaries and glabrous alate petioles D-shaped in cross-section (RBGS 960507, 960543). This form coexists at Sepilok, where it is uncommon, with the scabrid-leafed form (common at this locality) just discussed. They appear not to intergrade there, but at Gomantong (Sabah) an intermediate form occurs (RBGS 960526). It is weakly scabrid to glabrous on the petiole, the blade is more or less ovate with a narrowly and shallowly cordate base and the venation is intermediate. This latter form matches the illustration that accompanies the protologue of $S$. trifasciata.

Differently intermediate forms occur in southern Sabah, in the vicinity of Tibau (RBGS 960502, 960562) and at Kalabakan Virgin Jungle Reserve (RBGS 960538). In these the leaf is sagittate, but the petiole is glabrous; the interprimary veins are not as robust as in the type form, the primary veins not as numerous and they branch little. At the Maliau Basin, a very robust form was collected (RBGS 960572) which also has glabrous sagittate leaves, but the primary venation is much branched. This last form coexists at Maliau with a much less robust ovate-leaved form with simple primary venation, weak interprimary veins, glabrous petioles weakly alate in the upper part and narrowly and shallowly cordate bases (RBGS 960497).

There is also some variation in reproductive features, however, it does not appear to correlate enough with vegetative variability to enable division of this unwieldy species on currently available evidence. The pistils vary from subglobose to subcylindric. This is correlated with robustness: the more robust the female zone of the spadix the more the pistils tend to be relatively narrow and crowded. However, this correlation exists more or less throughout the genus and it might be inferred to be a plastic consequence of larger size of the female part of the spadix, and not something of taxonomic significance in itself. Another variable feature is the shape of the spadix level with the spathe constriction: there may or may not be an attenuate portion here; again, this is correlated with robustness and appears to be a mechanical consequence of a thicker spadix developing within the constraints of the spathe constriction. The interpistillar staminodes vary from slightly shorter than the pistils to twice their height, but this is not correlated with other variation, and may indeed vary widely in similar plants: for example, in A.H.'s otherwise very similar collections from the vicinity of Tibau, the interpistillar staminodes vary from slightly taller than the pistils to twice their height. Likewise not only the shape, but also the density and distribution (especially with respect to whether or not they form a basal row) of the interpistillar staminodes may vary markedly between vegetatively similar forms. The extent to which the male zone is held within the lower spathe chamber is also variable, but apparently more or less independently of other variations; so too the shape of the appendix, which may be widest at the base or slightly above the base, and at the base slightly wider or not than the top of the male zone. The appendical staminodes, blunt- to sharp-tipped, can vary between vegetatively similar plants in the same locality. 
Differentiating this species, in its less strongly sagittate forms, from forms of S. motleyana with more elongate inflorescences, may be difficult (see under that species), and it would appear that these two species together form a complex group that is actively evolving and consequently taxonomically somewhat intractable. It would doubtless be a profitable subject for further analysis, molecular and ecological.

Other specimens examined: BORNEO: SARAWAK: Cult. Redlynch, Queensland, ex Semenggoh, Dearden s.n. (NSW); 4th Divn, Sg. Bok, a branch of Tinjar R., near Long Teru, Hotta 6108 (KYO). BRUNEI: Temburong Prov., vicinity of Labu, Bukit Peradayan, Hotta 13584 (KYO); Temburong Prov., Sg. Tongkat, a branch of Sg. Batu Apoi, Hotta 13719 (KYO); Temburong Prov., Batu Apoi FR, Sg. Belalong, nr Field Studies Centre, Poulsen 9943 (AAU, K). SABAH: Cult. RBG Kew Acc. No. 143-86.01352 ex Lahad Datu, Danum Valley Field Studies Centre, Palum Tambun R. (orig. coll. Bradley 87), Anon. s.n. (K); Cult. RBG Sydney Acc. No. 960497 ex Maliau Basin, Gunung Rara Forest Reserve, $2.5 \mathrm{~km}$ above main Maliau Falls (orig. coll. Hay et al. 12062) Herscovitch s.n. (K, KEP, L, NSW, SAN); Cult. RBG Sydney Acc. No. 960502 ex Kinabatangan Distr., Tibau Forest Station area, orig. coll. Hay et al. 12029 (SAN)), Herscovitch s.n. (K, KEP, L, NSW, SAN); Cult. RBG Sydney Acc. No. 960507 ex Sepilok Forest reserve (orig. coll. Hay et al. 12150), Herscovitch s.n. (K, KEP, L, NSW, SAN); Cult. RBG Sydney Acc. No. 960526 ex Gomantong Caves (orig. coll. Hay et al. 12171), Herscovitch s.n. (K, KEP, L, NSW, SAN); Cult. RBG Sydney Acc. No. 960538 ex Kinabatangan Distr., Kalabakan Virgin Jungle Reserve (orig. coll. Hay et al. 12016), Herscovitch s.n. (K, KEP, L, NSW, SAN); Cult. RBG Sydney Acc. No. 960542 \& 960543 both ex Sepilok Forest Reserve (orig. coll. Hay et al. 12155 \& 12156 (SAN)), both Herscovitch s.n. (K, KEP, L, NSW, SAN); Cult. RBG Sydney Acc. No. 960562 ex Kinabatangan Distr., Tibau Forest Station area (orig. coll. Hay et al. 12137) Herscovitch s.n. (K, KEP, L, NSW, SAN); Cult. RBG Sydney Acc. No. 960572 ex Maliau Basin, Gunung Rara Forest Reserve, $2.5 \mathrm{~km}$ above main Maliau Falls (orig. coll. Hay et al. 12094 (SAN)) Herscovitch s.n. (K, KEP, L, NSW, SAN); Pensianang Distr., Batu Urun, Kiew \& Anthony RK4447 (NSW, SING); Sandakan, Gomantong Caves, Ogata 10973 (L); Sandakan, Kabili FR, Puasa 9943 (K, KEP, L); Sandakan and vicinity, Ramos 1347 (US).

\section{Schismatoglottis trivittata Hallier $\mathrm{f}$.}

Schismatoglottis trivittata Hallier f., Ann. Jard. Bot. Buitenzorg 13 (1896) 324, fig.30. - Schismatoglottis calyptrata var. trivittata (Hallier f.) Hallier f., Ann. Jard. Bot. Buitenzorg 14 (1897) 260. - Schismatoglottis picta var. trivittata (Hallier f.) Engl., Pflanzenr. 55 (IV.23Da) (1912) 114. - Type [iconotype]: Ann. Jard. Bot. Buitenzorg 13 (1896) fig. 30.

Schismatoglottis engleriana Alderw., Bull. Jard. Bot. Buitenzorg III, 4 (1922) 217. — Type: Cult. Hort. Bogor. XI.B.X.111 (orig. coll. Nieuwenhuis 991), C.R.W.K. van Alderwerelt van Rosenburgh 342 (BOKR + BO spirit, holo).

Robust herb to $60 \mathrm{~cm}$ tall. Stem hypogeal, hapaxanthic, clump-forming or sometimes stoloniferous, c. $2 \mathrm{~cm}$ diam. Leaves to 4 together; petiole to c. $45 \mathrm{~cm}$ long, sheathing in the lower $2 / 5$; wings of sheath fully attached, tapering, apically truncate; blade (broadly to narrowly) ovato-sagittate, $18-38 \mathrm{~cm}$ long $\times 8-20 \mathrm{~cm}$ wide, adaxially mid- to dark green, sometimes variegated with a greyish irregular central band or with a central band and a band on each side between the midrib and margin, paler abaxially, base cordate with spreading rather acutely rounded posterior lobes to $8 \mathrm{~cm}$ long (much reduced in Hirano s.n.), the tip acute and acuminate for $2-4 \mathrm{~cm}$; midrib not prominent (dry), with 8-11 primary lateral veins on each side, irregularly alternating with lesser interprimaries and diverging at c. $60^{\circ}$, the lower ones usually branched, giving off 1 or 2 veins similar in size to the interprimaries; secondary venation arising from the midrib and from along the lower c. $1 / 2$ of the proximal primary veins; tertiary venation obscure. Inflorescences (1-)2-5 together; peduncle c. 11-15 cm long. Spathe 12-18 cm long; lower spathe narrowly ovoid, 4-6 cm long, differentiated from the limb by a strong constriction; limb broadly ovate, 8-12 cm long, whitish, inflated over the appendix, caducous. Spadix sessile, $8.5-13 \mathrm{~cm}$ long, subcylindric (weakly hourglassshaped); female zone $4-6 \mathrm{~cm}$ long, adnate to the spathe for c. $1 / 2$ its length, $0.8-1.2 \mathrm{~cm}$ 
wide in the middle, distally slightly conic, c. $4-7 \mathrm{~cm}$ diam. at the top; pistils crowded, bottle-shaped, c. $1 \mathrm{~mm}$ diam.; stigma sessile to slightly elevated on a short style, button-like, papillate, about as wide as the ovary; interpistillar staminodes scattered among the pistils, stalked, clavate with the head subspherical, slightly exceeding the pistils and occasionally much exceeding them; sterile interstice ill-defined, the upper part of female zone (sometimes partly naked and) covered with squashed pistils level with the spathe constriction and at the base of the male zone a concentration of staminodes resembling headless interpistillar staminodes, these intergrading distally with fertile stamens (occasionally a few whorls of sterile anthers); male zone subcylindric - slightly obconic, $2.4-3.4 \mathrm{~cm}$ long, 8-9 $\mathrm{mm}$ diam. at top; stamens densely crowded, truncate, c. $1 \mathrm{~mm}$ across, dumbbell-shaped with the connective narrow and very slightly elevated into a low point; appendix bluntly conoid, $1.7-2.6 \mathrm{~cm}$ long, the base slightly and abruptly wider than top of male zone, $0.9-1.1 \mathrm{~cm}$ diam. at base; staminodes of appendix columnar, irregularly polygonal with very rounded angles, flat-topped and usually slightly impressed to somewhat rounded, c. $0.5 \mathrm{~mm}$ diam. Infructescence unknown.

Distribution - Malesia: Borneo (widespread but scattered).

Habitat - Lowland rainforest floor and elevated soil patches in swampy forest, and low montane forest; sea level to $1000 \mathrm{~m}$ alt.

Notes - The current concept of Schismatoglottis trivittata is of a variable, widespread and rather scattered species. In inflorescence it is only distinguishable from S. niahensis by the sterile interstice usually lacking a zone of sterile anthers and by the connective being less clearly elevated into a low peak between the thecae. However, the leaf is relatively shorter and broader, without the very broad midrib and primary veins characteristic of S. niahensis. More importantly, the stem is hypogeal and hapaxanthic in S. trivittata where it is epigeal and pleionanthic in S. niahensis.

The collection from Brunei cited below is fragmentary, with an immature inflorescence. The spadix is rather slender for this species, approaching that of S. motleyana. However the position of the interstice indicates that the male zone would be exserted from the lower spathe, which is not characteristic of that species. The narrowness of the spadix may be a consequence of its immaturity.

Schismatoglottis trivittata does not appear to have had any type material preserved, and so is typified by the illustration which accompanied the protologue. It was reduced to varietal status in S. calyptrata by Hallier (loc.cit.) and then in S. picta (= S. calyptrata) by Engler (loc. cit.). It is evident from the iconotype that $S$. trivittata has a leaf conforming more closely (by the relatively large number of primary veins) to the species defined here than $S$. calyptrata. The appendix illustrated is somewhat short but well within the continuum of variability in this species.

Other specimens examined: BORNEO: SARAWAK: Sg. Begu, Padawan Rd, Bogner 1406 (US); 2nd Divn, Sg. Dor, shortly after Bandar Sri Aman on the Kuching-Sibu Rd, Boyce 754 (K); 3rd Divn, Nanga Mujong, Brooke 8926 (G); Gat, Upper Rejang R., Clemens \& Clemens 22132 (NY) \& 22134 (NY); Cult. RBG Sydney Acc. No. 920739 ex Kapit (orig. coll. Dearden s.n.), Herscovitch s.n. (NSW, KEP, SAR); Cult. RBG Sydney Acc. No. 940518 ex Niah National Park, Batu Niah (orig. coll. Hay et al. 9367), C. Herscovitch s.n. (K, KEP, L, M, NSW, SAR, US); Along Sg. Anap, a branch of Sg. Tatau, Bintulu Distr., Hirano s.n. (KYO); Cult. Bot. Gard. Osaka City Univ. ex Bukit Kama, Hotta s.n. (KYO); 4th Divn, along Sg. Payau from S Melinau paku to Rubang Payau, foot of G. Mulu, Hotta 15305 (KYO); 2nd Divn, Betong, Sg. Engkabang, Btg. Layar, Lee S. 41972 (K, KEP, L, US). BRUNEI: Temburong Distr., G. Retak, headwaters of Temburong River to NE G. Retak, Johns 6734 (K). SABAH, Banguey Isl., Castro \& Melegrito 1343 (BM, P); Kinabalu NP, Sosopodon and Sg. Liwagu, Kokawa \& Hotta 4626, 4631 \& 4708 (all KYO); Kinabalu NP, en route from Poring Hot Springs to Langanan Water Fall, Kokawa \& Hotta 4740, 4744, 4762 \& 4796 (all KYO); Kinabalu NP, en route from Poring to Kg Nalumad, Kokawa \& Hotta 5248 \& 5251 (both KYO); Tambunan Distr., Trusmadi, Joseph 
B et al. SAN 113722 (K, SAN). KALIMANTAN: Central Kalimantan, Bukit Raya, SE side, c. 10 km NNW of Tumbang Tosah, Mogea $\mathcal{E}$ de Wilde 3906 (L).

79. Schismatoglottis trusmadiensis A. Hay \& J. Mood, sp. nov.

A Schismatoglottide moodii inflorescentia femina longiore in dimidio inferiore spathae adnata, inflorescentiae feminae staminodiis brevioribus, connectivo crassiore, appendice conoidea differt. - TYPUS: Cult. Haleiwa, Hawaii ex Malaysia, Sabah, Kengaran Distr., Trus Madi (orig. coll. Mood M791a), J. Mood s.n. (NSW + NSW spirit, holo).

Herb to c. $60 \mathrm{~cm}$ tall. Stem hypogeal, hapaxanthic, clump-forming. Leaves 2-3 per crown; petiole c. $30 \mathrm{~cm}$ long, sheathing in the lower $1 / 3$; wings of sheath fully attached, tapering, the apex narrowly ligular for c. $2 \mathrm{~mm}$; blade broadly hasto-sagittate, c. $27 \mathrm{~cm}$ long $\times 14 \mathrm{~cm}$ wide, the base deeply divided into two somewhat out-turned acutely rounded posterior lobes $8-10 \mathrm{~cm}$ long, the apex obtuse then acuminate for c. $4 \mathrm{~cm}$; midrib not or hardly prominent (dry) with c. 10 primary lateral veins on each side, alternating with lesser interprimaries and diverging $50-80^{\circ}$, occasionally branched near the midrib; secondary veins mostly arising from the primary veins in the lower part of the leaf and mostly from the midrib in the upper part of the leaf; tertiary venation obscure. Inflorescence normally solitary; peduncle over $15 \mathrm{~cm}$ long, rather stout. Spathe $13 \mathrm{~cm}$ long; lower spathe $6.5 \mathrm{~cm}$ long, narrowly ovoid to subcylindric, differentiated from the limb by a constriction; limb very broadly ovate, somewhat cucullate, $6.5 \mathrm{~cm}$ long, caducous. Spadix $9 \mathrm{~cm}$ long; female zone long, slender subcylindric, $6 \mathrm{~cm}$ long, adnate to the spathe in the lower half, $6 \mathrm{~mm}$ diam. in the middle, distally tapering to $3 \mathrm{~mm}$ diam.; pistils crowded, bottle shaped, c. $0.7 \mathrm{~mm}$ diam., the upper ones partially squashed by the spathe constriction; stigma subsessile, button-like, papillate, c. $0.5 \mathrm{~mm}$ diam.; interpistillar staminodes scattered among the pistils, rather few, stalked, clavate, round-topped, about as high as the pistils; interstice ill-defined, exserted from the mouth of the lower spathe, c. $5 \mathrm{~mm}$ long, partially naked, with a concentration of interpistillar staminodes and in the upper part some sterile anthers, mixed with scattered fertile elements; male zone obconoid, $1.5 \mathrm{~cm}$ long, basally isodiametric with the interstice, apically $1.1 \mathrm{~cm}$ diam.; stamens crowded, truncate, hourglass-shaped, the connective thick but not or hardly elevated above the thecae; pores small with the rims narrowly cleft on the outer edges; appendix $1.4 \mathrm{~cm}$ long, conoid, obtuse, at the base indistinctly wider than the top of the male zone, c. $1.2 \mathrm{~cm}$ diam.; staminodes of appendix flat-topped, irregularly polygonal, c. $0.5 \mathrm{~mm}$ diam.

Distribution - Malesia: endemic to Borneo (Sabah); known only from the type locality on Gunung Trus Madi.

Habitat - Terrestrial in secondary forest at $920 \mathrm{~m}$ alt.

Notes - This species is similar in leaf shape to the more robust $S$. moodii. It differs from that species in the female zone of the spadix relatively longer and half adnate to the spathe, the shorter interpistillar staminodes, the stamens with small pores separated by a rather thick connective, the obtusely conoid appendix not abruptly thicker than the male zone, and the smaller diameter appendical staminodes.

80. Schismatoglottis unifolia A. Hay E P.C. Boyce, sp. nov.

In habitu Schismatoglottidem longispatham simulans sed petiolo aspero longiore, vagina breviore, folii lamina cordato-sagittata majore, inflorescentia femina libera, stigmate crasse discoideo, inflorescentia mascula intra spatham inferiorem sedenti, thecis dimeris differt. - TYPUS: Malaysia, Sabah, Tenom Distr., Ulu Senagong, 21 Oct 1999, P.C. Boyce E J. Linton 1432 (K + K spirit, holo; iso L, NSW + NSW spirit, SAN, SP (Sabah Parks)). 
Colony-forming herb to $25 \mathrm{~cm}$ tall. Stem short and slender, hapaxanthic, hypogeal, long-stoloniferous, c. $8 \mathrm{~mm}$ diam.; leaf solitary, subtended by lanceolate cataphylls to $8 \mathrm{~cm}$ long; petiole 13-30 cm long, red-brown to mid-green, asperous, minutely and densely papillate especially distally, sheathing in the lower c. $1 / 10$; wings of sheath persistent, fully attached, tapering; blade ovato- to cordato-sagittate, $23-29 \mathrm{~cm}$ long $\times 15-16 \mathrm{~cm}$ wide, adaxially dull mid-green variegated with two broad irregularly blotched grey-green bands one on each side between the midrib and margin, the apex acute and acuminate for $1-2 \mathrm{~cm}$, the base cordate with broadly rounded posterior lobes 4-5 cm long; midrib more or less flush with the lamina (dry), abaxially asperous near the base, with 6-7 primary lateral veins on each side, alternating with very fine interprimary veins and diverging at c. $50-70^{\circ}$; secondary venation very fine, arising mostly from the midrib, some also from the bases of the primary lateral veins; tertiary venation forming a faint tessellate reticulum in the dry state more clearly visible on the adaxial side. Inflorescence solitary; peduncle 4-8 cm long, subtended by lanceolate cataphylls to c. $5 \mathrm{~cm}$ long. Spathe slender, 5.5-9 cm long, pink throughout, darker below; lower spathe ovoid, $2-3 \mathrm{~cm}$ long, differentiated from the limb by a weak constriction; limb lanceolate, $3.5-6 \mathrm{~cm}$ long, gaping, then abscising rather irregularly and more or less disintegrating. Spadix sessile, subcylindric, 4.5-6.5 cm long; female zone obliquely inserted, $0.9-1.4 \mathrm{~cm}$ long, slightly conoid, apically c. $4 \mathrm{~mm}$ diam.; pistils squat, crowded, pale pink; ovary very shortly cylindric, concealed from above by the large thick discoid papillate sessile contiguous stigmas c. $1 \mathrm{~mm}$ diam.; interpistillar staminodes pale pink, frequent, scattered among the pistils and in a row around the base of the female zone, shortly stipitate, truncate-clavate, about the height of the pistils; interstice absent; male zone contiguous and isodiametric with top of female zone, cylindric, held within the lower spathe chamber, $0.8-1.2 \mathrm{~cm}$ long; stamens dark pink, crowded, truncate, irregularly rectangular to rhomboid, c. $1 \mathrm{~mm}$ across, with the connective thick and not elevated above the thecae; rims of thecae broad and deeply cleft on the outer edge; pollen sacs discharging through a common pore in each theca; appendix mid-pink, c. 3-4 cm long (more than half the length of the spadix), subcylindric, basally isodiametric with top of male zone, tapering to a fine point; staminodes of appendix flat-topped to slightly impressed, irregularly polygonal with very rounded angles, c. $1.1 \mathrm{~mm}$ diam. Fruiting spathe broadly urceolate, c. $3 \mathrm{~cm}$ long; berries greenish white.

Distribution - Malesia: endemic to Borneo (Sabah); known only from the type.

Habitat - Terrestrial in deep leaf litter over sandy loam in secondary gallery forest on a steep slope, $470 \mathrm{~m}$ alt.

Note - The affinities of this species are rather unclear. It seems to have hapaxanthic shoots, which are restricted to the $S$. calyptrata group, but the irregularly abscising and more or less disintegrating (rather than caducous) spathe limb suggest it belongs in the $S$. asperata group. The male zone held within the lower spathe chamber is shared with $S$. pudenda and S. grabowskii, and suggests a breeding system unusual in this genus.

\section{Schismatoglottis venusta $A$. Hay, sp. nov.}

A Schismatoglottide calyptrata habitu lithophytica calcicola, folii lamina coriacea atroviride, spathae lamina alba, ovario subgloboso, inflorescentiae feminae staminodiis truncatis ovaria haud superantis, appendice breviter cylindroidea obtusa differt. TYPUS: Cult. RBG Sydney Acc. No. 960559 ex Malaysia, Sabah, Gomantong Caves (orig. coll. Hay et al. 12167 - voucher SAN) C. Hercovitch s.n. (SAN, holo; iso K, KEP, L, NSW, US).

Herb 15-30 cm tall. Stem condensed in leafy part (sometimes etiolated below) hypogeal, hapaxanthic, clump-forming, c. $1 \mathrm{~cm}$ diam. Leaves c. 4 together; petiole c. $12-21 \mathrm{~cm}$ long, very minutely (strong lens required) and densely papillate, sheathing 
in the lower $1 / 4-1 / 3$; wings of sheath tapering, fully attached; blade (oblong-)ovatosagittate, somewhat coriaceous, adaxially very dark matt green, concolorous or variegated with a central silver stripe or three stripes (one about the midrib and one on each side c. half-way between the midrib and margin), or irregularly spattered silver-grey throughout or spattered and striped, abaxially much paler, 13-17 cm long $\times 7-9 \mathrm{~cm}$ wide, the base rather broadly cordate with more or less rounded spreading to sometimes overlapping posterior lobes to $2.5 \mathrm{~cm}$ long, the apex acute to broadly acute and acuminate for c. $1 \mathrm{~cm}$; midrib prominent (fresh; not so when dry); primary lateral veins c. 7 on each side of midrib, not prominent, alternating with fine interprimaries, diverging at $60-90^{\circ}$ and gradually up-curved before joining the margin; secondary venation adaxially obscure, arising mostly from the midrib, some from the bases of the primary veins; tertiary venation forming a rather indistinct tessellate reticulum abaxially. Inflorescence solitary to 2(-3) together; peduncle to c. $3.5 \mathrm{~cm}$ long, subtended by short oblong cataphylls c. $2 \mathrm{~cm}$ long. Spathe 6-7 cm long; lower spathe ovoid, 2-2.5 cm long, dark green; limb ovate, c. 4-4.5 cm long, white, caducous, inflated over the appendix, apically acuminate for $1 \mathrm{~cm}$. Spadix sessile, $3.5-4.5 \mathrm{~cm}$ long, more or less hourglass-shaped; female zone 1.3-2 cm long, adnate to the spathe for about half its length, c. $5 \mathrm{~mm}$ diam. in the middle, distally very attenuate; pistils subglobose, basally somewhat lax and distally very lax, c. $1 \mathrm{~mm}$ diam.; stigma subsessile, button-like, c. $0.25 \mathrm{~mm}$ diam.; interpistillar staminodes few to many, scattered among the pistils, rather more crowded along the spathe/spadix adnation, flat-topped, slightly stipitate, lower than to about the same height as the ovary, to $0.5 \mathrm{~mm}$ diam., (sometimes drying black); sterile interstice ill-defined, the apex of the female zone being attenuate and partly naked, sometimes with a few abortive ovaries and reduced interpistillar staminodes contiguous with the base of the male zone; male zone obconic, c. $1 \mathrm{~cm}$ long, c. $1.5 \mathrm{~mm}$ diam. at base, $4 \mathrm{~mm}$ diam. at top; stamens crowded, truncate, connective not or hardly exceeding the thecae, dumbbell-shaped, c. $0.75 \mathrm{~mm}$ diam., with the rim of the pores broken by a slit on the outer side; appendix $1.2-1.7 \mathrm{~cm}$ long, subcylindric to lozenge-shaped, the base hardly wider than the top of the male zone, apically obtuse, c. $6 \mathrm{~mm}$ diam.; staminodes of appendix flat-topped, irregularly polygonal with rounded angles, c. $1 \mathrm{~mm}$ diam. Fruiting spathe narrowly urceolate, c. $3 \mathrm{~cm}$ long.

Distribution - Malesia: endemic to Borneo (eastern Sabah).

Habitat - Lithophytic on limestone (occasional on nearby forest floor) in mixed dipterocarp forest, at 50-400 $\mathrm{m}$ alt.

Notes - This species is clearly allied to Schismatoglottis calyptrata, sharing the hapaxanthic modules, sagittate leaf blade, caducous spathe limb and hourglassshaped spadix with partially adnate female zone. It differs in the very dark green somewhat coriaceous (almost subsucculent) leaves, lithophytic habit, larger pistils, shorter and wider interpistillar staminodes and the shortly cylindric appendix.

Schismatoglottis venusta is one of several limestone species in Borneo including S. niahensis, S. bauensis, S. viridissima and S. puberulipes. In some of its variegated forms, it is one of the most attractive of the species allied to $S$. calyptrata - hence the epithet, meaning beautiful. It has some horticultural potential with its tightly clump-forming habit and, unusually for this genus, rather coriaceous leaves with seem to be associated with its being tolerant of some drought and occasional low humidity.

Other specimens examined: BORNEO: SABAH: Lahad Datu, Bukit Tempadong, along Segama R., Beaman et al. 10083 (K, US ); Elopura Distr., Gomantong, Cuadra A1490 (K, KEP, L, SAN); Cult. RBG Sydney Acc. No. 960582 ex Medai Caves (orig. coll. Hay et al. 12179 (voucher SAN)), Herscovitch s.n. (K, KEP, L, NSW, SAN, US); Gomantong Caves, Kokawa \& Hotta 587 (KYO); Gomantong Caves hill, bottom of Libingpayu hole, $20 \mathrm{mi} \mathrm{S}$ of Sandakan, Wood A4602 (KEP, L). 


\section{Schismatoglottis viridissima $A$. Hay, sp. nov.}

A Schismatoglottide calyptrata folii lamina claroviride tenuiter subsucculenta, spadici parte attenuato crassiore, pistillis sublaxis claroviridis, inflorescentia mascula partim intra spatham inferiora sedenti differt. - TYPUS: Cult. RBG Sydney Acc. No. 940550 ex Malaysia, Sarawak, Lundu, Gunung Gading (orig. coll. Hay et al. 9397) C. Herscovitch s.n. (holo, SAR; iso K, KEP, L, NSW, US).

Herb to $25 \mathrm{~cm}$ tall. Stem hypogeal, hapaxanthic, clump-forming, c. $0.5 \mathrm{~cm}$ diam. Leaves c. 3 together; petiole to $20 \mathrm{~cm}$ long, sheathing in the lower third; wings of sheath fully attached, tapering but apically truncate; blade narrowly ovate, brilliant green with a rubbery thinly subsucculent texture, c. $16 \mathrm{~cm}$ long $\times 7 \mathrm{~cm}$ wide, the base cordate with rounded posterior lobes to $1.5 \mathrm{~cm}$ long, the tip acute; midrib not prominent (dry), with c. 7 primary lateral veins on each side, irregularly alternating with lesser interprimaries and diverging at $60-80^{\circ}$; secondary venation mostly arising from the midrib, some from the bases of the primary veins; tertiary venation forming an indistinct tessellate reticulum on both surfaces (dry). Inflorescences 2-3 together; peduncle fleshy, c. $4 \mathrm{~cm}$ long, mostly hidden by sheaths of subtending leaves. Spathe $9 \mathrm{~cm}$ long; lower spathe narrowly ovoid, $4 \mathrm{~cm}$ long, differentiated from the limb by an abrupt constriction; limb $5 \mathrm{~cm}$ long, very broadly ovate, inflated over the male zone and appendix and then acute, finally acuminate for c. $1 \mathrm{~cm}$, greenish, caducous. Spadix $5-6 \mathrm{~cm}$ long, sessile, more or less hourglass-shaped; female zone about half the length of the spadix, c. $3 \mathrm{~cm}$ long, adnate to the spathe in the lower $2 / 3,7 \mathrm{~mm}$ diam. in the middle, then somewhat conic and attenuate to $5 \mathrm{~mm}$ diam.; pistils somewhat lax, more so in the distal part of the female zone, bottle-shaped, bright green, c. $1 \mathrm{~mm}$ diam. in the lower part of the zone, c. $2 \mathrm{~mm}$ diam. higher up; interpistillar staminodes scattered among the pistils, more or less mushroom-shaped, equalling the ovaries in height, c. $0.5 \mathrm{~mm}$ diam.; sterile interstice ill-defined, the upper $4 \mathrm{~mm}$ of the female zone thickly attenuate and occupied by mixed staminodes, stamens and ?abortive pistils; male zone $1.4 \mathrm{~cm}$ long, subcylindric and $5 \mathrm{~mm}$ diam. in the lower $5 \mathrm{~mm}$ (held within the lower spathe chamber), the rest abruptly obconic, to $9 \mathrm{~mm}$ diam. and exserted from the lower spathe chamber; stamens crowded, truncate, hourglass-shaped, with the connective thin and not at all elevated above the thecae, c. $1 \mathrm{~mm}$ across; appendix shortly bullet-shaped, the base slightly but abruptly wider than the top of the male zone, c. $1 \mathrm{~cm}$ wide at the base, $1.3 \mathrm{~cm}$ long; staminodes of appendix flat-topped, centrally impressed, irregularly polygonal, $0.5-0.7 \mathrm{~mm}$ diam. Fruit unknown.

Distribution - Malesia: endemic to Borneo (southern Sarawak); known only from the type locality and Bau.

Habitat - On lowland dipterocarp forest floor over limestone at c. $300 \mathrm{~m}$ alt.

Notes - This species is distinguished from S. calyptrata, to which it is evidently very closely allied, by the mushroom-shaped interpistillar staminodes, the attenuate but nevertheless thick interface between the male and female zones, the basal third of the male zone being held within the lower spathe chamber and the peculiarly brilliant green (hence the specific epithet) and subsucculent-textured leaf blades.

Other specimen examined: BORNEO: SARAWAK: 1st Divn, Bukit Krian, Bau limestone hills, Anderson S.31966 (US).

\section{Schismatoglottis wahaiana Alderw.}

Schismatoglottis wahaiana Alderw., Bull. Jard. Bot. Buitenzorg III, 4 (1922) 209. - Type: Cult. Hort. Bogor. XI.B.X.127 ex Maluku, Ceram, Wahai, (orig. coll. L. Rutten s.n.), C.R.W.K. van Alderwerelt van Rosenburgh 306 (BOKR + BO spirit, lecto; selected here). 
Small herb 13-20 cm tall. Shoot ?hypogeal, hapaxanthic, condensed, c. $7 \mathrm{~mm}$ diam. Leaves few (3-4 together); petiole 6-14 cm long, sheathing in the lower $1 / 3$; wings of sheath fully attached with the margins subparallel to the petiole and apically truncate to retuse; blade ovato- to triangular-sagittate, $6-11 \mathrm{~cm}$ long $\times 3-5 \mathrm{~cm}$ wide, the base cordate with more or less rounded posterior lobes 1-2 cm long, the tip acute and acuminate for c. $1 \mathrm{~cm}$ and finally shortly mucronate; midrib slightly raised abaxially and adaxially, with 5-6 primary lateral veins on each side alternating with lesser interprimaries and diverging at c. $60^{\circ}$; secondary venation arising from the midrib and from near the bases of the primary veins; tertiary venation forming a faint tessellate reticulum. Inflorescences 1-3 together; peduncle c. $1.5 \mathrm{~cm}$ long at anthesis, later slightly elongating and declinate, subtended by and becoming exserted from small lanceolate cataphylls. Spathe slender, $2.5-3.5 \mathrm{~cm}$ long; lower spathe $0.5-1 \mathrm{~cm}$ long, very narrowly ovoid and slightly curved, differentiated from the limb by a weak constriction; limb narrowly lanceolate, $2-2.5 \mathrm{~cm}$ long, somewhat falcate (curved in the opposite direction to the lower spathe, so the whole somewhat sigmoid), apically acuminate for c. $6 \mathrm{~mm}$. Spadix slender, $1.5-3 \mathrm{~cm}$ long; female zone $4-8 \mathrm{~mm}$ long, adnate to the spathe in the lower $1 / 2$, the free part somewhat conoid, apically 1.5-2 mm diam.; pistils crowded, subglobose, $0.3 \mathrm{~mm}$ diam.; stigma raised on a very short style, button-like, finely papillate; interpistillar staminodes absent from among the pistils, confined to a single row along the spathe/spadix adnation and a cluster at the base of the female zone on the ventral side, clavate, round-topped, shorter than the pistils, drying orange-ish; sterile interstice well-defined, a zone $2 \mathrm{~mm}$ long $\times 1.5-2 \mathrm{~mm}$ diam., of somewhat swollen abortive anthers corresponding with the spathe constriction; male zone subcylindric (slightly obconoid), 0.5-1 cm long, apically $2.2-3 \mathrm{~mm}$ diam.; stamens crowded, truncate, dumbbell-shaped, large, c. $0.8 \mathrm{~mm}$ across, with the connective conspicuously broad (i.e. the thecae wide apart) and very slightly raised between the thecae; pores of pollen sacs partly confluent and conspicuous in each theca, the rims slightly raised and deeply cleft on the outer edges; appendix subcylindric, basally faintly thicker than the top of the male zone, distally tapering to a blunt point, $7 \mathrm{~mm}$ long; staminodes of appendix irregularly polygonal with rounded angles, c. $0.5 \mathrm{~mm}$ diam. Fruiting spathe urceolate and slightly falcate, c. $1 \mathrm{~cm}$ long. - Fig. 18.

Distribution - Malesia: endemic to Maluku (Seram).

Habitat - Not specified, 550-790 m alt.

Notes - This species is similar to S. eymae in inflorescence, but differs significantly in vegetative features, having hapaxanthic shoots and the leaf distinctly sagittate. It is the easternmost local endemic species of Schismatoglottis in Malesia.

Schismatoglottis wahaiana is lectotypified with the most complete of Alderwerelt's specimens from cultivated plants.

Other specimens examined: MALUKU: Seram, Gunung Selangor, nr Kampung Selangor, Buwalda 5775 (L, BO); Cult. Hort. Bogor XI.B.X.10 ex Seram, van Alderwerelt van Rosenburgh 327 (BO).

\section{Schismatoglottis wallichii Hook. $f$.}

Schismatoglottis wallichii Hook. f., Fl. Brit. Ind. 6 (1893) 537; Ridl., Materials Fl. Mal. Pen. 3 (1907) 33, Fl. Mal. Pen. 5 (1925) 112; Engl., Pflanzenr. 55 (IV.23Da) (1912) 98, fig. 63; Henderson, Mal. Wildfl. Monoc. (1954) 232, fig. 137, B,C,D; Hay, Sandakania 7 (1996) 15, fig. 2B. - Type: Malaysia, Perak, Scortechini 237b (K, lecto; iso-lecto, SING; selected by Hay, 1996).

Schismatoglottis wallichii var. oblongata Hook. f., loc. cit.; Ridl. Materials Fl. Mal. Pen 3 (1907) 33 \& Fl. Mal. Pen. 5 (1925) 112. — Schismatoglottis wallichii f. oblongata (Hook. f.) Engl. \& K. Krause, loc. cit. p.100. - Type: Malaysia, Perak, Gopeng, Kunstler 4660 (K, lecto; iso-lecto, CAL; selected by Hay, 1996). 


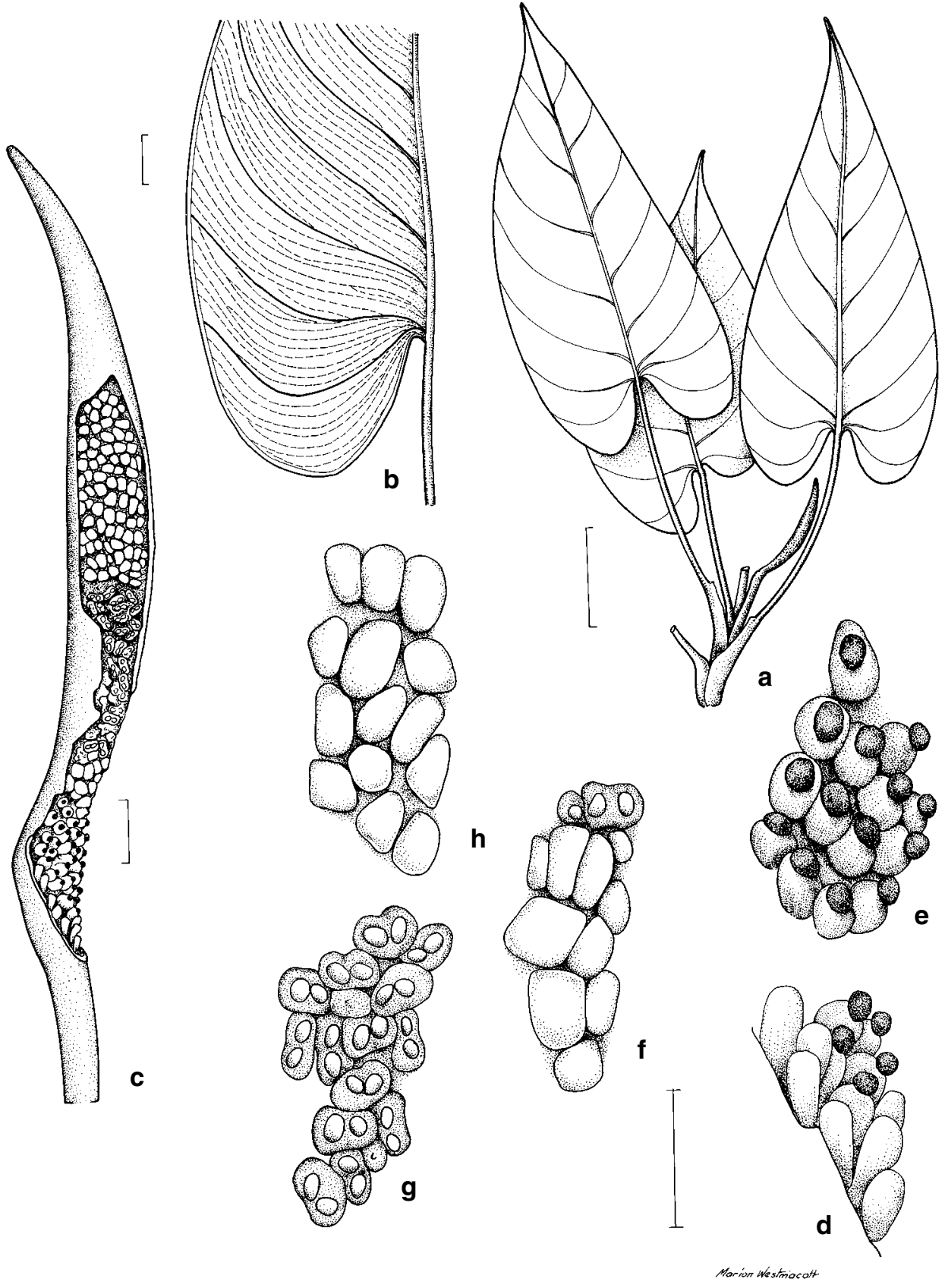

Fig. 18. Schismatoglottis wahaiana Alderw. a, Habit; b, Venation; c, Inflorescence; d, Basal interpistillar staminodes; e, Pistils; $\mathbf{f}$, Staminodes of interstice; $\mathbf{g}$, Stamens; $\mathbf{h}$, Staminodes of appendix (Buwalda 5775). Scale bar: $\mathrm{a}=2 \mathrm{~cm} ; \mathrm{b}=4 \mathrm{~mm} ; \mathrm{c}=2 \mathrm{~mm} ; \mathrm{d}-\mathrm{h}=1 \mathrm{~mm}$. 
Schismatoglottis wallichii var. fasciata Ridl., Materials Fl. Mal. Pen 3 (1907) 33 \& J. Straits Branch Roy. Asiat. Soc. 57 (1910) 112 \& Fl. Mal. Pen 5 (1925) 112. - Type: Malaysia, Selangor, Pahang Track, Ridley 14443 (SING, holo).

Schismatoglottis longicuspis Engl., Pflanzenr. 55 (IV.23Da) (1912) 100. - Type: Cult. Hort. Bogor ex Borneo, Jan 1906, A. Engler 4058 (B, holo).

Schismatoglottis conversa Alderw., Bull. Jard. Bot. Buitenzorg III, 4 (1922) 344. - Type: Indonesia, Sumatera, Riau Priv., Lingga Archipelago, Pulau Lingga, Resun, 18 Jul 1919, H.A.B. Bünnemeijer 6782 (BO + BO spirit, holo; iso $\mathrm{K}, \mathrm{L})$.

Schismatoglottis calyptrata f. resupinata Alderw., Bull. Jard. Bot. Buitenzorg III, 4 (1922) 343. - Type: Indonesia, Sumatera, Berhala Island, 2 Nov 1919, J.A. Lörzing 6988 (BO, holo).

Clump- to colony-forming, usually stoloniferous herb, sometimes with individual crowns markedly distant. Stems hapaxanthic, hypogeal, with up to c. 5 leaves together; petiole c. 15-45 cm long, smooth, adaxially flattened to somewhat channelled, the angles blunt to somewhat acute, but not alate, sheathing in lower c. $1 / 4$; wings of sheath persistent, membranous, straight to slightly inrolled, to c. $1 \mathrm{~cm}$ wide, tapering, fully attached except for c. $1 \mathrm{~mm}$ ligular apex; blades $8-30 \mathrm{~cm}$ long $\times 2-17 \mathrm{~cm}$ wide, very variable in shape, mostly more or less oblong-ovate, occasionally broadly ovate to oblong-lanceolate, the base acute to obtuse, more rarely truncate to cordate with posterior lobes $0-6 \mathrm{~cm}$ long, mid- to very dark green and dull to somewhat glossy adaxially, paler and dull green abaxially, often variegated with a central dark green strip, or bivittate grey-green, or spotted yellow-green (observed by A.H. only in Sarawak material), or occasionally with a pale midrib; midrib somewhat prominent abaxially, with primary lateral veins impressed adaxially, prominent abaxially, (6-)10-14 on each side of the midrib, $1.5-3 \mathrm{~cm}$ apart, diverging at 30-90 ; interprimary veins irregular but conspicuous, especially in larger-leaved forms; secondary venation often very inconspicuous, tertiary venation barely visible. Inflorescences (1-)2-several together, with a powerful esteric odour; peduncle mostly hidden within the subtending leaf sheath, to c. $12 \mathrm{~cm}$ long. Spathe c. (4.5-)8-18 cm long; lower spathe more or less cylindric at anthesis, green, (0.4-)1-2.5 cm diam.; limb (incl. mucro) about equalling the lower spathe in length, ivory to pale yellow, inflated up to c. $4 \mathrm{~cm}$ diam. and turbinate at anthesis, slightly gaping or with the margins loosely overlapping, thence abruptly caducous, the interface between the limb and the lower spathe only weakly constricted. Spadix (2.5-)6-12 cm long, sessile, cylindric to distally subclavate; female zone about half the length of the spadix, obliquely inserted to adnate for c. $1 / 2$ its length to the spathe; ovaries more or less flask shaped, c. $1 \mathrm{~mm}$ tall; stigma sessile, button-like; interpistillar staminodes scattered, narrowly stalked and clavate-headed, about twice the height of the pistils, sometimes also crowded at the interface between the female and sterile zones; sterile zone interposed between female and male zones abruptly but slightly thicker than distal part of female zone, cylindric, somewhat shorter than (then hidden within lower spathe) to somewhat exceeding (then distally exposed from mouth of lower spathe, rarely completely exserted) the male zone, composed of columnar, flat-topped staminodes markedly dissimilar to interpistillar ones; male zone cylindric with the apex rounded, to somewhat clavate, c. (0.3-) $0.7-1 \mathrm{~cm}$ diam.; stamens more or less rectangular to dumbbell-shaped from above (connective reaching anther apex in the former, not in the latter), c. $0.7 \mathrm{~mm}$ across, the thecae impressed apically, the rims interrupted laterally by a narrow slit; pollen ivory, dusty; appendix absent or reduced to a small cluster of columnar staminodes at the summit of the male zone apex. Fruiting spathe very narrowly urceolate to subcylindric, to c. $5 \mathrm{~cm}$ long. 
Distribution - Malesia: widespread in the Malay Peninsula where it is very common; in Borneo recorded a few times from Southern Sarawak; sporadically along the east side of Sumatera.

Habitat - Lowland and lower montane rain forest to c. $1500 \mathrm{~m}$ alt., often in disturbed places such as canopy gaps or in secondary forest. Near Lundu A.H. saw it in an old rubber plantation.

Notes - In the Malay Peninsula this species is extraordinarily variable in vegetative characters. Habit ranges from stoloniferous with few-leaved crowns through to clump-forming with multifoliar crowns. Leaf shape varies from cordato-sagittate (rare) through sagittate, subtriangular, oblong, ovate-elliptic to oblong-lanceolate. Leaf colour ranges from dark to pale green, variegated yellow-green or grey-green or not, variegated in fasciate or spotted patterns, primary lateral venation widely to narrowly spaced and diverging at low to high angles. There is much less variation in Borneo, where the leaves are more or less narrowly ovate with obtuse to slightly cordate bases. The habit is not clear from the Bornean specimens seen, though the plants A.H. collected at Lundu were loosely clump-forming. The Bornean plants seem on the whole to be rather smaller than the Malay Peninsula ones and the inflorescences are all produced singly; in the smallest the leaf blades are as little as $8 \times$ $2 \mathrm{~cm}$ and the spadix only $2.5 \mathrm{~cm}$ long .

Of the Sumateran material, only three collections have well-preserved flowering structure. Of these, in de Wilde $\mathcal{E}$ de Wilde-Duyfjes 20494 the sterile zone is completely exserted from the lower spathe chamber where in other parts of the range the sterile zone is held partly within the lower spathe chamber. Afriastini 1863 is a minute plant (dimensions in parentheses above) with the spathe c. $4.5 \mathrm{~cm}$ long and very slender and the spadix just over $2.5 \mathrm{~cm}$ long. The female zone is very lax and not at all adnate to the spathe. Interestingly this specimen is from the Mentawi islands off the west coast of Sumatera and quite widely disjunct from other Sumateran collections of this species. Possibly it should be recognised as a separate taxon, but given the great range of plant size exhibited by this species in Borneo, it is left provisionally included in this species until material from the Mentawi Islands can be examined in the living state.

The unifying factor is the otherwise comparatively constant inflorescence morphology with its very distinctive long sterile zone between the female zone and the male zone which is terminal (though a few staminodes may be present at the very apex of the spadix).

The type of Schismatoglottis longicuspis Engl., described from cultivation at Bogor without provenance details, is fertile but incomplete, having a single inflorescence in early fruit. It matches $S$. wallichii in its narrowly ovate leaf, the presence of stolons, the rather long peduncle, the female zone rather extensively adnate to the lower spathe, the narrowly clavate interpistillar staminodes, the sessile, button-like stigma, and the remains (albeit much degraded) of a length of neuter rather than fertile male zone contiguous with the female part. Engler annotated the type specimen with the number 116 - the plant number in the Bogor Gardens. Later material in the Bogor Gardens Herbarium of plant XI.B.X.116 had originally been labelled S. longicuspis, but this has been crossed out and the specimen does not match the description - suggesting that the plant label had become misplaced, and so the specimen is of no use in interpreting this species. The very long cuspidate leaf tip of the type is extreme but arguably not exceptional for S. wallichii. Schismatoglottis longicuspis does not match material other than of $S$. wallichii at all, and given the inadequacy of the data on provenance and the incompleteness of the specimen it seems reasonable to dispose of it into the synonymy of $S$. wallichii rather than continue to recognise it as an incompletely known species in its own right. 
In the Malay Peninsula Hay (1996) recorded that occasional specimens are encountered intermediate between Schismatoglottis wallichii and S. calyptrata, noting that hybridisation may be occurring. The type of Schimatoglottis calyptrata f. resupinata Alderw., from Sumatera, is one such, having the spadix much the same shape as S. calyptrata, but the fertile male zone is terminal and distal to a zone of staminodes as in S. wallichii. A second collection (van der Meer Mohr 39 (BO)) from the same area, Pulau Berhala, appears to have the same form (it is badly insect-damaged). In both specimens the leaf blade is more or less cordato-sagittate as in S. calyptrata.

Other specimens examined: MALAY PENINSULA: Cult. RBG Kew Acc. No. 4728204988 ex Selangor, Ulu Gombak (orig. coll. Hay 2026), anon. s.n. (K); Pondok Tanjung FR, Redang Panjang Forest, Baharuddin s.n. (USM); Selangor, Ulu Gombak, Boyce 675 (K); Johor, Pulau Tinggi, Burkill 917 (SING); Selangor, Sungei Buloh, Chin \& Jacobsen 3364 (K, L); Johore, Sg. Buloh, Corner 29987 (B, BO); Pahang, Kemaman, Bukit Kajang, Corner 30233 (B, K, SING); Selangor, Kuala Lumpur, Curtis 2393 (SING); Province Wellesley, Ulu Kubang, Curtis s.n. (SING); Melaka, Bukit Sadanen Reserve, Derry 345 (SING); Trengganu, Bukit Bauk Forest Reserve, Hardial Singh 4 (K, L, SING); Pahang, Sungei Yu, Hardial Singh \& Mohd. Nur 105 (K, LAE SING); Cult. RBG Sydney Acc. No. 940095, 940098, 940099 ex Selangor, Gombak Valley, (orig. coll. Hay et al. 9051, 9054, 9055), Herscovitch s.n. (NSW); Cult. RBG Sydney Acc. No. 940155 ex Negeri Sembilan, Jaram Toi Recreation Area, (orig. coll. Hay et al. 9159), Herscovitch s.n. (NSW); Cult. RBG Sydney Acc. No. 940263, 940264, 940266 ex Johor, G. Panti via Kg Lukit, (orig. coll. Hay et al. 9195, 9196, 9198), Herscovitch s.n. (NSW); Cult. RBG Sydney Acc. No. 940275 ex Johor, Kota Tinggi-Mersing Rd., (orig. coll. Hay et al. 9207), Herscovitch s.n. (NSW); Cult. RBG Sydney Acc. No. 940286, 940287, 940297, 940310, 940312, 940313, 940314, 940323, 940326 ex Terengganu, Ayer Terjun, Sekayu F.R., (orig. coll. Hay et al. 9218, 9219, 9229, 9242, 9244, 9245, 9246, 9255, 9258), all Herscovitch s.n. (NSW); Cult. RBG Sydney Acc. No. 940354 ex Pahang, Bukit Fraser, (orig. coll. Hay et al. 9287), Herscovitch s.n. (NSW); Selangor, Rantau Panjang Forest Reserve, Hume 7544 (SING); Johor, G. Pulai, Maxwell 81-8 (AAU); Negeri Sembilan, Bukit Tangga, Nur 11782 (BO, K, SING); Perak, Scortechini 237b (K); Perak, Tapah, Wray 803 (CAL). SINGAPORE: Bukit Timah, Goodenough s.n. (SING), Hallier s.n. (G), Ridley s.n. (SING), SUMATERA: West Sumatera, Mentawi Islands, Siberut, Teiteibati Nature Reserve, Afriastini 1863 (BO); Aceh, W of Trung Luai, E of Trumon, Asdat 35 (BO); Riau, Lingga Archipelago, Pulau Singkep, Manggu Rd, Bünnemeijer 7188 (BO, L); North Sumatera, Kota Pinang, Langgapayung, on Sg. Kanan, Rahmat si Toroes 3379 (NY, US); North Sumatera, Kota Pinang, Laboehan Batoe, G. Si Papan, Rahmat Si Toroes 3883 (US); Aceh, P.T. Hargas logging concession, S of rd Sibulussalan-Gelombang, nr Belintang, de Wilde \& de Wilde-Duyfies 20494 (L). BORNEO: SARAWAK: Serian, Bogner 1575 E 1579 (both M); Samarakan, Brooke 9665 (BM, L); Simanggang, Brooke 10728 (BM, G); Cult. RBG Sydney Acc. No. 940543 ex Lundu (orig. coll. Hay et al. 9390), Herscovitch s.n. (K, KEP, L, M, MO, NSW, SAR, US); Cult. RBG Kew Entry No. 335.58 ex Sarawak (orig. coll. R. E. Holttum s.n.) (K); Matang FR, 10 mi W of Kuching, Nicolson 1277 (US).

\section{Schismatoglottis warburgiana Engl.}

Schismatoglottis warburgiana Engl., Bot. Jahrb. Syst. 25 (1898) 20; Engl., Pflanzenr. 55 (IV.23Da) (1912) 90, fig. 57; Merr., Enum. Philipp. Fl. Pl. 1 (1922) 182. - Type: Philippines, Mindanao, Davao Prov., Sagapan, Warburg 14605 (B, holo - 2 sheets).

Herb to $30 \mathrm{~cm}$ tall. Stem condensed, ?hypogeal, ?hapaxanthic, c. $0.5 \mathrm{~cm}$ diam.; petiole 8-17 cm long, slender, sheathing in the lower $2 / 5$, with the wings of the sheath fully attached and tapering; blade oblong-lanceolate, tapering in the distal half, c. 10-20 cm long $\times 2-4 \mathrm{~cm}$ wide, the base obtuse to truncate, the tip acute and acuminate for $\mathrm{c} .1 \mathrm{~cm}$; midrib more or less flush with the lamina, with 8-10 primary lateral veins alternating with lesser interprimaries and diverging at c. $45^{\circ}$; secondary venation very finely striate, arising from the midrib and the bases of the lower primary veins; tertiary veins forming a minute faint tessellate reticulum. Inflorescences 2-3 together; peduncle exserted from the subtending leaf and cataphylls, $3-4 \mathrm{~cm}$ (fl.) to c. $10 \mathrm{~cm}$ long (fr.), erect. Spathe 2.5-3 cm long, constricted at c. $1 / 3$ of the way from the base; lower spathe narrowly ovoid; limb narrowly turbinate and mucronate for c. $3 \mathrm{~mm}$, ?caducous. Spadix sessile, c. $2.2 \mathrm{~cm}$ long, subcylindric; female zone c. $6 \mathrm{~mm}$ long $\times 1.5 \mathrm{~mm}$ wide (dry), adnate to the spathe in the lower $1 / 3$, the free part subcylindric; ovaries 
subglobose, c. $0.5 \mathrm{~mm}$ diam.; stigma subsessile, punctate; interpistillar staminodes absent; interface between male and female zones occupied by c. 4 irregular whorls of robust sterile stamens c. $0.5 \mathrm{~mm}$ diam.; male zone very narrowly obconic, c. $6 \mathrm{~mm}$ long, $3 \mathrm{~mm}$ diam. at top; stamens dumbbell-shaped from above, more or less flattopped, or with the connective very slightly protruding between the thecae, c. $0.7 \mathrm{~mm}$ across; appendix bluntly conic, c. $6 \mathrm{~mm}$ long, $4 \mathrm{~mm}$ diam. at base; appendical staminodes paler than stamens, narrowly columnar, with the tops rounded and centrally somewhat impressed. Fruiting spathe urceolate, asymmetric, c. $1 \mathrm{~cm}$ long.

Distribution - Malesia: endemic to the Philippines (Mindanao); known only from the type collection.

Habitat — In lowland hill forest with ebony at c. $600 \mathrm{~m}$ alt.

Notes - This species bears some resemblance to the rheophytic S. luzonensis, but differs in the more numerous primary lateral veins of the leaf blade, the relatively longer and less conspicuously obconic male zone and the elongate-conoid appendix. The dried specimen also does not have the rather characteristic dark straw colour of that species. Though the leaves are rather narrow, S. warburgiana does not appear to be rheophytic.

Engler's illustration (loc. cit.) is inaccurate, not showing the spathe/spadix adnation nor the sterile interstice.

86. Schismatoglottis wongii $A$. Hay, sp. nov.

['Schismatoglottis cf. longispatha' A. Hay, Plant Talk 5 (1996) un-numbered photo pp. 24-26.]

A Schismatoglottide trifasciata, statura valde minore, habitu stolonifera, staminodiis appendicis ad apicem planis differt; a Schismatoglottide longispatha antheris dimeris differt. - TYPUS: Cult. RBG Sydney Acc. No. 950363 ex Malaysia, Sabah, Ulu Dusun (orig. coll. Hay et al. 10026), C. Herscovitch s.n. (SAN, holo; iso K, KEP, NSW).

Small carpet-forming stoloniferous herb to c. $15 \mathrm{~cm}$ tall. Stem condensed, hypogeal, c. $0.5 \mathrm{~mm}$ diam., with subterranean stolons to c. $6 \mathrm{~cm}$ long. Leaves c. 3 together; petiole c. $10 \mathrm{~cm}$ long, sheathing in the lower $1 / 2$; wings of sheath fully attached, tapering and finally truncate to obtuse; blade ovate to oblong-ovate, variegated with two greyish bands, or spattered greyish, or both, or spattered pale green or not variegated, c. $11 \mathrm{~cm}$ long $\times 4.5 \mathrm{~cm}$ wide, the base shallowly cordate with posterior lobes to $1 \mathrm{~cm}$ long, the tip acute and acuminate for c. $2 \mathrm{~cm}$; midrib somewhat prominent on both surfaces (dry); primary lateral veins c. 9 on each side of midrib, regularly alternating with lesser interprimaries, diverging at $70-90^{\circ}$ and gradually deflected acropetally before joining the margin; secondary venation adaxially somewhat obscure, abaxially fine and dense, arising from the midrib and sometimes from the lower parts of the primary veins; tertiary venation forming an indistinct tessellate reticulum abaxially. Inflorescence solitary to 3 together; peduncle $3.5-4.5 \mathrm{~cm}$ long, subtended by a somewhat reduced foliage leaf or a short cataphyll. Spathe to $10.5 \mathrm{~cm}$ long, slender; lower spathe c. $3.5 \mathrm{~cm}$ long, very narrowly ovoid, green, differentiated from the limb by a weak constriction; limb lanceolate, hardly opening, c. $7 \mathrm{~cm}$ long and elevated above the leaves, white, caducous. Spadix c. $8.5 \mathrm{~cm}$ long, slender, elongate subcylindric; female zone $2.7 \mathrm{~cm}$ long, adnate to the spathe for c. $4 / 5$ its length, c. $4 \mathrm{~mm}$ wide in the middle and the free part narrowly conic, $2.5 \mathrm{~mm}$ diam. at the top; pistils crowded; ovaries subglobose and longitudinally 2-4-lobed (sometimes faintly), c. $0.75 \mathrm{~mm}$ diam.; stigma sessile, buttonlike, papillate, almost as wide as the ovary, $0.5-0.6 \mathrm{~mm}$ diam.; interpistillar staminodes scattered among the pistils, narrowly clavate to clavate, somewhat taller than the ovary, the heads rounded to flat and then somewhat impressed centrally; sterile interstice absent; male zone cylindric, c. $2 \mathrm{~cm}$ long $\times 2 \mathrm{~mm}$ diam., very slightly obconic 
and distally $3 \mathrm{~mm}$ diam., the basal $1 / 4$ held within the lower spathe chamber; stamens crowded, truncate, hourglass-shaped, c. $0.5 \mathrm{~mm}$ across, the connective very slender and hardly elevated above the thecae; appendix slender, to $4 \mathrm{~cm}$ long, the base very slightly wider than the top of the male zone (fresh; narrower when dry), $4 \mathrm{~mm}$ wide, gradually tapering to a fine point; staminodes of appendix columnar, sometimes 2-3 connate, with rounded tips, c. $0.25 \mathrm{~mm}$ diam. Fruiting peduncle subequalling the petioles; fruiting spathe very narrowly urceolate, to $3 \mathrm{~cm}$ long.

Distribution - Malesia: endemic to Borneo (Sabah); known only from the type locality and at Sepilok Forest Reserve.

Habitat - Forming dense clonal carpets sometimes several metres across on the floor of mixed lowland dipterocarp forest at low elevation.

Notes - This species is similar in habit to S. longispatha, from which it differs in the cordate leaf base and dimerous anthers. It is named for Dr Wong Khoon Meng (University of Malaya), who has contributed much to knowledge of the flora of Borneo, and who enabled A.H. to collect Aroids in Sabah in 1995 and 1996.

The form from Sepilok differs from the type in having flat-topped (rather than roundtipped) staminodes of the appendix, rounded (rather than flat and centrally impressed) heads to the interpistillar staminodes, slightly larger stigmas and slightly less strongly lobed ovaries.

Schismatoglottis wongii, in some of its variegated forms, is highly ornamental and would seem to have horticultural potential as a ground-cover plant.

Other specimen examined: BORNEO: SABAH: Cult. RBG Sydney Acc. No. 960517 ex Sepilok Forest Reserve (orig. coll. Hay et al. 12154) Herscovitch s.n. (NSW, spirit only).

87. Schismatoglottis zonata Hallier $\mathrm{f}$.

Schismatoglottis zonata Hallier f., Ann. Jard. Bot. Buitenzorg 13 (1896) 323, fig. 29; Engl., Pflanzenr. 55 (IV.23Da) (1912) 121. - Type: Indonesia, Cult. Hort. Bogor ex Kalimantan, Mt Amai Ambit (orig. coll. Hallier B3454), 13 Apr 1895, H. Hallier s.n. (BO + BO spirit, holo; iso G, L, M). [Later clonotype material at NSW originating from Bogor without collector or date].

Herb c. $30 \mathrm{~cm}$ tall. Stem (seen only in habit photos) ?hypogeal, condensed, hapaxanthic. Leaves c. 4 together; petiole c. $20 \mathrm{~cm}$ long, sheathing in the lower 1/5; wings of sheath fully attached, persistent, tapering and very shortly ligular apically; blade ovato-sagittate, variegated with four broad and somewhat diffuse longitudinal greyish bands, 16-18 cm long $\times$ c. $12 \mathrm{~cm}$ wide, the base cordate with more or less rounded posterior lobes $4-5 \mathrm{~cm}$ long and usually markedly asymmetric, the apex obtuse, then shortly and abruptly acuminate and finally mucronate for c. $8 \mathrm{~mm}$; midrib more or less flush with the lamina abaxially and adaxially (dry), with c. 9 primary lateral veins on each side, very irregularly alternating with interprimary veins and diverging at c. $60^{\circ}$; secondary venation very faint, mostly arising from the midrib; tertiary venation obscure. Inflorescence ?2-several together (organisation not observed); peduncle c. $10 \mathrm{~cm}$ long. Spathe 10-12 cm long; lower spathe narrowly ovoid, $4.5-5 \mathrm{~cm}$ long, differentiated from the limb by a fairly strong constriction; limb ovate, inflated over the appendix, apically acuminate for c. $1 \mathrm{~cm}, 6-7 \mathrm{~cm}$ long, yellowish, caducous. Spadix sessile, c. $8 \mathrm{~cm}$ long, weakly hourglass-shaped; female zone c. $2.5 \mathrm{~cm}$ long, adnate to the spathe in the lower $1 / 3$, the free part slightly conoid and distally $5 \mathrm{~mm}$ diam.; pistils crowded; ovary ovoid, small, c. $0.5 \mathrm{~mm}$ diam.; stigma subsessile, buttonlike, about $1 / 2$ the diameter of the ovary; interpistillar staminodes (fide Engler - no longer observable on the type) positioned beneath the pistils chiefly in the lower part of the female zone, claviform, white; sterile interstice well-defined, more or less 
corresponding with lower part of spathe constriction, $5 \mathrm{~mm}$ long $\times 5 \mathrm{~mm}$ thick, slightly conoid, basally isodiametric with top of female zone, composed of crowded, flattopped irregularly polygonal staminodes resembling those of the appendix; male zone narrowly but distinctly obconoid, c. $2 \mathrm{~cm}$ long, basally somewhat compressed by top of spathe constriction, apically c. $7 \mathrm{~mm}$ diam.; stamens crowded, truncate, dumbbellshaped, with the connective slightly mounded between the thecae, c. $0.5 \mathrm{~mm}$ across; pores somewhat C-shaped; appendix conoid, basally slightly and abruptly wider than the top of the male zone, $2 \mathrm{~cm}$ long, c. $8 \mathrm{~mm}$ diam., the tip narrowly obtuse; staminodes of appendix flat-topped, irregularly polygonal, c. $0.7 \mathrm{~mm}$ diam. Fruit unknown.

Distribution - Malesia: endemic to Borneo (Kalimantan); known only from Mt Amai Ambit - the original locality of the cultivated type plant.

Habitat - Lithophytic with other Araceae on a large boulder in shade in sloping forest, $500-600 \mathrm{~m}$ alt.

Notes - This species is distinguished from $S$. trivittata, which it otherwise rather closely resembles, by the distinctive and prominent sterile interstice of flat-topped crowded staminodes resembling those of the appendix. It appears also, from Hallier's notes, to be lithophytic. It has never been re-collected.

The leaf is variegated with four longitudinal bands of grey-green, a pattern not found in any other species. Schismatoglottis zonata is highly ornamental, and was cultivated in Europe, evidently not very widely - the only material seen is a specimen from Leiden Botanic garden preserved early this century. However, it recently reappeared in a plant collection in Hawaii, where it had been obtained from the famous aroid collection of Roberto Burle Marx in Brazil near Rio de Janeiro (T. B. Croat, pers. comm.). The cultivated plants appear to be clonally identical with the type plant and presumably derive from distribution from Bogor, where it no longer survives.

Other specimen examined: Cult. Hort. Leiden, 1903, Lotsy s.n. (L).

\section{Schismatoglottis tecturata group}

Shoot pleionanthic. Leaf sheath very short and fully attached; foliage leaves alternating with cataphylls. Spathe limb persistent/marcescent. Spadix erect. Sometimes rheophytic.

2 species, Borneo.

88. Schismatoglottis petri $A$. Hay, sp. nov.

Schismatoglottis tecturata (Schott) Engl. affinis sed statura majore, lamina spathae omnino marcescenti, appendice valde incrassata, staminis connectivo producto differt. - TYPUS: Brunei, Belait Distr., Ulu Ingei, Bukit Batu Patam, 9 Jun 1989, P.C. Boyce J. Dransfield E Jangarun 283 (K, holo).

Lithophytic herb to $30 \mathrm{~cm}$ tall. Stem condensed, ?pleionanthic, c. $1.3 \mathrm{~cm}$ diam. (dry), rooting through and among the leaf bases. Leaves few together, alternating with tapering lanceolate dark brown cataphylls to $6 \mathrm{~cm}$ long; petiole c. $27 \mathrm{~cm}$ long, sheathing only at extreme base; blade somewhat coriaceous, glossy deep green adaxially, mid-green abaxially, elliptic, somewhat falcate, to $28 \mathrm{~cm}$ long $\times 8.5 \mathrm{~cm}$ wide, the base narrowly rounded, the tip rather abruptly acuminate for $1.5-2 \mathrm{~cm}$; midrib adaxially impressed, abaxially prominent; primary lateral veins adaxially rather obscure, distinct abaxially, not prominent, c. 15 on each side of midrib, diverging at $45-60^{\circ}$, alternating with lesser interprimary veins and running into a rather conspicuous intramarginal vein c. $1.5 \mathrm{~mm}$ from the margin; secondary venation adaxially obscure, abaxially very faint, arising from the midrib. Inflorescences 2 
together, subtended by lanceolate cataphylls to $4 \mathrm{~cm}$ long; peduncle short, mostly obscured by cataphylls. Spathe c. $5 \mathrm{~cm}$ long; lower spathe pale green, squat subcylindric, $1.5 \mathrm{~cm}$ long $\times 1 \mathrm{~cm}$ diam., oblique-based, differentiated from the limb by a slight constriction; limb marcescent, somewhat cucullate, c. $3 \mathrm{~cm}$ long, apically mucronate. Spadix sessile, $3.7 \mathrm{~cm}$ long; female zone (in early fruit) $1.2 \mathrm{~cm}$ long, obliquely inserted but not adnate to the spathe; pistils ovoid, crowded, c. $1.5 \mathrm{~mm}$ diam. (in early fruit); stigma sessile, discoid and centrally raised, narrower than the ovary, c. $0.7 \mathrm{~mm}$ diam.; interpistillar staminodes apparently absent (but spadix in early fruit); sterile interstice $4 \mathrm{~mm}$ long $\times 5 \mathrm{~mm}$ diam., a few whorls of sterile stamens c. $1 \mathrm{~mm}$ across; male zone $2 \mathrm{~cm}$ long, partly within the lower spathe chamber, somewhat attenuate, c. 3-4 mm diam.; stamens dark brown (dry), crowded; anther sessile, with the narrowly pyramidal connective extended for almost $1 \mathrm{~mm}$ above the thecae, apically c. $0.25 \mathrm{~mm}$ across, flat-topped, polygonal; appendix clavate-cylindric, about twice as thick as the male zone, c. $6 \mathrm{~mm}$ diam., composed of columnar flat-topped, irregularly polygonal (sometimes united), ochreous (dry) staminodes c. $0.8 \mathrm{~mm}$ diam. Infructescence (immature) with the spathe limb marcescent and the distal parts of the spadix persistent. - Fig. 19.

Distribution - Malesia: endemic to Borneo (Brunei); known only from the type.

Habitat - Lithophytic on Belait series sandstone cliff in ridgetop kerangas/mixed dipterocarp forest transition; $180 \mathrm{~m}$ alt.

Notes - This species appears allied to the rather widespread Bornean S. tecturata (Schott) Engl., sharing similar shoot organisation (qualified by the difficulty of interpreting this feature from the dry material), the female zone of the spadix not adnate to the spathe, the marcescent somewhat cucullate spathe limb. It differs in the larger size, the thick clavate-cylindric appendix, the extended connective of the anthers and the entirely marcescent spathe limb (the latter marcescent at the margins only in S. tecturata).

The specific epithet is for Peter Boyce $(\mathrm{K})$, the first and only collector of this species.

89. Schismatoglottis tecturata (Schott) Engl.

Schismatoglottis tecturata (Schott) Engl. Pflanzenr. 55 (IV.23Da) (1912) 86. - Colobogynium tecturatum Schott, Oesterr. Bot. Zeit. 15 (1865) 34. - [Schismatoglottis variegata Hook. f. ex Engl. in A. \& C. DC., Monogr. Phan. 2 (1879) 353, nom. illeg.; Colobogynium tecturatum Schott in synon.]. - Neotype: Schott Icones 1682-1684 (W; designated here; fiche 47: b2-4 in the microfiche edition).

Schismatoglottis beccariana Engl., Bull. Soc. Tosc. Ortic. 4 (1897) 297; Pflanzenr. 55 (IV.23Da) (1912) 87 [incl. var. oblonga - nom. superfl. pro var. typ.]. Type: Malaysia, Sarawak, Beccari P.B. 523 (FI, holo).

Schismatoglottis beccariana var. albolineata Engl.,Bull. Soc. Tosc. Ortic. 4 (1879) 297; Pflanzenr. 55 (IV.23Da) (1912) 87. — Type: Malaysia, Sarawak, O. Beccari P.B. 3478 (FI, holo; iso K).

Schismatoglottis beccariana var. angustifolia Engl. in Beccari, Malesia 1 (1882) 287; Pflanzenr. 55 (IV.23Da) (1912) 87. - Type: Indonesia, Kalimantan, Kapuas, 1898/9, H. Grabowski 51 (B, holo; iso L).

Homalomena fasciata Ridl., J. Straits Branch Roy. Asiat. Soc. 44 (1905) 174. — Schismatoglottis fasciata (Ridl.) Engl., Pflanzenr. 55 (IV.23Da) (1912) 87. - Type: Cult. Singapore Botanic Garden ex Sarawak, Oct 1903, Ridley s.n. (SING, holo). 


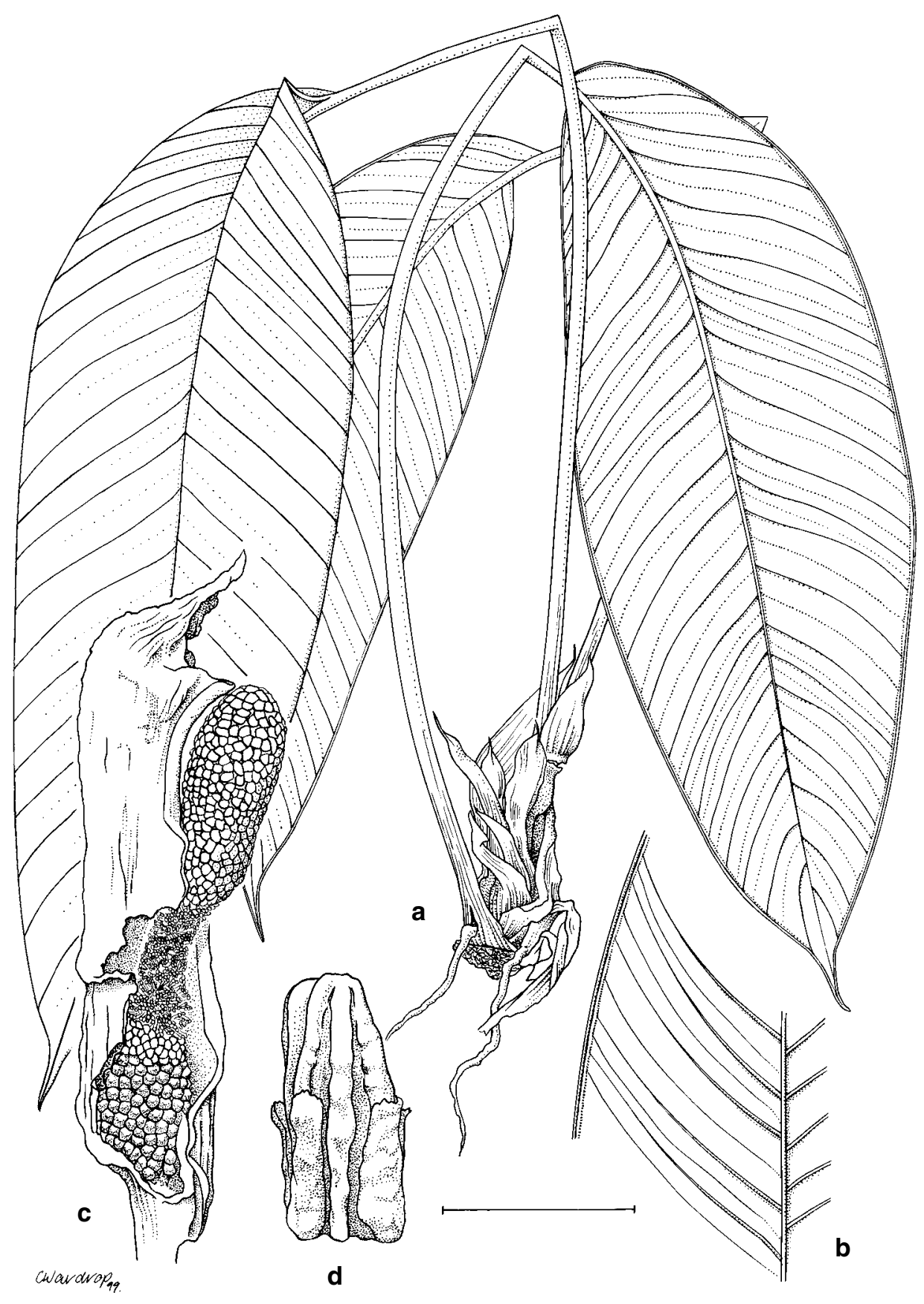

Fig. 19. Schismatoglottis petri A. Hay. a, Habit; b, Venation; $\mathbf{c}$, Inflorescence; d, Stamen (Boyce et al. 283). Scale bar: $a=5 \mathrm{~cm} ; b=3.3 \mathrm{~cm} ; c=1.3 \mathrm{~cm} ; d=0.8 \mathrm{~mm}$. 
Schismatoglottis crassifolia Engl., Pflanzenr. 55 (IV.23Da) (1912) 86; van Steenis, Rheophytes of the World (1981) 195. - Type: Indonesia, Kalimantan, Boetoe Lessoeng, Amdjah 422 (B, lecto; isolecto $\mathrm{BO}$, L; selected here).

Schismatoglottis opaca Engl., Pflanzenr. 55 (IV.23Da) (1912) 86. - Neotype: Indonesia, Kalimantan, Bukit Lemprai, (without date), J. Teysmann 8103 (BO; designated here).

Schismatoglottis ornata Alderw., Bull. Jard. Bot. Buitenzorg. III, 4 (1922) 220. - Type: Cult. Hort. Bogor. XI.B.X.124 ex Borneo (orig. coll. Nieuwenhuis 1935), C.R.W.K. van Alderwerelt van Rosenburgh 328 (BOKR + BO spirit, holo).

Schismatoglottis homalomenoidea M. Hotta, Mem. Coll. Sci. Univ. Kyoto, Ser. B, 32 (1966) 225, fig. 1, A-J; van Steenis, Rheophytes of the World (1981) 195. - Type: Brunei, vicinity of Brunei town, 16 Jan 1964, M. Hotta 13212 (KYO, holo; iso L).

Schismatoglottis parviflora M. Hotta, Mem. Coll. Sci. Univ. Kyoto, Ser. B, 32 (1966) 225, fig. 1, K-M. - Type: Brunei, Serias, vicinity of Kg Mandaram, 17 Dec 1963, M. Hotta 12582 (KYO, holo).

Herb to c. $30 \mathrm{~cm}$ tall, solitary to forming small clumps. Stem condensed, epigeal, pleionanthic, c. $5 \mathrm{~mm}-1 \mathrm{~cm}$ diam., to c. $10 \mathrm{~cm}$ long (usually much less). Foliage leaves several to many together, subtended by papery linear dark brown (when dry) cataphylls to $5 \mathrm{~cm}$ long; petiole 11-24 cm long, slender, sheathing only at very base; sheath very shortly and truncately ligular or not; leaf blade often pendent, usually about equalling the petiole but sometimes longer or shorter, lanceolate to oblongovate, dark green adaxially, sometimes whitish about the midrib (very rarely with whitish spots throughout the blade) or concolorous, abaxially paler, somewhat coriaceous, the base cuneate, rarely rounded (never cordate), the tip more or less markedly acuminate, $8-22(-25) \mathrm{cm}$ long $\times 1-8(-9.5) \mathrm{cm}$ wide; venation more or less obscure adaxially; midrib usually drying with a more or less conspicuous narrow central channel adaxially, abaxially prominent; primary lateral veins slender, 6-9 on each side of midrib, alternating with lesser interprimaries and diverging at c. $45^{\circ}$; secondary venation fine and dense, the tertiary venation forming a fine faint reticulum. Inflorescences (solitary to) clustered in groups of up to eight; peduncle slender, much shorter than the petiole c. 3-6 cm long. Spathe green except greenish ivory spathe limb margins, sometimes irregularly flushed purplish; lower spathe very narrowly ovoid, becoming ovoid, c. $1 \mathrm{~cm}$ long; limb slender, more or less clasping the spadix, more or less straight to distinctly incurved ventrally, c. $2.5 \mathrm{~cm}$ long, apically mucronate for c. $2 \mathrm{~mm}$, persistent except the marcescent margins, eventually deciduous in fruit. Spadix sessile, slender, subcylindric, c. $2 \mathrm{~mm}$ diam. (dry) throughout, somewhat ventrally curved, slightly shorter than the spathe, c. $3 \mathrm{~cm}$ long; female zone c. $5 \mathrm{~mm}$ long, almost entirely free from the spathe; pistils crowded; ovary squat, drying irregularly rhomboid, c. $0.7 \mathrm{~mm}$ diam.; style distinct, c. $0.5 \mathrm{~mm}$ long; stigma minutely papillate, hardly wider than the style; interpistillar staminodes absent except for a single basal ring of truncate staminodes c. $1 \mathrm{~mm}$ diam.; male and female zones contiguous or separated by one or two whorls of sterile stamens or a short naked zone; male zone c. $1.4 \mathrm{~cm}$ long, cylindric, more or less isodiametric with top of female zone; stamens c. $0.6 \mathrm{~mm}$ across, with the thecae truncate and much exceeding the connective, opening through conspicuous apical slits; appendix cylindric to tapering, $1 / 4-1 / 3$ the length of the spadix, basally isodiametric with to slightly wider than the top of the male zone, blunt-tipped, composed of columnar trapezoid to triangular staminodes. Fruiting spathe to c. $5 \mathrm{~cm}$ long, with the lower part broadly ovoid, the slender limb finally disintegrating.

Distribution - Malesia: Borneo (Sarawak, Brunei, Kalimantan; not yet recorded from Sabah); with a disjunct extension to the Riau Archipelago (Sumatera). 
Habitat - On rocks in and by streams and on steep soil banks; facultatively rheophytic; sea level to c. $1250 \mathrm{~m}$ alt.

Notes - The three illustrations designated as the neotype of Schismatoglottis tecturata are regarded here as a single entity, the first being a habit painting, the second a study of the inflorescence with analytical drawings of the fruit and seed, and the third with analytical drawings of the spadix and floral structures. They were evidently prepared from living material, and herbarium specimens which may have been preserved are now lost.

Perhaps led astray by the persistent spathe, Ridley described his material of this species as Homalomena fasciata, which Engler transferred into Schismatoglottis, noting, when he did so, that it barely differed from S. beccariana.

Schismatoglottis crassifolia is known from sterile plants and a single immature and poorly preserved inflorescence. The lectotype is the fertile of the two syntypes Engler cited. Engler distinguished this species from $S$. beccariana only on the slightly thicker leaves and the shorter pistil - the latter feature which he noted was observed on immature material. There is some variation in the thickness of the leaf blade of $S$. tecturata and the type of $S$. crassifolia does not seem exceptional in this respect. Engler also distinguished S. crassifolia and the four other species he grouped with it S. opaca, S. tecturata, S. beccariana and S. fasciata - on minor details of leaf shape and flatness of the petiole, details which do not seem to correlate with any other features in a way which seems to form a satisfactory basis for maintaining the taxa as separate.

Schismatoglottis opaca was described from material cultivated at Bogor in 1906, taken by Engler to Berlin and flowered there in 1911. If any material from those cultivated plants was preserved, it does not appear to have survived. The description is not very detailed, but is compatible with the current concept of $S$. tecturata. The neotype is a specimen annotated by Engler with the name S. opaca in 1906 (though it was not cited by him in Pflanzenreich). It is evidently identical with $S$. tecturata as defined here, having the characteristic shoot organisation combined with a persistent spathe limb on the infructescences.

Schismatoglottis ornata falls uncontroversially into S. tecturata. It is represented by supposedly clonotype material at SING sent to Furtado in the 1930s. However, that specimen is of a different species (?S. calyptrata); presumably the plant had become mislabelled at Bogor.

Schismatoglottis homalomenoidea and S. parviflora fall uncontroversially within S. tecturata, except for their placentation - there are generally two placentas in S. tecturata and one, according to Hotta (1966) in S. homalomenoidea and in S. parviflora. Some material of $S$. tecturata has these placentation states mixed in the same spadix, and, given the strong morphological similarity of these 'species', the interpretation here is that this is a variable characteristic within a broadly conceived S. tecturata.

$S$. tecturata seems somewhat isolated in the genus, combining unusual shoot organisation - with the leaf-protective role of the sheath taken over by cataphylls (cf. Alocasia peltata M. Hotta (Hay, 1998)), and almost competely persistent spathe limbs. Schismatoglottis petri (q.v.) however, appears related.

Purseglove P5591, from Bako National Park, Sarawak, has exceptionally large leaves (in which it resembles Nicolson 1323 from the same area; dimensions in parentheses above) and an extremely slender appendix with very small staminodes. Possibly it represents a segregate species; however, the inflorescences are not well preserved and it is merely drawn attention to here. The notes on Nicolson 1323 include inflorescence details, but there is no longer fertile material on the sheet. In leaf these specimens resemble $S$. nicolsonii, which is restricted to Bako National Park, but they differ in the short leaf sheath and alternating cataphylls typical of $S$. tecturata. 
Three Bünnemeijer collections from the Riau Archipelago, off the tip of the Malay Peninsula represent a significant, disjunct range extension for this species. Unfortunately none includes adequate floral structures with which to confirm the identity of these specimens with certainty. However, the match with S. tecturata in vegetative features is very close, and in one sheet the distinctive shape of the spathe is evident.

Schismatoglottis beccariana var. cuspidata Engl. is not conspecific with S. tecturata (see under S. mayoana).

Other specimens examined: SUMATERA: Riau Archipelago, P. Tujuh, G. Ranai, Bünnemeijer 5809, 5911 \& 5820 (all BO). BORNEO: SARAWAK: Bukit Mersing, Ulu Anap, Ashton S.19154 (SAR, US); Entabai, Bogner 1345 (K, US); Sg. Lalang, Kg Klulong, Bogner 1361 (US); Matang, Sg. Cina, Bogner 1404 (K, US); Matang, Bogner 1554 (K, US) \& 1592 (M) \& 1607 (KYO, M) \& 1608 (KYO, M); Matang, Matang Family Park, Sg. Cina, Boyce $715(\mathrm{~K})$; outside Kubah NP above intake dam on Sg. Bungen, Boyce 773 (K); without locality, Brooke 8185 (G); Gilam Bakun, Brooke 9078 (BM, L); 1st Divn, Sungei Raya, Brooke 9367 (L); 4th Div., Lambir NP, Sg. Liam Libau, Burtt 11538 (E, M); Kapit, Upper Rejang R., Clemens \& Clemens 21937 (NY); Cult. RBG Sydney Acc. No. 940464 ex 2.3 km past bridge over Kemena R, Bintulu-Sibu Rd (orig. coll. Hay et al. 9310), Herscovitch s.n. (K, KEP, L, SAR, US); Cult. RBG Sydney Acc. No. 940564 ex Matang, Kabah National Park (orig. coll. Hay et al. 9411), Herscovitch s.n. (NSW); Cult. RBG Sydney Acc. No. 940473 ex UPM research area, Bintulu (orig. coll. Hay et al. 9320), Herscovitch s.n. (K, KEP, L, NSW, SAR, US); Matang FR, Nicolson 1281 (L, US); Setapok F R, 6 mi S of Kuching, Nicolson 1347 \& 1356 (both US); Lintang Path, Bako National Park, Nicolson 1323 (US); Tanjong Delima, Bako National Park, Purseglove P5591 (K, L); Matang, Ridley 12352 (K); 4th Divn, nr Bintulu/Miri Rd, 20th mile, Yeo E Jugah S.38409 (SAR); 1st Divn, Sarawak/Kalimantan border, G. Penrissen, Yii S.61310 (US). BRUNEI: Belait, Labi, Kg Teraja, Boyce $238(\mathrm{~K}, \mathrm{~L})$ \& 242 (K) \& 257 (K); Temburong, Bukit Peradayan, vicinity of Labu, Hotta 13662 \& 13663 (both KYO); Tutong Dist., Ladan Hills FR, Johns 7107 (K); Tutong Dist., Ladan Hills FR, Sands 5730 (K); Belait, Bukit teraja, Wong s.n. (K). KALIMANTAN: Oeloe Bloe-oe, Amdjah 282 (BO); East Kalimantan, G. Batukenye, NW of Tabang, Murata et al. B-1721 (KYO); East Borneo, W Kutei, Mt Palimasan, nr Tabang on Belajan R, Kostermans 12811 (L); Terakan, Sesanip oilfield, Meijer 2498 (BO, L); Bukit Raya, Nooteboom 4650 (BO, L).

\section{Inadequately known species}

90. Schismatoglottis acutifolia Engl.

Schismatoglottis acutifolia Engl., Pflanzenr. 55 (IV.23Da) (1912) 88 [non S. acutifolia (Engl.) M. Hotta - i.e. S. hottae Bogner \& Nicolson, q.v.]. — Syntypes: Indonesia, Kalimantan, Sungei Doho, Jul 1897, Jaheri s.n. (BO, n.v.); Cult. Hort. Bogor. XI.B.X.151 ex Borneo, Kalimantan, Sungei Doho (orig. coll. Jaheri, exped. Nieuwenhuis, 1897), A. Engler 4040 (B).

The description is of the leaf only, which is lanceolate, somewhat falcate and longacuminate. The sheath is fully attached. The nearest match that can presently be made is with Schismatoglottis longifolia Ridl., but in the absence of an inflorescence this is speculative. Engler appears to cite a Nieuwenhuis [probably Jaheri, who is cited as a locality] collection at BO as well as cultivated material. Only the latter has been found and it does not appear from the description that Engler used any more complete specimen than his own sterile fragmentary one made from the cultivated plant.

\section{Schismatoglottis eximia Engl.}

Schismatoglottis eximia Engl., Pflanzenr. 55 (IV.23Da) (1912) 101. — Type: Cult. Hort. Bogor., Bed?, Plant No. 65, Jan/Feb 1906, A. Engler 4050 (B, holo).

Engler provided a description of the inflorescence, as well as the vegetative parts, though all that remains are two detached leaves. These bear some resemblance to narrower-leaved forms of $S$. asperata, but the petioles are both glabrous and non-alate 
and the inflorescence description does not match that species. No other material has been found which matches the type or description of $S$. eximia.

\section{Schismatoglottis glauca Engl.}

Schismatoglottis glauca Engl., Pflanzenr. 55 (IV.23Da) (1912) 106. - Type: Cult. Hort. Bogor. XI.B.X 115 ex Borneo, Jan/Feb 1906, A. Engler 4051 (B, holo - 2 sheets).

Described from sterile material of uncertain origin; the hypogeal stem and more or less elliptic leaves with narrowly and shallowly cordate, more or less emarginate bases suggest this plant falls within with the widespread and variable S. motleyana. However, the rather distinctly glaucous-looking leaves of the dried specimen, if not an artefact of preservation, do not match that species.

\section{Schismatoglottis lancifolia Hallier f. \& Engl.}

Schismatoglttis lancifolia Hallier f. \& Engl., Pflanzenr. 55 (IV.23Da) (1912) 88. - Type: Cult. Hort. Bogor., ?H. Hallier (?BO, holo - not found).

This name has been applied by Hotta et al. (1985) to Sumateran S. acuminatissima. There, they translated and condensed the notes beneath Engler's protologue of S. lancifolia as "collected from Borneo (?) by J.G. Hallier", and went on to discuss the possibility that Hallier could have collected the plant in Sumatera. However, the note reads 'Haec species in horto Bogoriensi culta a cl. Hallier $f$. jam nominata fuit, attamen descriptionen haud inveni', meaning 'This species cultivated in Bogor gardens has already been named by Hallier f., though I have not come across a description'. The distribution was given separately as 'Borneo?'. Thus no indication was given that it had been originally collected by Hallier. However, Hallier may have made a specimen from the cultivated plant, though no specimen of his from the gardens has been found which is annotated with this name or which fits the description. There is no Engler specimen at B, which would suggest that Engler did indeed base his description on a previously made specimen rather than a plant living at the time of his visit to Bogor in 1905/6. Hotta et al. (1985) discussed a type at Bogor, but did not cite a collector or locality. They said it was in very poor condition and consisted only of two small lanceolate white-mottled leaves. A.H. was unable to find this specimen at BO (though it may resurface after the current remounting program is completed). The description in the protologue is specific about the leaves being concolorous, and the inflorescence was partially described, suggesting that the type included fertile material originally. It is therefore concluded that they misinterpreted this specimen as the type of S. lancifolia. Since their discussion of it did not specify details, it should not be interpreted as a formal neotypification.

In the Bogor Gardens Herbarium there is an un-numbered Alderwerelt specimen labelled S. lancifolia made from a cultivated plant XI.B.X.18 (originally collected from Deli, Sumatera, by Jaheri), which he (van Alderwerelt van Rosenburgh, 1922a) suspected to be the same plant as that on which S. lancifolia was based - this is certainly possible, as Jaheri collected in Sumatera in 1895, while Hallier was still based at Bogor. This specimen matches S. okadae, and the original description of S. lancifolia could also fit that species (in particular the abaxially prominent primary lateral veins arising from the midrib at a strongly ascending or low angle). This, of course, suggests that S. lancifolia is an earlier name for S. okadae. However, because of the potential for misplacement of labels and other uncertainties associated with living collections maintained over a period of many years, this cannot be proved until the type, if extant, is located. It might be considered desirable (or at least simple) to neotypify S. lancifolia with Alderwelt's specimen. However, there is an issue of usage: both S. lancifolia sensu Hotta et al. (i.e. S. acuminatissima) and S. okadae (potentially a synonym of S. lancifolia sensu Hallier f. \& Engl.) have been the subjects of non-taxonomic biological studies 
(Hotta et al., 1985; Okada, 1989; Okada \& Hotta, 1987) and, relative at least to most names in Schismatoglottis, can be considered to be in current use. If Hotta et al.'s usage of S. lancifolia was in fact taxonomically correct, that name should go into the synonymy of $S$. acuminatissima. That does not seem unusually problematic. What would be undesirably confusing would be to transpose an incorrectly used name to supercede another used name, on the basis of a doubtful chain of evidence, which would be the case if $S$. lancifolia were neotypified with Alderwelt's later material of S. okadae. It is very doubtful that the level of usage of either name would be enough to support a formal proposal for conservation, and for now the problem is merely presented, proposing $S$. lancifolia as a doubtful species and retaining S. okadae.

\section{Schismatoglottis penangensis Engl.}

Schismatoglottis penangensis Engl., Pflanzenr. 55 (IV.23Da) (1912) 88. — Type: Malaysia, Penang, 'Balch Poula' [?= Balik Pulau], Deschamps s.n. (CAL, holo, not found).

Translated from the Latin, Engler's description reads: 'Stem hypogeal; petiole equalling to exceeding half the length of the blade, $8-12 \mathrm{~cm}$ long, channelled adaxially, sheathing for 2-3 cm; blade oblong-lanceolate, subequally narrowed on each side, the base running cuneate into the petiole, the apex acuminate; primary veins 4 on each side diverging at c. $30^{\circ}$ and curving distally, distinctly prominent abaxially; peduncle of infructescence shorter than petiole, $10 \mathrm{~cm}$ long; fruiting spathe $2 \mathrm{~cm}$ long, $1.5 \mathrm{~cm}$ wide, cup-shaped.'.

Distribution - Malesia: Malay Peninsula (Penang); known only from the type.

From the protologue, it is evident that this species is imperfectly known; A.H. has looked for the type at CAL where it was said by Engler (loc. cit.) to be, but was unable to find it in either the Type or the General Herbarium. The hypogeal stem and oblonglanceolate blade with cuneate base suggest $S$. wallichii but it differs from that in the rather short cup-shaped fruiting spathe.

\section{Excluded species}

Schismatoglottis crispa Pitcher \& Manda

Schismatoglottis crispa Pitcher \& Manda, Gen. Ill. Cat. New and Rare Seeds. U.S. Nurseries (1892) 95. = Aglaonema crispum (Pitcher \& Manda) Nicolson.

Schismatoglottis elongata Engl.

Schismatoglottis elongata Engl., Bull. Soc. Tosc. Ortic. 4 (1879) 298. = Piptospatha elongata (Engl.) N.E. Br.

Schismatoglottis havilandii (Engl.) M. Hotta

Schismatoglottis havilandii (Engl.) M. Hotta, Mem. Coll. Sci. Univ. Kyoto, ser. B, 32 (1966) 233; van Steenis, Rheophytes of the World (1981) 195. - Rhynchopyle havilandii Engl., Bot. Jahrb. Syst. 37 (1905) 125. - Piptospatha havilandii (Engl.) Engl., Pflanzenr. 55 (IV.23Da) (1912) 128. = Piptospatha grabowskii (Engl.) Engl.

Schismatoglottis marginata Engl.

Schismatoglottis marginata Engl., Bull. Soc. Tosc. Ortic. 4 (1879) 298. = Piptospatha elongata (Engl.) N.E. Br.

Schismatoglottis robelinii (Pitcher \& Manda) Pitcher \& Manda Schismatoglottis robelinii (Pitcher \& Manda) Pitcher \& Manda, Gen. Ill. Guide Pl. (1895) 141. = Aglaonema crispum (Pitcher \& Manda) Nicolson. 
Schismatoglottis sumatrana Schott ex Miq. Schismatoglottis sumatrana Schott ex Miq., Ann. Mus. Lugd.-Bat. 3 (1867) 80; Engl. in A. \& C. DC., Monogr. Phan. 2 (1879) 353 \& Pflanzenr. 55 (IV.23Da) (1912) 100. - Type: Indonesia, Sumatera, West Sumatera, Balang Singalang, P.W. Korthals s.n. (?L, holo n.v.). - Iconotype: Schott, Icones 3082 (W - fiche 47:b1 in the microfiche edition). = Scindapsus sumatranus (Miq.) P.C. Boyce $\mathcal{E}$ A. Hay, comb. nov.

We have not been able to find the type of Schismatoglottis sumatrana, but from Schott's illustration, it is clearly a member of the Monstereae, and the epithet is evidently an earlier one for Scindapsus rupestris Ridl. (1905), a species widespread in West Malesia.

\section{Acknowledgments}

We are very grateful to Conrad D. Fleming for generous financial support of fieldwork over the years, including Yuzammi's fieldwork in Java. The Christensen Fund and Dr Matthew Jebb, the former Director of the Christensen Research Institute at Madang, Papua New Guinea, kindly awarded A.H. research fellowships in 1989 and 1990. A.H. is also grateful to the Smithsonian Institution for awarding him a visiting fellowship in 1996 to study the Philippine species, and to Dr Dan Nicolson for arranging that fellowship. For invaluable assistance in the field A.H. is very grateful to Prof. Ruth Kiew, Anthonysamy and Roy Banka (University Pertanian Malaysia) in 1994, Yahud Bin Hj. Wat, Saupel B. Atot and Chang Ban Sem (Sarawak Forestry Department) in 1994, Dr Wong Khoon Meng, A. Berhaman, Ubaldus, Postar and Ahmad (Forest Research Centre, Sepilok) in 1995 and 1996, and Dr Ir. Suhirman, Yuzammi and Pak Tahrodin (Kebun Raya Bogor) in 1996 and 1997. Yuzammi wishes to thank those who accompanied her during fieldtrips in Java in the last two years: Julisasi Tri Hadiah, Pak Tahrodin, Pak Samsu Sujahman, Pak Cecep Rayadi and Pak Rustandi. The Directors or Curators of the following herbaria made their material available or accessible: AAU, B, BM, BO, BRUN, CAL, E, FI, G, GH, K, KEP, KYO, L, M, MO, NY, P, PNH, SAN, SAR, SING, U, UC, UPM, US, USM, WRSL. Thanks are also due to Dr Dedy Darnaedi, Director of the Kebun Raya Indonesia, for enabling A.H. to examine material in the Kebun Raya herbarium ('BOKR') recently. Ruth Kiew (SING), Peter Boyce (K), Ch'ien Lee, Arden Dearden, John Mood and Josef Bogner kindly supplied material from their recent field or cultivated living collections. We would also like to thank Randy Sing and nursery staff of the RBG Sydney for cultivating the living plants cited here, Lesley Elkan, Catherine Wardrop and Marion Westmacott for the botanical drawings and Clare Herscovitch for stoic technical assistance and curation of the living Aroid collection at Sydney. We are grateful to Prof. David Mabberley (NSW) for advice on the formation of epithets and to him and Dr Peter Wilson (NSW) for advice on typifications, the latter also for correcting the Latin. Wilbert Hetterscheid kindly assisted with finding information in the library at L and Peter Boyce at BM. We thank David Mabberley, Peter Boyce and members of the Telopea Editorial Committee for critically reading and commenting on the manuscript. Special thanks are due to Joy Everett for her painstaking and skillful editing and Debby McGerty for her careful typesetting and for incorporating numerous late alterations.

\section{References}

Alderwerelt van Rosenburgh, C.R.W.K. van (1922 a \& b) New or noteworthy Malayan Araceae II. Bull. Jard. Bot. Buitenzorg III, 4: 163-229. — Ditto III. Ibid. 4: 320-347.

Beaman, J.H. \& Beaman, R.S. (1998) The Plants of Mount Kinabalu, 3. Gymnosperms and non-Orchid Monocotyledons. (Natural History Publications (Borneo) in assoc. with Royal Botanic Gardens Kew, Kota Kinabalu). 
Bogner, J. \& Nicolson, D.H. (1991) A revised classification of the Araceae with dichotomous keys. Willdenowia 21: 35-50.

Brown, N.E. (1882) Schismatoglottis pulchra. Ill. Hort. 31: 73.

Bunting, G.S. (1960) The genus Schismatoglottis (section Philonotion) in America. Ann. Missouri Bot. Gard. 47: 69-71.

Bunting, G.S. \& Steyermark, J.A. (1969) A new species of Schismatoglottis (Araceae). Brittonia 21: 187-190.

Corner, E.J.H. (1949) The Durian Theory, or the origin of the modern tree. Ann. Bot. Lond. 13: $367-414$

Elmer, A.D.E. (1938) Irosin Araceae. Leafl. Philip. Bot. 10: 3611-3635.

Elmer, A.D.E. (1939) Miscellaneous new species. Leafl. Philip. Bot. 10: 3673-3810.

Engler, A. (1879a) Araceae. Pp. 1-681 in A. \& C. de Candolle (eds.), Monographiae Phanerogamarum. Vol. 2. (Masson: Paris).

Engler, A. (1879b) Araceae specialmente Borneensi e Papuane raccolte da O. Beccari. Bull. Soc. Tosc. Ortic. 4: 265-271, 295-302.

Engler, A. (1883) Araceae della Malesia e della Papuasia raccolte da O. Beccari. Pp. 259-304 in O. Beccari, Malesia, Vol. 1. (Instituto Sordo-Muti: Genova).

Engler, A. (\& K. Krause, p.p.) (1912) Araceae-Philodendroideae-Philodendreae, Homalomeninae und Schismatoglottidinae. Pflanzenreich 55 (IV.23Da): 1-134.

French, J.C., Chung, M. \& Hur, Y. (1995) Chloroplast DNA phylogeny of the Ariflorae. Pp. 255-275 in Rudall, P.J., Cribb, P.J., Cutler, D.F. \& Humphries, C.J. (eds), Monocotyledons: Classification and Evolution. Vol. 1. (Royal Botanic Gardens: Kew).

Gibbs, L.S. (1914) A contribution to the flora and plant formations of Mount Kinabalu and the highlands of British North Borneo. J. Linn. Soc. Lond. 42: 1-240.

Graf, A.B. (1978) Exotica, edn 9. (Roehrs Co. Inc.: East Rutherford, New Jersey).

Grayum, M.H. (1990) Evolution and phylogeny of the Araceae. Ann. Missouri Bot. Gard. 77: 628-697.

Grayum, M.H. (1992) Comparative external pollen ultrastructure of the Araceae and some putatively related taxa. Monogr. Syst. Bot. Missouri Bot. Gard. 43: 1-167.

Greuter, W., McNeill, J., Barrie, R., Burdet, H.-M., Demoulin, V., Filguerias, T.S., Nicolson, D.H., Silva, P.C., Skog, J.E., Trehane, P., Turland, N.J. \& Hawksworth, D.L. (2000) International Code of Botanical Nomenclature (Saint Louis Code). Regnum Vegetabile 138.

Hallé, F., Oldeman, R.A.A. \& Tomlinson, P.B. (1978) Tropical Trees and Forests: an Architectural Analysis. (Springer: Berlin).

Hallier, H. (1896) Neue und bemerkenswerte Pflanzen aus der malaiisch-papuanischen Inselmeer. Ann. Jard. Bot. Buitenzorg 13: 276-326.

Hallier, H. (1897) Die indonesischen Clematideen des Herbariums zu Buitenzorg. Ann. Jard. Bot. Buitenzorg 14: 248-276.

Hasskarl, J.K. (1842a) Plantarum genera et species novae aut reformatae javenses. Flora 25 (2), Beibl.1: 1-16.

Hasskarl, J.K. (1842b) Plantarum rariorum vel minus cognitarum horti Bogorienses — Decades (1) Tijdschr. Natuurl. Gesch. E Physiol. 9: 115-180.

Hay, A. (1992) A new Australian genus of Araceae, with notes on generic limits and biogeography of the Areae. Bot. J. Linn. Soc. 109: 427-434.

Hay, A. (1993) The genus Typhonium (Araceae-Areae) in Australasia. Blumea 37: 345-376.

Hay, A. (1996) The genus Schismatoglottis Zoll. \& Moritzi (Araceae-Schismatoglottideae) in Peninsular Malaysia and Singapore. Sandakania 7: 1-30.

Hay, A. (1998) The genus Alocasia (Araceae-Colocasieae) in West Malesia and Sulawesi. Gard. Bull. Singapore 50: 221-334.

Hay, A. (1999) Revision of Homalomena (Araceae-Homalomeneae) in New Guinea, the Bismarck Archipelago and Solomon Islands. Blumea 44: 41-71.

Hay, A. \& Mabberley, D.J. (1991) 'Transference of Function' and the origin of aroids: their significance in early angiosperm evolution. Bot. Jahrb. Syst. 113: 339-428.

Hay, A. \& Wise, R. (1991) The genus Alocasia (Araceae) in Australasia. Blumea 35: 499-545.

Hooker, J.D. 1893. (Araceae) Pp. 490-556 in Hooker, J.D., The Flora of British India. Vol. 6. (Reeve \& Co.: London).

Hotta, M. (1966) Notes on Schismatoglottidinae of Borneo. I. Mem. Coll. Sci. Univ. Kyoto, ser. B, 32: 223-238. 
Hotta, M. (1993) Male flower diversity in Schismatoglottidinae (Araceae). XVth International Botanical Congress, Yokohama, Abstracts: 235.

Hotta, M., Okada, H. \& Ito, M. (1985) Species diversity at wet tropical environment I. Polymorphic variation and population structure of Schismatoglottis lancifolia (Araceae) in West Sumatra. Contr. Biol. Lab. Kyoto Univ. 27: 9-71.

Mabberley, D.J. (1999) Edred John Henry Corner, C.B.E. Biog. Mems Fell. R. Soc. Lond. 45: 77-93.

Mayo, S. J., Bogner, J. \& Boyce, P.C. (1997) The Genera of Araceae. (Royal Botanic Gardens: Kew).

Miquel, F.A.W. (1856) Aroideae novae javanicae. Bot. Zeitung (Berlin) 14: 561-565.

Moritzi, A. (1845/46) Systematisches Verzeichniss. (Solothurn).

Nicolson, D.H. (1969) A revision of the genus Aglaonema. Smithsonian Contr. Bot. 1: 1-69.

Okada, H. (1984) Chromosome counts of some plants collected from West Sumatra. Pp. 89-90 in Hotta, M. (ed.), Forest Ecology and Flora of G. Gadut, West Sumatra. (Sumatran Nature Study (Botany): Kyoto University).

Okada, H. (1986) The cytotaxonomical observations of some plants collected from West Sumatra. Pp. 61-70 in Hotta, M. (ed.), Diversity and Dynamics of Plant Life in Sumatra. Part. 1. (Sumatra Nature Study (Botany): Kyoto University).

Okada, H. (1989) Population dynamics of Schismatoglottis lancifolia, an understorey aroid of tropical wet forests, during five years. Pp. 49-54 in Hotta, M. (ed.), Diversity and Plant-animal Interaction in Equatorial Rainforests. Report of the 1987-1988 Sumatra Research. (Sumatran Nature Study (Botany): Kagoshima University).

Okada, H. (1992) Population diversity of Schismatoglottis irrorata (Araceae) at Malesian wet tropics with reference to the distribution of B chromosomes. Cytologia 57: 401-407.

Okada, H. (1993) Cytotaxonomic studies of some rheophytic aroids (Araceae). XVth International Botanical Congress, Yokohama, Abstracts: 206.

Okada, H. \& Hotta, M. (1987) Species diversity at wet tropical environments II. Speciation of Schismatoglottis okadae (Araceae), an adaptation to the rheophytic habit of mountain stream in Sumatra. Contr. Biol. Lab. Kyoto Univ. 27: 153-170.

Okada, H., Tsukaya, H.\& Mori, Y. (1999) A new species of Schismatoglottis (Schismatoglottidinae, Araceae) from West Kalimantan and observations of its peculiar bulbil development. Syst. Bot. 24: 62-68.

Petersen, G. (1989) Cytology and systematics of the Araceae. Nordic J. Bot. 9: 119-166.

Ridley, H.N. (1905) The aroids of Borneo. J. Straits Branch Roy. Asiat. Soc. 44: 169-188.

Ridley, H.N. (1907) New or rare Malayan plants. III. J. Straits Branch Roy. Asiat. Soc. 49: 11-52.

Ridley, H.N. (1916) A report on the botany of the Wollaston expedition to Dutch New Guinea 1912-1913. Trans. Linn. Soc. Lond. ser. 2, Bot. 9: 1-269.

Roxburgh, W. (1832) Flora Indica. (Edn 2, Carey). (Thacker \& Co.: Calcutta).

Rumphius, G. (1747) Herbarium Amboinense. Vol. 5. (Amsterdam).

Schott, H.W. (1858a) Genera Aroidearum. (Ueberreuter: Vienna).

Schott, H.W. (1858b) Aroideen-skizzen. Oesterr. Bot. Z. 8: 317-318.

Schott, H.W. (1860) Prodromus Systematis Aroidearum. (Mechitarists' Press: Vienna).

Schott, H.W. (1865) Beitrage zur Aroideenkunde. Oesterr. Bot. Z. 15: 33-35.

Seubert, E. (1993) Die Samen der Araceen. (Koeltz: Koenigstein).

Steenis, C.G.G.J. van (1981) Rheophytes of the World. An Account of the Flood-resistant Flowering Plants and Ferns and the Theory of Autonomous Evolution. (Sijthoff \& Noordhoff: Alphen a/d Rijn).

Steenis-Kruseman, M.J. van (1950) Malaysian plant collectors and collections. In: Steenis, C.G.G.J. van (ed.), Flora Malesiana ser. I, 1: 3-639.

White, F. (1962) Geographic variation and speciation in Africa with particular reference to Diospyros. Pp. 71-103 in Nichols, D. (ed.), Taxonomy and Geography. (Systematics Association: London).

Yuzammi (2000) A Taxonomic Study of the Terrestrial Aroids of Java. Unpublished MSc Thesis, University of New South Wales.

Zollinger, H. (1854) Systematisches Verzeichniss der im indischen Archipel. Vol. 1. (Kiesling: Zurich).

\section{Manuscript received 29 February 2000 \\ Manuscript accepted 2 August 2000}

Editorial Note: This paper, as a precursor to Flora Malesiana, is not in standard Telopea format. 


\section{Index to scientific names}

[Synonyms in italics, new formal names in bold; authorities given only for names of taxa treated here. Bold page numbers indicate formal treatments; asterisks indicate illustrations.]

Aglaonema crispum

(Pitcher \& Manda) Nicolson 169

Aglaonema subundulatum

Zoll. ex Schott

145

Alocasia $8,10,33$

Alocasia robusta 7

Alocasia kerinciensis .. 9

Alocasia merrillii

Engl. \& K. Krause 139

Alocasia peltata .. 9

Apatemone Schott

3,17

Apatemone motleyana Schott .. 3, 17, 132

Apoballis Schott

4,17

Apoballis neglecta Schott ............ 4, 17, 49

Aridarum

.... 5

Arisarum esculentum Rumph. ..... 3, 106

Bucephalandra .. 5

Calla calyptrata Roxb.

3,106

Colobogynium Schott .. 17

Colobogynium tecturatum Schott

17,163

Colocasia? humilis Hassk.

3, 106

Colocasia? humilis var. major Hassk.

Colocasia? humilis var. minor Hassk. 107

Colocasia? humilis var. picta Hassk. 107

Colocasia neoguineensis

Linden ex André 107

Cryptocoryne 5,8

Cryptocoryneae .... 5

Cyrtosperma .. 9

Furtadoa ... 5

Gamogyne ... 5

Heteroaridarum .. 5

Homalomena $4,8,13$

Homalomena calyptrata

(Roxb.) Kunth 106

Homalomena fasciata Ridl. 163

Homalomeninae ... 5
Hottarum .............................................. 5

Hottarum sarikeense

Bogner \& M. Hotta ......................... 100

Lagenandra ........................................... 5

Microcasia ................................................ 5

Philodendreae ....................................... 5

Philodendron ......................................... 5

Philonotion …......................................... 6

Phymatarum ........................................... 5

Piptospatha ............................... 5, 6, 12

Piptospatha acutifolia Engl. ............... 101

Piptospatha elongata

(Engl.) N.E. Br. 169

Piptospatha grabowskii Engl. .... 5, 169

Piptospatha havilandii Engl. ............. 169

Piptospatha marginata (Engl.) N.E. Br. .............................. 169

Rhynchopyle .......................................... 5

Schismatoglottideae .............................. 5

Schismatoglottidinae ............................. 5

Schismatoglottis Zoll. \& Moritzi ...... 17

Schismatoglottis acuminatissima Schott $11,31,33$

Schismatoglottis acuminatissima var. concinna (Schott) Engl. ........... 31

Schismatoglottis acutangula Engl. .... 108

Schismatoglottis acutangula $\mathrm{f}$. staminodiifera Alderw.

Schismatoglottis acutifolia Engl. .... 167

Schismatoglottis acutifolia (Engl.)

M. Hotta 101

Schismatoglottis ahmadii

A. Hay …................... 7, 9, 102, 103*

Schismatoglottis angustifolia

Alderw. 109

Schismatoglottis asperata Engl. ............. 6, 10, 11, 12, 18, 54, 56*

Schismatoglottis asperata group $6,7,54$

Schismatoglottis asperata var. albomaculata Engl. 54 
Schismatoglottis barbata

Engl. ................. 5, 9, 10, 12, 13, 17, 57

Schismatoglottis batoensis Engl.

42

Schismatoglottis bauensis

A. Hay \& C. Lee ............. 8, 9, 84, 86*

Schismatoglottis beccariana Engl. .. 5, 163

Schismatoglottis beccariana var.

albolineata Engl.

Schismatoglottis beccariana var.

angustifolia Engl.

Schismatoglottis beccariana var. cuspidata Engl.

Schismatoglottis beccariana var. oblonga Engl.

Schismatoglottis belophylla

Alderw.

Schismatoglottis bifasciata

Engl.

16,104

Schismatoglottis bitaeniata Engl. ...... 108

Schismatoglottis bogneri

A. Hay

13, 105

Schismatoglottis brevicuspis

Hook. f.

$6,17,59$

Schismatoglottis brevipes

Hook. f.

$6,18,35$

Schismatoglottis brooksii Alderw.

42

Schismatoglottis bulbifera H. Okada,

H. Tsukaya \& Y. Mori

Schismatoglottis calyptrata

(Roxb.) Zoll. \& Moritzi .... 3, 4, 6, 7, 8, $11,12,16,17,106$

Schismatoglottis calyptrata f. grandifolia Engl. 107

Schismatoglottis calyptrata f. minor Engl. 108

Schismatoglottis calyptrata $\mathrm{f}$.

multimargarita Alderw. 109

Schismatoglottis calyptrata f. resupinata Alderw. 157

Schismatoglottis calyptrata group $6,7,14,101$

Schismatoglottis calyptrata var. albidomaculata (Hallier f.) Ridl . .... 107

Schismatoglottis calyptrata var. bivittata Hallier $\mathrm{f}$. 108

Schismatoglottis calyptrata var. celebica Koord. 108
Schismatoglottis calyptrata var. concolor Hallier $\mathrm{f}$. 106

Schismatoglottis calyptrata var. concolor f. dahlii Engl. 107

Schismatoglottis calyptrata var. concolor f. glaucescens Hallier f. .... 107

Schismatoglottis calyptrata var. concolor f. grandifolia Engl.

Schismatoglottis calyptrata var. concolor f. minor Engl.

Schismatoglottis calyptrata var. concolor f. olivacea Hallier f. .......... 108

Schismatoglottis calyptrata var. dahlii Engl.

Schismatoglottis calyptrata var. flavidomaculata Hallier $\mathrm{f}$.

Schismatoglottis calyptrata var. maculata Hallier f.

Schismatoglottis calyptrata var. maculata f. albidomaculata Hallier $\mathrm{f}$. 107

Schismatoglottis calyptrata var. maculata f. flavidomaculata (Hallier f.) Hallier $\mathrm{f}$.

Schismatoglottis calyptrata var. ornata Ridl. ex Engl. \& K. Krause .......... 108

Schismatoglottis calyptrata var. picta (Schott) Hallier $\mathrm{f}$. 107

Schismatoglottis calyptrata var. trivittata (Hallier f.) Hallier f. 149

Schismatoglottis calyptratoides Alderw. 109

Schismatoglottis canaliculata Engl. 16,117

Schismatoglottis cardiophylla Quisumb. \& Merr. 139

Schismatoglottis caulescens Ridl. 63

Schismatoglottis celebica Engl. 145

Schismatoglottis ciliata A. Hay …......... 10, 11, 13, 14, 60, 62*

Schismatoglottis clarae

A. Hay 118

Schismatoglottis clemensiorum

A. Hay 8,61

Schismatoglottis colocasioidea M. Hotta 146

Schismatoglottis concinna Schott 31

Schismatoglottis concinna var. immaculata (N.E. Br.) Engl. 
Schismatoglottis concinna var. purpurea (N.E. Br.) Engl. 31

Schismatoglottis conoidea Engl.

$63,65^{*}$

Schismatoglottis conversa Alderw. .... 157

Schismatoglottis convolvula

$$
\text { P.C. Boyce }
$$

Schismatoglottis cordifolia M. Hotta 5,70

Schismatoglottis cordifolia Ridl. 108

Schismatoglottis corneri A. Hay $3,4,6,7,8,11,12,13,17,29,30^{*}$

Schismatoglottis corneri group ... 29

Schismatoglottis crassifolia Engl. 165

Schismatoglottis crinitissima A. Hay 10,64

Schismatoglottis crispa Pitcher \& Manda ... 169

Schismatoglottis crispata Hook. f. ...... 55

Schismatoglottis cyria P.C. Boyce .... 85

Schismatoglottis decipiens

A. Hay …...................... 7, 11, 16, 120

Schismatoglottis decora W. Bull 132

Schismatoglottis diversicolor

Alderw. 132

Schismatoglottis djamuensis Engl. 108

Schismatoglottis dorensis Gibbs 109

Schismatoglottis ecaudata

A. Hay

Schismatoglottis edanoi

A. Hay 121

Schismatoglottis elegans

A. Hay $12,18,67$

Schismatoglottis elongata Engl. 169

Schismatoglottis emarginata Engl. .... 108

Schismatoglottis engleriana

Alderw. 149

Schismatoglottis erecta M. Hotta $6,9,14,87$

Schismatoglottis eximia Engl. 167

Schismatoglottis eymae

$$
\text { A. Hay }
$$

Schismatoglottis fasciata (Ridl.) Engl.

Schismatoglottis ferruginea Merr. $8,10,11,18,68$
Schismatoglottis forbesii Engl. 41

Schismatoglottis gamoandra M. Hotta $11,14,18,123$

Schismatoglottis gillianae

P.C. Boyce ........................................ 88

Schismatoglottis glauca Engl. ....... 168

Schismatoglottis grabowskii Engl. .. 69

Schismatoglottis grandiflora

Alderw. ........................................... 38

Schismatoglottis hastata Elmer ......... 142

Schismatoglottis hastifolia Hallier

f. ex Engl. .......................................... 39

Schismatoglottis havilandii (Engl.)

M. Hotta ................................... 5, 169

Schismatoglottis hellwigiana Engl. .... 108

Schismatoglottis homalomenoidea M. Hotta

Schismatoglottis hottae Bogner \& Nicolson ............................... 10, 70

Schismatoglottis irosinensis Elmer .... 142

Schismatoglottis irrorata Engl. 132

Schismatoglottis javanica Engl. $39,40^{*}$

Schismatoglottis josefii

A. Hay $89,90^{*}$

Schismatoglottis kingii Engl. ............... 81

Schismatoglottis klossii Ridl. ............. 109

Schismatoglottis kurimana Alderw. .... 32

Schismatoglottis lancifolia

Hallier f. \& Engl. 168

Schismatoglottis latevaginata Engl. 71

Schismatoglottis latifolia Miq. .......... 3, 49

Schismatoglottis latifolia Miq. var. rubescens Engl. 49

Schismatoglottis latifolia Miq. var. viridis Engl.

Schismatoglottis lavallei L. Linden ...... 31

Schismatoglottis lavallei var. immaculata N.E. Br. 31

Schismatoglottis lavallei var. lansbergiana L. Linden ex N.E. Br. ..................... 31

Schismatoglottis lavallei var. purpurea N.E. Br. .......................................... 31 Schismatoglottis leptophylla Alderw. .. 42 


\section{Schismatoglottis lingua}

A. Hay $124,126^{*}$

Schismatoglottis linguiformis Engl. .... 42

Schismatoglottis longicaulis Ridl. .... 41

Schismatoglottis longicuspis Engl. .... 157

Schismatoglottis longifolia

Ridl. $6,11,17,125$

Schismatoglottis longipes Miq. 107

Schismatoglottis longispatha

W. Bull $9,14,18,127$

Schismatoglottis luzonensis

Engl.

7, 128

Schismatoglottis luzonensis Engl. ..... 139

Schismatoglottis maculata Alderw. .... 109

Schismatoglottis marginata Engl. ..... 169

Schismatoglottis marginata Ridl. ....... 81

Schismatoglottis mayoana

Bogner \& M. Hotta ....... 8, 14, 91, 92*

Schismatoglottis merrillii Engl. .. 7, 129

Schismatoglottis mindanaoana

Engl.

$7,8,11,130$

Schismatoglottis minor Hook. f. ......... 35

Schismatoglottis modesta Schott .... 130

Schismatoglottis monoplacenta

M. Hotta

5,93

Schismatoglottis monticola Alderw. .... 42

Schismatoglottis moodii

A. Hay $131,133^{*}$

Schismatoglottis motleyana (Schott) Engl . $3,7,11,13,14,16,17$, $132,135^{*}$

Schismatoglottis multiflora group $7,12,17,84$

Schismatoglottis multiflora

Ridl. $7,9,10,94$

Schismatoglottis multiflora var. latifolia Ridl.

Schismatoglottis multinervia M. Hotta 72

Schismatoglottis muluensis

M. Hotta

Schismatoglottis mutata

Hook. f. $6,16,18,42$

Schismatoglottis neoguineensis (André)

N.E. Br. 107

Schismatoglottis nervosa Ridl. $10,73,75^{*}$
Schismatoglottis niahensis

A. Hay 7,137

Schismatoglottis nicolsonii
A. Hay
$8,95,96^{*}$

Schismatoglottis nieuwenhuisii

Engl. 108

Schismatoglottis okadae

M. Hotta

$7,9,46$

Schismatoglottis opaca Engl. 165

Schismatoglottis ornata Alderw. 165

Schismatoglottis ovata Schott $10,47,48^{*}$

Schismatoglottis parviflora

M. Hotta 5,165

Schismatoglottis parvifolia Alderw. .. 109

Schismatoglottis patentinervia

Engl. $7,11,76$

Schismatoglottis pectinervia

A. Hay 138

Schismatoglottis penangensis

Engl. 169

Schismatoglottis petri

A. Hay $7,16,162,164^{*}$

Schismatoglottis picta

[Hassk. ex] Schott 107

Schismatoglottis picta $\mathrm{f}$. bivittata

Engl. 108

Schismatoglottis picta f. robusta

Engl. 108

Schismatoglottis picta var. trivittata (Hallier f.) Engl.

Schismatoglottis platystigma

M. Hotta $5,8,13,97$

Schismatoglottis plurivenia Alderw. 7,139

Schismatoglottis potamophila

Alderw.

Schismatoglottis pseudocalyptrata

Alderw. 109

Schismatoglottis puberulipes Alderw. $9,10,11,77,79 *$

Schismatoglottis pudenda

A. Hay $11,12,13,14,98$

Schismatoglottis pulchra N. E. Br. .... 132

Schismatoglottis pumila Hallier $\mathrm{f}$. ex Engl. 141

Schismatoglottis pusilla Engl. ....... 142 
Schismatoglottis pyrrhias

A. Hay 10,78

Schismatoglottis ramosii Engl. 129

Schismatoglottis retinervia Furtado $8,11,80$

Schismatoglottis ridleyana Engl. 43

Schismatoglottis riparia Schott 107

Schismatoglottis rizalensis Engl. 129

Schismatoglottis robelinii (Pitcher \& Manda) Pitcher \& Manda 169

Schismatoglottis roseospatha Bogner $3,9,99$

Schismatoglottis rotundifolia Engl. ...... 42

Schismatoglottis rubiginosa

M. Hotta 57

Schismatoglottis rubrocincta Engl.

Schismatoglottis rupestris Group $6,7,11,16,31$

Schismatoglottis rupestris Zoll. $3,4,6,8,10,12,16,17,49,51^{*}$

Schismatoglottis ruttenii Alderw. ..... 109

Schismatoglottis sagittifolia Alderw 53

\section{Schismatoglottis samarensis}

$$
\text { A. Hay }
$$

Schismatoglottis sarikeensis (Bogner \& M. Hotta) A. Hay \& Bogner .. 13, 100

Schismatoglottis schottii Bogner \& Nicolson $5,9,14,101$

Schismatoglottis scortechinii Hook. $f$ $6,11,12,18,81$

Schismatoglottis sejuncta

$$
\text { A. Hay }
$$

Schismatoglottis silamensis

$$
\text { A. Hay }
$$

Schismatoglottis sublaxiflora Alderw. 109

Schismatoglottis subundulata (Zoll. ex Schott) Nicolson 145

Schismatoglottis sumatrana Schott ex Miq. 170

Schismatoglottis sylvestris Alderw. 47

Schismatoglottis sylvestris var. subcordata Alderw. 47

Schismatoglottis tecturata group
Schismatoglottis tecturata (Schott) Engl. ......... 4, 5, 6, 7, 9, 12, 16, 17, 163

Schismatoglottis tenuifolia Engl. ....... 108

Schismatoglottis treubii Engl. ............. 50

Schismatoglottis treubii $\mathrm{f}$. viridipes Alderw. 50

Schismatoglottis trifasciata

Engl. $7,10,12,16,18,146$

Schismatoglottis trivittata Hallier $\mathrm{f}$. $7,16,149$

Schismatoglottis trusmadiensis A. Hay \& J. Mood 151

Schismatoglottis unifolia A. Hay \& P.C. Boyce 10,151

Schismatoglottis vanouurenii Alderw. 109

Schismatoglottis variegata Hook. f. ex Engl.

Schismatoglottis venusta

A. Hay $7,8,9,152$

\section{Schismatoglottis viridissima} A. Hay $7,8,154$

Schismatoglottis wahaiana Alderw. $8,154,156^{*}$

Schismatoglottis wallichii Hook. f. $6,12,13,155$

Schismatoglottis wallichii f. oblongata (Hook. f.) Engl. \& K. Krause 155

Schismatoglottis wallichii var. fasciata Ridl.

Schismatoglottis wallichii var. oblongata Hook. f. 155

Schismatoglottis warburgiana Engl.

Schismatoglottis wigmannii Engl. ....... 50

Schismatiglottis winkleri Engl. ......... 132

Schismatoglottis wongii

A. Hay 160

Schismatoglottis zonata Hallier $\mathrm{f}$. $11,13,161$

Scindapsus sumatranus (Miq.) P.C. Boyce \& A. Hay 170

Scindapsus rupestris Ridl. ................. 170

Typhonium ........................................ 8

Zantedeschia calyptrata (Roxb.)

C. Koch 106 